\title{
Onkogenomische Aspekte Zytokin-assoziierter Signaltransduktion
}

\author{
Dissertation \\ zur Erlangung des mathematisch-naturwissenschaftlichen Doktorgrades \\ "Doctor rerum naturalium" \\ der Georg-August-Universität Göttingen
}

vorgelegt von

Nils Schoof

aus Bonn

Göttingen 2008 
D7

Referent:

Prof. Dr. Bernd Herrmann

Korreferent:

PD Dr. Dieter Kube

Tag der mündlichen Prüfung: $\quad 21.10 .2008$ 
Für Hanna 


\section{Inhaltsverzeichnis}

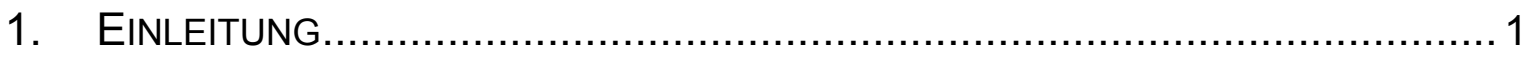

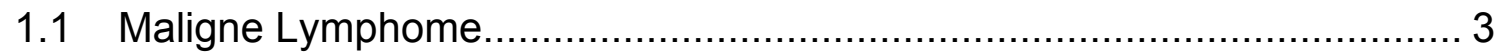

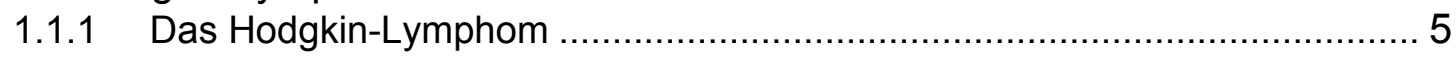

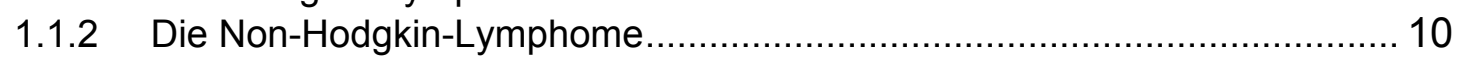

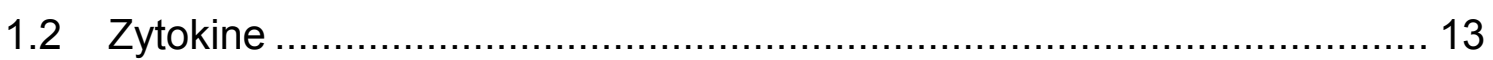

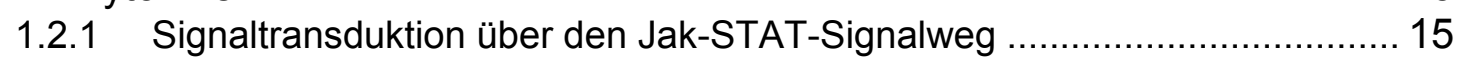

1.2.2 Genvariationen in Zytokinen und Zytokinrezeptoren .............................. 20

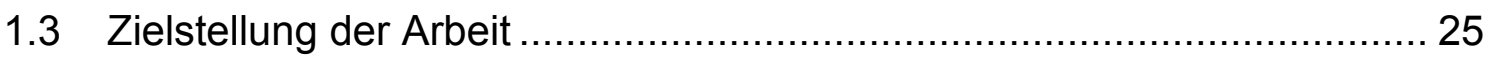

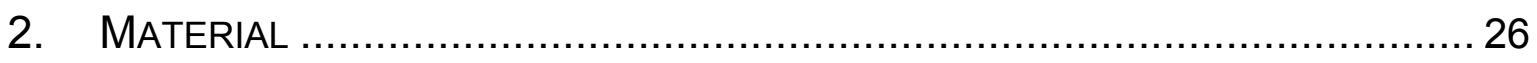

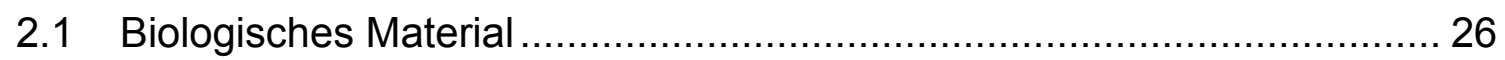

2.2 Chemikalien \& Verbrauchsmaterialien ............................................ 27

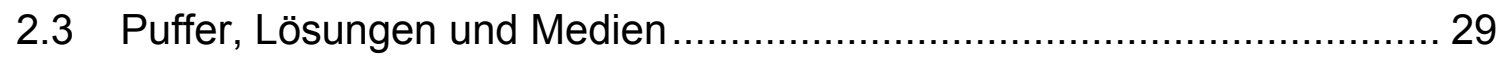

2.4 Häufig verwendete Geräte ............................................................ 30

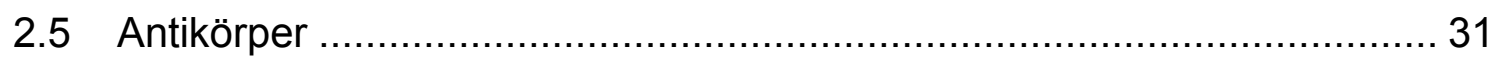

2.6 Gebrauchsfertige Reaktionssysteme ……........................................ 32

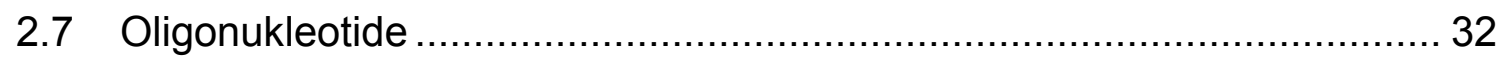

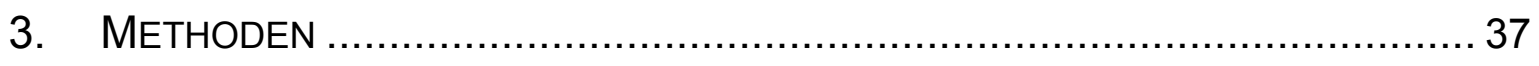

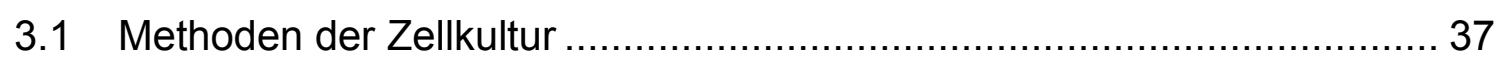

3.1.1 Auftauen und Kryokonservierung der Zelllinien .........................................37

3.1.2 Kultivierung der Zelllinien .................................................................... 37

3.1.3 Behandlung der Zelllinien mit chemischen Inhibitoren...............................38

3.1.4 Herstellung von Gefrierproben der Zellen ............................................... 38

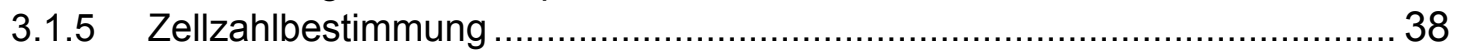

3.1.6 Einbringen von siRNA in die cHL-Zellen .............................................39

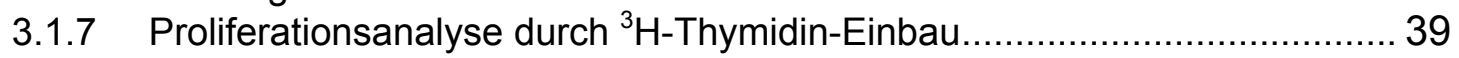

3.1.8 Matrigel-Invasionsassay ................................................................... 40

3.2 Durchflusszytometrische Methoden ............................................... 40

3.2.1 Analyse von Zellen durch Fluoreszenzanregung ..................................... 41

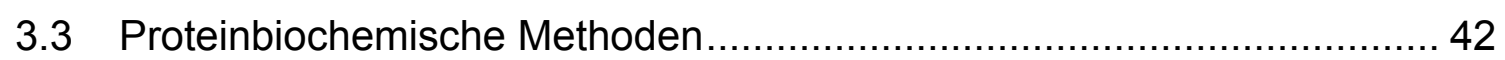

3.3.1 Immunpräzipitation von Proteinen ................................................... 42

3.3.2 Herstellung von Zelllysaten für SDS-PAGE ........................................ 42

3.3.3 Proteinkonzentrationsbestimmung nach Bradford ..................................... 43 
3.3.4 Sodiumdodecylsulfat-Polyacrylamid-Gelelektrophorese.......................... 43

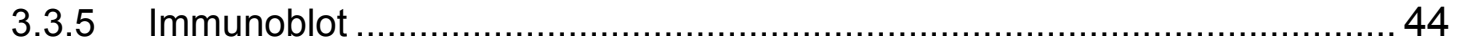

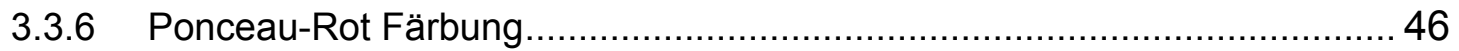

3.3.7 Enzyme-linked Immunosorbent Assay (ELISA) ..................................... 46

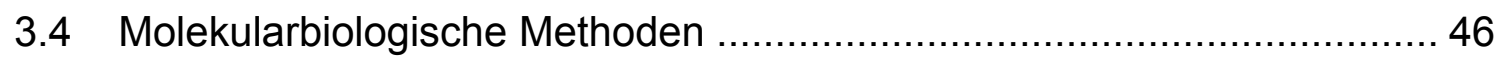

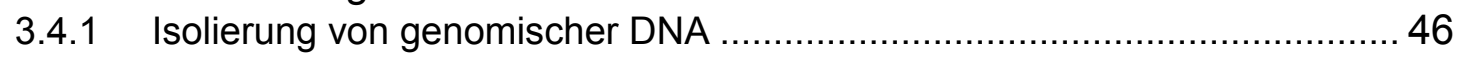

3.4.2 Isolierung von RNA und Reverse Transkription.................................... 46

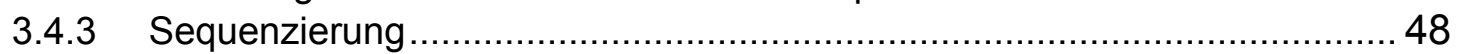

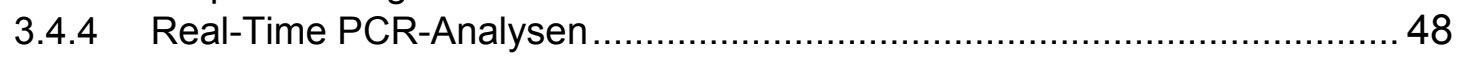

3.4.5 Konzentrationsbestimmung von Nukleinsäuren..................................... 49

3.4.6 Allelische Diskriminierung mittels Taqman-PCR ..................................... 50

3.5 Definitionen und statistische Analysen...................................... 51

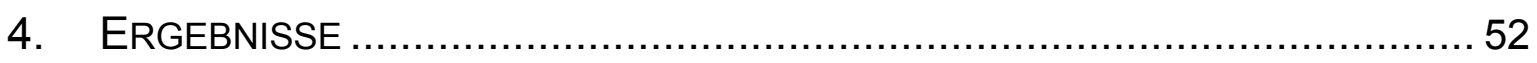

4.1 Die Janus-Kinasen als therapeutisches Ziel in cHL-Zellen .................... 52

4.1.1 Aktivierungszustand der Janus-Kinasen in cHL-Zelllinien ..........................5 52

4.1.2 Mutationsanalysen von Jak2 und Tyk2 in cHL-Zelllinien ...........................5 54

4.1.3 Der Jak-STAT-Signalweg ist in den cHL-Zelllinien abhängig von HSP90 ... 55

4.2 Transkriptionelle Ziele von STAT3 und STAT6 in der cHL-Zelllinie L428 60

4.2.1 Hemmung von STAT3 und STAT6 durch RNA-Interferenz ........................60

4.2.2 Zellproliferation nach Hemmung von STAT3 und STAT6 ..........................61 61

4.2.3 Genexpressionsanalyse nach Hemmung von STAT3 und STAT6 ............... 62

4.2.4 Validierung differenziell exprimierter Gene aus der Genexpressionsanalyse............................................................ 66

4.3 Genvariationsanalysen von Zytokinen und Zytokinrezeptoren................ 79

4.3.1 Überblick über die durchgeführten Genvariationsanalysen ........................79

4.3.2 Analyse von Th2-Zytokin- und Zytokinrezeptorgenvariationen in DLBCL-

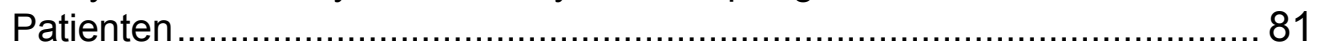

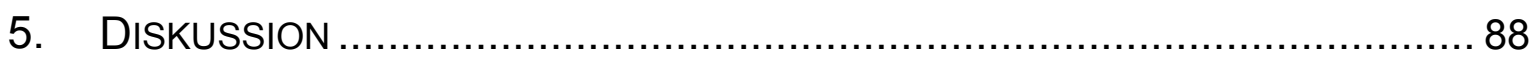

5.1 Rolle der Janus-Kinasen im cHL.............................................. 88

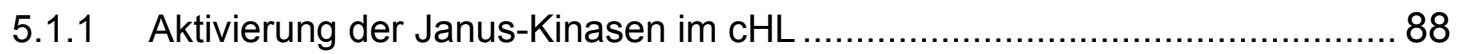

5.1.2 HSP90 ist essentiell für die Jak-STAT-Signaltransduktion im cHL .............. 91

5.2 Zielgene der Transkriptionsfaktoren STAT3 und STAT6 im cHL ............. 94

5.2.1 Genexpressionsanalyse nach Hemmung von STAT3 und STAT6 .............. 95

5.2.2 Transkriptionelle Ziele von STAT6 ....................................................... 96

5.3 Zytokin-Genvariationen in malignen Lymphomen ............................. 104

5.3.1 IL-10-Genvariationen im malignen NHL........................................... 104

5.3.2 Variationen in Th2-Zytokin- und Zytokinrezeptorgenen im DLBCL............ 107

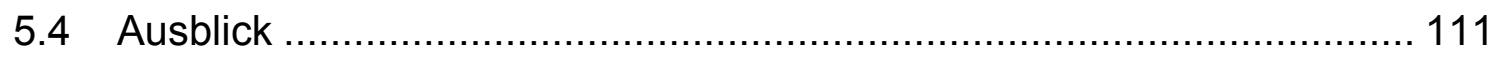


6. ZUSAMMENFASSUNG

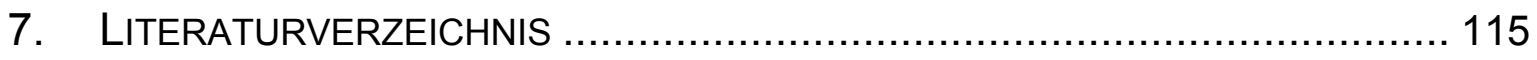

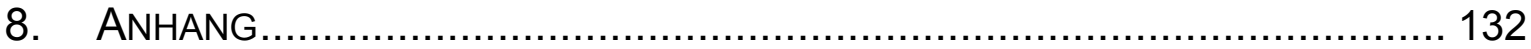

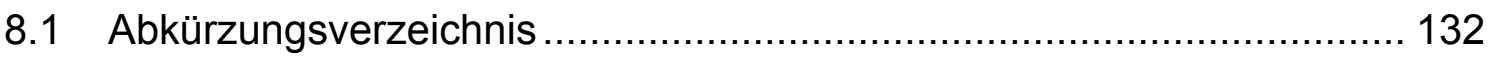

8.2 Publikation Kube et al. Clin. Cancer. Res. (2008) ........................... 135

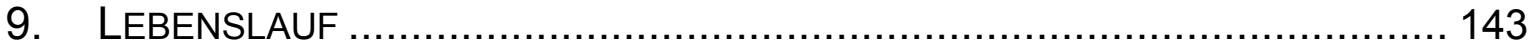

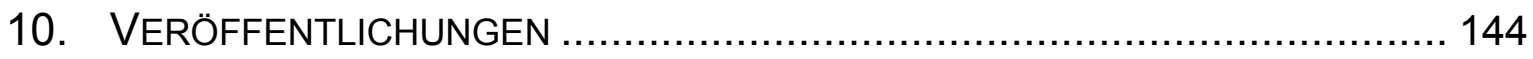

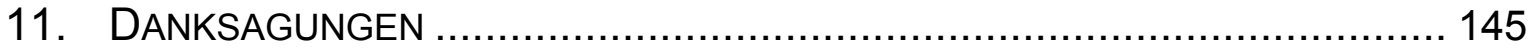




\section{EINLEITUNG}

Krebserkrankungen gehören zu den häufigsten Todesursachen in der westlichen Welt. Die Häufigkeit vieler Krebsarten nimmt mit dem Alter zu, so dass im Rahmen des demographischen Wandels auch eine starke Zunahme an Neuerkrankungen festzustellen ist. Neben den häufigen soliden Tumoren des Darms und der Lunge, steigt die Inzidenz maligner Erkrankungen des lymphatischen Systems in Deutschland und anderen Industriestaaten stetig (Batzler et al., 2008).

Als Krebs bezeichnet man die maligne Entartung von Zellen, die im Gegensatz zu benignen Erkrankungen durch infiltratives und destruktives Wachstum, sowie die Fähigkeit zur Metastasenbildung charakterisiert ist. Die Tumorigenese ist ein multifaktorieller und mehrstufiger Vorgang, der nach heutigem Kenntnisstand zu einer Veränderung grundlegender zellphysiologischer Funktionen führen muss (Hanahan et al., 2000). Eine Vorraussetzung für die Entartung ist die stetige Versorgung mit wachstumsfördernden Signalen. Dies kann durch Mutationen in so genannten Proto-Onkogenen, die zur konstitutiven Aktivierung bestimmter Signalwege führen, oder durch die aberrante Produktion von Wachstumsfaktoren wie z.B. Zytokine geschehen. Einhergehend können wachstumsinhibierende Faktoren, wie z.B. durch die Mutation von Tumorsuppressorgenen, unterbunden werden, um eine weitere Steigerung der Zellteilung (Proliferation) zu erreichen. Aberrant proliferierende Zellen werden in der Regel durch das Immunsystem erkannt und über den programmierten Zelltod (Apoptose) eliminiert. Viele Tumorzellen weisen daher zum einen eine Unempfindlichkeit gegenüber der Apoptoseinduktion auf z.B. durch eine verminderte Expression an proapoptotischen Rezeptoren. Zum anderen kann die Erkennung der Tumorzellen durch das Immunsystem durch eine geringe Immunogenität z.B. durch die geringere Produktion der Proteine des humanen Leukozytenantigen-Komplex (HLA) oder aber durch Immunsuppression z.B. durch das Zytokin Interleukin-10 (IL-10) verhindert werden. Weiteren Faktoren, die zur malignen Entartung und dem Krankheitsverlauf beitragen, sind die Steigerung der Nährstoffversorgung (durch Angiogenese), die Invasivität sowie die Metastasierung der Tumorzellen.

Die Ursachen, die zu diesen Veränderungen führen, scheinen beinahe unbegrenzt. Dennoch ist die maligne Entartung von Zellen ein seltenes zufälliges 
Ereignis. Zudem bringt das über die letzten Jahrzehnte gewonnene Wissen über die Biologie der Tumorzellen erste Erfolge im Bereich der Therapie.

Die in dieser Arbeit betrachteten Lymphome gehören $\mathrm{zu}$ malignen Tumorerkrankungen, die im Allgemeinen gute Überlebenschancen durch die aktuellen Therapiestrategien aufweisen. Es gibt jedoch eine stetig hohe Anzahl von Therapie-resistenten Patienten, viele Therapie-assoziierte Toxizitäten sowie sekundäre Neoplasien, die oft erst Jahre nach der Ersttherapie auftauchen. Um gerade die Behandlung dieser Patienten zu verbessern, ist die Entwicklung neuer Therapiemöglichkeiten unbedingt notwendig. Insbesondere hofft man, dass die zielgerichteten Therapien (so genannte "targeted therapies“) in den nächsten Jahren zu einer besseren Behandlung und Lebensqualität bei reduzierter Therapie-bedingter Toxizität der Lymphompatienten führt. "Targeted therapies“ richten sich nicht wie heutige Standardchemotherapeutika gegen alle Zellen des Organismus, sondern zeichnen sich durch Selektivität gegenüber bestimmten Zielstrukturen der Tumorzellen wie z.B. aktivierten Signalwegen aus. Durch die Analyse dieser Signalwege in den Tumorzellen können molekulare Strukturen als Ziele einer Therapie definiert und deren Applikation getestet werden.

Diese Arbeit befasst sich mit Zytokinen und deren Signaltransduktion in malignen Lymphomen. Die physiologischen Funktionen von Zytokinen, wie die Regulation der Zellproliferation, Zellüberleben, Angiogenese, Migration, Invasion und Immunmodulation sind auch bei Lymphomerkrankungen von hoher Bedeutung. Da ihr Ursprung in Zellen des Immunsystems liegt, zeigen viele Lymphomentitäten eine hohe eigene Zytokinproduktion. Der Verlauf der Lymphomerkrankungen wird stark von umgebenen nicht-malignen Zellen beeinflusst, deren Interaktion auch durch Zytokine gesteuert wird.

Im den ersten beiden Teilen der Arbeit wird vor allem die ZytokinSignaltransduktion des Janus-Kinase (Jak) - Signal transducer and activator of transcription (STAT) - Signalwegs in Bezug auf das Verständnis der Pathologie als auch auf die Möglichkeit zur gerichteten Therapie betrachtet. Hierbei werden Zelllinien des klassischen Hodgkin-Lymphoms verwendet, die sich durch eine hohe Zytokinproduktion sowie eine permanente Aktivierung von Transkriptionsfaktoren, die durch Zytokine aktiviert werden, auszeichnen. 
Der dritte Teil der Arbeit befasst sich mit Genvariationen von Zytokinen und deren Rezeptoren. Es soll untersucht werden, ob die Genvariationen einen Einfluss auf das Überleben von Lymphompatienten haben könnten. Dies ist vor dem Hintergrund der stetig steigenden Zahl nicht-therapierbarer Lymphompatienten von Bedeutung, da diese Variationen weitere bisher unbekannte Risikofaktoren darstellen können.

\subsection{Maligne Lymphome}

Aktuell werden maligne Lymphome nach der 2003 entstandenen WHOKlassifikation in mehrere Gruppen unterteilt (WHO, 2003). Hierbei werden die Hodgkin-Lymphome $(\mathrm{HL})$ von den Non-Hodgkin-Lymphome (NHL) getrennt. Beide Gruppen unterteilen sich in weitere Subtypen, die sich sowohl in der Pathogenese als auch im klinischen Verlauf unterscheiden können. Nach aktuellen Schätzungen des Robert-Koch-Institutes liegt die Inzidenz in Deutschland für das HodgkinLymphom bei etwa 2000 Fällen pro Jahr und für die Non-Hodgkin-Lymphome bei etwa 6500 Fällen pro Jahr. Letztere machen somit etwa 3\% der neu diagnostizierten Krebsfälle aus (Batzler et al., 2008).

Lymphome haben ihren Ursprung in nicht malignen Lymphozyten verschiedener Entwicklungsstadien und Herkunft. So sind die meisten Lymphome B-lymphozytären und nur in seltenen Fällen T-lymphozytären Ursprungs. Man ist heute der Ansicht, dass B-Zell-Lymphome vorrangig bei der so genannten Keimzentrumsreaktion in den sekundären Lymphorganen entstehen (Abbildung 1.1).

Die B-Zell-Keimzentrumsreaktion - Ursprung vieler Lymphomentitäten

Um den Körper vor Infektionen zu schützen, führt die Keimzentrumsreaktion zu einer Reihe wichtiger Modifikationen in den B-Lymphozyten, die eine schnelle und effektive spezifische Immunantwort auf ein bestimmtes Pathogen ermöglichen. Nach dem Antigenkontakt können einige aktivierte B-Lymphozyten Keimzentren in den sekundären lymphatischen Organen bilden (Centroblast). Dort findet eine klonale Expansion der Zellen und dabei die so genannte somatische 
Hypermutation (SHM) der Immunglobulingene statt (Centrozyt). Dadurch können die variablen Immunglobulingensegmente durch zufällig eingeführte Punktmutationen verändert werden. Dies kann zur Veränderung der Affinität des Immunglobulins zum Antigen führen. Die sich anschließende Affinitätsreifung führt zur Selektion derjenigen B-Lymphozyten mit erhöhter Antigenaffinität. Dazu muss eine korrekte Interaktion mit T-Helfer-Zellen (Th-Zellen) sowie follikulären Dendritischen Zellen (FDCs) erfolgen, die zu Überlebenssignalen in den B-Lymphozyten führt. Zellen, die eine geringere Antigenaffinität aufweisen oder die durch die eingeführten Punktmutationen kein funktionelles Immunglobulin exprimieren, können nicht adäquat mit den T-Lymphozyten interagieren und werden durch Apoptose eliminiert. Durch die Kombination verschiedener Stimulanzien im Zusammenspiel mit Zytokinen können die selektierten B-Zellklone einen Isotypenwechsel (class switch recombination (CSR)) des Immunglobulins durchlaufen (Plasmablast). Zum Beispiel können Interleukin-4 und Interleukin-13 zusammen mit der Stimulation von CD40 zu einem Klassenwechsel zum IgEIsotyp oder Interleukin-10 zu Wechsel zum IgA-Isotyp führen. Die konstante Region der Immungloblulin-Schwerkette wird durch Rekombination der DNA verändert, so dass ein breites Repertoire an Antikörperisotypen (vor allem IgG, $\lg E$ und $\lg A$ ) mit verschiedenen Effektorfunktionen entsteht. Die modifizierten B-Lymphozyten können so zu Antikörper-produzierenden Plasmazellen oder Gedächtnis-B-Zellen reifen (Rajewsky, 1996; Klein et al., 2008).

Durch molekulare Analysen konnte der Ursprung vieler Lymphome einer spezifischen Phase der B-Zellentwicklung zugeordnet werden. Die Zellen vieler Subtypen des $\mathrm{NHL}$ aber auch des $\mathrm{HL}$ tragen charakteristische Merkmale von Keimzentrums-B-Lymphozyten. So finden sich in diesen Lymphomzellen Veränderungen in den variablen Regionen der Immunglobulingene, die durch die somatische Hypermutation verursacht sind, oder ein bereits vollzogener Isotypenwechsel in den konstanten Regionen der Immunglobulingene. Die so gewonnene Zuordnung hat sowohl zur Klassifikation und als auch zum Verständnis der pathologischen Mechanismen dieser Entitäten beigetragen (Klein et al., 2008). 


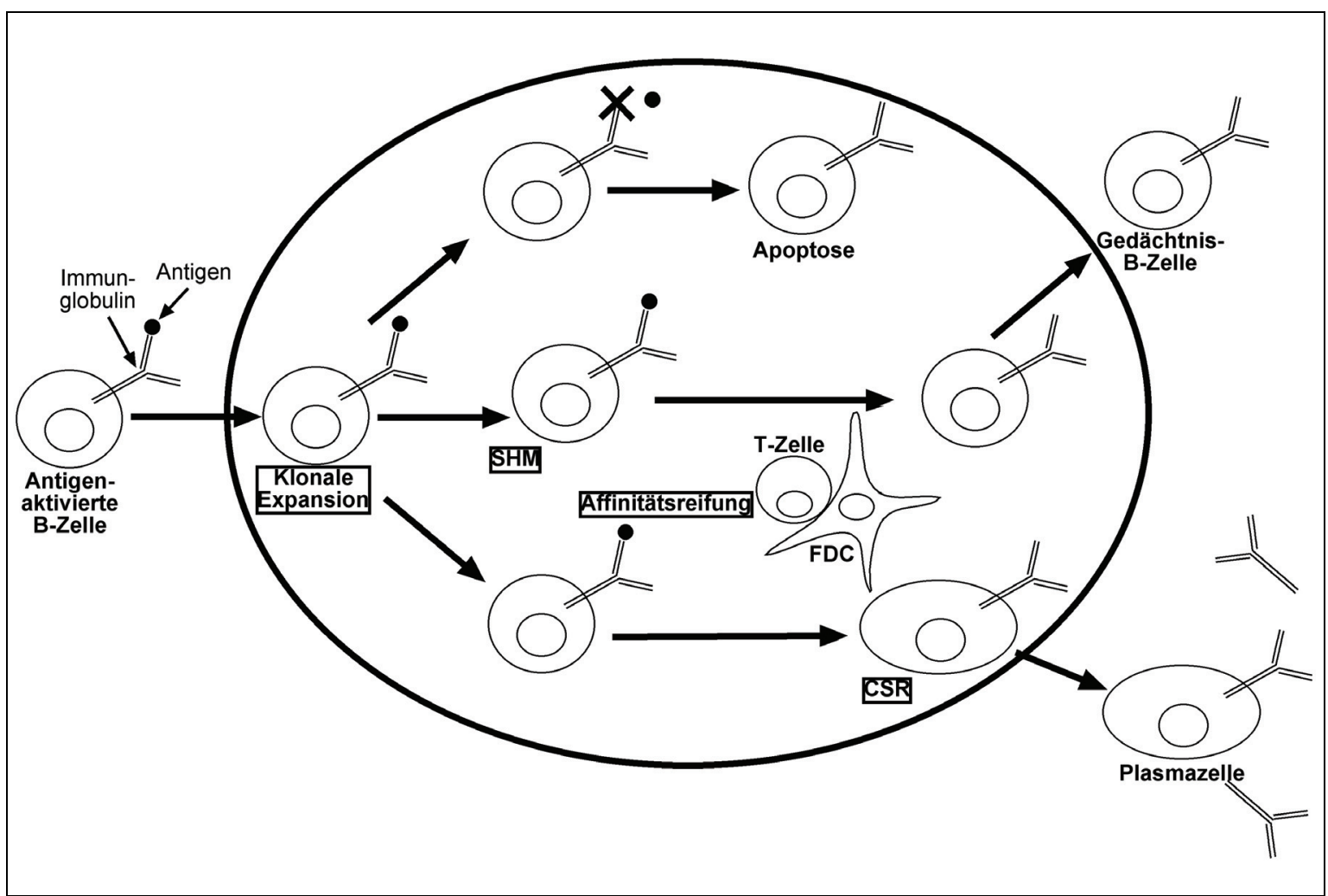

Abbildung 1.1 Keimzentrumsreaktion von B-Zellen (verändert nach Klein et al., 2008). Antigen-aktivierte B-Zellen können zu Centroblasten differenzieren, die eine klonale Expansion im Keimzentrum durchlaufen. Während der Expansion führt der Prozess der somatischen Hypermutation (SHM) Punktmutationen in die variablen Regionen der Immunglobulingene ein, die zu einem Aminosäurenaustausch im Protein führen können. Die Centroblasten differenzieren zu Centrozyten und werden über die Affinitätsreifung durch Interaktion mit Th-Zellen und follikulären Dendritischen Zellen (FDC) auf erhöhte Antigen-Affinität selektiert. Centrozyten mit geringerer Antigen-Affinität werden über die Apoptose eliminiert. Ein Teil der selektierten Centrozyten differenziert zu Gedächtnis-B-Zellen und ein weiterer Teil differenziert über einen ImmunglobulinIsotypenwechsel (CSR) zu Antikörper-produzierenden Plasmazellen.

\subsubsection{Das Hodgkin-Lymphom}

Das Hodgkin-Lymphom, auch Morbus Hodgkin oder Lymphogranulomatose genannt, wurde erstmalig 1832 von Sir Thomas Hodgkin beschrieben (Hodgkin, 1832). Histologisch wird zwischen dem klassischen Hodgkin-Lymphom (cHL) und dem selteneren Lymphozyten-prädominanten Hodgkin-Lymphom unterschieden. Das in dieser Arbeit betrachtete klassische Hodgkin-Lymphom wird weiter unterteilt in das nodulär-sklerosierende $\mathrm{HL}$, das $\mathrm{HL}$ gemischter Zellularität, das Lymphozyten-arme HL und das zuletzt klassifizierte noduläre lymphozytenreiche klassische HL (WHO, 2003).

Die entarteten Zellen des cHLs sind die mononukleären Hodgkin- und multinukleären Reed-Sternberg-Zellen (HRS-Zellen). Letztere wurden erstmalig 
1898 von Carl Sternberg und 1902 von Dorothy Reed beschrieben (Sternberg, 1898; Reed, 1902). Der Ursprung der HRS-Zellen sind in den meisten cHL-Fällen entartete B-Lymphozyten und in sehr seltenen Fällen entartete T-Lymphozyten (Bräuninger et al., 2006). Die HRS-Zellen stellen nur etwa 1\% des Tumorgewebes in den Lymphknoten der Patienten dar. Quantitativ dominiert hier ein reaktives Infiltrat, das je nach Subtyp des cHLs aus verschiedenen inflammatorischen Zellen wie T-Lymphozyten, Plasmazellen sowie eosinophilen und neutrophilen Granulozyten besteht (Bräuninger et al., 2006).

\section{Das Hodgkin-Lymphom - ein Zytokin-produzierender Tumor}

An der Rekrutierung des Mikromillieus sind vor allem parakrine Wirkungen verschiedener Zytokine und Chemokine beteiligt. Das $\mathrm{cHL}$ ist als Zytokinproduzierender Tumor bekannt (Skinnider et al., 2002b). Die Zelllinien des cHL bieten für die Analyse der durch Zytokine aktivierten Signalwege ein Modelsystem, da sie viele Zytokine produzieren und über eine permanente Aktivierung der STAT-Transkriptionsfaktoren verfügen, die hauptsächlich durch Zytokine aktiviert werden. Da es bisher kein Tiermodell für die Erkrankung des cHLs gibt, bieten die cHL-Zelllinien die Möglichkeit zur Erforschung dieser Erkrankung. Die Ergebnisse müssen aber an primärem Tumorgewebe von cHL-Patienten validiert werden.

Für das cHL werden zurzeit unter anderem die Zytokine Interleukin (IL) -3, -4, -5, $-6,-9-10$ und -13 als bedeutsame Faktoren diskutiert. Die Zelllinien produzieren hauptsächlich IL-13 und IL-6. Einige Zelllinien zeigen jedoch auf Grund ihrer Heterogenität auch eine Produktion von IL-4, IL-5, IL-9 und IL-10. In primären Tumorgewebe von cHL-Patienten konnten vorrangig die Zytokine IL-13, -5, -6 und -9 nachgewiesen werden. IL-10 wurde in Verbindung mit einer Epstein-Barr-Virus (EBV) Infektion in etwa einem Drittel der cHL-Fälle nachgewiesen. IL-3 wird nur in wenigen cHL-Fällen von den HRS-Zellen produziert und auch in den Zelllinien konnte nur der Rezeptor für IL-3 nachgewiesen werden. Die cHL-Zelllinien können aber die Produktion von IL-3 in T-Lymphozyten anregen, was für eine parakrine Wirkung von IL-3 auf die cHL-Zellen sprechen könnte (Skinnider et al., 2002b; Aldinucci et al., 2005).

Neben den parakrinen Effekten sind für viele dieser Faktoren autokrine Effekte postuliert worden. Für IL-13 konnte sowohl die Produktion des Zytokins als auch 
der IL-13-Rezeptor auf den cHL-Zellen nachgewiesen sowie eine Wirkung auf die Aktivierung von STAT6 gezeigt werden (Skinnider et al., 2001a; Skinnider et al., 2002a). Obwohl auch STAT3 sowie STAT5 in den cHL-Zelllinien permanent aktiviert sind, wurde hierfür bisher kein autokriner Faktor identifiziert (Kube et al., 2001a; Hinz et al., 2002; Weniger et al., 2006). In klinischen Studien konnte ein negativer Einfluss des Serumwertes der Zytokine IL-9 und IL-10 auf das Überleben der cHL-Patienten gezeigt werden (Sarris et al., 1999; Fischer et al., 2003). Der IL-9 Serumwert kann ebenfalls Einfluss auf die Zusammensetzung des reaktiven Infiltrats um die HRS-Zellen haben (Glimelius et al., 2006).

\section{Zelluläre Charakteristika des Hodgkin-Lymphoms}

Trotz der Abstammung der meisten cHL-Fälle von B-Lymphozyten exprimieren HRS-Zellen nur sehr wenige B-Zell-spezifische Marker. HRS-Zellen tragen in den meisten Fällen keine Immunglobuline (Ig) (B-Zellrezeptor) auf ihrer Zelloberfläche und eine Expression der Ig spezifischen Transkriptionsfaktoren PU.1, B-cellspecific coactivator OBF-1 (BOB1), Octamer-binding transcription factor-2 (OCT2) sowie weiterer typischen B-Zellmarker (Cluster of Differentiation (CD)19, CD20, CD79a/b, CD45) konnte nicht nachgewiesen werden (Re et al., 2001; Stein et al., 2001; Torlakovic et al., 2001; Schwering et al., 2003). Dennoch verfügen HRS-Zellen über Transkriptionsfaktoren der E2F-Familie (Paired box protein 5 (Pax5), Early B-cell factor 1 (EBF1) und Kappa-E2-binding factor (E2A)). Die Expression dieser Transkriptionsfaktoren ist entscheidend für die Differenzierung der hämatopoetischen Vorläuferzelle in die Linie der B-Lymphozyten und für die Aktivierung des B-Zellprogramms. Unter anderem aktiviert z.B. Pax5 die Activation induced cytidine deaminase (AICDA), die essentiell für die somatische Hypermutation und den Isotypenklassenwechsel ist (Abschnitt 1.2 Keimzentrumsreaktion). Erst zur weiteren Differenzierung der B-Lymphozyten zu Plasmazellen ist die Inaktivierung von Pax5 notwendig (Klein et al., 2008). Trotz der Expression der E2F-Faktoren im $\mathrm{cHL}$, wird vermutet, dass ihre Funktion durch die Expression des Inhibitor of DNA binding 2 (ID2) und des Activated B-cell factor 1 (ABF1) gehemmt wird. Dies könnte eine Erklärung für den Verlust der B-Zellspezifischen Genexpression sein (Mathas et al., 2006; Renne et al., 2006). Ein weiterer Faktor, der in fast allen cHL-Fällen exprimiert wird, ist der 
Transkriptionsfaktor Interferon regulatory factor 4 (IRF4) (Buettner et al., 2005). IRF4 wird zur Differenzierung von B-Lymphozyten zu Plasmazellen benötigt und reguliert für diese Differenzierung essentielle Faktoren wie z.B. X-box binding protein 1 (XBP1) und B-cell lymphoma 6 (BCL6) (Klein et al., 2008). In T-Lymphzyten kommt es bei Stimulation mit IL-4 zu einer Expression von IRF4. IRF4 kann dabei zur Aktivierung des Th2-spezifischen Transkriptionsfaktors GATA binding factor 3 (GATA3) führen (Atayar et al., 2005; Buettner et al., 2005).

Ein weiteres Merkmal der HRS-Zellen zeigt sich in der Expression von B-Zelluntypischen Genen. So konnten unter anderem die T-Zell-spezifischen Faktoren Neurogenic locus notch homolog protein 1 (Notch1), die Transkriptionsfaktoren T-box expressed in T-cells (T-Bet) und GATA3 sowie das Chemokin Thymus and activation-regulated chemokine (TARC), das in der Regel von Dendritischen Zellen sekretiert wird, nachgewiesen werden (van den Berg et al., 1999; Jundt et al., 2002; Atayar et al., 2005). Dies könnte ebenfalls auf die Hemmung der E2FFaktoren zurückzuführen sein, da z.B. Notch1 durch Pax5 transkriptionell gehemmt wird (Souabni et al., 2002).

Des Weiteren werden im $\mathrm{cHL}$ verschiedene Rezeptortyrosinkinasen (RTKs) aberrant exprimiert (Renne et al., 2005). Die Expression der RTKs variiert allerdings abhängig von cHL-Subtyp. Neben dem tyrosine kinase receptor $A$ (TRKA) und der Met proto-oncogene tyrosine kinase (c-Met), die auch in nicht malignen B-Lymphozyten exprimiert werden, konnte in vielen cHL-Fällen eine Expression des platelet-derived growth factor receptor alpha (PDGFRA), des Discoidin domain receptor 2 (DDR2), des EPH receptor B1 (EPHB1), des macrophage stimulating 1 receptor (RON) und des tyrosine kinase receptor $B$ (TRKB) nachgewiesen werden. Das nodulär-sklerosierende HL weist die meiste Expression der RTKs auf, gefolgt vom HL gemischter Zellularität und dem nodulär lymphozytenreichen $\mathrm{cHL}$.

Die cHL-Zellen sind resistent für Apoptose-induzierende Stimuli wie beispielsweise der FAS-Ligand (CD95L) oder Staurosporin (Re et al., 2000; Kashkar et al., 2002). Die Apoptose kann durch extrazelluläre und intrazelluläre Faktoren erfolgen. Extrazellulär ist die Aktivierung der Apoptosekaskade über Bindung von Liganden an so genannte Todesrezeptoren möglich. Hierbei ist vor allem die Familie der Tumor-Nekrose-Faktor (TNF)-Rezeptoren von Bedeutung, zu der auch der 
bekannte FAS (CD95)-Rezeptor gehört. Im cHL werden verschiedene TNFRezeptoren exprimiert. Es konnten in den cHL-Zellen Mutationen im CD95Rezeptor nachgewiesen werden, die vermutlich zur Resistenz gegenüber dem CD95L führen. Gleichfalls kann die erhöhte Proteinmenge des anti-apoptotischen Proteins Cellular FLICE-like inhibitory protein (cFLIP) zur Verhinderung der Apoptose beitragen (Bräuninger et al., 2006).

Andererseits kann die Apoptose durch zellulären Stress ausgelöst werden, was in der Ausschüttung von Cytochrom $\mathrm{C}$ aus den Mitochondrien resultiert. Dabei sind die Proteine der Bcl2-Familie zu erwähnen, die durch die Balance zwischen pround anti-apoptotischer Faktoren das Überleben der Zelle beeinflussen. Die unterschiedlichen Aktivierungswege der Apoptose führen zur Aktivierung von Caspasen, einer Familie von Cysteinproteasen. Dies aktiviert entsprechende Faktoren, was letztendlich die Degradation der DNA und die Auflösung der Zelle zur Folge hat. Eine erhöhte Proteinmenge des $X$-linked inhibitor of apoptosis protein (XIAP) - einem Caspase-3-Antagonisten - könnte so die ApoptoseInduktion verhindern (Bräuninger et al., 2006).

\section{Therapie des Hodgkin-Lymphoms}

Das cHL hat mit der heutigen Kombination aus Radio- und Chemotherapie eine 5-Jahresüberlebensrate von etwa $90 \%$ und auch bei einem Rezidiv sind $40 \%$ der Patienten mit alternativen Strategien therapierbar (Re et al., 2005; Batzler et al., 2008). Das eigentliche Problem der Erkrankung liegt im sehr jungen Alter der Patienten begründet. $65 \%$ der Patienten sind unter 40 Jahre alt. Die Patienten haben ein hohes Risiko an akuten und späten Toxizitäten der stark belastenden Therapie zu sterben. So führen die Spätfolgen der Therapie zu einem 6,8-fach erhöhten Risiko an einer Sekundärneoplasie wie z.B. dem myelodysplastischen Syndrom oder einer akuten Leukämie zu erkranken. Die Aufgabe für die nächsten Jahre ist es, die Erkenntnisse der molekularen Analyse in Therapieformen umzuwandeln, die eine geringe Toxizität bei gleich bleibenden Überlebensraten bringen (Re et al., 2005).

Im Falle des cHLs wurden verschiedene deregulierte Signalwege nachgewiesen, die aus therapeutischer Sicht interessant sein könnten. Von wichtiger Bedeutung sind vor allem die permanente Aktivierung von Nuclear factor-kappa B (NFkB), 
STAT-Molekülen und MAPKJERK kinase (MEK) / extracellular signal-related kinase (ERK) (Bargou et al., 1997a; Izban et al., 2001; Kube et al., 2001a; Skinnider et al., 2002a; Zheng et al., 2003). Alle drei Signalwege bieten Ansätze für eine spezifische Intervention. Der Proteasome-Inhibitor Bortezomib ist in der klinischen Testung verschiedener Lymphomentitäten. In Hodgkin-LymphomZelllinien konnte eine Inhibition des NFKB-Signalwegs mit einhergehender Sensitivierung für Apoptose-induzierende Agenzien durch Behandlung mit Bortezomib nachgewiesen werden (Kashkar et al., 2007). In klinischer Testung war allerdings eine Monotherapie mit Bortezomib im cHL nicht erfolgreich (Blum et al., 2007). Sowohl für den Jak-STAT- als auch den MEK/ERK-Signalweg sind Proteinkinase-Inhibitoren bekannt (Kube et al., 2001a; Zheng et al., 2003; Holtick et al., 2005). Die Arbeitsgruppe Kube konnte zeigen, dass die Inhibitoren der Tyrphostin-Klasse AG490 sowie AG17 die Proliferation der cHL-Zelllinien reduzieren, einhergehend mit der Hemmung der Tyrosinphosphorylierung der Transkriptionsfaktoren STAT3 und STAT6. AG490 gilt als spezifischer Inhibitor der Janus Kinase Jak2, wogegen die Ziele von AG17 im cHL noch unbekannt sind (Kube et al., 2001a; Holtick et al., 2005).

Durch den Einsatz dieser selektiven Inhibitoren könnten die Signalwege spezifisch moduliert werden. Die Erforschung von weiteren Molekülen, die eine Rolle im Überleben der Lymphomzellen spielen und sogar mehrere Signalwege zugleich modulieren, könnte entscheidende Fortschritte in der Therapie bringen.

\subsubsection{Die Non-Hodgkin-Lymphome}

In der Gruppe der Non-Hodgkin-Lymphome werden alle malignen Lymphome erfasst, die nicht der Pathologie des Hodgkin-Lymphoms entsprechen. Es handelt sich um eine sehr heterogene Gruppe von Erkrankungen, die sich stark im zellulären Ursprung, genetischen Aberrationen sowie klinischem Verlauf unterscheiden.

Einige der häufigsten malignen NHL-Subtypen B-zellulären Ursprungs sind das diffus-großzellige B-Zell-Lymphom (DLBCL) und das Burkitt Lymphom (BL). Etwa 10\% der NHLs bilden T-Zell-Neoplasien, die schwer therapierbar und durch einen aggressiven klinischen Verlauf gekennzeichnet sind. 


\section{Genexpressionsanalysen von Non-Hodgkin-Lymphomen}

Auf Grund der hohen Heterogenität der malignen NHLs ist eine Klassifikation häufig schwierig und die alleinige Betrachtung von histologischen Merkmalen oder genetischen Aberrationen oft nicht ausreichend. Die Weiterentwicklung der Genexpressionsanalysen mittels Microarray-Technologie hat in den letzten Jahren zum molekularen Verständnis von malignen Lymphomerkrankungen beigetragen (Alizadeh et al., 2000). Die Gruppe der DLBCLs konnte auf Grund von Genexpressionsprofilen in zwei weitere Subgruppen unterteilt werden. Die eine Gruppe ist charakterisiert durch ein Genexpressionsprofil typisch für Keimzentrums-B-Zellen (GCB) wie z.B. der Expression von CD10 und BCL6, ist mit einer Translokation von B-cell lymphoma 2 (BCL2) assoziiert und hat einen relativ guten klinischen Verlauf. Die zweite Gruppe entspricht dem ExpressionsProfil für aktivierte B-Zellen ( $A B C$ ) wie z.B. der Expression von IRF4, hat einen konstitutiv aktiven NFKB-Signalweg und einen schlechteren klinischen Verlauf im Vergleich zu GCB-DLBCLs (Alizadeh et al., 2000).

Zwei Lymphom-Konsortien haben im Jahr 2006 gezeigt, dass durch die Microarray-Technologie eine molekulare Unterscheidung zwischen BL und DLBCL möglich ist (Dave et al., 2006; Hummel et al., 2006). Des Weiteren zeigte eine Genexpressionsanalyse, dass die Rolle des Tumormikromilieus in DLBCLPatienten für den Krankheitsverlauf von Bedeutung ist. Es wurde eine Subgruppe von DLBCLs, die durch eine inflammatorische Immunreaktion (,host response“) charakterisiert ist, identifiziert (Monti et al., 2005). Da insbesondere Zytokine an inflammatorischen Prozessen beteiligt sind, könnten diese Faktoren und ihre Regulation die Lymphomerkrankung beeinflussen.

\section{Therapie des NHLs}

Im Vergleich zum Hodgkin-Lymphom haben Patienten mit malignem NHL durch die heutigen Therapieschemata schlechtere Überlebensraten. Abhängig vom Subtyp liegt die 5-Jahresüberlebenrate bei etwa 60\% (Batzler et al., 2008). Bis vor einigen Jahren war die CHOP/CHOEP-Therapie (Cyclophosphamid, Doxorubicin, Vincristin, Prednison, Etoposid) der Standard für Patienten mit malignem NHL. Die Technologie zur Produktion von humanisierten, monoklonalen Antikörpern führte 
zur Entwicklung des therapeutischen Antikörpers Rituximab. Dieser Antikörper erkennt das CD20 Epitop, welches sich auf B-Zellen und ihren malignen Konterparts befindet. Inzwischen wird Rituximab zusätzlich zur CHOP-Therapie in malignen NHLs eingesetzt (Kahl, 2008; Pfreundschuh et al., 2008).

Die starke Heterogenität der malignen NHLs ist auch aus therapeutischer Sicht ein Problem. Es bedarf einer klaren Risikoeinschätzung der Patienten, um eine hoch oder niedrig dosierte Chemotherapie anzuwenden. Neben der Klassifikation der Subentitäten, die in den letzten Jahren große Fortschritte gemacht hat, müssen Risikofaktoren, die den Verlauf der Krankheit beeinflussen, charakterisiert werden. Maligne NHLs werden heute nach den Faktoren des International Prognostic Index (IPI) in 4 Risikogruppen eingeteilt. Die im IPI enthaltenen Faktoren sind das Alter (<= 60 Jahre vs. >60Jahre), ein erhöhter Laktatdehydrogenasewert im Serum, Allgemeinzustand (nach Vorgabe der Eastern Cooperative Oncology Group (ECOG)), Krankheitsstadium (nach Ann-Arbor-Klassifikation) und Anzahl der Extranodalbefälle (Shipp, 1994). Auch wenn alle Faktoren unabhängig voneinander mit dem klinischen Verlauf verbunden sind, beschreiben sie hauptsächlich subjektive Patientencharakteristika. Faktoren, die die Biologie und die pathologischen Mechanismen des jeweiligen Lymphoms widerspiegeln, werden bisher nicht in der Therapie berücksichtigt. 


\subsection{Zytokine}

Im komplexen Zusammenspiel zwischen den Komponenten des Immunsystems spielen Zytokine eine essenzielle Rolle (Lucey et al., 1996; Hofmann et al., 2002). Zytokine sind von Zellen sezernierte Glykoproteine von etwa $25 \mathrm{kDa}$, die nach ihrer Bindung an den entsprechenden Rezeptorkomplex pleiotrope Reaktionen auslösen können. Diese Wirkungen können entweder autokrin auf die sezernierende Zelle selbst oder aber parakrin auf andere Zellen wirken. Zytokine werden in die Familie der Interleukine, Interferone und Tumor-Nekrose-Faktoren unterteilt.

Interleukine sind bei vielen Prozessen wie der Proliferation und Differenzierung verschiedener Zelltypen innerhalb des Immunsystems beteiligt. Interferone haben vor allem eine Funktion in antiviralen und antitumoralen Immunreaktionen. TumorNekrose-Faktoren sind insbesondere an inflammatorischen Prozessen beteiligt. Interleukine und Interferone aktivieren bei Rezeptorbindung hauptsächlich den Jak-STAT-Signalweg, während die Tumor-Nekrose-Faktoren vor allem den NFkBSignalweg aktivieren.

Die Zytokin-Expression ist abhängig vom jeweiligen Zelltyp und wird durch das Zusammenspiel verschiedener Transkriptionsfaktoren reguliert. Neben der Abhängigkeit von den spezifischen Transkriptionsfaktoren ist die Zugänglichkeit der Gene im chromosomalen Kontext entscheidend. Während der Differenzierungsprozesse der Zellen wird eine Zelltyp-spezifische Chromatinstruktur festgelegt, die die Expression der Zytokine bedingt (Holloway et al., 2002). Darüber hinaus gibt es große interindividuelle Unterschiede in der Zytokinproduktion, die zu einem sehr großen Anteil auf genetische Faktoren wie Genvariationen zurückzuführen sind (Turner et al., 1997; Westendorp et al., 1997).

Rolle der Zytokine im Immunsystem und malignen Zellen

Bei der angeborenen Immunabwehr sind Zytokine an inflammatorischen Prozessen beteiligt, die zur Erkennung und Beseitigung der Infektion notwendig sind. Aktivierte Makrophagen sezernieren insbesondere IL-1, IL-6, IL-12 und TNF- $\alpha$, die jeweils unterschiedliche lokale Wirkungen wie z.B. Lymphozytenaktivierung aber auch systemische Wirkungen wie z.B. Fieber 
hervorrufen. Die anti-inflammatorische Funktion von IL-10 dient der Hemmung von aktivierten T-Lymphozyten, Makrophagen und NK-Zellen, die neben der Pathogenbeseitigung auch Gewebeschäden hervorrufen können. IL-10 wird hauptsächlich von Makrophagen, dendritischen Zellen und regulatorischen T-Zellen ( $T_{\text {reg }}$ ) produziert (Couper et al., 2008). Auf B-Lymphozyten hat IL-10 eine andere Wirkung. IL-10 fördert das Überleben, ist ein Kofaktor für die Proliferation der B-Zellen und kann verschiedene Differenzierungsprozesse auslösen (Moore et al., 2001).

Bei der adaptiven Immunantwort sind Zytokine insbesondere für die initiale Polarisierung der T-Lymphozyten also auch für die weiterführende Immunreaktion von Bedeutung. Man unterscheidet vorrangig die zellvermittelte (Th1) von der humoralen (Th2) Immunität. Erstere richtet sich vor allem gegen intrazelluläre Pathogene, während die Th2-Immunantwort zur B-Lymphozyten-Aktivierung und Antikörperproduktion hauptsächlich gegen extrazelluläre Pathogene führt (Romagnani, 1997). Die Polarisierung zu einer der beiden Arten von Immunantwort ist stark von zwei Zytokinen abhängig. Interferon- $\gamma$ (IFN- $\gamma$ ) führt zu einer Th1-Reaktion, blockiert aber gleichzeitig die Th2-Immunantwort. Für die Etablierung von Th2-Reaktionen ist IL-4 das wichtigste Zytokin. Die so polarisierten T-Lymphozyten unterscheiden sich wiederum stark in ihren Zytokinproduktionsprofilen. Th1-Zellen bilden weiterhin hauptsächlich IFN-ץ sowie IL-2. Th2-Zellen dagegen produzieren viele verschiedene Zytokine, hauptsächlich aber IL-4, IL-5, IL-6, IL-10 und IL-13, die unter anderem für die Aktivierung von B-Lymphozyten und die Antikörperproduktion sorgen (Lucey et al., 1996; Romagnani, 1997). Neben Th1- und Th2-Immunantworten wurde kürzlich die Th17-Immunreaktion entdeckt, die durch die Produktion von IL-17 und IL-22 gekennzeichnet ist. Sie spielt sowohl eine Rolle bei der Infektionsbeseitigung, ist aber auch an vielen Autoimmunerkrankungen beteiligt (Dong, 2008).

Auch in der Tumorimmunologie sind Zytokine von Bedeutung. Die Tumorerkennung und -beseitigung läuft hauptsächlich über Th1-Immunantworten ab. Durch die Produktion von z.B. IL-4, IL-13 oder IL-10 können Tumorzellen die Erkennung durch das Immunsystem verhindern, in dem die Th1-Immunantwort in Richtung Th2-Immunantwort polarisiert wird. Gleichzeitig können diese Faktoren auch als autokrine Wachstumsfaktoren der Tumorzellen fungieren. Wie bereits 
erwähnt ist IL-10 in der Lage immunsupressiv auf Effektorzellen des Immunsystems wie z.B. cytotoxische T-Zellen zu wirken. Dies kann auch indirekt über die Produktion von TGF- $\beta$ geschehen, welches die Differenzierung $z u$

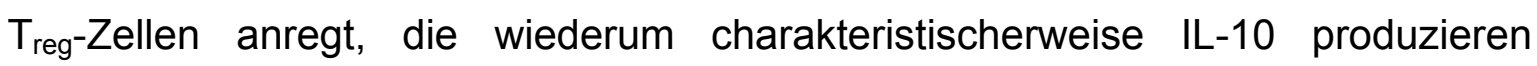
(Zitvogel et al., 2006). Ebenso sind chronische Entzündungsreaktionen, verursacht durch Zytokine wie TNF-a, häufig bei Tumorerkrankungen zu finden, die den Verlauf der Erkrankung beeinflussen können (Karin et al., 2005).

Neben den Zytokinen können lösliche Zytokinrezeptoren einen Einfluss auf die Wirkung von Zytokinen und einhergehende Erkrankungen haben. Lösliche Rezeptoren können durch alternatives Spleißen oder durch Abspaltung von der Zelloberfläche entstehen. Durch die löslichen Rezeptoren können extrazelluläre Zytokine entweder stabilisiert werden oder aber eine Bindung der Zytokine an Membran-gebundene Rezeptoren und somit die Signaltransduktion in den Zielzellen verhindern (Fernandez-Botran, 2000). Dadurch kann die Wirkung der Zytokine entweder verstärkt oder aber gehemmt werden. Der Serumwert von löslichen Zytokinrezeptoren konnte mit dem Verlauf von Lymphomerkrankungen in Verbindung gebracht werden. Sie könnten als prognostische Marker dienen und gegebenenfalls den aktuellen Verlauf der Erkrankung widerspiegeln (Stasi et al., 1995).

\subsubsection{Signaltransduktion über den Jak-STAT-Signalweg}

Zytokine der Gruppe der Interleukine und Interferone aktivieren nach Bindung an ihren Rezeptor hauptsächlich den Jak-STAT-Signalweg (Abbildung 1.2). Die Zytokinrezeptoren oligomerisieren nach Bindung der Zytokine entweder mit gleichen, unterschiedlichen oder signalweiterleitende Rezeptoreinheiten. Die an den Rezeptoreinheiten assoziierten Janus-Kinasen werden durch die Oligomerisierung autophosphoryliert und somit aktiviert. Die aktivierten Janus-Kinasen phosphorylieren nun Tyrosinreste im cytoplasmatischen Teil der Rezeptoren, an die die STAT-Moleküle mittels Src-homology 2 (SH2)-Domäne binden können. Dort können sie von den Janus-Kinasen phosphoryliert werden. Die so aktivierten STAT-Moleküle bilden Homo- und Heterodimere, die in den 
Nukleus translozieren und dort transkriptionsaktivierende Wirkung haben können (Heinrich et al., 2003).

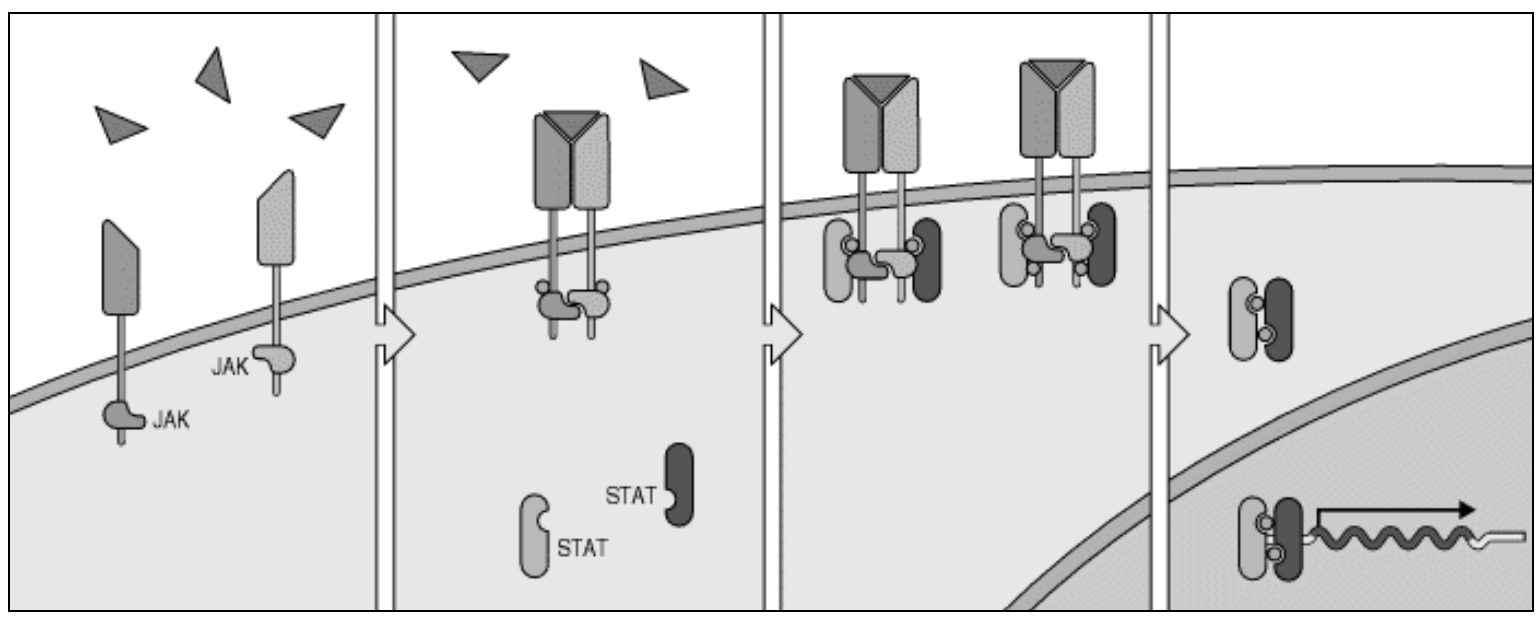

Abbildung 1.2 Schematische Darstellung des Jak-STAT-Signalwegs nach Janeway et al., 2005. Die Bindung von Zytokinen an ihre Rezeptoruntereinheiten führt zur Dimerisierung des Rezeptors. Die an den intrazellulären Teil der Rezeptoren gebundenen Janus-Kinasen werden dabei autophosphoryliert und so aktiviert. Die Janus-Kinasen phosphorylieren spezifische Tyrosinreste an den Rezeptoren, an die die STAT-Moleküle mittels SH2-Domäne binden können. Die so gebundenen STAT-Moleküle werden ebenfalls von den Janus-Kinasen phosphoryliert und können dann Dimere bilden. In diesem aktivierten Zustand wandern die STAT-Dimere in den Zellkern, wo sie als Transkriptionsfaktoren verschiedene Zielgene aktivieren.

\section{Janus-Kinasen}

Bei Säugern werden vier Mitglieder der Janus-Kinase-Familie unterschieden: Jak1, Jak2, Jak3 und Tyk2. Sie gehören zur Gruppe der Nicht-Rezeptor-TyrosinKinasen und spielen eine zentrale Rolle bei der Signaltransduktion von Zytokinen (Heinrich et al., 2003). Alle Janus-Kinasen bestehen aus einer „Four-point-one, Ezrin, Radixin, Moesin“ (FERM)-, SH2-, Pseudokinase- und Kinase-Domäne (Abbildung 1.3). Die FERM-Domäne vermittelt hierbei den Kontakt zum Rezeptor und reguliert unter Mitwirkung der Pseudokinase-Domäne die katalytische Aktivität der Kinase-Domäne. Die Bindungspartner der SH2-Domäne sind bisher nicht genau bekannt, es werden aber vermutlich weitere Phosphotyrosin-Proteine in diesen Komplex einbezogen. Die Aktivität der Janus-Kinasen wird durch Phosphorylierung der C-terminalen Tyrosinreste (Y) in der „activation loop“ der Kinase Domäne reguliert (Heinrich et al., 2003). Die in dieser Arbeit betrachteten Tyrosinphosphorylierungen der Janus-Kinasen beziehen sich auf die Tyrosinreste 
1022/1023 von Jak1, 1007/1008 von Jak2, 980/981 von Jak3 und 1054/1055 von Tyk2.

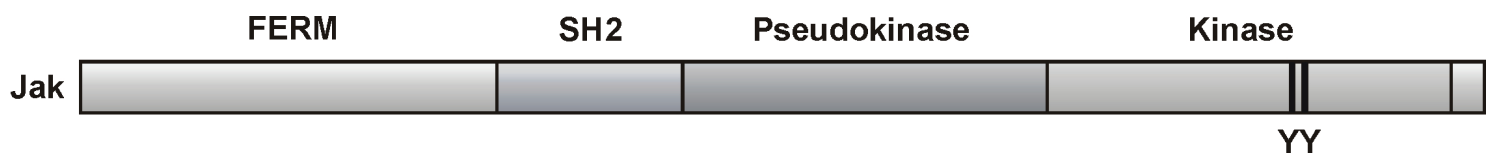

Abbildung 1.3 Schematischer Aufbau der Janus-Kinasen verändert nach Heinrich et al., 2003. Alle Janus-Kinasen bestehen vom $\mathrm{N}$ - zum C-Terminus aus einer FERM-, SH2-, Pseudokinase- und Kinase-Domäne. Die Phosphorylierung der Tyrosinreste (Y) reguliert die Aktivität der Janus Kinase.

Auf Grund der wichtigen Funktion der Janus-Kinasen bei der Zytokin-Signaltransduktion sind verschiedene hämatopoetische Tumore mit einer Deregulation der Janus-Kinasen assoziiert. Es wurde beispielsweise eine Translokation in den leukämischen Zellen bei Patienten mit akuter lymphatischen Leukämie (ALL) gefunden, bei der die Kinase-Domäne der Jak2 mit der DNA-Bindungsdomäne eines Ets-Transkriptionsfaktors fusioniert ist (Tel-Jak2) (Lacronique et al., 1997). Dies führte zu einer permanenten Aktivierung von Jak2 und der Transformation der Zelle. Ebenfalls wurde vor kurzem in verschiedenen myeloproliferativen Erkrankungen eine somatische Mutation des Jak2-Gens (Jak2 V617F) detektiert, die zu einer konstitutiven Aktivierung von Jak2 und damit zur Zytokin-unabhängigen Proliferation der Zellen führt (Levine et al., 2005).

Im cHL wurde eine erhöhte Anzahl des Jak2-Gens auf Grund chromosomaler Abberationen gefunden (Joos et al., 2000; Joos et al., 2003). Diese Amplifikation scheint jedoch nicht zu einer erhöhten Proteinmenge von Jak2 in den cHL-Zellen zu führen (Renne et al., 2007).

\section{Signal transducer and activator of transcription (STATS)}

Die Mitglieder der Transkriptionsfaktor-Familie der STATs leiten das Signal vom membranständigen Rezeptor in den Zellkern und aktivieren dort die Transkription spezifischer Zielgene. Die Familie umfasst bei Säugetieren sieben Mitglieder: STAT1, -2, -3, -4, -5a, -5b und -6. Strukturell bestehen sie aus einer „coiled-coil“-, DNA-Bindungs-, „Linker“-, SH2- und Transaktivierungs-Domäne (Abbildung 1.4). Die SH2-Domäne dient zur Bindung an phosphorylierte Tyrosinreste des Rezeptorkomplexes. Die Janus-Kinasen phosphorylieren die STAT-Moleküle an einem Tyrosinrest $(Y)$ in der Transaktivierungsdomäne. Die in dieser Arbeit 
betrachteten Tyrosinphosphorylierungen der STATs beziehen sich auf die Tyrosinreste 701 von STAT1, 705 von STAT3, 694 von STAT5 und 641 von STAT6. Die „coiled-coil“-Domäne ist für die Dimerisierung der phosphorylierten STAT-Moleküle entscheidend. Die DNA-Bindungs-Dömane vermittelt die Bindung des STAT-Dimers an die spezifische DNA-Bindungssequenz. Die Transkriptionsaktivierung wird durch die Transaktivierungs-Domäne vermittelt. (Heinrich et al., 2003).

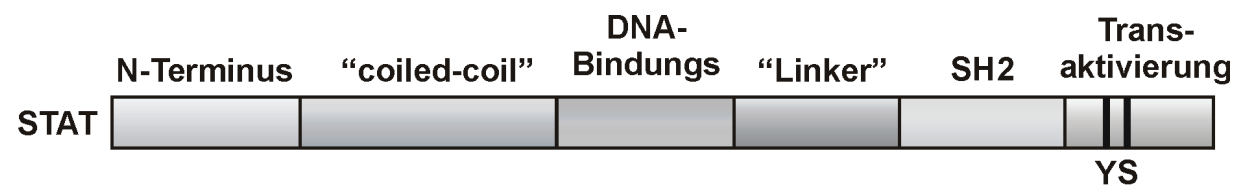

Abbildung 1.4 Schematischer Aufbau der STAT-Proteine verändert nach Heinrich et al., 2003. Alle STAT-Proteine bestehen vom N- zum C-Terminus aus einer „coiled-coil“-, DNABindungs-, „Linker“-, SH2- und Transaktivierungs-Domäne. Die STAT-Moleküle werden an einem Tyrosinrest (Y) in der Transaktivierungsdomäne von den Janus-Kinasen phosphoryliert. Die Rolle der Serin-Phosphorylierung (S) ist zurzeit weitgehend ungeklärt.

Neben den Janus-Kinasen wurden weitere Kinasen beschrieben, die an der Phosphorylierung der STATs beteiligt sein können. Dazu gehören verschiedene Tyrosinkinasen der Gruppe der Src-Kinasen, RTKs wie z.B. c-Met oder aber auch Onkogene wie z.B. BCR-ABL.

Permanent aktivierte STAT-Moleküle werden häufig in transformierten Zellen gefunden, so z. B. auch beim multiplem Myelom (MM), anaplastisch grosszelligem Lymphom (ALCL) und Mantelzellymphom (MCL) (Catlett-Falcone et al., 1999; Adams et al., 2003; Khoury et al., 2003; Lai et al., 2003).

Im cHL wurden bisher STAT3, STAT6 und STAT5 als permanent aktiviert beschrieben (Kube et al., 2001a; Hinz et al., 2002; Skinnider et al., 2002a; Weniger et al., 2006). Die Mechanismen der permanenten Aktivierung sind weitgehend unbekannt. Für STAT6 konnte ein Zusammenhang mit der Produktion von IL-13 gezeigt werden. Die Daten legen nahe, dass IL-13 autokrin über den IL-13-Rezeptor zur Aktivierung von STAT6 führt und mit der Proliferation der Zellen in Verbindung steht (Skinnider et al., 2001a; Skinnider et al., 2002a).

Aus therapeutischer Sicht ist die permanente Aktivierung der STAT-Moleküle von großer Bedeutung. Die transkriptionellen Ziele der STAT-Moleküle sind funktionell in verschiedenen Zusammenhängen mit der Zellproliferation (z.B. Cyclin D1), dem Zellüberleben (z.B. BCL2-like $\left.1\left(\mathrm{BCL}-\mathrm{X}_{\mathrm{L}}\right)\right)$ und der Angiogenese (z.B. Vascular 
endothelial growth factor (VEGF)) in Zusammenhang gebracht worden (Yu et al., 2004). Sie steuern also eine Vielzahl von Funktionen, die am malignen Phänotyp von Lymphomen beteiligt sein können.

Im cHL konnte die Hemmung der Tyrosinphosphorylierung von STAT3 und STAT6 durch Proteintyrosinkinase-Inhibitoren der Klasse der Tyrphostine sowohl mit einer reduzierten Zellproliferation als auch mit einer Sensibilisierung für Apoptoseinduzierende Agenzien in Verbindung gebracht werden (Kube et al., 2001a; Holtick et al., 2005). Durch die Hemmung dieser Transkriptionsfaktoren könnten sich also neue Therapiestrategien für das $\mathrm{cHL}$ ergeben, welche für andere Erkrankungen bereits in der klinischen Testung sind (Yu et al., 2004). Hierfür müssen die aktivierenden Mechanismen unter Betrachtung der Möglichkeit zur Therapie näher analysiert werden. Ebenfalls müssen die transkriptionellen Ziele der STAT-Transkriptionsfaktoren in Lymphomzellen analysiert werden, um deren Funktionen $\mathrm{zu}$ verstehen und neue mögliche Zielstrukturen für Therapieoptimierungen zu erhalten. 


\subsubsection{Genvariationen in Zytokinen und Zytokinrezeptoren}

Ein wichtiger Aspekt zur Verbesserung der Therapiemöglichkeiten maligner Lymphome ist die Identifizierung von Risikofaktoren, die den Krankheitsverlauf oder die Inzidenz von Lymphomen beeinflussen. Interindividuelle genetische Unterschiede sind insbesondere bei Lymphomerkrankungen nur wenig untersucht. Durch die große Bedeutung der Zytokine und ihrer Signaltransduktion in malignen Lymphomen könnten Variationen innerhalb dieser Gene die Erkrankungen beeinflussen.

Interindividuelle Sequenzvariationen sind im gesamten humanen Genom häufig zu finden. In diesem Zusammenhang sind "single nucleotide polymorphisms“ (SNPs), neben verschiedenen Arten von Längenpolymorphismen repetitiver Sequenzen, die häufigste Form der Variationen. Derzeit befinden sich 14,7 Millionen SNPs in der öffentlichen Datenbank dbSNP (Build 129, http://www.ncbi.nlm.nih.gov/SNP/). Die Relevanz und die Funktion der meisten SNPs sind jedoch unbekannt. Große Konsortien wie das International HapMap Project untersuchen die Zusammenhänge und ethnischen Unterschiede der Polymorphismen und machen diese für die Öffentlichkeit zugänglich. Hierdurch können Assoziationen von SNPs mit bestimmten Krankheiten besser untersucht werden (HapMap, 2003).

Die Gene von Zytokinen und ihren Rezeptoren liegen häufig gemeinsam in so genannten "gene clustern", die hoch polymorph sind. Die meisten Polymorphismen führen jedoch nicht zu einem Aminosäureaustausch im Protein (sog. codierende SNPs), sondern sind in 5'-untranslatierten Regionen (UTR)-, Intron-, oder 3'-UTR-Sequenzen (sog. regulatorische SNPs) zu finden (Keen, 2002). Es wird angenommen, dass einige Polymorphismen mit der Expression sowie der Funktion der Zytokine bzw. Rezeptoren verbunden sein könnten. Es können z.B. die in nicht-codierenden DNA-Abschnitten vorkommenden Bindestellen für Transkriptionsfaktoren oder aber Spleiß-Sequenzen durch SNPs verändert sein.

In den letzten Jahren wurden viele Analysen durchgeführt, die belegen, dass Genvariationen mit dem Risiko und dem Verlauf von bestimmten Krankheiten assoziiert sein können (Chanock, 2001). Insbesondere wurden Zytokin- und Zytokinrezeptor Genvariationen im Rahmen von Autoimmunerkrankungen intensiv 
untersucht. Erst später kamen Studien zu Tumorerkrankungen darunter auch Lymphome hinzu (Hollegaard et al., 2006).

\section{IL-10-Genvariationen in malignen Lymphomen}

IL-10 hat, wie in Abschnitt 1.2 dargestellt, wichtige immunmodulatorische Wirkungen und somit können Veränderungen in Expression von IL-10 unter pathologischen Bedingungen von Bedeutung sein. Es konnte gezeigt werden, dass ein hoher IL-10 Serumwert einen negativen Einfluss auf das Überleben von HL aber auch NHL-Patienten hat (Blay et al., 1993; Sarris et al., 1999).

Die am häufigsten analysierten Polymorphismen in der Promotorregion von IL-10 bilden die drei proximalen (Transkriptionsstart-nahegelegenen) SNPs IL-10-1087AG, IL-10_824CT und IL-10_597AC. Des Weiteren wurden die distalen (Transkriptionsstartfernen) Genvariationen IL-10-7400InDel, IL-10-6752AT, IL-10_6208GC und IL-10-3538AT der IL-10 5'-Region beschrieben (Kube et al., 2001b). Die Abbildung 1.5 zeigt schematisch die Positionen der für diese Arbeit relevanten IL-10-Genvariationen auf Chromosom 1q31/32.

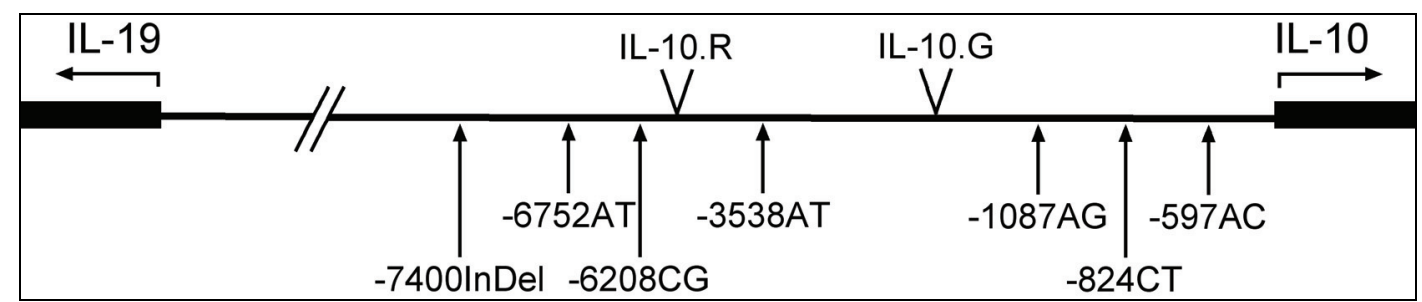

Abbildung 1.5 Schematische Darstellung der für diese Arbeit relevanten Genvariationen 5'-flankierend des Transkriptionsstarts von IL-10 nach Kube et al., 2001b und Mörmann et al., 2004. Die drei proximalen Polymorphismen IL-10 ${ }_{-1087 A G}$ IL-10-824CT und IL-10-597AC befinden sich zwischen Transkriptionsstart und dem IL-10.G Mikrosatellit. Der distale IL-10-3538AT Polymorphismus befindet sich zwischen dem IL-10.G und dem IL-10.R Mikrosatelliten. Die drei distalen Genvariationen IL-10-74001nDel, IL-10-6752AT und IL-10-6208GC befinden sich 5'-flankierenddes IL-10.R Mikrosatelliten. Die Frequenzen der Haplotypen der Genvariationen sind in Anhang 8.2 Fig. 1 aufgeführt (Kube et al., 2008).

In vitro Stimulationsversuche von peripheren Blutleukozyten gesunder Probanden mit verschiedenen Agenzien zeigten, dass die Produktion von IL-10 starke interindividuelle Unterschiede aufweist. Über $70 \%$ dieser Unterschiede scheinen durch den genetischen Hintergrund bestimmt zu sein (Turner et al., 1997; Westendorp et al., 1997). So konnte ein Zusammenhang zwischen verschiedenen Genvariationen und der IL-10 Produktion belegt werden. Für den Haplotyp ATA 
der drei distalen Polymorphismen IL-10-1087AG, IL-10-824Cт und IL-10-597AC wurde eine geringere in vitro IL-10 Produktion postuliert (Turner et al., 1997; Crawley et al., 1999). Aber auch verschiedene Haplotypen der Mikrosatelliten IL-10.G und IL-10.R zeigten interindividuelle Unterschiede in der IL-10 Produktion (Eskdale et al., 1998). Die Analyse der distalen Genvariationen und daraus resultierenden Haplotypen konnte ebenso auf die in vitro IL-10 Produktion bezogen werden (Gibson et al., 2001; Mörmann et al., 2004; Rieth et al., 2004). Individuen, die homozygot für die IL-10-7400Del Genvariationen sind, zeigten eine sehr hohe in vitro IL-10 Produktion bei Stimulation der Leukozyten mit Lipopolysaccharid (LPS). Individuen mit dem Haplotyp der distalen Genpolymorphismen IL-10_6752AT, IL-10-6208GC und IL-10-3538AT (TCA) zeigten eine mittelhohe IL-10 Produktion (Mörmann et al., 2004; Rieth et al., 2004).

Diese Analysen verdeutlichen, dass es einen großen genetischen Einfluss auf die IL-10 Produktion gibt und diese interindividuellen Unterschiede demnach einen Einfluss auf Erkrankungen, in denen IL-10 eine Rolle spielt, haben könnten.

Lech-Maranda et al. postulierte einen Zusammenhang zwischen dem IL-10 Serumwert, dem IL-10-1087AG SNP und dem klinischen Verlauf von DLBCLPatienten (Lech-Maranda et al., 2004). In einer Studie einer skandinavischen Gruppe konnte der Einfluss des IL-10-1087AG SNPs auf das Überleben von DLBCLPatienten jedoch nicht bestätigt werden (Berglund et al., 2005). Auffällig ist, dass in der ersten Studie viele junge Patienten und in der zweiten Studie mehr alte Patienten eingeschlossen wurden. Beide Patientenkollektive haben eine eher untypische Altersverteilung für das DLBCL. Der Effekt des Polymorphismus auf das Patientenüberleben scheint bei jungen Patienten stärker ausgeprägt zu sein.

Widersprüchliche Ergebnisse ergaben sich auch bei der Analyse der IL-10Genpolymorphismen in Bezug auf das Risiko, eine Lymphomerkrankung zu entwickeln. Cunningham et al. zeigte eine Assoziation des IL-10 ATA Haplotyps der drei distalen Polymorphismen IL-10_-1087AG, IL-10_824CT und IL-10_597AC mit einem erhöhten Risiko an NHL zu erkranken, wogegen die Studie von Breen et al. gegenteiliges in Lymphompatienten mit AIDS Erkrankungen belegte (Breen et al., 2003; Cunningham et al., 2003). Die erste Studie hat aber nur eine bedingte Aussagekraft, da hier eine geringe Fallzahl von NHL-Patienten betrachtet wurde. 
Eine interindividuelle IL-10 Produktion kann mit verschiedenen IL-10 Promotorvariationen im Zusammenhang stehen. Der Einfluss der proximalen IL-10-Genvariationen auf Lymphomerkrankungen zeigte aber widersprüchliche Ergebnisse. Es ist daher sinnvoll, Studien unter Einbezug aller IL-10Genvariationen in möglichst großen, repräsentativen Patientenkollektiven durchzuführen, um den Einfluss von IL-10 und den IL-10-Genvariationen auf diese Erkrankung zu analysieren.

\section{Polymorphismen in Th2-Immunantwort assoziierten Genen}

Sowohl IL-4 als auch IL-13 sind essentielle Faktoren der Th2-Immunantworten. Darüber hinaus wirken beide als Wachstums- sowie Differenzierungsfaktoren in B-Lymphozyten. In B-Zell-Neoplasien können sie autokrin und parakrin die Proliferation der Lymphomzellen fördern. Auch das Zusammenspiel zwischen Lymphomzellen und nicht-malignen Zellen (wie z.B. T-Lymphozyten oder Makrophagen) könnte durch diese Zytokine beeinflusst sein. Beide Zytokine benötigen auf ihren Zielzellen den IL-4Ra für die Signaltransduktion und aktivieren intrazellulär hauptsächlich STAT6 (Shirakawa et al., 2000).

Polymorphismen in diesen drei Genen wurden in Erkrankungen des Immunsystems untersucht (Shirakawa et al., 2000). So wurden die Promotorpolymorphismen von IL-4 (IL-4_590CT) und IL-13 (IL-13-1069CT) mit verschiedenen Autoimmunerkrankungen und erhöhter IgE-Produktion in diesen Patienten in Verbindung gebracht (Rosenwasser, 1999; Hunninghake et al., 2007). Bisher unbekannt ist, ob diese Promotorpolymorphismen einen Einfluss auf die Produktion der beiden Zytokine haben.

Für den IL-4Ra sind drei codierende Polymorphismen gut charakterisiert. Einer der Polymorphismen liegt im DNA Abschnitt, der die extrazelluläre Domäne des IL-4Ra (IL-4Ra $\left.a_{175 v}\right)$ codiert, und zwei im DNA Bereich, der die intrazelluläre Domäne (IL-4Ra $\mathrm{S}_{503 \mathrm{P}}$ und IL-4Ra $\mathrm{Q}_{\mathrm{Q} 56 \mathrm{R}}$ ) codiert. Der Aminosäureaustauch in den beiden intrazellulären Polymorphismen von Serin zu Prolin (IL-4Ra ${ }_{503 P}$ ) bzw. von Glutamin zu Arginin (IL-4Ra ${ }_{576 R}$ ) modulieren die Signaltransduktion über STAT6 sowie von Insulin receptor substrate 1 und 2 (IRS1/2) (Kruse et al., 1999). Der IL-4Ra ${ }_{175 v}$-Polymorphismus ist assoziiert mit einer veränderten STAT6 Aktivität. 
Die Isoleucin Variante (IL-4Ra $a_{175}$ ) führt zu einer stärkeren Phosphorylierungen von STAT6 bei Stimulation mit IL-4 und zu einer höheren IgE-Produktion von B-Zellen. Eine Änderungen in der Th1/Th2-Differenzierung der T-Lymphozyten durch die Rezeptorvarianten konnte nicht gezeigt werden (Mitsuyasu et al., 1998; Stephenson et al., 2004). In einer klinischen Studie konnte der IL-4Ra ${ }_{175 \mathrm{~V}}$ Polymorphismus mit dem Risiko und dem Krankheitsverlauf von Nierenzellkarzinompatienten assoziiert werden (Nakamura et al., 2002).

Auf Grund der wichtigen Rolle der Zytokine IL-4 und IL-13 sowie deren Rezeptor IL-4Ra als potenzielle Wachstumsfaktoren für Lymphome und essentielle Mediatoren der Immunreaktion, könnten Genpolymorphismen dieser Faktoren Einfluss auf den Krankheitsverlauf von Lymphompatienten haben. 


\subsection{Zielstellung der Arbeit}

Die erhöhte Produktion von Zytokinen sowie die Aktivierung der durch Zytokine aktivierten Signalwege sind mit dem Verlauf von Lymphomerkrankungen verbunden. Zytokine fördern durch autokrine Wirkungen das Wachstum der Lymphomzellen und haben durch parakrine Wirkungen Einfluss auf das Immunsystem der Patienten. Dies macht Zytokine und ihre respektive Signaltransduktion $z u$ essentiellen Faktoren, die im Sinne einer Therapieoptimierung von großer Bedeutung sein können. Daher sollen in dieser Arbeit die therapeutische Interventionsmöglichkeit über den Jak-STAT-Signalweg, die Zielgene der STAT-Transkriptionsfaktoren sowie die genetischen Variationen der Zytokine und ihrer Rezeptoren in Bezug auf Lymphomerkrankungen untersucht werden.

Im ersten Teil der Arbeit ist das Ziel die Aktivität der Janus-Kinasen als potenzielle Aktivatoren der STAT-Moleküle im cHL zu analysieren und diese als Ziele neuer Therapiemöglichkeiten zu prüfen. Die molekularbiologischen Untersuchungen sollen hierbei an Zelllinien des cHLs, als ein Modellsystem für ein Zytokinproduzierendes Lymphom mit aktivierten STAT-Molekülen, durchgeführt werden. Ziel des zweiten Teils dieser Arbeit ist es, die Zielgene der STAT-Moleküle zu identifizieren und deren Relevanz in Bezug auf die Lymphomerkrankung einzuordnen. Daher ist es eine weitere Aufgabe in dieser Arbeit mittels RNAInterferenz die Transkriptionsfaktoren STAT3 und STAT6 in einer cHL-Zelllinie auszuschalten und die differenzielle Genexpression zu untersuchen. Hierdurch sollen Gene identifiziert werden, die eine funktionelle Bedeutung für Lymphomerkrankungen haben und so weitere Angriffspunkte für Therapien darstellen könnten.

Im dritten Teil der Arbeit ist das Ziel Genvariationen von Zytokinen und ihren Rezeptoren, die einen Einfluss auf die Inzidenz von Lymphomen sowie den Krankheitsverlauf von Lymphompatienten haben, zu identifizieren. Dabei sollen prognostische Faktoren definiert werden, die zukünftig zur Risikoabschätzung von Lymphompatienten eingesetzt werden könnten. 


\section{MATERIAL}

\subsection{Biologisches Material}

Zelllinien

Die in dieser Arbeit verwendeten Zelllinien sowie ihre Herkunft sind in Tabelle 2.1 aufgeführt. Für die meisten Analysen wurden die Zelllinien L428, L591, L1236 und HDLM2 verwendet.

Tabelle 2.1 Verwendete Zelllinien und ihre zelluläre Herkunft.

\begin{tabular}{ll}
\hline Zelllinie & zelluläre Herkunft \\
\hline L428 & B-Zell-Abstammung, Hodgkin-Lymphom (Schaadt et al., 1979) \\
L591 & B-Zell-Abstammung, Hodgkin-Lymphom, EBV (Kirchner et al., 1983) \\
L1236 & B-Zell-Abstammung, Hodgkin-Lymphom (Wolf et al., 1996) \\
KMH2 & B-Zell-Abstammung, Hodgkin-Lymphom (Kamesaki et al., 1986) \\
HDLM2 & T-Zell-Abstammung, Hodgkin-Lymphom (Drexler et al., 1986) \\
L540 & T-Zell-Abstammung, Hodgkin-Lymphom (Diehl et al., 1981) \\
Ramos & B-Zell-Abstammung, Burkitt Lymphom (Klein et al., 1975) \\
Jurkat & T-Zell-Abstammung, T-Zell-Lymphom (Schneider et al., 1977)
\end{tabular}

\section{Lymphompatienten-DNA}

Für die Analyse der Genvariationen in Lymphompatienten wurde Patienten-DNA der NHL-B1/B2-Studien der Deutschen Studiengruppe für hochmaligne NonHodgkin-Lymphome (DSHNHL) verwendet (Pfreundschuh et al., 2004a; Pfreundschuh et al., 2004b). Für die Analysen der IL-10 Promotorgenvariationen wurde eine Kohorte von 500 NHL-Patienten ausgewählt, die repräsentativ für die gesamte Studie war (Anhang 8.2 Tab. 1) (Kube et al., 2008). Für die Analyse der IL-4, IL-13 und IL-4Ra Genpolymorphismen wurde ein Kollektiv von 228 DLBCL ausgewählt, das ebenfalls repräsentativ für alle DLBCL innerhalb der NHL-B1/B2Studien ist und darüber hinaus Serumanalysen zum löslichen IL-4R (sIL-4R) vorlagen. In Tabelle 2.2 sind die Patientencharakteristika und die histologische Verteilung im Vergleich zu allen DLBCL-Patienten der Studien aufgeführt. 
Tabelle 2.2 Klinische Charakteristika und Histologie der auf Genpolymorphismen analysierten DLBCL-Patienten im Vergleich zu allen DLBCL-Patienten der NHL-B1/B2Studien.

\begin{tabular}{|c|c|c|}
\hline Patienten Charakteristika & $\begin{array}{c}\text { alle DLBCL-Patienten der } \\
\text { NHL-B1/B2-Studien } \\
(n=913)\end{array}$ & $\begin{array}{l}\text { Analysierte DLBCL- } \\
\text { Patienten } \\
(\mathrm{n}=\mathbf{2 2 8})\end{array}$ \\
\hline Geschlecht & $507(55.5 \%)$ & $126(55.3 \%)$ \\
\hline weiblich & $406(44.5 \%)$ & $102(44.7 \%)$ \\
\hline Durchschnittliches Alter (Min.; Max.) & $61(18 ; 75)$ & $60.5(22 ; 75)$ \\
\hline Serum LDH > üNW & $225(24.6 \%)$ & $49(21.5 \%)$ \\
\hline Alter $>60$ Jahre & $489(53.6 \%)$ & $114(50.0 \%)$ \\
\hline Performance Status ECOG > 1 & $110(12.0 \%)$ & $28(12.3 \%)$ \\
\hline Ann-Arbor-Klassifikation III,IV & $371(40.6 \%)$ & $91(39.9 \%)$ \\
\hline Extranodalbefall $>1$ & $166(18.2 \%)$ & $38(16.7 \%)$ \\
\hline \multicolumn{3}{|l|}{ International Prognostic Index (IPI) } \\
\hline Low $(I P I=0,1)$ & $531(58.2 \%)$ & $140(61.4 \%)$ \\
\hline Low intermediate (IPI=2) & $164(18.0 \%)$ & $44(19.3 \%)$ \\
\hline High intermediate (IPI=3) & $131(14.3 \%)$ & $24(10.5 \%)$ \\
\hline High $(I P I=4,5)$ & $87(9.5 \%)$ & $20(8.8 \%)$ \\
\hline B Symptome & $247(27.1 \%)$ & $54(23.7 \%)$ \\
\hline \multicolumn{3}{|l|}{ Histologie } \\
\hline Diffus großzelliges B-Zell-Lymphom & $913(100.0 \%)$ & $228(100.0 \%)$ \\
\hline Zentroblastisch diffus & $687(75.2 \%)$ & $165(72.4 \%)$ \\
\hline Monomorph & $83(9.1 \%)$ & $25(11.0 \%)$ \\
\hline Multilobulär & $57(6.2 \%)$ & $11(4.8 \%)$ \\
\hline Polymorph & $349(38.2 \%)$ & $86(37.7 \%)$ \\
\hline Nicht spezifiziert & $198(21.7 \%)$ & $43(18.9 \%)$ \\
\hline Immunoblastisch & $114(12.5 \%)$ & $32(14.0 \%)$ \\
\hline T-Zell-reiche & $24(2.6 \%)$ & $7(3.1 \%)$ \\
\hline Anaplastisches & $28(3.1 \%)$ & $11(4.8 \%)$ \\
\hline Nicht spezifiziert & $60(6.6 \%)$ & $13(5.7 \%)$ \\
\hline
\end{tabular}

\subsection{Chemikalien \& Verbrauchsmaterialien}

Alle in Tabelle 2.3 aufgeführten und verwendeten Chemikalien hatten jeweils den höchsten Reinheitsgrad. Sämtliche Verbauchsmaterialien und PlastikEinmalartikel wie Zellkulturflaschen, Reaktionsgefäße oder Pipettenspitzen stammten von den Firmen Sarstedt (Nürnbrecht), Nunc (Wiesbaden), Eppendorf (Hamburg), GE Healthcare (München), Braun (Melsungen), Eppendorf (Hamburg), Becton Dickinson (Heidelberg) und Greiner (Nürtingen). 
Tabelle 2.3 Verwendete Chemikalien

\begin{tabular}{|c|c|}
\hline Chemikalie & Hersteller \\
\hline 17-AAG (17-Allylaminogeldanamycin) & Merck, Darmstadt, D \\
\hline Acrylamid/Bisacrylamid $40 \%$ & BioRad, München, D \\
\hline $\begin{array}{l}\text { AG17 (a-Cyano-(3,5-di-t-butyl-4- } \\
\text { hydroxy)cinnamonitril) }\end{array}$ & Merck, Darmstadt, D \\
\hline Ammoniumpersulfat & Sigma-Aldrich, Taufkirchen, D \\
\hline Ampicillin & Sigma-Aldrich, Taufkirchen, D \\
\hline Bradford-Reagenz & BioRad, München, D \\
\hline Brij97 & Sigma-Aldrich, Taufkirchen, D \\
\hline Bromphenolblau & Sigma-Aldrich, Taufkirchen, D \\
\hline BSA & Serva, Heidelberg, D \\
\hline BSA (Zellkultur getestet) & Sigma-Aldrich, Taufkirchen, D \\
\hline Complete Mini & Roche, Mannheim, D \\
\hline DMSO & Sigma-Aldrich, Taufkirchen, D \\
\hline DTT & Serva, Heidelberg, D \\
\hline dNTP-Mix (dATP, dTTP, dGTP, dCTP) & Promega, Mannheim, D \\
\hline EDTA & Sigma-Aldrich, Taufkirchen, D \\
\hline Essigsäure (p.a.) & Sigma-Aldrich, Taufkirchen, D \\
\hline Ethanol $98 \%$ (p.a.) & J.T. Baker, Niederlande \\
\hline Ethidiumbromid & Serva, Heidelberg, D \\
\hline FacsFlow & Becton Dickinson, Heidelberg, D \\
\hline FBS & Sigma-Aldrich, Taufkirchen, D \\
\hline GeneRuler plus 1kB DNA Leiter & Fermentas, St. Leon-Roth, D \\
\hline Geneticin & Invitrogen, Karlsruhe, D \\
\hline Glycin & Roth, Karlsruhe, D \\
\hline HEPES-Puffer & Sigma-Aldrich, Taufkirchen, D \\
\hline Isopropanol & Roth, Karlsruhe, D \\
\hline Kaliumchlorid & Merck, Darmstadt, D \\
\hline L-Glutamin-Penicillin-Streptomycin-Lösung & Sigma-Aldrich, Taufkirchen, D \\
\hline Membrane Blocking Agent & GE Healthcare, München, D \\
\hline$\beta$-Mercaptoethanol & Sigma-Aldrich, Taufkirchen, D \\
\hline Methanol $100 \%$ (p.a.) & J.T. Baker, Niederlande \\
\hline$\mu$ MACS Protein A MicroBeads & Miltenyi Biotec, Bergisch Gladbach, D \\
\hline Natriumacetat & Serva, Heidelberg, D \\
\hline Natriumchlorid & Merck, Darmstadt, D \\
\hline Natriumdeoxycholat & Merck, Darmstadt, D \\
\hline Natriumdodecylsulfat & Merck, Darmstadt, D \\
\hline Natriumfluorid & Roth, Karlsruhe, D \\
\hline Natriumvanadat & Sigma-Aldrich, Taufkirchen, D \\
\hline Nonidet P40 & Sigma-Aldrich, Taufkirchen, D \\
\hline PBS & Invitrogen, Karlsruhe, D \\
\hline PMSF & Sigma-Aldrich, Taufkirchen, D \\
\hline Ponceau S & Sigma-Aldrich, Taufkirchen, D \\
\hline RPMI-1640 Zellkulturmedium & Sigma-Aldrich, Taufkirchen, D \\
\hline Protein-Standard für SDS-PAGE & GE Healthcare, München, D \\
\hline Re-Blot Plus & Chemicon International, Hofheim, D \\
\hline Roti-Load 1 (4x) Protein-Gelladepuffer & Roth, Karlsruhe, D \\
\hline
\end{tabular}




\begin{tabular}{ll}
\hline Chemikalie & Hersteller \\
\hline Salzsäure 37\% & Merck, Darmstadt, D \\
Schwefelsäure & J.T. Baker, Niederlande \\
TEMED & Sigma-Aldrich, Taufkirchen, D \\
Tris & Sigma-Aldrich, Taufkirchen, D \\
Tween 20 & Serva, Heidelberg, D
\end{tabular}

\subsection{Puffer, Lösungen und Medien}

Die Zusammenstellung der häufig verwendeten Puffer, Lösungen und Medien sind in Tabelle 2.4 zu finden.

Tabelle 2.4 Verwendete Puffer, Lösungen und Medien

\begin{tabular}{|c|c|}
\hline Zellkultur & \\
\hline Einfriermedium: & $90 \%(v / v)$ FBS (fetales bovines Serum, hitzeinaktiviert) \\
\hline & $10 \%(v / v)$ DMSO \\
\hline Nährmedium: & RPMI-1640 \\
\hline & $10 \%(v / v)$ FBS \\
\hline & 200U/ml Penicilin \\
\hline & $200 \mu \mathrm{g} / \mathrm{ml}$ Streptomycin \\
\hline & 4mM L-Glutamin \\
\hline Durchflusszytometri & \\
\hline FACS-Puffer: & 1x PBS \\
\hline & $0,5 \%(w / v) B S A$ \\
\hline Proteinbiochemie & \\
\hline TBS (1x): & $\begin{array}{l}\text { 20mM Tris-Base, } \\
137 \mathrm{mM} \mathrm{NaCl}, \mathrm{pH} 7,6\end{array}$ \\
\hline TBS-T: & $1 \times$ TBS \\
\hline & $0,1 \%(v / v)$ Tween-20 \\
\hline IP-Puffer: & 200mM Tris-HCL pH 7,6 \\
\hline & $150 \mathrm{mM} \mathrm{NaCl}$ \\
\hline & $10 \mathrm{mM} \mathrm{NaF}$ \\
\hline & $1 \mathrm{mM}$ EDTA \\
\hline & $1 \%(v / v)$ Brij97 \\
\hline IP-Lysepuffer: & IP-Puffer + \\
\hline & $10 \mu \mathrm{M}$ PMSF \\
\hline & $5 \mu \mathrm{g} / \mathrm{ml}$ Leupeptin \\
\hline & $5 \mu \mathrm{g} / \mathrm{ml}$ Pepstatin A \\
\hline & $1 \mathrm{mM}$ Natriumvanadat \\
\hline Laemmli-Puffer (2x): & $187,5 \mathrm{mM}$ Tris/HCl pH 6,8 \\
\hline & $6,0 \%(w / v)$ SDS \\
\hline & $30,0 \%(v / v)$ Glyzerin \\
\hline & 0,01\% (w/v) Bromphenolblau \\
\hline
\end{tabular}




\begin{tabular}{|c|c|}
\hline & 10\% (v/v) ß-Mercaptoethanol \\
\hline Trenngelpuffer: & 1,5M Tris-HCL $(\mathrm{pH} 8,8)$ \\
\hline Sammelgelpuffer: & 1,0M Tris-HCL $(\mathrm{pH} 6,8)$ \\
\hline \multirow[t]{6}{*}{ RIPA-Puffer: } & 1x PBS \\
\hline & $1 \%(v / v)$ Igepal \\
\hline & $0,5 \%(\mathrm{w} / \mathrm{v})$ Natrium-deoxycholat \\
\hline & 0,1 mg/ml PMSF (in Isopropanol gelöst) \\
\hline & $1 \mathrm{mM}$ Na-Orthovanadat \\
\hline & $\begin{array}{l}\text { Complete-Lösung ( } 40 \mu \mathrm{l} \text { Stocklösung auf } 1 \mathrm{ml} \text { RIPA; } \\
\text { Stocklösung: } 1 \mathrm{Tbl} \text {. auf } 1,5 \mathrm{ml} \mathrm{H} 2 \mathrm{O})\end{array}$ \\
\hline \multirow[t]{3}{*}{ Laufpuffer (1x): } & 25mM Tris-Base \\
\hline & 192mM Glycin \\
\hline & $1 \%$ SDS \\
\hline \multirow[t]{3}{*}{ Transferpuffer $(1 \mathrm{x})$ : } & 25mM Tris-Base \\
\hline & 192mM Glycin \\
\hline & $15 \% \mathrm{MeOH}$ \\
\hline
\end{tabular}

\subsection{Häufig verwendete Geräte}

In Tabelle 2.5 sind die in dieser Arbeit regelmässig verwendeten Geräte aufgeführt.

\section{Tabelle 2.5 Verwendete Geräte}

\begin{tabular}{ll}
\hline Gerät & Hersteller \\
\hline Biofuge Pico & Fa. Heraeus Instruments, Hanau, D \\
Biofuge Primo R & Fa. Heraeus Instruments, Hanau, D \\
Brutschrank Cytoperm & Fa. Heraeus Instruments, Hanau, D \\
Consort E734 Power Supply & Fa. Schütt Labortechnik, Göttingen, D \\
Hera freeze $-80^{\circ} \mathrm{C}$ Kühleinheit & Fa. Heraeus Instruments, Hanau, D \\
IKA KS 260 Schüttler & Fa. IKA, Staufen, D \\
IKAMAG RCT Magnetrührer/Heizplatte & Fa. IKA, Staufen, D \\
Incudrive Inkubator & Fa. Schütt Labortechnik, Göttingen, D \\
Leitz DM IL Inverses Fluoreszenzmikroskop & Fa. Leica, Wetzlar, D \\
Microflow Laminar Downflow Workstation & Fa. Bioquell, England \\
Mikrokühlzentrifuge 1-15k & Fa. Sigma, Osterode, D \\
Multifuge 3 L-R & Fa. Heraeus Instruments, Hanau, D \\
Power Pac 300 Power Supply & Fa. Bio-Rad, München, D \\
Reax2 Rotorschüttler & Fa. Heidolph, Schwabach, D \\
Televal 31 Inverses Durchlichtmikroskop & Fa. Zeiss, Jena, D \\
Thermocycler 60 & Fa. Biomed, Theres, D \\
Ultra Low -152 ${ }^{\circ}$ C Kühleinheit & Fa. Sanyo, Japan \\
Vortex Genie 2 & Fa. Schütt Labortechnik, Göttingen, D \\
Multi-Detection Microplate Reader,Synergy HT & Fa. Bio-TEK, Bad Friedrichshall, D
\end{tabular}




Gerät $\quad$ Hersteller

Wasserbad

Fa. Köttermann Labortechnik, Hänigsen, D

Alle weiteren Geräte sind im entsprechenden Methodenteil zu finden.

\subsection{Antikörper}

Alle in dieser Arbeit verwendeten Antikörper sind in Tabelle 2.6 zu finden.

Tabelle 2.6 Verwendete Antikörper für die Immundetektion von Proteinen.

\begin{tabular}{|c|c|c|c|}
\hline Antikörper & Artikel-Nr. & Spezifität & Firma \\
\hline anti-Actin $(A b-1)$ & CP01 & $\begin{array}{l}\text { monoklonaler Maus- } \\
\text { Ak }\end{array}$ & Oncogene, USA \\
\hline anti-c-CBL & 6104411 & $\begin{array}{l}\text { monoklonaler Maus- } \\
\text { Ak }\end{array}$ & $\begin{array}{l}\text { BD Transduction } \\
\text { Laboratories, USA }\end{array}$ \\
\hline anti-CD23-PE & 347797 & $\begin{array}{l}\text { monoklonaler Maus- } \\
\text { Ak }\end{array}$ & BD Bioscience, USA \\
\hline anti-CD25-FITC & 347643 & $\begin{array}{l}\text { monoklonaler Maus- } \\
\text { Ak }\end{array}$ & BD Bioscience, USA \\
\hline anti-CD52-FITC & SM1722F & $\begin{array}{l}\text { monoklonaler Maus- } \\
\text { Ak }\end{array}$ & $\begin{array}{l}\text { DPC Biermann, Bad } \\
\text { Nauheim }\end{array}$ \\
\hline anti-HSP90 & SPA-835 & $\begin{array}{l}\text { monoklonaler Ratte- } \\
\text { Ak }\end{array}$ & Stressgen, USA \\
\hline anti-Jak1 & sc-277 & $\begin{array}{l}\text { polyklonaler } \\
\text { Kaninchen-Ak }\end{array}$ & $\begin{array}{l}\text { Santa Cruz } \\
\text { Biotechnology, USA }\end{array}$ \\
\hline anti-JAK2 (C20) & sc-294 & $\begin{array}{l}\text { polyklonaler } \\
\text { Kaninchen-Ak }\end{array}$ & $\begin{array}{l}\text { Santa Cruz } \\
\text { Biotechnology, USA }\end{array}$ \\
\hline anti-JAK3 (C21) & sc-513 & $\begin{array}{l}\text { polyklonaler } \\
\text { Kaninchen-Ak }\end{array}$ & $\begin{array}{l}\text { Santa Cruz } \\
\text { Biotechnology, USA }\end{array}$ \\
\hline anti-phospho-STAT1 (Tyr701) & 9172 & $\begin{array}{l}\text { polyklonaler } \\
\text { Kaninchen-Ak }\end{array}$ & $\begin{array}{l}\text { Cell Signaling } \\
\text { Technology, USA }\end{array}$ \\
\hline anti-phospho-STAT3 (Tyr705) & 9131 & $\begin{array}{l}\text { polyklonaler } \\
\text { Kaninchen-Ak }\end{array}$ & $\begin{array}{l}\text { Cell Signaling } \\
\text { Technology, USA }\end{array}$ \\
\hline anti-phospho-STAT5 (Tyr694) & 9351 & $\begin{array}{l}\text { polyklonaler } \\
\text { Kaninchen-Ak }\end{array}$ & $\begin{array}{l}\text { Cell Signaling } \\
\text { Technology, USA }\end{array}$ \\
\hline anti-phospho-STAT6 (Tyr641) & 9366 & $\begin{array}{l}\text { monoklonaler Maus- } \\
\text { Ak }\end{array}$ & $\begin{array}{l}\text { Cell Signaling } \\
\text { Technology, USA }\end{array}$ \\
\hline $\begin{array}{l}\text { anti-Phosphotyrosin Klon } \\
4 \mathrm{G} 10\end{array}$ & $05-321$ & $\begin{array}{l}\text { monoklonaler Maus- } \\
\text { Ak }\end{array}$ & $\begin{array}{l}\text { Upstate Cell Signaling, } \\
\text { USA }\end{array}$ \\
\hline anti-STAT1 & 9171 & $\begin{array}{l}\text { polyklonaler } \\
\text { Kaninchen-Ak }\end{array}$ & $\begin{array}{l}\text { Cell Signaling } \\
\text { Technology, USA }\end{array}$ \\
\hline anti-STAT3 & 9132 & $\begin{array}{l}\text { polyklonaler } \\
\text { Kaninchen-Ak }\end{array}$ & $\begin{array}{l}\text { Cell Signaling } \\
\text { Technology, USA }\end{array}$ \\
\hline anti-STAT5 & 610191 & $\begin{array}{l}\text { monoklonaler Maus- } \\
\text { Ak }\end{array}$ & $\begin{array}{l}\text { BD Transduction } \\
\text { Laboratories, USA }\end{array}$ \\
\hline anti-STAT6 & 611291 & $\begin{array}{l}\text { monoklonaler Maus- } \\
\text { Ak }\end{array}$ & $\begin{array}{l}\text { BD Transduction } \\
\text { Laboratories, USA }\end{array}$ \\
\hline anti-TYK2 (C21) & sc-169 & $\begin{array}{l}\text { polyklonaler } \\
\text { Kaninchen-Ak }\end{array}$ & $\begin{array}{l}\text { Santa Cruz } \\
\text { Biotechnology, USA }\end{array}$ \\
\hline
\end{tabular}




\begin{tabular}{|c|c|c|c|}
\hline Antikörper & Artikel-Nr. & Spezifität & Firma \\
\hline $\begin{array}{l}\text { anti-Kannichen (HRP- } \\
\text { konjuqiert) }\end{array}$ & sc-2313 & polyklonaler Esel-Ak & $\begin{array}{l}\text { Santa Cruz } \\
\text { Biotechnology, USA }\end{array}$ \\
\hline anti-Maus (HRP-konjugiert) & sc-2005 & polyklonaler Ziege-Ak & $\begin{array}{l}\text { Santa Cruz } \\
\text { Biotechnology, USA }\end{array}$ \\
\hline anti-Ratte (HRP-konjugiert) & Sc-2032 & polyklonaler Ziege-Ak & $\begin{array}{l}\text { Santa Cruz } \\
\text { Biotechnology, USA }\end{array}$ \\
\hline
\end{tabular}

\subsection{Gebrauchsfertige Reaktionssysteme}

Die in dieser Arbeit verwendeten gebrauchsfertigen Reaktionssysteme folgen in Tabelle 2.7 .

Tabelle 2.7 In der Arbeit häufig verwendete Reaktionssysteme.

\begin{tabular}{ll}
\hline Bezeichnung & Hersteller \\
\hline Cell line Nucleofector ${ }^{\circledR}$ Kit L & Fa. Amaxa, Köln, D \\
ECL $^{\text {TM }}$ Advance Western Blotting Detection Kit & Fa. Amersham Biosciences, England \\
QIAamp DNA Blood Mini Kit & Fa. Qiagen, Hilden, D \\
RNeasy® plus Mini Kit & Fa. Qiagen, Hilden, D \\
SuperScript II Reverse Transcriptase & Fa. Invitrogen, Karlsruhe, D \\
BigDye Terminator Cycle Sequencing Kit v1.1 & Fa. Applied Biosystems, USA \\
SYBR Green Mastermix & Fa. Applied Biosystems, USA \\
Fast SYBR Green Mastermix & Fa. Applied Biosystems, USA \\
TaqMan® Genotyping PCR Master Mix & Fa. Applied Biosystems, USA \\
IL-10 Eli-pair ELISA Kit & Fa. Diaclone, Giessen, D
\end{tabular}

\subsection{Oligonukleotide}

In Tabelle 2.8 sind die in dieser Arbeit verwendeten Sequenzen der verwendeten Oligonukleotide und deren Bezugsquellen aufgeführt, die für Sequenzierungen sowie PCR-Reaktionen verwendet worden sind.

Tabelle 2.8 Oligonukleotide für die quantitative realtime-PCR. Alle hier aufgeführten Oligonukleotide wurden von der Firma IBA (Göttingen) hergestellt.

\begin{tabular}{lll}
\hline Name & Sequenz & Verwendung \\
\hline qPCR-b2m-5' & GTGCTCGCGCTACTCTCTCT & B2M - Sybr-Green RT-PCR \\
qPCR-b2m-3' & TTCAATGTCGGATGGATGAA & B2M - Sybr-Green RT-PCR \\
BCL6 forward & ACCTGCAGATGGAGCATGTTG & BCL6 - Sybr-Green RT-PCR \\
BCL6 reverse & TGAGGAACTCTTCACGAGGAGG & BCL6 - Sybr-Green RT-PCR
\end{tabular}




\begin{tabular}{|c|c|c|}
\hline Name & Sequenz & Verwendung \\
\hline qPCR-AICDA-s & GAAATGGAGTCTCAAAGCTTCA & AICDA - Sybr-Green RT-PCR \\
\hline qPCR-AICDA-as & GCTTCGTAGCACCATTACTGC & AICDA - Sybr-Green RT-PCR \\
\hline qPCR-XBP1-s & САТTТСТСТТСССССТTТTТG & XBP1 - Sybr-Green RT-PCR \\
\hline qPCR-XBP1-as & AAAGAGCCCCСTCAGCAG & XBP1 - Sybr-Green RT-PCR \\
\hline qPCR-CBL-s & GTTGTCTTCCATGGCCTGTT & c-CBL - Sybr-Green RT-PCR \\
\hline qPCR-CBL-as & AGGGTAGGTCAGGAGGCATT & c-CBL - Sybr-Green RT-PCR \\
\hline qPCR-IRF4-s & CACAGCTTTGAGGAACATGC & IRF4 - Sybr-Green RT-PCR \\
\hline qPCR-IRF4-as & GTTTGAAGCAACACGGGAAT & IRF4 - Sybr-Green RT-PCR \\
\hline qPCR-IL13RA1-s & CCCAACAAACATTGATGCTG & IL13Ra1 - Sybr-Green RT-PCR \\
\hline qPCR-IL13RA1-as & ССТСССТTTТСССТСАGСТА & IL13Ra1 - Sybr-Green RT-PCR \\
\hline qPCR-EphB1-s & TCTCAAGACTGTGGCAACCA & EphB1 - Sybr-Green RT-PCR \\
\hline qPCR-EphB1-as & GTCATCCACGGTGGTAAAGG & EphB1 - Sybr-Green RT-PCR \\
\hline qPCR-PIK3CG-s & AATGTGTGCAAAAGCCCAAA & PIK3CG - Sybr-Green RT-PCR \\
\hline qPCR-PIK3CG-as & CCCCAGGCTGATAAGAGTGT & PIK3CG - Sybr-Green RT-PCR \\
\hline qPCR-MYBL1-as & CCATGCAAGTATGGCTGCTA & A-Myb - Sybr-Green RT-PCR \\
\hline qPCR-MYBL1-s & TCAGGCATCTTAAGTCACCTTT & A-Myb - Sybr-Green RT-PCR \\
\hline qPCR-PTPRK-s & TGTGAACAAATCAATGCCAGA & PTPRK - Sybr-Green RT-PCR \\
\hline qPCR-PTPRK-as & ACAGCTACGTGGAGCATGTG & PTPRK - Sybr-Green RT-PCR \\
\hline qPCR-STAT6-s & AGCTGGCACCTTAGTTGCAT & STAT6 - Sybr-Green RT-PCR \\
\hline qPCR-STAT6-as & СTTGCTGCTGTCTTCTGTGC & STAT6 - Sybr-Green RT-PCR \\
\hline qPCR-GATA3-s & AAGCCTAAACGCGATGGATA & GATA3 - Sybr-Green RT-PCR \\
\hline qPCR-GATA3-as & TCACAGATGGGGTCCAGATT & GATA3 - Sybr-Green RT-PCR \\
\hline Jak2-1s & GCGACGGCAAATGTTCTGAA & Jak2-Sequenzierung \\
\hline Jak2-1as & GCCACTGAGCAAAGAGGTAA & Jak2-Sequenzierung \\
\hline Jak2-2s & GTGCTGAAGCTCCTCTTCTT & Jak2-Sequenzierung \\
\hline Jak2-2as & CCCTCTTGGTTTGCTTGCTT & Jak2-Sequenzierung \\
\hline Jak2-3s & CAGTGGTCAAGAGGGAAACA & Jak2-Sequenzierung \\
\hline Jak2-3as & TGTCTGAGCGAACAGTTTCC & Jak2-Sequenzierung \\
\hline Jak2-4s & CAACCTCAGTGGGACAAAGA & Jak2-Sequenzierung \\
\hline Jak2-4as & TTCTCGTCTCCACAGACACA & Jak2-Sequenzierung \\
\hline Jak2-5s & GAGCAAGCTTTCTCACAAGC & Jak2-Sequenzierung \\
\hline Jak2-5as & AATTCTGCCCACTTTGGTGC & Jak2-Sequenzierung \\
\hline Jak2-6s & TGCAGTGGAGGAGATAAACC & Jak2-Sequenzierung \\
\hline Jak2-6as & TTTAGATTACGCCGACCAGC & Jak2-Sequenzierung \\
\hline Jak2-7s & CCTGAAATCCCTACAGCATG & Jak2-Sequenzierung \\
\hline Jak2-7as & TCATCCAGCCATGTTATCCC & Jak2-Sequenzierung \\
\hline Tyk2-s & GAGTGGTGCTCAAAGTGCTG & Tyk2-Sequenzierung \\
\hline Tyk2-as & GGCCACACACATTACCATGA & Tyk2-Sequenzierung \\
\hline
\end{tabular}


In Tabelle 2.9 sind die mRNA-Zielsequenzen der verwendeten siRNAs (Fa. Dharmacon, USA) aufgeführt.

Tabelle 2.9 Zielsequenzen der verwendeten siRNAs der Fa. Dharmacon

\begin{tabular}{lll}
\hline Name & Artikel-Nr. & Zielsequenzen \\
\hline ON-Targetplus SMARTpool Human STAT3 & L-003544-00 & GAGAUUGACCAGCAGUAUA \\
& & CAACAUGUCAUUUGCUGAA \\
& CCAACAAUCCCAAGAAUGU \\
& CAACAGAUUGCCUGCAUUG \\
ON-Targetplus SMARTpool Human STAT6 & L-006690-00 & GGAUGGCUCUCCACAGAUA \\
& & GCGGCUCUAUGUCGACUUU \\
& GUUACUAGCCUUCUUCUCA \\
& GGAAUGGCGCACCGUUUGA \\
ON-Targetplus SMARTpool Human HSP90a & L-005186-00 & GAAGUAGACUAAUCUCUGG \\
& & GACCAAAUCUUGUUAUUGA \\
& GUUCAGUACUCUACAAUUC \\
ON-Targetplus SMARTpool Human HSP90b & ACUAAGUGAUGCUGUGAUA \\
& L-005187-00 & GAAGAAGUCGUUAGGUUA \\
& GAGCUGCUGCGCUAUCAUA \\
ON-Targetplus siControl Non-Targeting Pool & CGACAAGAAUGAUAAGGCA \\
(Scrambled) & UGACAGACCCUUCGAAGUU \\
& & Nicht vom Hersteller \\
angegeben
\end{tabular}

In Tabelle 2.10 sind die für die Genotypisierungen verwendeten Oligonukleotide und Taqman Genotyping Assay aufgeführt.

Tabelle 2.10 Oligonukleotide, die für Genotypisierungen verwendet worden sind. Die forwardbzw. reverse-Primer sind jeweils von der Fa. IBA bezogen worden. Die fluoreszenzmarkierten MGB-Proben sind wurden von der Fa. Applied Biosystems hergestellt.

\begin{tabular}{|c|c|c|c|c|}
\hline SNP-Name & refSNP ID & Primer & Sequenz & Allel \\
\hline \multirow[t]{4}{*}{ IL-4Ra I75V } & rs1805010 & Fw-Primer & ACCCAGCCCCTGTGTCT & \\
\hline & & Rev-Primer & TGAGCAGGTGGCACACG & \\
\hline & & $\begin{array}{l}\text { Sonde1 } \\
\text { (FAM) }\end{array}$ & CACGTGTGTCCCTG & A \\
\hline & & $\begin{array}{l}\text { Sonde2 } \\
\text { (VIC) }\end{array}$ & ACACGTGTATCCCTG & G \\
\hline \multirow[t]{4}{*}{$\begin{array}{l}\text { IL-4Ra } \\
\text { S503P }\end{array}$} & rs1805015 & Fw-Primer & AGGCAACCCTGCTTACCG & \\
\hline & & Rev-Primer & TCTCTGGGACACGGTGACT & \\
\hline & & $\begin{array}{l}\text { Sonde1 } \\
\text { (FAM) }\end{array}$ & TTCAGCAACTCCCTG & $\mathrm{T}$ \\
\hline & & Sonde2 & CTTCAGCAACCCCCTG & C \\
\hline
\end{tabular}




\begin{tabular}{|c|c|c|c|c|}
\hline SNP-Name & refSNP ID & $\begin{array}{l}\text { Primer } \\
\text { (VIC) }\end{array}$ & Sequenz & Allel \\
\hline \multirow[t]{4}{*}{$\begin{array}{l}\text { IL-4Ra } \\
\text { Q576R }\end{array}$} & rs1801275 & Fw-Primer & GCCGAAATGTCCTCCAGCAT & \\
\hline & & Rev-Primer & ССTGCTCCACCGCATGTA & \\
\hline & & $\begin{array}{l}\text { Sonde1 } \\
\text { (FAM) }\end{array}$ & CAGTGGCTATCGGGAGT & G \\
\hline & & $\begin{array}{l}\text { Sonde2 } \\
\text { (VIC) }\end{array}$ & CAGTGGCTATCAGGAGT & A \\
\hline \multirow[t]{4}{*}{ IL-13 -1069 } & rs1800925 & Fw-Primer & AACACCCAACAGGCAAATGC & \\
\hline & & Rev-Primer & TGCAGCATGTCGCCTTTTC & \\
\hline & & $\begin{array}{l}\text { Sonde1 } \\
\text { (FAM) }\end{array}$ & ТСССТСАТТТТСС & $\mathrm{T}$ \\
\hline & & $\begin{array}{l}\text { Sonde2 } \\
\text { (VIC) }\end{array}$ & TCCCTCGTTTTCC & $\mathrm{C}$ \\
\hline \multirow[t]{4}{*}{ IL-4 -524 } & rs2243250 & Fw-Primer & TGTCСТTCTCAAAАCACСТАAACTTG & \\
\hline & & Rev-Primer & GCAGAATAACAGGCAGACTCTCCTA & \\
\hline & & $\begin{array}{l}\text { Sonde1 } \\
\text { (FAM) }\end{array}$ & AGAACATTGTCCCCCAGT & $\mathrm{C}$ \\
\hline & & $\begin{array}{l}\text { Sonde2 } \\
\text { (VIC) }\end{array}$ & AGAACATTGTTCCCCAGTG & $\mathrm{T}$ \\
\hline \multirow[t]{2}{*}{ IL-10 -7400 } & InDel & Fw-Primer & AAGGAACATCTGAGCTGAGAGCT & NED \\
\hline & & Rev-Primer & TTGAACTCCTAGCTCAAGTAATCCT & \\
\hline \multirow[t]{4}{*}{ IL-10 -6752 } & rs6676671 & Fw-Primer & AGCTCAGGGCCTTTGCA & \\
\hline & & Rev-Primer & TGAGAAAAGACAAGTTAAGGGTGCAT & \\
\hline & & $\begin{array}{l}\text { Sonde1 } \\
\text { (FAM) }\end{array}$ & ATACCAGTGTTGGCCCA & $A$ \\
\hline & & $\begin{array}{l}\text { Sonde2 } \\
\text { (VIC) }\end{array}$ & CATACCAGTGATGGCCCA & $\mathrm{T}$ \\
\hline \multirow[t]{4}{*}{ IL-10 -6208 } & rs10494879 & & Applied Biosystems Validated Assay & \\
\hline & & & C__26593071_10 & \\
\hline & & $\begin{array}{l}\text { Sonde1 } \\
\text { (FAM) }\end{array}$ & & $\mathrm{C}$ \\
\hline & & $\begin{array}{l}\text { Sonde2 } \\
\text { (VIC) }\end{array}$ & & G \\
\hline \multirow[t]{4}{*}{ IL-10 -3538 } & rs1800890 & & Applied Biosystems Validated Assay & \\
\hline & & & C__8828790_10 & \\
\hline & & $\begin{array}{l}\text { Sonde1 } \\
\text { (FAM) }\end{array}$ & & $A$ \\
\hline & & $\begin{array}{l}\text { Sonde2 } \\
\text { (VIC) }\end{array}$ & & $\mathrm{T}$ \\
\hline \multirow[t]{4}{*}{ IL-10 -1087 } & rs1800896 & & Applied Biosystems Validated Assay & \\
\hline & & & C__1747360_10 & \\
\hline & & $\begin{array}{l}\text { Sonde1 } \\
\text { (FAM) }\end{array}$ & & G \\
\hline & & $\begin{array}{l}\text { Sonde2 } \\
\text { (VIC) }\end{array}$ & & A \\
\hline
\end{tabular}




\begin{tabular}{lllll}
\hline SNP-Name & refSNP ID & Primer & Sequenz & Allel \\
\hline IL-10 -597 & rs1800872 & Fw-Primer & GGTAAAGGAGCCTGGAACACATC & \\
& & $\begin{array}{l}\text { Rev-Primer } \\
\text { Sonde1 } \\
(\text { FAM) } \\
\text { Sonde2 } \\
\text { (VIC) }\end{array}$ & GCCCTTCCATTTTACTTTCCAGAG & \\
& & TGGCTTCCTACAGGAC & C & A
\end{tabular}




\section{Methoden}

\subsection{Methoden der Zellkultur}

\subsubsection{Auftauen und Kryokonservierung der Zelllinien}

Um die bei $-150^{\circ} \mathrm{C}$ gelagerten Zelllinien in Kultur zu nehmen, wurden die Zellen bei $37^{\circ} \mathrm{C}$ aufgetaut und in $10 \mathrm{ml}$ Nährmedium überführt. Zügiges Arbeiten verhinderte cytotoxische Effekte des DMSO aus dem Einfriermedium. Die Zellen wurden dann sedimentiert ( $250 \times \mathrm{g}, 5 \mathrm{~min}, \mathrm{RT})$ und das Medium abgenommen. Abschließend wurden die Zellen bei einer Zelldichte von $5 \times 10^{5} \mathrm{Zellen} / \mathrm{ml}$ in einer $25 \mathrm{~cm}^{2}$ Schräghalsflasche in Nährmedium aufgenommen.

Für die Aufbewahrung der Zelllinien wurden Kryokulturen angelegt. Hierbei wurden der Zellkultur etwa $1 \times 10^{6}$ bis $1 \times 10^{7}$ Zellen entnommen und sedimentiert (250 $\left.\mathrm{x} \mathrm{g}, 4^{\circ} \mathrm{C}, 5 \mathrm{~min}\right)$. Das Medium wurde abgenommen, die Zellen in $1 \mathrm{ml}$ Einfriermedium aufgenommen und in ein Kryoröhrchen (Fa. Nalgene ${ }^{\circledR}$ Labware, England) überführt. Eine Isopropanol-gefüllte Einfrierbox (Fa. Nalgene® Labware, England) diente zur graduellen Absenkung der Temperatur von $1^{\circ} \mathrm{C}$ pro min bis $-80^{\circ} \mathrm{C}$. Durch die langsame Absenkung der Temperatur wird die Bildung der Eiskristalle zellverträglich durchgeführt. Die Zellen wurden über Nacht in der Einfrierbox bei $-80^{\circ} \mathrm{C}$ aufbewahrt und am nächsten Tag bei $-150^{\circ} \mathrm{C}$ eingelagert.

\subsubsection{Kultivierung der Zelllinien}

Die Zellen wurden steril bei $37^{\circ} \mathrm{C}, 5 \% \mathrm{CO}_{2}$ und $90 \%$ Lufteuchtigkeit im Inkubator kultiviert. Als Nährmedium diente stets Roswell Park Memorial Institute Medium (RPMI)-1640 (Fa. Sigma, Deisenhofen). Die Zellen wurden bei einer Zellzahl von $5 \times 10^{5}$ Zellen pro $\mathrm{ml}$ kultiviert und je nach Proliferation und Stoffwechselaktivität alle 2 bis 3 Tage in frisches vorgewärmtes Medium überführt. Da alle verwendeten Zelllinien Suspensionszellen waren, entfiel eine Trypsinierung der Zellen vor dem Umsetzen. Je nach Volumen der Zellsuspension wurden die Zellen in $25 \mathrm{~cm}^{2}$ (5$10 \mathrm{ml}), \quad 75 \mathrm{~cm}^{2} \quad(30-50 \mathrm{ml})$ oder $175 \mathrm{~cm}^{2} \quad(50-120 \mathrm{ml})$ Schräghalsflaschen mit Belüftungskappe (Fa. Sarstedt, Nürnbrecht) inkubiert. 


\subsubsection{Behandlung der Zelllinien mit chemischen Inhibitoren}

Vor Zugabe der Agenzien wurden die Zellen gezählt, sedimentiert $(250$ x g, 5 min, RT), das alte Medium abgenommen und in einer Zellzahl von $5 \times 10^{5}$ Zellen pro $\mathrm{ml}$ in frischem vorgewärmtem Medium aufgenommen. Je nach Volumen wurden die Zellen in 24-Loch-Platten oder Schräghalsflaschen übertragen. Zur Behandlung der Zellen mit Inhibitoren wurden diese zunächst in einer definierten Menge DMSO solubilisiert. Die Inhibitoren wurden dann zur Zellsuspension im entsprechenden Volumen zugegeben, um die entsprechenden Endkonzentrationen zu erreichen. Als Kontrolle wurde DMSO verwendet, das in gleichem Volumen wie der Inhibitor zugesetzt wurde. Unspezifische Effekte durch DMSO ließen sich hierdurch ausschließen. Nach definierten Zeitpunkten wurden Proben der Zellen entnommen und weiter analysiert.

\subsubsection{Herstellung von Gefrierproben der Zellen}

Um die Zellen aus den Versuchen zu konservieren, bevor sie analysiert wurden, stellte man Gefrierproben her.

Hierzu entnahm man aus der Zellsuspension eine bestimmte Menge an Zellen und sedimentierte diese bei $250 \times \mathrm{g}, 4^{\circ} \mathrm{C}$ für $5 \mathrm{~min}$. Anschließend wurden die Zellen mit $1 \mathrm{ml}$ PBS $+1 \mathrm{mM}$ Natriumvanadat ( $\mathrm{Fa}$. Sigma, Deisenhofen) gewaschen und wiederum sedimentiert $\left(250 \times \mathrm{g}, 4^{\circ} \mathrm{C}, 5 \mathrm{~min}\right)$. Natriumvanadat verhindert die Dephosphorylierung von Proteinen durch Phosphatasen und ist daher für die proteinbiochemischen Untersuchungen wichtig. Die Zellpellets wurden bis zur weiteren Verwendung bei $-80^{\circ} \mathrm{C}$ gelagert.

\subsubsection{Zellzahlbestimmung}

Die Zellzahl wurde durch die Verwendung einer Neubauer-Improved Zählkammer bestimmt. Die Neubauer-Improved Zählkammer dient zur mikroskopischen Bestimmung der Zellzahl durch die Zählung der Zellen in einem definierten Volumen, das sich dann in „Zellen pro ml“ umrechen lässt. Die Unterscheidung der lebenden von den toten Zellen erfolgte durch die Färbung der Zellen mit Trypanblaulösung (0,5\% (w/v) Trypanblau in PBS, Fa. Sigma, Deisenhofen). Tote Zellen sind für diesen Farbstoff permeabel, und lebende Zellen werden nicht gefärbt. 


\subsubsection{Einbringen von siRNA in die cHL-Zellen}

Die Zelllinie L428 wurde mittels Nukleofektion (Fa. Amaxa) transfiziert. Für die transiente RNA-Interferenz wurden SMART-Pool siRNAs der Firma Dharmacon verwendet. Dabei befinden sich 4 verschiedene siRNAs gegen ein Transkript zusammen in einer Lösung, um möglichst wenig unspezifische Effekte bei effizienter Expressionshemmung zu erhalten.

Am Abend vor der Transfektion wurden die Zellen in frisches Medium umgesetzt. $12 \mathrm{~h}$ später wurden die Zellen ( $\left.250 \times \mathrm{g}, 4^{\circ} \mathrm{C}, 5 \mathrm{~min}\right)$ sedimentiert und $3 \times 10^{6}$ Zellen

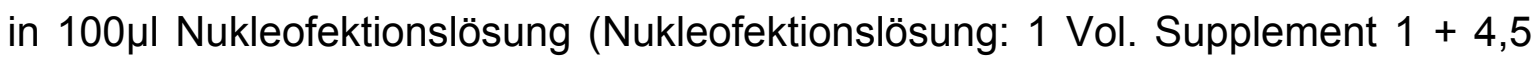
Vol. Nucleofector ${ }^{\circledR}$ Solution L; Cell line Nucleofector $®$ Kit L; Fa. Amaxa, Köln) aufgenommen. In die im Kit enthaltenen Küvetten wurde nun $3 \mu \mathrm{g}$ siRNA vorgelegt, $100 \mu \mathrm{l}$ Zellsuspension zugegeben und mit dem Programm X-001 des Nucleofector2 (Fa. Amaxa, Köln) die Transfektion gestartet. Im Anschluss wurden die Zellen (nach dem Amaxa-optimierten Protokoll für die Zelllinie L428) für 10min in der Küvette bei RT inkubiert und anschließend in $12 \mathrm{ml}$ Medium überführt. Nach $48 \mathrm{~h}$ Inkubation wurde der Vorgang wiederholt. Hierbei wurden aus jedem Transfektionsansatz zwei Nukleofektionsküvetten für die zweite Transfektion verwendet und hiernach wieder zusammen geführt. Nach weiteren 48h Stunden wurden die Zellen geerntet oder für weitere Analysen (Durchflusszytometrie, Proliferationsanalyse) verwendet.

\subsubsection{Proliferationsanalyse durch ${ }^{3} \mathrm{H}$-Thymidin-Einbau}

Zur Analyse der Zellproliferation wurde die Methode des ${ }^{3} \mathrm{H}$-Thymidin-Einbaus angewendet. Das radioaktiv-markierte Thymidin wird von den Zellen aufgenommen und bei der Replikation der DNA in den Tochterstrang mit eingebaut. Die Menge der Radioaktivität ist somit proportional zur Zahl der proliferierenden Zellen.

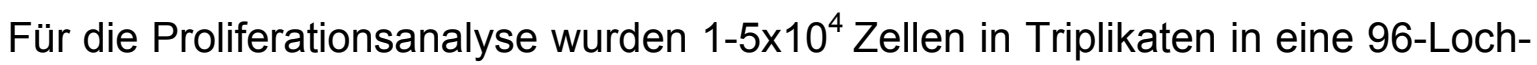
Platte übertragen und $16 \mathrm{~h}$ vor Ablauf der Inkubationsdauer (über Nacht) $0,5 \mu \mathrm{Ci}$

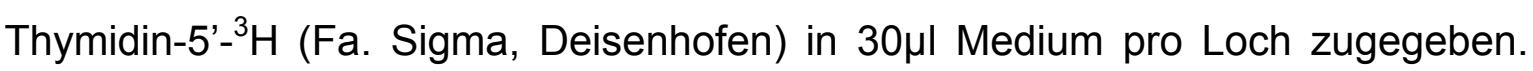
Zur Ernte wurden die Zellen auf einem Filterpapier gezogen (Inotech Cell Harvester, Fa. Wallac Distribution, Freiburg), das anschließend für $1 \mathrm{~h}$ bei $60^{\circ} \mathrm{C}$ 
getrocknet wurde. Die Radioaktivität wurde in einem Flüssigkeitsszintillationszähler gemessen (1450 Microbeta Trilux, Fa. Wallac Distribution, Freiburg) und der Mittelwert der Triplikate gebildet.

\subsubsection{Matrigel-Invasionsassay}

Die Invasivität von Tumorzellen ist ein wichtiger Faktor, der die Malignität widerspiegelt. Die Zellen müssen hierbei in der Lage sein die Basalmembran (extrazelluläre Matrix), hauptsächlich aus Laminin, Kollagenen und Proteoglycanen bestehend, zu durchdringen. Um die in vitro Invasivität der cHLZellen zu testen, wurden 24-Loch-Invasionskammern, die mit extrazellulärer Matrix beschichtet sind, verwendet (BD Biocoat Matrigel Invasions Chamber, BD Bioscience, Heidelberg). Diese künstlich hergestellte extrazelluläre Matrix befindet sich auf einer Nitrozellulosemembran und muss zunächst von den Zellen proteolytisch aufgelöst werden, bevor die Zellen durch die Membran wandern können.

Hierzu wurden die Zellen vor Versuchsbeginn gezählt, sedimentiert (250 x g, $5 \mathrm{~min}$ ) und auf eine Zellzahl von $5 \times 10^{5}$ Zellen/ml eingestellt. Die Invasionskammern wurden $2 \mathrm{~h}$ vor Versuchsbeginn aufgetaut und obere und untere Kammer für $2 \mathrm{~h}$ bei $37^{\circ} \mathrm{C}$ mit RPMI Medium rehydriert. Dannach wurden $750 \mu l$ der Zellsuspension in die obere Kammer überführt und für $48 \mathrm{~h}$ inkubiert. Nach Ablauf der Inkubationsdauer wurden die Zellen, die sich in der unteren Kammer befanden, gezählt.

\subsection{Durchflusszytometrische Methoden}

Die Durchflusszytometrie (im Englischen: Flow cytometry) dient zur Analyse der Eigenschaften von großen Mengen einzelner Zellen. Dazu werden diese aus dem Probenröhrchen in einen laminaren Trägerflüssigkeitsstrom hydrodynamisch fokussiert und einzeln an einem scharf gebündelten Laser (Argonlaser, $\lambda=$ $488 \mathrm{~nm}$ ) vorbeigeführt. Jede Zelle streut dabei den Laser. Die Vorwärts-Streuung (im Englischen: forward scatter, FSC) entspricht dabei der Größe der Zelle und die Seitewärts-Streuung (im Englischen: sideward scatter, SSC) ist ein Maß für die Granularität der Zelle. Besitzt die Zelle auf ihrer Oberfläche Fluorochrome z. B. durch markierte Antikörper, die durch die Wellenlänge des Lasers angeregt 
werden können, so detektiert das Gerät diese Signale ebenfalls. Das Gerät kann bis zu 3 verschiedene Fluoreszenzen gleichzeitig detektieren. Die durchflusszytometrischen Analysen erfolgten an einem FACScan Gerät (Fa.

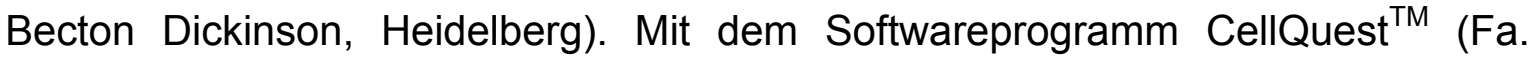
Becton Dickinson, Heidelberg) werden diese Vorgänge grafisch dargestellt, so dass Zellpopulationen und auch einzelne Zellen sichtbar werden. Spätere Auswertung der Analyse erfolgte neben CellQuest ${ }^{\mathrm{TM}}$ durch die Software FlowJo (Fa. Treestar, USA).

\subsubsection{Analyse von Zellen durch Fluoreszenzanregung}

In dieser Arbeit wurden zum einen EGFP-exprimierende Zellen und durch fluorochrome Antikörper markierte Zellen analysiert.

Die Transfektion der EGFP-Expressionsplasmids (pMax-GFP, Amaxa, Köln) wurde zur Kontrolle der Transfektionseffizienz der L428-Zellen verwendet. Die EGFP-exprimierenden Zellen wurden zunächst sedimentiert $\left(250 \times \mathrm{g}, 4^{\circ} \mathrm{C}, 5 \mathrm{~min}\right)$ und in einem der Zellzahl entsprechenden Volumen (300-500 $\mu$ l) FACS-Puffer aufgenommen. Durch die Zugabe von $1 / 10$ Volumen Propidium-Jodid $(5 \mu \mathrm{g} / \mathrm{ml}$ in PBS, Fa. Sigma, Deisenhofen) kurz vor der Analyse am FACScan konnte zwischen toten und lebenden Zellen differenziert werden. Nur tote Zellen sind permeabel für Propidium-Jodid, wodurch die Nukleinsäuren in der Zelle angefärbt werden.

Für die Färbung der Zellen durch Fluorochrom-markierte Antikörper wurden die zu färbenden Zellen in 400 $\mu$ l FACS-Puffer überführt, sedimentiert und anschliessend in $45 \mu$ l FACS-Puffer aufgenommen. Darauf folgte die Zugabe von $5 \mu$ des markierten Antikörpers, der durch Schütteln mit der Probe vermischt wurde. Die Färbung wurde für $10 \mathrm{~min}$ bei $4^{\circ} \mathrm{C}$ im Dunkeln durchgeführt. Hiernach wurde mit 1 ml FACS-Puffer gewaschen, die Zellen in einem Volumen von 250-500 $\mu$ l aufgenommen und am FACScan analysiert. 


\subsection{Proteinbiochemische Methoden}

\subsubsection{Immunpräzipitation von Proteinen}

Die Immunpräzipitation (IP) dient dazu, Proteine aus einem Gemisch zu isolieren und anzureichern. Hierzu wurde die Methode der magnetischen Selektion durch MMACS $^{\mathrm{TM}}$ Protein A MicroBeads (Fa. Miltenyi Biotech, Bergisch Gladbach) angewendet. Dabei wird das Zelllysat zusammen mit dem spezifischen Primärantikörper inkubiert, der dann durch den Fragment crystallizable (Fc)-Teil an die Protein A MicroBeads gebunden wird. Die magnetische Selektion der MicroBeads, die den Antikörper samt Protein gebunden haben, führt zur Aufreinigung des gewünschten Proteins.

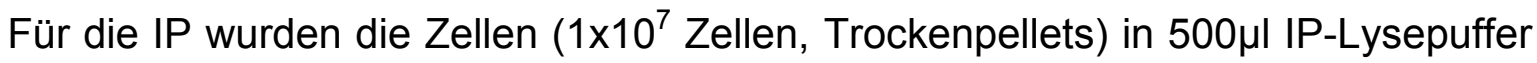
resuspendiert. Nach 30min Inkubation auf Eis zentrifugierte man die Proben $\left(15000 \times \mathrm{g} ; 4^{\circ} \mathrm{C} ; 15 \mathrm{~min}\right)$ und überführte den Überstand in ein neues Gefäß. Anschließend wurden $2 \mu \mathrm{g}$ des Antikörpers zu dem Überstand gegeben und im Kühlraum unter stetiger Bewegung über Nacht inkubiert. Am nächsten Morgen gab man 30 $\mu$ l der Protein A MicroBeads hinzu und inkubierte die Proben für 30min auf Eis. Währendessen wurden die Säulen ( $\mu$ Columns, Fa. Miltenyi Biotech, Bergisch Gladbach) in die Magnethalterung ( $\mu$ MACS $^{\mathrm{TM}}$ Separator, Fa. Miltenyi

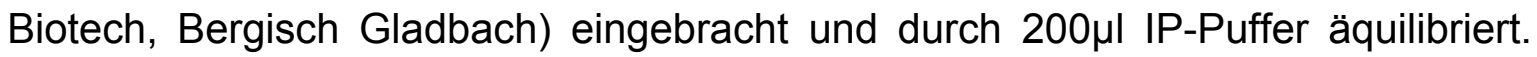
Anschließend wurden die Proben auf die Säulen aufgetragen. Hiernach wurde die

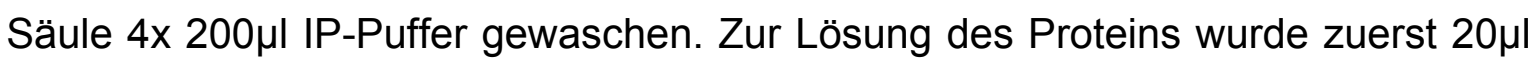
Laemmli-Puffer $\left(95^{\circ} \mathrm{C}\right)$ auf die Säule gegeben und nach 5 min Inkubation das Protein durch $50 \mu \mathrm{l}$ Laemmli-Puffer $\left(95^{\circ} \mathrm{C}\right)$ eluiert. Für die weitere Analyse wurde eine reguläre SDS-PAGE (Abschnitt 3.3.4) mit anschließender Immunoblot Analyse (Abschnitt 3.3.5) durchgeführt.

\subsubsection{Herstellung von Zelllysaten für SDS-PAGE}

Für die Herstellung von Proteinlysaten wurden stets Gefrierproben der Zellen (siehe Abschnitt 3.1.4) benutzt. Die Zellen wurden auf Eis aufgetaut und durch

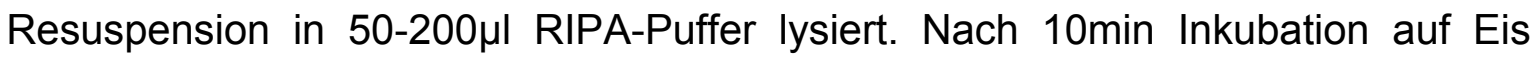
wurden die Proben zentrifugiert $\left(15000 \times \mathrm{g} ; 4^{\circ} \mathrm{C} ; 15 \mathrm{~min}\right)$, der Überstand in ein neues Gefäß übertragen und bei $-80^{\circ} \mathrm{C}$ gelagert. 


\subsubsection{Proteinkonzentrationsbestimmung nach Bradford}

Die Konzentration der Proteine in den Zelllysaten (Abschnitt 3.3.2) wurde nach der Bradford-Methode bestimmt (Bradford, 1976). Hierzu wurde der Farbstoff (Bio-Rad Protein Assay, Fa. Bio-Rad, München) 1:5 in $\mathrm{dd}_{2} \mathrm{O}$ verdünnt und mit der 1:500 verdünnten Proteinprobe vermischt. Nach 10min Inkubation wurde die Absorption bei einer Wellenlänge von $750 \mathrm{~nm}$ in einem Photometer (BioPhotometer, Fa. Eppendorf, Hamburg) bestimmt. Mittels einer Standardkurve verschiedener BSAKonzentrationen wurden die erhaltenen Absorptionsmesswerte (Duplikate) in Proteinkonzentrationen umgerechnet.

\subsubsection{Sodiumdodecylsulfat-Polyacrylamid-Gelelektrophorese}

Durch die SDS-PAGE können Proteine nach ihrem Molekulargewicht aufgetrennt werden. Die Proteine werden durch das stark anionische Detergenz SDS entfaltet und die Ladungen der Proteine nivelliert. So entstehen anionische Mizellen mit einer konstant negativen Ladung pro Masseneinheit, die im elektrischen Feld zur Anode wandern.

Die Methode erfolgte nach Laemmli (Laemmli, 1970). Zur Trennung wurden diskontinuierliche Gele mit einem grobporigen Sammelgel $(\mathrm{pH} \mathrm{6,8)} \mathrm{und} \mathrm{einem}$ feinporigen Trenngel $(\mathrm{pH} 8,8)$ verwendet. Es wurden stets $30 \mu \mathrm{g}$ Protein pro Probe verwendet. Diese wurden mit 1/3 Volumen Probenpuffer (4 x Rotiß-Load 1, Fa. Roth, Karlsruhe) vermischt, für $5 \mathrm{~min}$ bei $95^{\circ} \mathrm{C}$ denaturiert und in die Geltasche übertragen. Die Auftrennung erfolgte zusammen mit einem Molekulargewichtsstandard (Full Range Rainbow Molecular Weight Markers RPN800, Amersham Biosciences, England) in Laufpuffer bei einer konstanten Spannung von 160V für 1,5-2h. Es wurden Gele mit Acrylamid-Konzentrationen (Acrylamid/Bisacrylamid 37,5/1, Stocklösung (v/v) 40\%; Fa. Bio-Rad, München) von $10-15 \%$ verwendet. Die Arbeiten wurden in einem vertikalen Elektrophoresesystem (Mini-Protean ${ }^{\circledR}$ 3, Fa. Bio-Rad, München) durchgeführt. Nach der Elektrophorese wurden die aufgetrennten Proteine auf eine Nitrozellulosemembran transferiert (3.3.5.1). In Tabelle 3.1 ist die exemplarische Zusammensetzung eines $15 \%$ igen SDS-Polyacrylamidgels aufgeführt. 
Tabelle 3.1 Zusammensetzung eines Polyacrylamidgels (Exemplarisch für ein 15\%iges Trenngel).

\begin{tabular}{lcc}
\hline Reagenz & Sammelgel 5\% & Trenngel 15\% \\
\hline Trenngelpuffer & - & $2,5 \mathrm{ml}$ \\
Sammelgelpuffer & $1,25 \mathrm{ml}$ & - \\
AA/BA (37,5/1) $40 \%$ & $625 \mu \mathrm{l}$ & $3,8 \mathrm{ml}$ \\
Aqua bidest & $3,125 \mathrm{ml}$ & $3,7 \mathrm{ml}$ \\
$10 \%$ SDS & $45 \mu \mathrm{l}$ & $100 \mu \mathrm{l}$ \\
$10 \%$ APS & $20 \mu \mathrm{l}$ & $38 \mu \mathrm{l}$ \\
TEMED & $6,5 \mu \mathrm{l}$ & $12,5 \mu \mathrm{l}$
\end{tabular}

\subsubsection{Immunoblot}

Das Verfahren des Immunoblots dient zum Nachweis eines bestimmten Proteins aus einer komplexen Mischung. Die nach ihrem Molekulargewicht aufgetrennten Proteine werden hierzu auf eine inerte Filtermembran übertragen. Zur Identifizierung des spezifischen Proteins wird eine Immundetektion durch Antikörper durchgeführt.

\subsubsection{Proteintransfer}

Die elektrophoretisch aufgetrennten Proteine wurden im elektrischen Feld vom SDS-Gel auf eine Nitrozellulosemembran (Hybond-C-extra, Amersham Biosciences, England) überführt (Towbin et al., 1979). Es wurde hierbei das Naßblot-Verfahren (auch Tankblot genannt) durch das Mini Trans-Blot Cell囚 System (Fa. Bio-Rad, München) angewendet. Bei dieser Methode werden Gel und Membran zwischen Whatman-Filterpapier (Diethylaminoethyl-Cellulose, Whatman $®$ International Ltd, England) und Schwammtüchern in eine mit Transferpuffer gefüllte vertikale Blotkammer integriert. Alle Komponenten werden vorher in Transferpuffer äquilibriert.

Folgender Aufbau wurde verwendet:

Anode (+)
Schwamm
3 Lagen Whatman-Filterpapier
Nitrozellulosemembran
SDS-Gel
3 Lagen Whatman-Filterpapier
Schwamm
Kathode (-)

Der Vorgang wurde bei $4^{\circ} \mathrm{C}$ durchgeführt und die Apparatur zusätzlich durch einen Eisblock gekühlt. Der Transfer erfolgt bei einer konstanten Spannung von 0,1kV 
für 4h. Dabei wurden der Transferpuffer und der Eisblock nach $2 \mathrm{~h}$ gewechselt. Unmittelbar danach wurde der Proteintransfer durch Ponceau-Rot Färbung (3.3.8) kontrolliert.

\subsubsection{Immundetektion von Proteinen}

Die Membran wurde zum Absättigen unspezifischer Bindungsstellen für $1 \mathrm{~h}$ bei Raumtemperatur in Blockpuffer $\left(5 \%(\mathrm{w} / \mathrm{v})\right.$ ECL ${ }^{\mathrm{TM}}$ Blocking Agent in TBS-T, Amersham Bioscience, England) inkubiert. Zur Identifizierung des gesuchten Proteins im geblotteten Bandenmuster wurde die Membran zunächst mit einem spezifischen Primärantikörper inkubiert. Ungebundene Antikörper wurden durch Waschen (3x10min mit TBS-T unter Schwenken) entfernt, und die Inkubation mit dem Sekundärantikörper, der gegen die Spezies des Primärantikörper gerichtet war, folgte darauf. Die in dieser Arbeit benutzten sekundären Antikörper waren alle mit einer Meerettich-Peroxidase (im Englischen horseradish peroxidase, HRP) gekoppelt, die in der Lage ist, Luminol zu oxidieren. Bei der Oxidation von Luminol wird Licht emittiert, das durch autoradiographische Filme detektiert werden kann.

Die Antikörperdetektion wurde über ein Luminol-enthaltendes ChemiluminiszenzSystem (ECL ${ }^{\text {тM }}$ Advance Western Blotting Detection Kit, Fa. Amersham Biosciences, England) durchgeführt. Dazu wurden die Membranen mit zwei zu gleichen Teilen vermischten Komponenten des $\mathrm{ECL}^{{ }^{\mathrm{M}}}$-Systems für $1 \mathrm{~min}$ im Dunkeln inkubiert und anschließend in eine Filmkassette (Hypercasette $^{\mathrm{TM}}$, Amersham Bioscienes, England) übertragen. Im Dunkelraum wurden nun Filme (Hyperfilm $^{\mathrm{TM}} \mathrm{ECL}^{\mathrm{TM}}$, Fa. Amersham Biosciences, England) aufgelegt, unterschiedlich lange belichtet und entwickelt (Protec Optimax X-Ray Film Processor, Fa. Maco, Hamburg).

\subsubsection{Wiederverwendung von Nitrozellulosemembranen}

Um eine bereits entwickelte Membran erneut verwenden zu können, ohne die gleichen Signale erneut zu detektieren, wurden die Antikörper entfernt. Dazu inkubierte man die Membran für 30min unter Schwenken mit einem 1:10 in $\mathrm{dd}_{2} \mathrm{O}$ verdünnten Puffer (Re-Blot plus Mild, Fa. Chemicon, Hofheim). Nach einer erneuten Blockierung der unspezifischen Bindungsstellen konnte die Membran wiederholt mit Antikörpern inkubiert werden. 


\subsubsection{Ponceau-Rot Färbung}

Zur Prüfung der Proteinbeladung und der Kontrolle des Immunoblots wurde eine Proteinfärbung auf der Nitrozellulose-Membran mittels Ponceau-Rot durchgeführt. Hierzu wurde die Membran für 2-3min in die Ponceau-Lösung (2\% (w/v) Ponceau $\mathrm{S}, 3 \%(\mathrm{v} / \mathrm{v})$ Essigsäure) gelegt und danach die Hintergrundfärbung durch $\mathrm{ddH}_{2} \mathrm{O}$ entfernt. Eine vollständige Entfärbung erfolgte durch Inkubation mit TBS-T.

\subsubsection{Enzyme-linked Immunosorbent Assay (ELISA)}

Um den Proteingehalt von IL-10 im Lymphompatientenserum zu bestimmen wurde die ELISA Methode angewendet. Das Serum der Patienten wurde nach ProbenEingang bei $-75^{\circ} \mathrm{C}$ gelagert und kurz vor der Analyse auf Eis aufgetaut. Zur Bestimmung der IL-10 Proteinmenge im Patientenserum wurde das IL-10 Eli-pair ELISA Kit (Fa. Diaclone, Giessen) nach Herstellerangaben verwendet. Die Absorbtion der Proben wurde bei einer Wellenlänge von 450nm detektiert (MultiDetection Microplate Reader,Synergy HT, BIO-TEK, Bad Friedrichshall).

\subsection{Molekularbiologische Methoden}

\subsubsection{Isolierung von genomischer DNA}

Die Isolierung von genomischer DNA aus Blutproben erfolgte durch Verwendung des QIAamp DNA Blood Mini Kit (Fa. Qiagen, Hilden) nach Angaben des Herstellers. Zur Erhöhung der isolierten DNA-Menge wurde jeweils die doppelte Menge der im Herstellerprotokoll verwendeten Angabe benutzt. Die DNA wurde in einem Volumen von $200 \mu$ l eluiert und bei $4^{\circ} \mathrm{C}$ bis zur weiteren Verwendung gelagert.

\subsubsection{Isolierung von RNA und Reverse Transkription}

Für die Isolierung der RNA aus den Zellen wurde das RNeasy plus Mini Kit (Fa. Qiagen, Hilden) nach Angaben des Herstellers verwendet. Zur Homogenisierung wurden QiaShredder Säulen (Fa. Qiagen, Hilden) verwendet. Die RNA wurde in

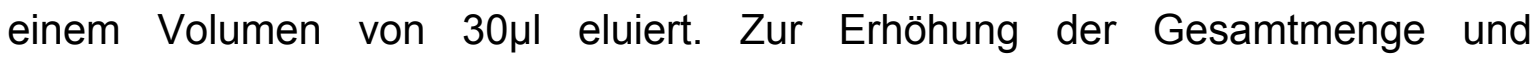
Konzentration der RNA wurde der Elutionsschritt mit denselben $30 \mu$ l wiederholt. 
Zur Erststrang-cDNA-Synthese wurde in dieser Arbeit das SuperScript II Reverse Transkriptase Kit (Fa. Invitrogen, Karlsruhe) benutzt. Folgender Reaktionsansatz und Inkubationsbedingungen wurden nach Angaben des Herstellers verwendet:

\begin{tabular}{|c|c|c|}
\hline \multicolumn{3}{|l|}{$1-5 \mu \mathrm{g}$ RNA } \\
\hline \multirow{2}{*}{\multicolumn{3}{|c|}{$\begin{array}{l}\text { ad } 12 \mu \mathrm{l} \mathrm{H}_{2} \mathrm{O} \\
0,20 \mu \mathrm{l} \text { random Hexamer Primer }(50 \mu \mathrm{M})\end{array}$}} \\
\hline & & \\
\hline \multicolumn{3}{|c|}{$\begin{array}{l}0,20 \mu l \text { random Hexamer Primer }(50 \mu M) \\
4,00 \mu l \text { Erststrang-Puffer }(5 x)\end{array}$} \\
\hline \multicolumn{3}{|c|}{$2,00 \mu \mathrm{l}$ dNTPs $(10 \mathrm{mM})$} \\
\hline \multicolumn{3}{|l|}{$2,00 \mu \mathrm{l}$ DTT $(0,1 \mathrm{M})$} \\
\hline \multicolumn{3}{|c|}{$1,00 \mu \mathrm{l}$ Reverse Transkriptase $(200 \mathrm{U} / \mu \mathrm{l})$} \\
\hline \multirow[t]{4}{*}{ Thermocycler-Programm: } & $65^{\circ} \mathrm{C}$ & $5 \mathrm{~min}$ \\
\hline & $25^{\circ} \mathrm{C}$ & $10 \mathrm{~min}$ \\
\hline & $42^{\circ} \mathrm{C}$ & $50 \mathrm{~min}$ \\
\hline & $70^{\circ} \mathrm{C}$ & $15 \mathrm{~min}$ \\
\hline
\end{tabular}

Zuerst wurde nur die RNA, das Wasser sowie der Random Hexamer Primer im Thermocycler (TRIO Thermoblock, Fa. Biometra, Göttingen) bei $65^{\circ} \mathrm{C}$ inkubiert, während der $10 \mathrm{~min}$ Inkubation bei $25^{\circ} \mathrm{C}$ wurden die restlichen Komponenten hinzugefügt. Die synthetisierte cDNA wurde dann bis zur Verwendung bei $-20^{\circ} \mathrm{C}$ gelagert. 


\subsubsection{Sequenzierung}

Die Analyse von Nukleotidsequenzen wurde durch die Verwendung von Fluoreszenz-markierten 2'3'-Desoxynukleotiden (BigDye Terminator Cycle Sequencing-Kit v1.1, Fa. Applied Biosystems, USA) durchgeführt. Folgender Reaktionsansatz und Inkubationsbedingungen wurde verwendet:

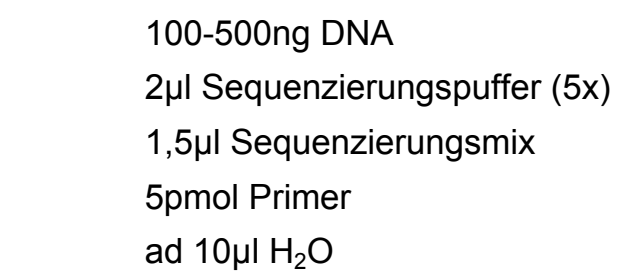

$\begin{array}{lll}\text { Thermocycler-Programm: } & 95^{\circ} \mathrm{C} & 30 \mathrm{sec} \\ & 50^{\circ} \mathrm{C} & 15 \mathrm{sec} \\ & 60^{\circ} \mathrm{C} & 4 \mathrm{~min} \quad 25 \text { Zyklen } \\ & 4^{\circ} \mathrm{C} & \end{array}$

\subsubsection{Real-Time PCR-Analysen}

3.4.4.1 Durchführung der TaqMan® Real-Time PCR

Zur Analyse der Transkriptmenge wurde in dieser Arbeit ein SYBR Green basiertes System verwendet. SYBR Green ist ein Cyanin-Farbstoff, der an doppelsträngige DNA bindet und in gebundener Form nach Anregung Licht der Wellenlänge $521 \mathrm{~nm}$ emittiert. Es wurden das Fast SYBR Green und das SYBR Green Mastermix Kit (Fa. Applied Biosystems, USA) verwendet. Die Reaktionen

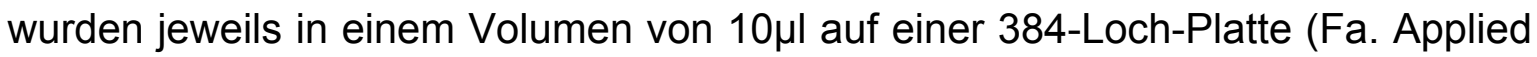
Biosystems, USA) durchgeführt. Die PCR Reaktion bestand dabei aus $5 \mu$ (Fast) SYBR Green Mastermix (2x), $1 \mathrm{pmol}$ der beiden Transkript-spezifischen Primer und 20ng cDNA. Für jede Probe wurde eine Dreifachbestimmung durchgeführt. Zur Kontrolle evtl. Kontaminationen wurde eine Dreifachbestimmung ohne cDNA, sondern nur mit Wasser durchgeführt. Die Reaktion wurde im ABI Prism 7900HT realtime-PCR System (Fa. Applied Biosystems) durchgeführt. Folgendes Programm wurde hierfür verwendet:

\begin{tabular}{|l|l|l|}
\hline Fast SYBR Green Kit & SYBR Green Kit & \\
\hline $95^{\circ} \mathrm{C} 20 \mathrm{~s}$ & $95^{\circ} \mathrm{C} 10 \mathrm{~min}$ & \\
\hline $95^{\circ} \mathrm{C} 1 \mathrm{~s}$ & $95^{\circ} \mathrm{C} 15 \mathrm{sec}$ & \multirow{2}{*}{40 Zyklen } \\
\hline $60^{\circ} \mathrm{C} 20 \mathrm{~s}$ & $60^{\circ} \mathrm{C} 1 \mathrm{~min}$ & \\
\hline
\end{tabular}


Am Ende der Reaktion wurde eine Schmelzkurvenanalyse durchgeführt, um die spezifische Amplifikationen eines PCR-Produkts zu überprüfen. Bei unspezifischen oder multiplen Amplifikaten wurden die Ergebnisse der Analyse verworfen.

\subsubsection{Bestimmung der relativen Transkript-Menge}

Um ein Amplifikationsplot auszuwerten, wird in den exponentiellen Bereich der PCR der Schwellenwert (Threshold, horizontale rote Linie Abb. 8) gelegt, in diesem Bereich lassen sich die einzelnen Reaktionen untereinander vergleichen. Der Schnittpunkt einer Fluoreszenzkurve mit dem Schwellenwert markiert den CTWert (Threshold Cycle) für diese Reaktion. Der CT-Wert gibt die Zyklenzahl an, bei der der Schwellenwert in der exponentiellen Phase überschritten wird. Je geringer der CT-Wert desto mehr Transkript ist in der Probe vorhanden (die exponentielle Phase wurde nach weniger Zyklen erreicht).

Zur Berechnung der relativen RNA-Mengen wird zunächst die Differenz aus den CT-Werten des spezifischen und des "house keepers“ $\beta 2 \mathrm{~m}-$ Gen gebildet:

$$
\mathrm{CT}_{\text {spez. }}-\mathrm{CT}_{\beta 2 \mathrm{~m}}=\Delta \mathrm{CT}
$$

Nun wird die Differenz aus den $\Delta \mathrm{CT}$-Werten der miteinander zu vergleichenden Proben gebildet:

$$
\Delta \mathrm{CT}_{\text {Probe A }}-\Delta \mathrm{CT}_{\text {Probe B }}=\Delta \Delta \mathrm{CT}
$$

Der $\Delta \Delta$ CT gibt an, ob im Vergleich zu Probe $A$ mehr oder weniger RNA in der Probe B vorliegt. Die Werte der Kontroll-Proben (hier „Scrambled“) wurden auf 1 normiert und die ermittelten Werte der anderen Proben hierzu ins Verhältnis gesetzt (x-fache der Kontroll-Probe).

\subsubsection{Konzentrationsbestimmung von Nukleinsäuren}

Die Konzentrationen der RNA und DNA wurden durch photometrische Messung im Nanodrop 1000 (Fa. Thermo Fisher Scientific, USA) bestimmt. Die Messung erfolgte bei einer Wellenlänge von 260nm gegen einen Leerwert des Lösungsmittels von RNA bzw. DNA. 


\subsubsection{Allelische Diskriminierung mittels Taqman-PCR}

Die allelische Diskriminierung mittels Taqman-PCR diente dazu, Genpolymorphismen an einer bestimmten Position der DNA zu detektieren. In der PCR-Reaktion befinden sich neben den Lokus-spezifischen Primern (5' und 3' des Polymorphismus) zwei Fluoreszenz-markierte Sonden, die sich nur in der unterschiedlichen Base des Polymorphismus sowie der Fluoreszenzmarkierung (FAM und VIC) unterscheiden. Beide Sonden tragen neben dem Reporterfarbstoff (5'-Ende) einen so genannten "Quencher" am 3'-Ende. Dieser unterdrückt bei räumlicher Nähe zum Reporter durch FRET (Förster type of energy transfer) die Anregung der Fluoreszenz des Reporters durch den Laser. Bei der PCR-Reaktion wird eine DNA-Polymerase verwendet, die eine 5'-3'-Exonukleaseaktivität besitzt. Trifft die Polymerase bei der Amplifikation auf die Sonde, so wird sie abgebaut. Hierbei löst sich der Reporter aus der Nähe des Quencher und kann zur Fluoreszenz angeregt werden. In Abhängigkeit des Genotyps der verwendeten DNA ergibt sich also nach 40 PCR-Zyklen eine Akkumulation von freien FAM-, VIC-, oder beiden Farbstoffen (heterozygot).

Zur Analyse der Genpolymorphismen wurde das Taqman Genotyping Mastermix Kit (Fa. Applied Biosystems, USA) verwendet. Die Reaktion wurde in einem Volumen von $5 \mu \mathrm{l}$ auf einer 384-Loch-Platte durchgeführt. Die spezifischen Primeransätze für die einzelnen Polymorphismen wurden entweder nach Angaben der SNP500Cancer Datenbank (http://snp500cancer.nci.nih.gov/) hergestellt oder als fertiger Mix der Fa. Applied Biosystem (Taqman SNP Genotyping Assay) bezogen (Tabelle 2.10).

Folgender Reaktionsansatz und Amplifikationsbedingen wurden verwendet:

\begin{tabular}{|c|c|l|}
\hline Eigener Mix & Applied Biosystems Mix & \\
\hline $2,50 \mu \mathrm{l}$ & $2,50 \mu \mathrm{l}$ & Taqman Genotyping Mastermix (2x) \\
\hline- & $0,25 \mu \mathrm{l}$ & Taqman SNP Genotyping Assay \\
\hline $0,20 \mu \mathrm{l}$ & - & Forward-Primer $(22,5 \mu \mathrm{M})$ \\
\hline $0,20 \mu \mathrm{l}$ & - & Reverse-Primer $(22,5 \mu \mathrm{M})$ \\
\hline $0,20 \mu \mathrm{l}$ & - & Sonde1 (FAM) $(5 \mu \mathrm{M})$ \\
\hline $0,20 \mu \mathrm{l}$ & - & Sonde2 (VIC) $(5 \mu \mathrm{M})$ \\
\hline $0,70 \mu \mathrm{l}$ & $1,25 \mu \mathrm{l}$ & $\mathrm{H}_{2} \mathrm{O}$ \\
\hline $1,00 \mu \mathrm{l}$ & $1,00 \mu \mathrm{l}$ & genomische DNA (10ng/ $\mathrm{ll})$ \\
\hline
\end{tabular}

\begin{tabular}{|l|l|l|}
\hline Thermocycler-Programm: & $95^{\circ} \mathrm{C} 10 \mathrm{~min}$ & \\
\hline & $95^{\circ} \mathrm{C} 15 \mathrm{sec}$ & \\
\cline { 1 - 2 } & $60^{\circ} \mathrm{C} 1 \mathrm{~min}$ & 40 Zyklen \\
\hline
\end{tabular}




\subsection{Definitionen und statistische Analysen}

Zur Analyse der genetischen Daten wurde die Genepop-Software (Version 3.4 http://genepop.curtin.edu.au/) verwendet. Die Analysen beinhalteten Tests für das Hardy-Weinberg-Equilibrium, allelische und genotypische Unterscheidungen zwischen Patientenkollektiven. Zur Analyse der Haplotypen wurde die Haplotype Estimation Software (MDC, Berlin http://www.bioinf.mdc-berlin.de/projects/hap/) verwendet.

Der Begriff Gesamtüberleben ist in dieser Arbeit als die Zeit zwischen Therapiebeginn und Versterben des Patienten aus jeglichen Gründen definiert. Ereignis-freies Überleben ist als Zeit zwischen Therapiebeginn und verschiedenen Ereignissen definiert. Als Ereignis wird der fortschreitenden Krankheitsverlauf unter Therapie, die fehlende komplette Remission, die Anwendung weiterer Therapieschemata zusätzlich zum definierten Therapieprotokoll, ein Rezidiv der Erkrankung oder das Versterben des Patienten aus jeglichen Gründen verstanden.

Ereignis-freies und Gesamtüberleben wurden nach Kaplan-Meier berechnet und durch den log-rank Test verglichen. Die multivariate Analyse wurde nach dem Cox-Hazard-Modell durchgeführt. Diese Analysen wurden durch Frau Samira Zeynalova (IMISE, Leipzig) durchgeführt.

Bei der Berechnung der Wahrscheinlichkeiten wurde auf eine Adjustierung auf multiples Testen verzichtet, da hier nur der bedeutendste Faktor betrachetet werden soll. 


\section{ERGEBNISSE}

\subsection{Die Janus-Kinasen als therapeutisches Ziel in cHL-Zellen}

In cHL-Zelllinien konnte eine permanente Aktivierung der Transkriptionsfaktoren STAT3 und STAT6 nachgewiesen werden (Kube et al., 2001a; Skinnider et al., 2002a). Die Aktivierung der STAT-Transkriptionsfaktoren durch Tyrosinphosphorylierung kann durch diverse Kinasen durchgeführt werden. Zytokine aktivieren nach Bindung an ihren Rezeptorkomplex die Janus-Kinasen, die wiederum die STAT-Moleküle aktivieren können. In verschiedenen malignen Zellen können auch andere Kinasen an der Aktivierung von STATs beteiligt sein. Über die Rolle der Janus-Kinasen im cHL ist bisher nur wenig bekannt. In diesem Teil der Arbeit soll untersucht werden, ob die Janus-Kinasen aktiviert in den cHLZelllinien vorliegen und ob sie eine Zielstruktur für therapeutische Ansätze bieten könnten.

\subsubsection{Aktivierungszustand der Janus-Kinasen in cHL-Zelllinien}

Für das cHL konnte bisher nur in Zelllinien, die ihren Ursprung in T-Zellen haben, eine Aktivierung von Jak1, Jak2 (HDLM2) und Jak3 (L540) bestätigt werden (Cochet et al., 2006). Da das cHL in den meisten Fällen von B-Zellen abstammt (ca. 98\%), wurden in dieser Arbeit drei cHL-Zelllinien B-zellulären Ursprungs analysiert. Zuvor konnte gezeigt werden, dass die Behandlung der Zelllinien des cHLs mit dem Tyrphostin AG17 zu einer Inhibition der Tyrosinphosphorylierung von STAT3 sowie STAT6 führt (Holtick et al., 2005). Um zu untersuchen, ob die Janus-Kinasen tyrosinphosphoryliert vorliegen und die Behandlung der cHL-Zellen mit AG17 dies inhibiert, wurden Jak1, Jak2, Jak3 und Tyk2 in den cHL-Zelllinien L428, L591 und L1236 untersucht. Hierfür wurden die Zelllinien mit dem

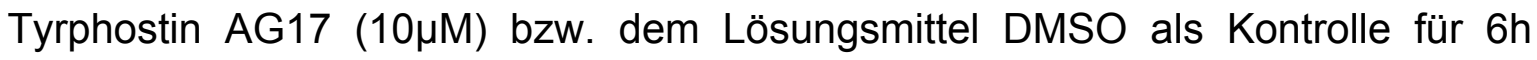
behandelt und nach Immunpräzipitation die Tyrosinphosphorylierung der JanusKinasen mittels Immunoblot untersucht (Abbildung 4.1). Die Behandlung der Zellen mit AG17 wurde möglichst kurz durchgeführt (6h), damit sekundäre Effekte, die zur Hemmung der Tyrosinphosphorylierungen der Janus-Kinasen beitragen 
könnten, reduziert werden. Die Hemmung der STAT-Phosphorylierung konnte erst nach $24 \mathrm{~h}$ festgestellt werden, so dass die STAT-aktivierenden Kinasen zuvor inhibiert sein müssen (Holtick et al., 2005).

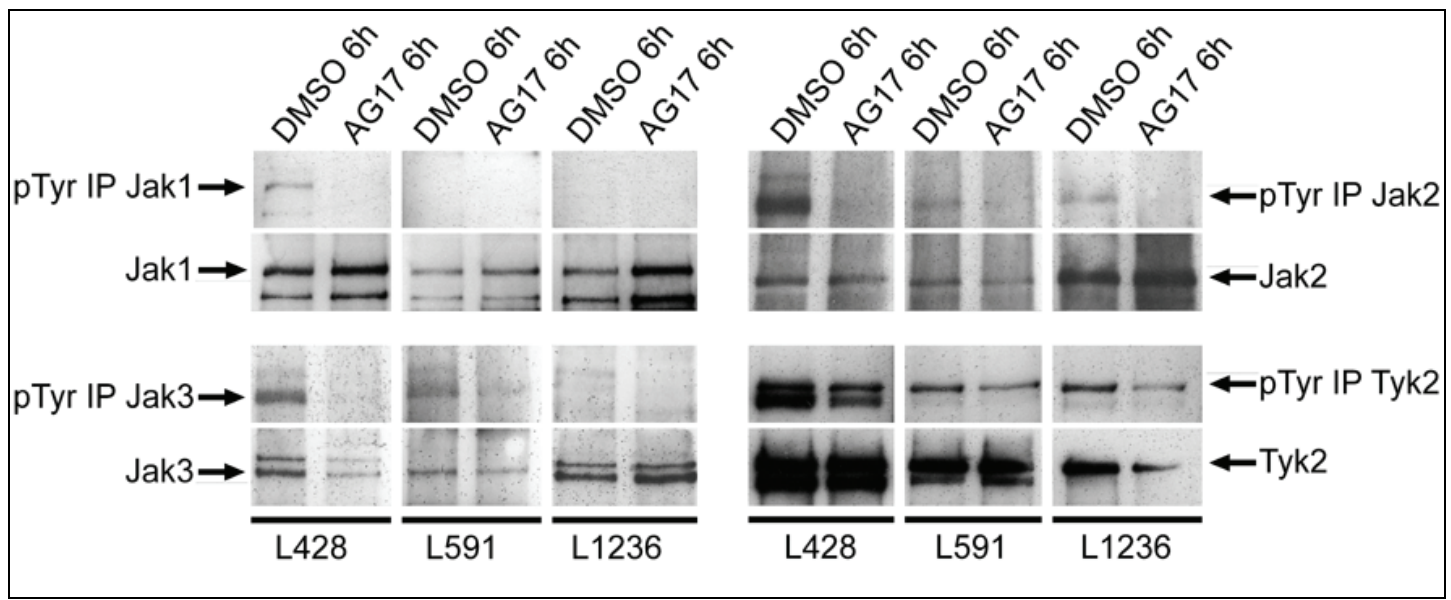

Abbildung 4.1 Tyrosinphosphorylierung der Janus-Kinasen und die Hemmung durch das Tyrphostin AG17 in den cHL-Zelllinien. Die cHL-Zelllinien L428, L591 and L1236 wurden für 6h

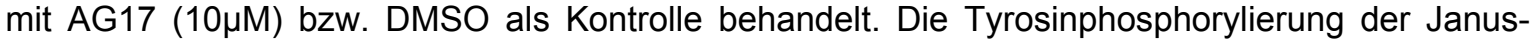
Kinasen wurde mittels Jak-spezifischer Immunpräzipitation und phosphotyrosin-spezifischer Immunoblot-Färbung (4G10) untersucht. Anschließend wurde eine Färbung mit den Jakspezifischen Antikörpern durchgeführt. In den $\mathrm{cHL}$-Zelllinien ist eine Aktivierung verschiedener Janus-Kinasen nachweisbar. Die Inkubation mit AG17 führt zur Hemmung dieser Aktivierung.

Wie in Abbildung 4.1 dargestellt, konnten alle 4 Janus-Kinasen in allen drei untersuchten Zelllinien mittels Immunoblot mit Jak-spezifischen Antikörpern nachgewiesen werden (in Abb. 4.1 als Jak1, Jak2, Jak3 und Tyk2 markiert). Ebenfalls sind in den einzelnen cHL-Zelllinien tyrosinphosphorylierte Janus-Kinasen detektierbar (in Abb. 4.1 als pTyr IP markiert).

In der Zelllinie L428 konnten in den Immunpräzipitaten der Janus-Kinasen nach Behandlung mit DMSO durch den Tyrosinsphosphorylierungs-spezifischen Antikörper (4G10) Signale bei allen 4 Janus-Kinasen nachgewiesen werden. In den beiden anderen Zelllinien L591 und L1236 wurden drei tyrosinphosphorylierte Janus-Kinasen detektiert.

Die Tyrosinphosphorylierung von Jak1 konnte nur in der Zelllinie L428 gezeigt werden, wobei Jak2 in allen Zellinien eine Tyrosinphosphorylierung zeigt. Die Immunpräzipitation von Jak3 zeigt bei Färbung mit dem Tyrosinphosphorylierungs-spezifischen Antikörper (4G10) ebenso ein Signal bei allen drei Zelllinien, jedoch mit deutlich unterschiedlichen Intensitäten. Die Zelllinie L1236 weist im Vergleich zu den beiden anderen Zelllinien ein wesentlich 
schwächeres Signal auf. Eine Tyrosinphosphorylierung von Tyk2 konnte in allen drei untersuchten Zelllinien nachgewiesen werden.

Die unterschiedlichen Tyrosinphosphorylierungen der Janus-Kinasen spiegeln die Heterogenität der cHL-Zelllinien wider, die schon bei der Zytokinproduktion der Zelllinien festgestellt werden konnte (Skinnider et al., 2002b).

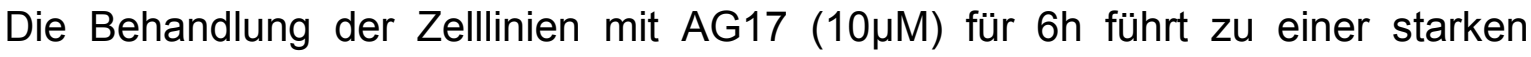
Reduktion der Tyrosinphosphorylierung der Jak1, Jak2 und Jak3 in allen drei Zelllinien. Für Tyk2 konnte nur eine geringe Abnahme der Tyrosinphosphorylierung nach Behandlung mit AG17 festgestellt werden. Die Proteinmenge der Janus-Kinasen bleibt weitgehend unbeeinflusst. Für Jak3 ist in den L428 und L591-Zellen eine Abnahme des Proteins durch die Behandlung mit AG17 nachweisbar, jedoch ist diese Proteinabnahme im Vergleich zur Reduktion der Tyrosinphosphorylierung gering.

Diese Analyse zeigt, dass auch in cHL-Zellen B-lymphozytären Ursprungs die Janus-Kinasen in einem aktivierten Zustand vorliegen. Ebenfalls lässt sich diese Aktivierung durch das Tyrphostin AG17 hemmen. Diese Ergebnisse sind aus therapeutischer Sicht von besonderem Interesse, da der Einsatz von JanusKinasen-spezifischen Inhibitoren zukünftig auch in der Therapie von Lymphompatienten möglich wäre.

\subsubsection{Mutationsanalysen von Jak2 und Tyk2 in cHL-Zelllinien}

Mutationen innerhalb der Gene von Kinasen können zu deren aberranter Aktivierung führen. Für Jak2 und Tyk2 wurden Mutationen beschrieben, die mit einer erhöhten Aktivität verbunden sind (Baxter et al., 2005; Staerk et al., 2005; Schnittger et al., 2006). In diesem Zusammenhang wurde für die so genannte Jak2 V617F Mutation eine Assoziation mit verschiedenen myeloproliferativen Erkrankungen festgestellt (Levine et al., 2005).

Da Jak2 und Tyk2 in allen drei hier untersuchten cHL-Zelllinien tyrosinphosphoryliert sind (Abbildung 4.1), könnten Mutationen dazu beitragen, dass diese Kinasen in einem aktivierten Zustand stabilisiert werden. Deshalb wurde das Transkript von Jak2 in den cHL-Zellinien L428, L1236, L591, KMH2, L540 und HDLM2 durch überlappende Primerpaare sequenziert und die Jak2 V617F homologe Mutation V678F in Tyk2 in den Zelllinien des cHLs untersucht. In 
Tabelle 4.1 ist die Analyse der bekannten Jak2 Mutation V617F, den Jak2 Variationen D620E und E627E sowie der Jak2 V617F homologen Mutation von Tyk2 V678F in den cHL-Zellen zusammengefasst.

Tabelle 4.1 Mutationsanalyse von Jak2 and Tyk2 in den cHL-Zelllinien. Die Transkripte der unmutierten Form sind als Wildtyp (wt) gekennzeichnet. ND bedeutet nicht durchgeführt.

\begin{tabular}{lcccc}
\hline Zelllinie & Jak2 V617F & Jak2 D620E & Jak2 E627E & Tyk2 V678F \\
\hline L428 & wt & $w t$ & $w t$ & $w t$ \\
L1236 & $w t$ & $w t$ & $w t$ & $w t$ \\
L591 & $w t$ & $w t$ & $w t$ & $w t$ \\
KMH2 & $w t$ & $w t$ & $w t$ & ND \\
L540 & $w t$ & $w t$ & $w t$ & wD \\
HDLM2 & wt & wt & wt & wt
\end{tabular}

Alle untersuchten cHL-Zelllinien weisen nur Transkripte der unmutierten Form (Jak2 V617, D620, E627 und Tyk2 V678) von Jak2 und Tyk2 auf. Die Abwesenheit der Jak2 V617F Mutation in cHL-Zellen wurde kürzlich in einer Publikation bestätigt (Melzner et al., 2006). Es ist daher anzunehmen, dass die Tyrosinphosphorylierung von Jak2 und Tyk2 innerhalb der cHL-Zelllinien nicht durch bekannte Mutationen verursacht ist.

\subsubsection{Der Jak-STAT-Signalweg ist in den cHL-Zelllinien abhängig von HSP90} Das Heat-shock protein 90 (HSP90) ist ein Chaperon, das für die Stabilität und Faltung vieler Proteine von Bedeutung ist (Whitesell et al., 2005). Die Arbeiten zum Tyrphostin AG17 zeigten, dass die Janus-Kinasen Zielstrukturen für zukünftige Therapien im cHL sein könnten (Abschnitt 4.1.1). Im Verlauf dieser Studien erschienen Publikationen, die in diesem Kontext interessant waren. Shang et al. wiesen eine Interaktion zwischen Jak1 bzw. Jak2 und HSP90 nach (Shang et al., 2006). Ebenfalls wurde eine vermehrte Expression von HSP90 in den Zellen des $\mathrm{cHL}$ detektiert, sowie eine reduzierte Proliferation und Überleben der cHLZellen durch HSP90 Inhibition beobachtet (Georgakis et al., 2006a; Janz et al., 2007).

Auf Grund dieser Analysen wurde in dieser Arbeit der Zusammenhang zwischen HSP90 und der Jak-STAT-Signalkaskade im cHL untersucht. Dazu wurde zunächst die Wirkung des HSP90-Inhibitors 17-AAG auf die Zellproliferation sowie auf die STAT-Tyrosinphosphorylierung in den drei cHL-Zelllinien L428, L1236 und HDLM2 untersucht (Abbildung 4.2 und 4.3). Für die Analyse der Zellproliferation 
wurden die cHL-Zelllinien mit 17-AAG $(5 \mu \mathrm{M})$ bzw. einer äquivalenten Menge DMSO als Kontrolle behandelt und die Proliferation mittels ${ }^{3} \mathrm{H}$-Thymidin-Einbau detektiert. Es konnte bestätigt werden, dass die Inkubation mit 17-AAG innerhalb von $24 \mathrm{~h} \mathrm{zu}$ einer Reduktion der Zellproliferation von über $50 \%$ in den drei analysierten cHL-Zelllinien führt (Abbildung 4.2). Diese Hemmung stimmt mit den veröffentlichten Daten von Georgakis et al. und Janz et al. überein.

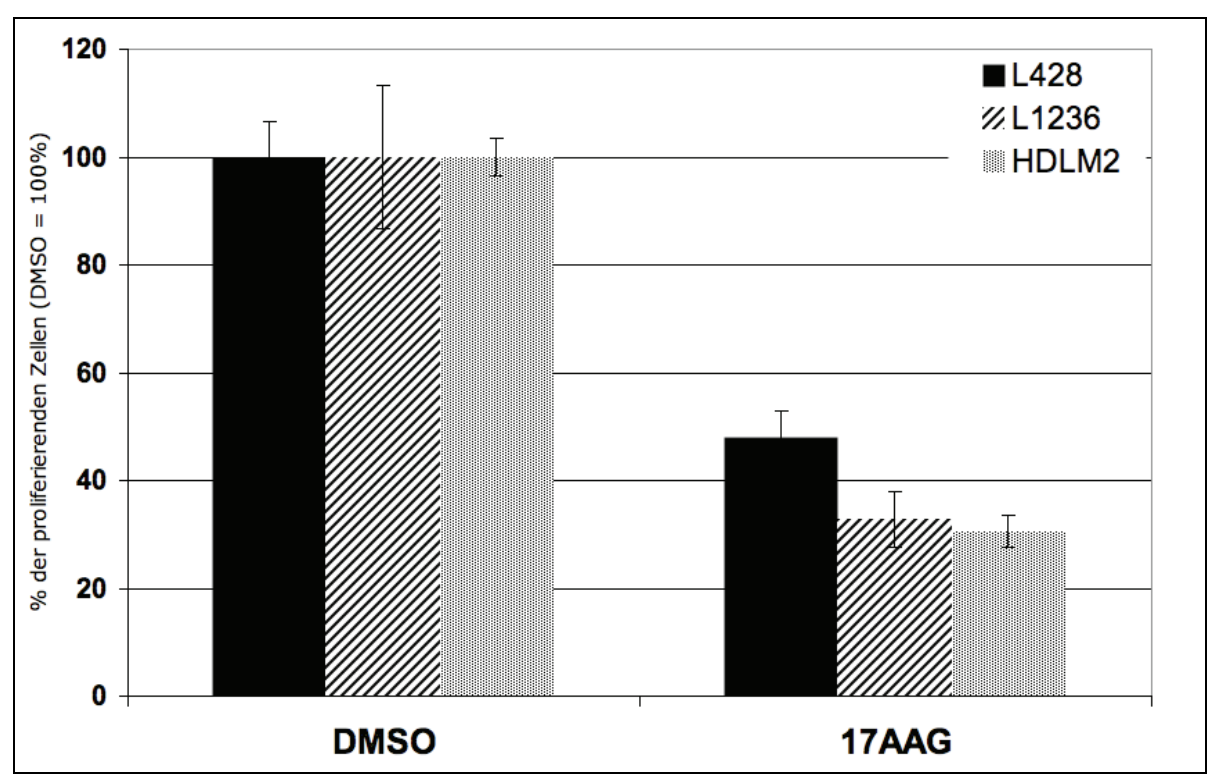

Abbildung 4.2 Reduktion der Zellproliferation durch den HSP90-Inhibitor 17-AAG in den

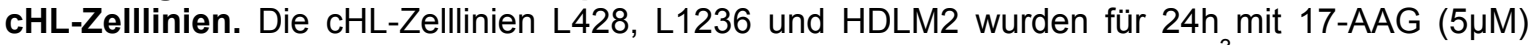
bzw. DMSO als Kontrolle behandelt. Die cHL-Zellproliferation wurde mittels ${ }^{3} \mathrm{H}$-Thymidin-Einbau ermittelt. Die Werte sind als Prozent $(\mathrm{DMSO}=100 \%$ ) dargestellt und die Fehlerbalken stellen die Standardabweichung von Triplikaten dar. Die Inkubation der cHL-Zelllinien mit 17-AAG führt zu einer Reduktion der Zellproliferation von über $50 \%$.

Um den Einfluss von 17-AAG auf die permanente Tyrosinphosphorylierung der STAT-Moleküle in den Zelllinien des cHLs zu untersuchen, wurden die Zellen nach 24h 17-AAG Behandlung geerntet und mittels Immunoblot analysiert (Abbildung 4.3).

Die Tyrosinphosphorylierung von STAT3 und STAT6 (Abbildung 4.3A), die bei Behandlung mit DMSO sichtbar ist, wird innerhalb von 24h 17-AAG Behandlung vollständig inhibiert. Gleichermaßen konnte eine Hemmung der Tyrosinphosphorylierung für die Proteine STAT1 und STAT5 nachgewiesen werden (Abbildung 4.3B). Jedoch konnte für STAT1 nur bei den HDLM2-Zellen eine Tyrosinphosphorylierung detektiert werden. Die Proteinmenge der STAT- 
Moleküle blieb unter Behandlung der Zellen mit 17-AAG weitgehend unbeeinflusst, so dass eine indirekte Wirkung über die STAT-aktivierenden Kinasen nahe liegt.

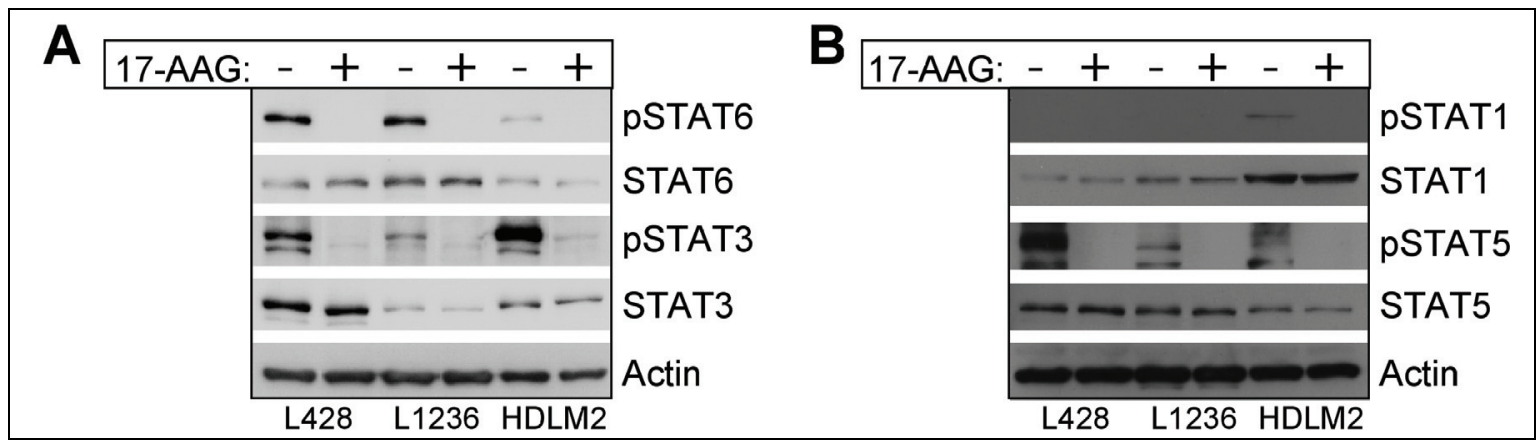

Abbildung 4.3 Inhibition der Tyrosinphosphorylierung von STAT1, STAT3, STAT5 und STAT6 durch den HSP90-Inhibitor 17-AAG. Die cHL-Zelllinien L428, L1236 und HDLM2 wurden für 24h mit 17-AAG $(5 \mu \mathrm{M})$ bzw. DMSO als Kontrolle behandelt und die Proteine mittels Immunoblot analysiert. (A) Die Tyrosinphosphorylierung von STAT3 and STAT6 wird innerhalb von $24 \mathrm{~h}$ durch 17-AAG inhibiert. (B) Ebenso ist die Tyrosinphosphorylierung von STAT1 und STAT5 nach 24h inhibiert. Die STAT1 Tyrosinphosphorylierung war nur in HDLM2-Zellen nachweisbar.

Auf Grund der bekannten Interaktion zwischen Janus-Kinasen und HSP90 wurden die Auswirkungen des HSP90-Inhibitors 17-AAG auf die Janus-Kinasen untersucht. Die Proteinmengen von Jak1, Jak2, Jak3 und Tyk2 wurden in drei Zelllinien des cHLs nach 17-AAG Behandlung mittels Immunoblot untersucht (Abbildung 4.4).

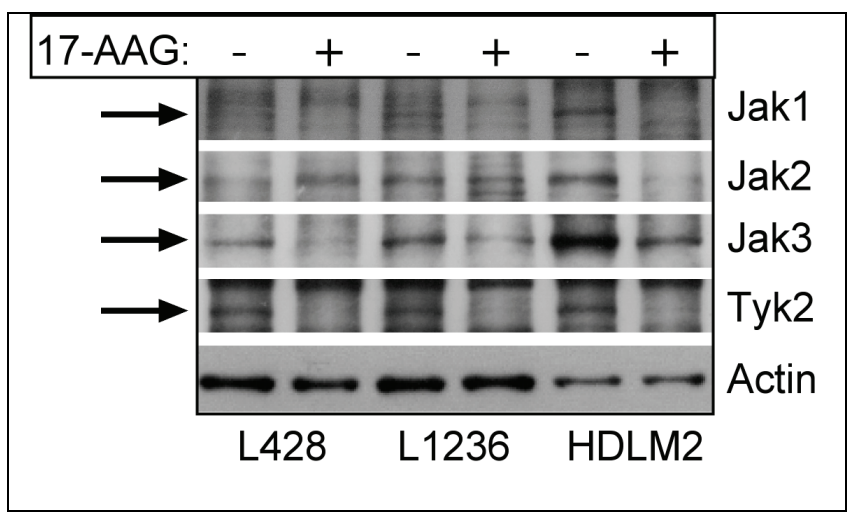

Abbildung 4.4 Der HSP90-Inhibitor 17-AAG führt zu einer reduzierten Proteinmenge der Janus-Kinasen in den cHL-Zelllinien. Die cHL-Zelllinien L428, L1236 und HDLM2 wurden für 24h mit 17-AAG $(5 \mu \mathrm{M})$ bzw. DMSO als Kontrolle behandelt und die Proteine mittels Immunoblot analysiert. Die Proteinmenge von Jak1, Jak3 und Tyk2 ist stark reduziert nach der Inkubation der Zellen mit 17-AAG. Die verminderte Proteinmenge von Jak2 konnte nur in HDLM2-Zellen, jedoch nicht in L428 und L1236-Zellen detektiert werden.

Es konnte gezeigt werden, dass die Proteinmengen von Jak1, Jak3 und Tyk2 bei Behandlung der Zellen mit 17-AAG reduziert sind. Für Jak2 konnte dies nur für die 
Zelllinie HDLM2 nachgewiesen werden, wogegen in den Zelllinien L428 und L1236 keine Reduktion der Proteinmenge von Jak2 detektierbar war.

Um unspezifische Effekte des Inhibitors 17-AAG auszuschließen, wurde ein alternativer experimenteller Ansatz verwendet. Hierzu wurden die Transkripte von HSP90a und HSP90b mittels RNA-Interferenz in L428-Zellen ausgeschaltet und die Effekte auf die Jak-STAT-Signalkaskade sowie die Zellproliferation analysiert (Abbildung 4.5). Auf Grund der schlechten Transfektionseffizienz von cHLZelllinien konnte diese Methode nur in L428-Zellen angewandt werden, bei der die optimierte Transfektionseffizienz bei guter Viabilität der Zellen bei ca. $90 \%$ liegt. Der Transfektionsvorgang wurde auf Grund der hohen Expression von HSP90 48h nach der ersten Transfektion wiederholt und die Zellen nach weiteren 48h geerntet.

Durch die Transfektion der HSP90-siRNA (Scrambled) konnte die Proteinmenge von HSP90 in den L428-Zellen im Vergleich zur Kontroll-siRNA reduziert werden (Abbildung 4.5A). Einhergehend mit der geringeren Proteinmenge von HSP90 ist ein Effekt auf die Tyrosinphosphorylierung der STAT-Moleküle erkennbar. STAT3, STAT5 sowie STAT6 zeigen in den mit HSP90-siRNA-transfizierten L428-Zellen eine geringere Tyrosinphosphorylierung als die mit Kontroll-siRNA-transfizierten Zellen. Auf die Analyse von STAT1 wurde verzichtet, da in L428-Zellen keine Tyrosinphosphorylierung von STAT1 vorliegt (Abbildung 4.3). Die Proteinmenge der STAT-Moleküle blieb weitgehend unverändert.

Weiterführend wurde die Proteinmenge von Jak1, Jak2, Jak3 und Tyk2 nach Behandlung der L428-Zellen mit HSP90-siRNA untersucht (Abbildung 4.5B). Hierbei konnten die Ergebnisse aus den Analysen des HSP90-Inhibitors 17-AAG bestätigt werden. Die verminderte Proteinmenge von HSP90 durch RNAInterferenz führt zu einer verminderten Proteinmenge der Janus-Kinasen. Im Unterschied zu den Ergebnissen, die mit 17-AAG erzielt worden sind, kommt es jedoch zu einer verminderten Proteinmenge aller vier Janus-Kinasen. Es ergibt sich somit eine Diskrepanz zwischen dem Effekt von 17-AAG und der HSP90siRNA in Bezug auf Jak2.

Es konnte gezeigt werden, dass die Zellproliferation bei verminderter HSP90 Proteinmenge durch die HSP90-siRNA um etwa 35\% reduziert ist (Abbildung 
4.5C). Diese Hemmung ist jedoch im Vergleich zur Proliferationsminderung durch 17-AAG schwächer.

Diese Analysen zeigen, dass das Chaperon HSP90 essentiell für die Signaltransduktion des Jak-STAT-Signalwegs ist. Die Hemmung von HSP90 durch den Inhibitor 17-AAG oder durch RNA-Interferenz führt zu einer verminderten Proteinmenge der Janus-Kinasen und einer Reduktion der Tyrosinphosphorylierung der STAT-Moleküle, der zu einer verminderten Proliferation der $\mathrm{cHL}-$ Zellen beiträgt.

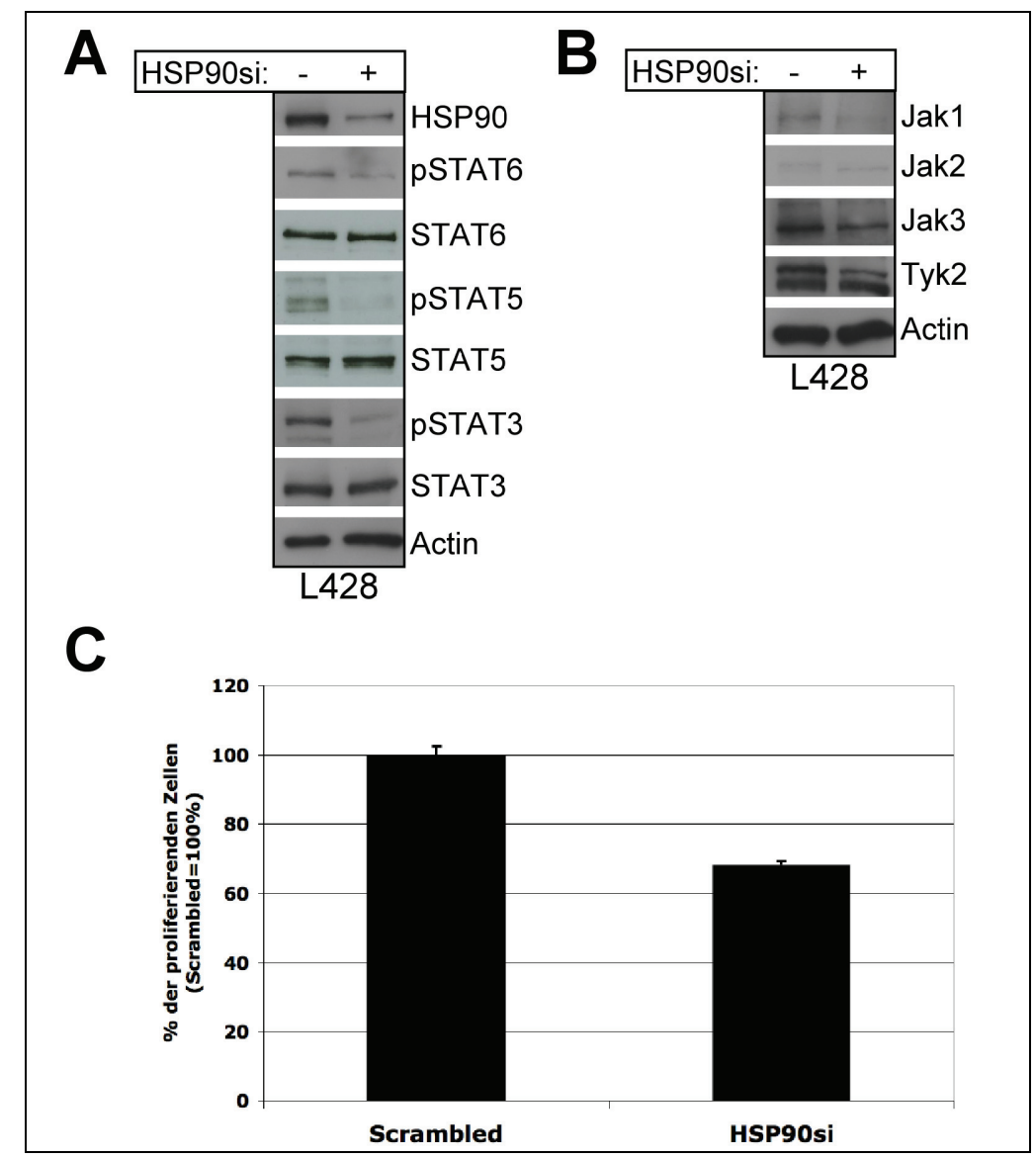

Abbildung 4.5 RNA-Interferenz gegen HSP90 in L428-Zellen führt zu einer reduzierten Tyrosinphosphorylierung der STATs, verminderter Proteinmenge der Janus-Kinasen und einer geringeren Zellproliferation. Die CHL-Zelllinie L428 wurde mit je $3 \mu \mathrm{g}$ siRNA gegen HSP90a und HSP9Ob bzw. mit $6 \mu \mathrm{g}$ Scrambled-siRNA transfiziert. Auf Grund der starken Expression von HSP90 wurde dieser Vorgang nach 48h wiederholt und nach weiteren 48h die Zellen geerntet bzw. die Proliferation der Zellen mittels ${ }^{3} \mathrm{H}$-Thymindin-Einbau gemessen. (A) Die verminderte Menge von HSP90 durch RNA-Interferenz führt zu einer geringeren Tyrosinphosphorylierung von STAT3, STAT5 und STAT6. (B) Alle 4 Janus-Kinasen zeigen eine verminderte Proteinmenge durch die Behandlung mit siRNA gegen HSP90. (C) Die Proliferation der L428-Zellen ist vermindert durch die geringere Proteinmenge von HSP90. 


\subsection{Transkriptionelle Ziele von STAT3 und STAT6 in der cHL- Zelllinie L428}

Die funktionelle Analyse des Jak-STAT-Signalwegs ist eine wichtige Voraussetzung für das Verständnis der Pathologie des cHLs sowie die Umsetzung der Erkenntnisse in neue therapeutische Möglichkeiten.

Die Hemmung der Tyrosinphosphorylierung der STATs durch verschiedene Inhibitoren konnte mit der Proliferation der Zellen, der Chemosensitivität und dem Überleben der Zellen in Verbindung gebracht werden (Kube et al., 2001a; Holtick et al., 2005; Baus et al., 2006; Cochet et al., 2006). Dennoch sind Zielgene dieser Transkriptionsfaktoren im cHL bisher weitgehend unbekannt und bedürfen näherer Untersuchungen. Dies ist von besonderer Bedeutung um die Funktion innerhalb der Erkrankung zu verstehen und potenzielle Zielstrukturen für neue Therapien im cHL zu identifizieren. Die Aktivierung von STAT-Molekülen hat pleiotrope Funktionen wie z.B. der Einfluss auf das Überleben der Zellen, die Zellproliferation sowie der Zelldifferenzierung. Die hier durchgeführte Analyse soll Aufschluss über mögliche Funktionen der transkriptionellen Ziele von STAT3 und STAT6 und deren Zusammenhang mit der Pathologie des cHLs geben. Zur Beantwortung dieser Frage wurde die Expression von STAT3 und STAT6 mittels RNAInterferenz in der cHL-Zelllinie L428 gehemmt und eine Genexpressionsanalyse mittels Microarray-Analyse erstellt.

\subsubsection{Hemmung von STAT3 und STAT6 durch RNA-Interferenz}

Zur funktionellen Analyse der Transkriptionsfaktoren STAT3 und STAT6 wurde zunächst die Expressionshemmung durch transiente RNA-Interferenz etabliert. Wie bereits beim Einsatz der RNA-Interferenz Technik gegen HSP90 beschrieben (Abschnitt 4.1.3), wurde die Transfektion der siRNAs 48h nach der ersten Transfektion wiederholt, um die Effektivität zu erhöhen.

Um neben den Effekten von STAT3 und STAT6 im Vergleich zur Kontrolle (Scrambled-siRNA) überlappende bzw. additive Effekte von STAT3 und STAT6 zu analysieren, wurden zusätzlich L428-Zellen mit einer Kombination aus STAT3 und STAT6-siRNAs transfiziert. Der experimentelle Ansatz sowie die erfolgreiche 
Reduktion der Proteinmenge von STAT3, STAT6 sowie STAT3 zusammen mit STAT6 sind in Abbildung 4.6 dargestellt.

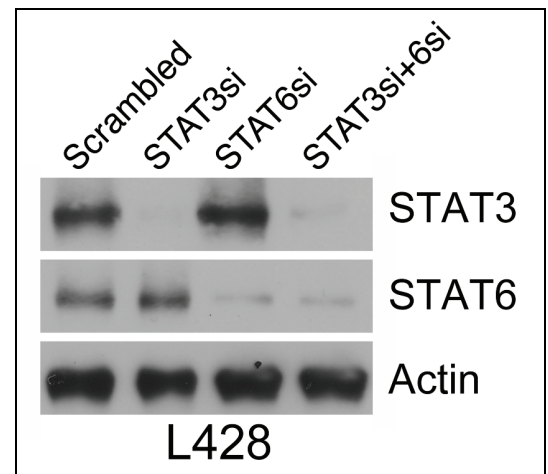

Abbildung 4.6 Hemmung von STAT3, STAT6 und STAT3/STAT6 in L428-Zellen durch RNA Interferenz. Die cHL-Zelllinie L428 wurde mit $6 \mu \mathrm{g}$ Scrambled-siRNA (Scrambled) als Kontrolle,

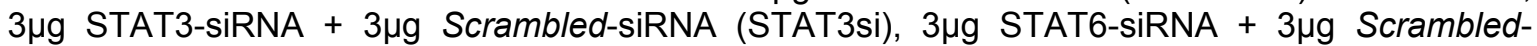

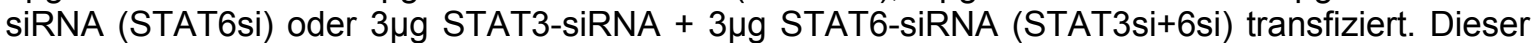
Vorgang wurde nach $48 \mathrm{~h}$ wiederholt, nach weiteren $48 \mathrm{~h}$ wurden die Zellen geerntet und die Proteinmenge von STAT3, STAT6 und Actin (Ladekontrolle) im Immunoblot analysiert. Gezeigt ist ein repräsentatives Beispiel von 5 Versuchen, die zur Genexpressionsanalyse weiterverwendet wurden.

\subsubsection{Zellproliferation nach Hemmung von STAT3 und STAT6}

Zur Bestimmung des Wachstumsverhaltens der mit siRNA-transfizierten cHLZelllinie L428 wurde 72h nach der zweiten Transfektion die Zellproliferation mittels

${ }^{3} \mathrm{H}$-Thymidin-Einbau gemessen (Abbildung 4.7).

Die Analyse der Zellproliferation zeigt unterschiedliche Wirkungen der STAT3 und STAT6 Inhibition mittels RNA-Interferenz auf die L428-Zellen. Die Hemmung von STAT3 führt zu einer Zellproliferationsminderung von $7 \%$ im Vergleich zu den Kontrollzellen $($ Scrambled $=100 \%)$. Eine stärkere Proliferationshemmung zeigt sich für die STAT6-siRNA-transfizierten Zellen. Es ergibt sich eine Minderung von 17\% im Vergleich zur Kontrolle. Die Transfektion der Zellen sowohl mit STAT3 als auch STAT6-siRNA hemmt die Zellproliferation um 13\%. Somit konnten keine additiven Effekte von STAT3 und STAT6 auf die Zellproliferation der L428-Zellen in diesem Versuchsansatz festgestellt werden. 


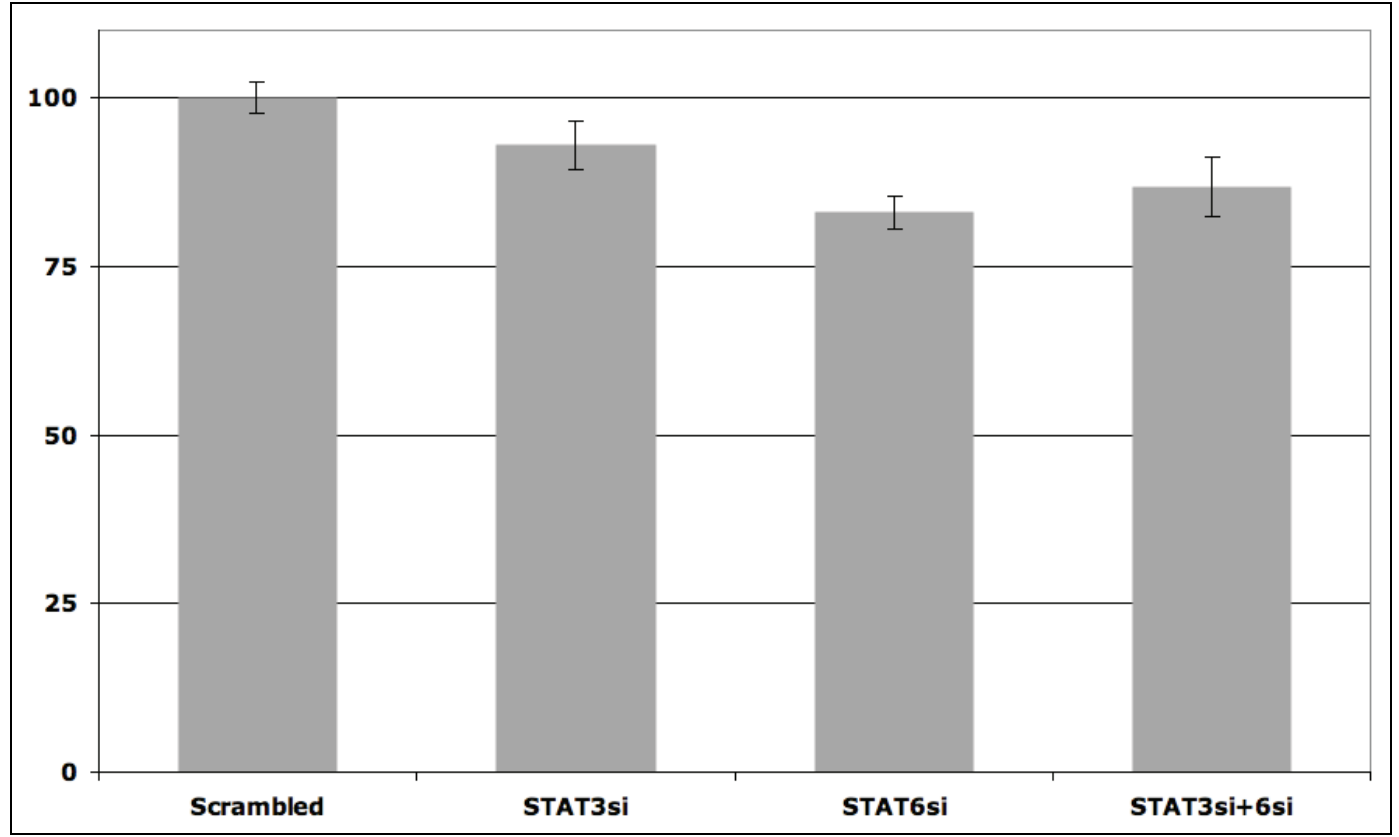

Abbildung 4.7 Analyse der Zellproliferation der siRNA-transfizierten L428-Zellen. Die Zellproliferation wurde mittels ${ }^{3} \mathrm{H}$-Thymidin-Einbau $72 \mathrm{~h}$ nach der zweiten Transfektion mit den siRNAs ermittelt. Die Werte sind als Prozent (Scrambled $=100 \%)$ dargestellt und die Fehlerbalken stellen die Standardabweichung von drei Wiederholungen dar. Die Behandlung der L428-Zellen mit der STAT6-siRNA führt zu einer Hemmung der Zellproliferation von etwa 17\%.

\subsubsection{Genexpressionsanalyse nach Hemmung von STAT3 und STAT6}

Zur Erstellung der Genexpressionsprofile wurden 5 unabhängige Versuche des in Abschnitt 4.2.1 beschriebenen Versuchsansatzes durchgeführt. Neben der Kontrolle der Reduktion der Proteinmenge im Immunoblot (Abbildung 4.6), wurde die RNA dieser Zellen isoliert.

Die Microarray-basierten Genexpressionsprofile wurden in Zusammenarbeit mit dem Kompetenzzentrum für Fluoreszente Bioanalytik Regensburg (Dr. Thomas Stempfl) sowie der AG Bioinformatik (Stefan Bentink \& Prof. Rainer Spang) am Institut für funktionelle Genomik der Universität Regensburg durchgeführt.

Je $2 \mu \mathrm{g}$ RNA dieser Proben wurden für die Analyse zum Kompetenzzentrum für Fluoreszente Bioanalytik nach Regensburg versendet. Hier fand die Aufbereitung der Proben für die Microarray-Analyse sowie die Hybridisierung auf Affymetrix U133A 2.0 Arrays statt. Die eingescannten Rohdaten der Arrays erhielt Stefan Bentink, der die statistische Auswertung der Daten vornahm. Mit Hilfe linearer Modelle wurde die differenzielle Genexpression der STAT3-, STAT6- und STAT3+STAT6-siRNA-transfizierten Zellen im Vergleich zu den Kontroll-siRNAtransfizierten Zellen (Scrambled) analysiert (Smyth, 2004). Die statistische 
Auswertung wurde auf multiples Testen adjustiert und eine False-Discovery-Rate von $1 \%$ angenommen.

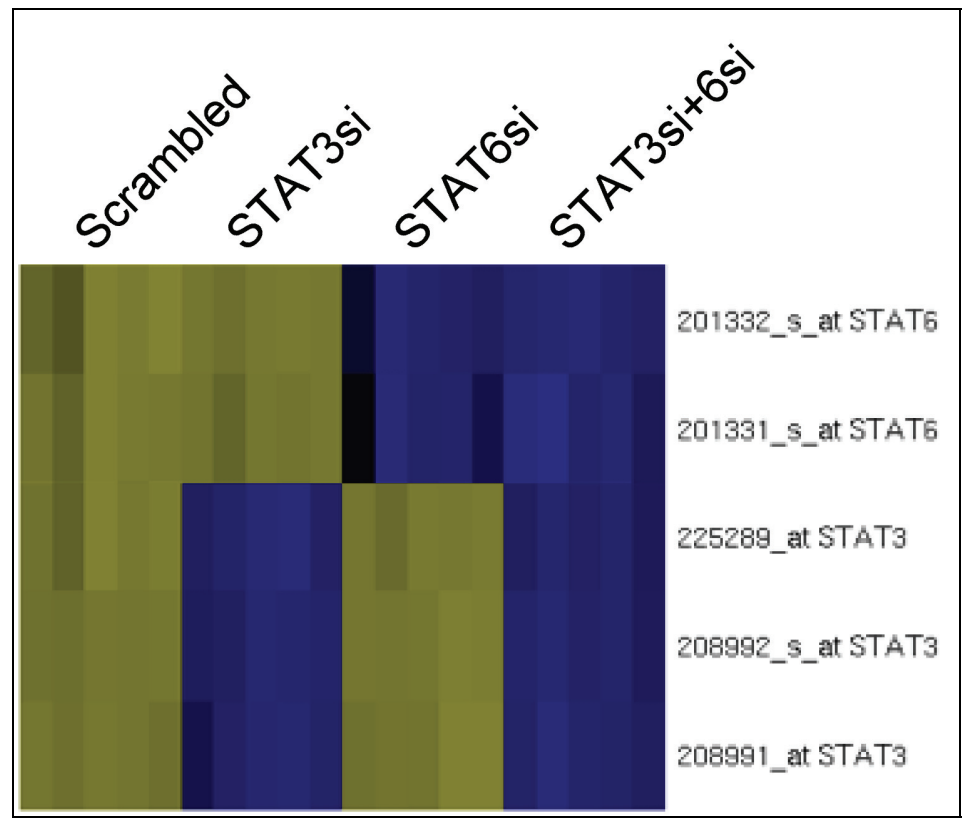

Abbildung 4.8 Graphische Darstellung der Microarray-Expressionsdaten für STAT3 und STAT6. Dargestellt sind farbcodierte Fluoreszenzintensitäten der STAT3 und STAT6 spezifischen Microarray-Probesets. Gelb stellt eine hohe Fluoreszenzintensität auf dem Microarray dar und symbolisiert eine hohe Expression der spezifischen mRNA. Blau bedeutet eine niedrige Fluoreszenzintensität auf dem Microarray und stellt die niedrige Expression der jeweiligen mRNA dar.

Die Reduktion der Proteinmenge der STATs durch die Transfektion der respektiven siRNA konnte durch die Immunoblotanalyse nachgewiesen werden (Abbildung 4.6). In der Microarray-Analyse konnte die verminderte Expression auf mRNA-Ebene bestätigt werden (Abbildung 4.8). Der verwendete Affymetrix U133A 2.0 Microarrays enthält jeweils mehrere spezifische Probesets für STAT3 und STAT6, die komplementär zu verschiedenen Abschnitten der jeweiligen mRNA sind. Wie in Abbildung 4.8 dargestellt, sind dies für STAT3 drei verschiedene Probesets und für STAT6 zwei verschiedene Probesets auf den Microarrays. Der Vergleich zwischen den Kontroll-Proben und den Proben der STAT-siRNAtransfizierten Zellen zeigt, das STAT3 in den mit STAT3-siRNA und STAT3+STAT6-siRNA-transfizierten Proben geringer exprimiert wird (blau) als in den Kontroll-Proben (gelb). Dies konnte ebenso für die Expression von STAT6 in den mit STAT6-siRNA und STAT3+STAT6-siRNA-transfizierten Zellen gezeigt werden (Abbildung 4.8). Dieses Ergebnis bestätigt also die Validität der Immunoblotanalyse für jedes der 5 Replikate. 
Hiervon ausgehend wurden die gesamten Änderungen der Genexpression innerhalb der unterschiedlich transfizierten Proben - adjustiert auf die Expression in den Kontroll-Proben - analysiert.

Zur Darstellung der Wirkung von STAT3-siRNA und STAT6-siRNA auf die L428Zellen sind in Abbildung 4.9 die mittleren "Log2-fold Changes" der replizierten STAT6-siRNA-Transfektionen im Vergleich zu den Kontrollen (y-Achse) gegen die mittleren "Log2-fold Changes" der replizierten STAT3-siRNA-Transfektionen im Vergleich zu den Kontrollen (x-Achse) aufgetragen. Signifikante, also konsistent in den einzelnen Wiederholungen nachweisbare „fold changes" sind rot eingefärbt. Für die STAT6-siRNA Proben sind das 2012 Transkripte, bei einer FalseDiscovery-Rate von 1\%. 1089 Transkripte zeigen eine Expressionhemmung bei Transfektion der STAT6-siRNA und 923 Transkripte eine Expressionssteigerung bei Transfektion der STAT6-siRNA.

Für die STAT3-siRNA Proben konnte nur für STAT3 selbst eine statistisch signifikante Änderung der Expression im Vergleich zur Kontrolle nachgewiesen werden.

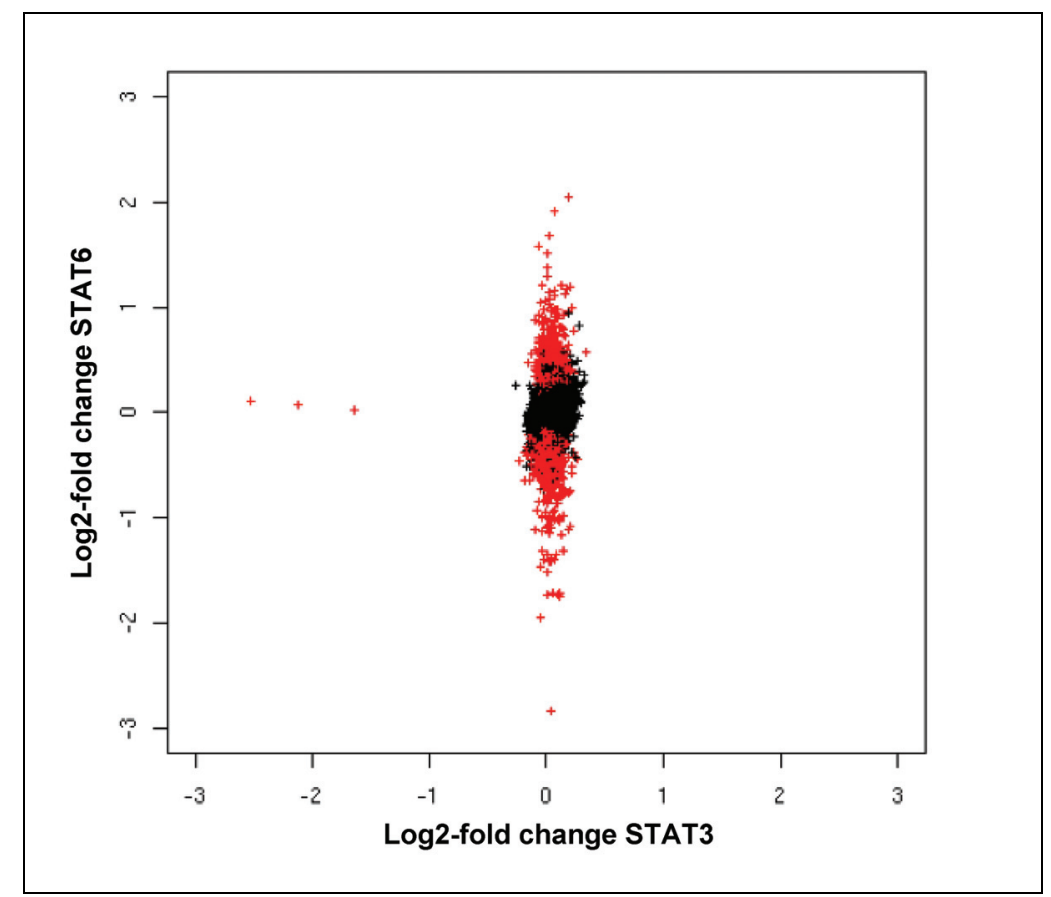

Abbildung 4.9 Darstellung der Effekte von STAT3-siRNA (x-Achse) gegenüber STAT6-siRNA (y-Achse) auf die Genexpression in L428-Zellen. Die STAT6-siRNA behandelten Proben zeigen eine Vielzahl von Transkripten, die eine differenzielle Expression gegenüber den Kontroll-Proben haben (rot). Für die STAT3-siRNA behandelten Zellen ergibt sich nur ein signifikanter Effekt auf STAT3 selbst (drei rote „Ausreißer“ links). 
Die Analyse der differentiellen Genexpression in den mit siRNA-transfizierten Zellen zeigt, dass in den 4 verschiedenen Versuchsansätzen(Scrambled, STAT3si, STAT6si, STAT3si+STAT6si) zwei unterschiedliche Genexpressionsprofile zu finden sind (Abbildung 4.10). Die Proben Scrambled und STAT3si sowie STAT6si und STAT3si+STAT6si weisen das gleiche Genexpressionsmuster auf. Es konnte keine differentielle Genexpression zwischen den STAT3-siRNA-transfizierten und der Kontrolle nachgewiesen werden, daher scheinen diese Proben das gleiche Genexpressionsprofile aufzuweisen. Bestätigt wird dies durch den Befund, dass die mit STAT6-siRNA alleine transfizierten Zellen das gleiche Genexpressionsmuster wie die Zellen, die gemeinsam mit STAT3-siRNA und STAT6-siRNA-transfiziert wurden Proben haben. Die differenzielle Genexpression scheint somit nur durch die Transfektion der STAT6-siRNA beeinflusst zu werden.

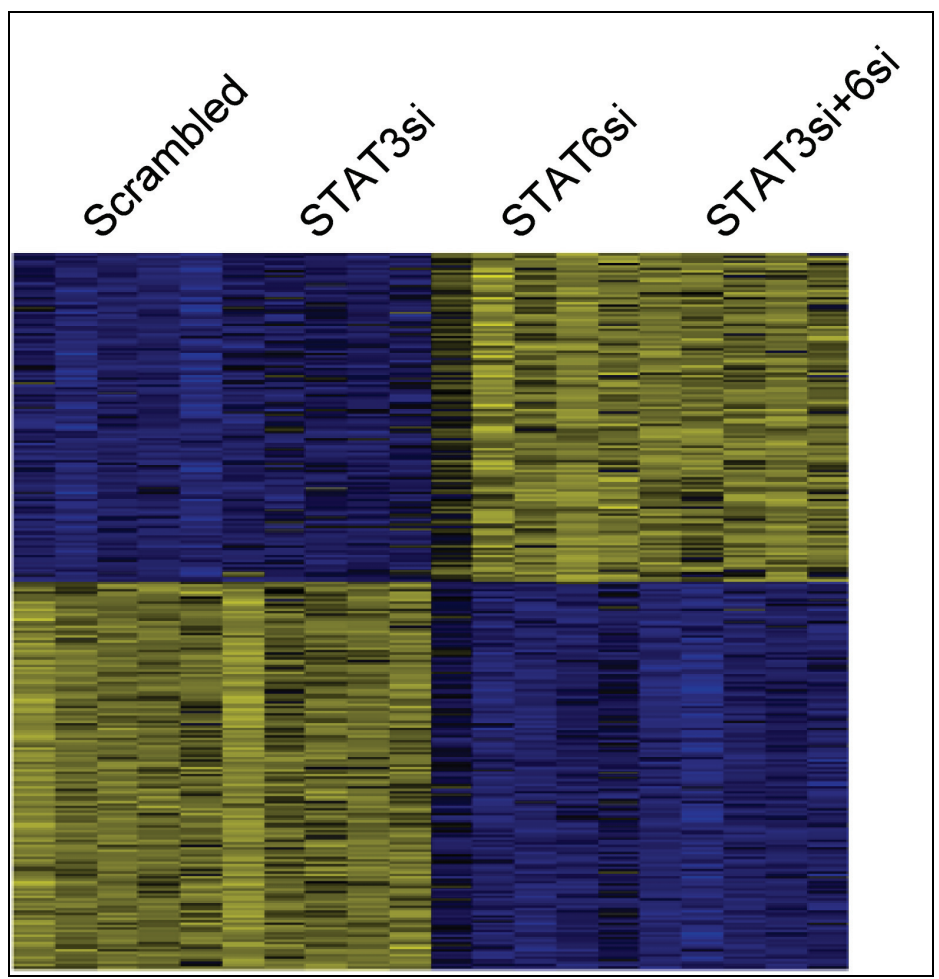

Abbildung 4.10 Graphische Darstellung der differenziellen Genexpression der STAT3siRNA- und STAT6-siRNA-transfizierten L428-Zellen. Dargestellt sind farbcodierte Fluoreszenzintensitäten der Microarray-Probesets, die ein bestimmtes Transkript auf dem Microarray abbilden. Gelb stellt hierbei eine hohe Fluoreszenzintensität auf dem Microarray dar und symbolisiert eine hohe Expression der spezifischen mRNA. Blau bedeutet eine niedrige Fluoreszensintensität auf dem Microarray und stellt die niedrige Expression der jeweiligen mRNA dar. Der statistische Vergleich der 4 verschiedenen Versuchsansätze ergab, dass nur STAT6siRNA-transfizierte Zellen (STAT6si und STAT3si+6si) einen Effekt auf die Genexpression im Vergleich zur Kontrolle haben. Dargestellt sind entsprechend die 2012 STAT6-siRNA regulierten Probesets (FDR<1\%). 
Da die Microarray-Analyse nur für die Transfektion der STAT6-siRNA statistisch signifikante Effekte zeigen konnte, wurden im Folgenden nur noch Gene betrachtet, die in diese Analyse eine entsprechende Regulation durch die STAT6siRNA zeigten.

\subsubsection{Validierung differenziell exprimierter Gene aus der Genexpressionsanalyse}

Aus den 2012 differenziell exprimierten Transkripten, die mit Hilfe der Genexpressionsanalyse identifiziert wurden, wurden Gene zur Validierung ausgesucht. Diese Gene wurden unter Berücksichtigung der Funktion und des Zusammenhangs zur Pathologie des cHLs ausgewählt. Die Funktion sowie zugehörige Quellen der ausgesuchten Gene sind in den einzelnen Abschnitten zur Validierung näher erläutert. In Tabelle 4.2 sind die Daten aus der Genexpressionsanalyse der ausgesuchten Gene, die in dieser Arbeit weiter analysiert wurden, aufgeführt.

Für die Validierung der ausgesuchten Kandidatengene mittels quantitativer realtime-PCR (qRT-PCR) wurden die gleichen RNA-Proben wie zur Genexpressionsanalyse verwendet. Aus diesen RNA-Proben wurde cDNA synthetisiert, die für die qRT-PCR eingesetzt wurde. Die Werte wurden gegen die

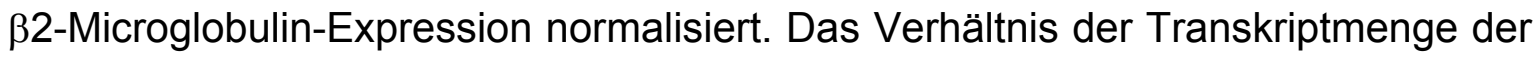
Kontroll-Proben (Scrambled) zu den mit STAT6-siRNA-transfizierten Proben wurde als $\mathrm{x}$-fache (fold change) Veränderung zur Kontrolle betrachtet. Angegeben sind Mittelwerte mit Standardabweichung der Analysen der RNA-Proben $(n=5)$. Auf Grund der Limitierung der RNA konnten bei den Genen ID2 und GATA3 nur 3 Versuche $(n=3)$ in die qRT-PCR-Analyse eingeschlossen werden. 
Tabelle 4.2 Zur Validierung ausgesuchte Gene der Microarray-Analyse von STAT6. Dargestellt sind die Gen-Symbole, der Gen-Name, die jeweiligen Probeset-IDs sowie die differenzielle Expression (log2-fold change) und p-Werte der zur Validierung ausgesuchten Gene dargestellt. Ein negatives Vorzeichen des log2-fold change bedeutet die Expressionsminderung bei Transfektion der L428-Zellen mit STAT6-siRNA. Ein positives Vorzeichen bedeutet die Expressionssteigerung bei STAT6-siRNA Transfektion.

\begin{tabular}{|c|c|c|c|c|}
\hline $\begin{array}{l}\text { Gen- } \\
\text { Symbol }\end{array}$ & Gen-Name & $\begin{array}{l}\text { Affymetrix } \\
\text { Probeset }\end{array}$ & $\begin{array}{r}\text { log2 fold } \\
\text { change }\end{array}$ & p-Wert \\
\hline \multirow[t]{2}{*}{ AICDA } & activation-induced cytidine & 219841_at & $-0,52$ & $3,88 \mathrm{E}-06$ \\
\hline & deaminase & $224499^{-} \mathrm{s}$ at & $-0,44$ & $1,24 \mathrm{E}-05$ \\
\hline A-Myb & Myb-related protein A & 213906_at & $-0,61$ & $1,16 \mathrm{E}-06$ \\
\hline BCL6 & B-cell lymphoma 6 protein & 203140 at & $-0,42$ & 2,97E-04 \\
\hline \multirow[t]{3}{*}{$\mathrm{c}-\mathrm{CBL}$} & Casitas B-lineage lymphoma proto- & 225234_at & $-0,66$ & 4,19E-05 \\
\hline & oncogene & 225231 at & $-0,64$ & $4,79 \mathrm{E}-06$ \\
\hline & & 229010_at & $-0,31$ & 1,39E-04 \\
\hline \multirow[t]{2}{*}{ CD23 } & Low affinity immunoglobulin epsilon & 206759_at & $-0,77$ & $4,12 \mathrm{E}-13$ \\
\hline & Fc receptor & 206760 s at & $-0,76$ & $9,97 \mathrm{E}-12$ \\
\hline \multirow[t]{2}{*}{ CD25 } & IL-2 receptor alpha subunit & 206341 at & 1,06 & $2,52 \mathrm{E}-09$ \\
\hline & & 211269_s_at & 1,51 & 4,96E-09 \\
\hline \multirow[t]{2}{*}{ CD52 } & CD52 antigen (CAMPATH1 & 204661_at & 0,95 & $1,00 \mathrm{E}-10$ \\
\hline & antigen) & 34210_at & 1,38 & $2,23 \mathrm{E}-13$ \\
\hline \multirow[t]{3}{*}{ EphB1 } & EPH receptor B1 & $21189 \overline{8} \mathrm{~s}$ at & $-0,67$ & $2,51 \mathrm{E}-08$ \\
\hline & & 210753_s_at & $-0,65$ & $6,75 \mathrm{E}-09$ \\
\hline & & 230425_at & $-0,58$ & $3,25 \mathrm{E}-08$ \\
\hline \multirow[t]{3}{*}{ ID2 } & Inhibitor of DNA binding 2 & 213931_at & 0,60 & 1,03E-09 \\
\hline & & $201566 x$ at & 0,95 & $3,66 \mathrm{E}-09$ \\
\hline & & 201565_s_at & 1,21 & $1,99 \mathrm{E}-11$ \\
\hline \multirow[t]{4}{*}{ IL13Ra } & IL13 receptor alpha-1 & $201887^{-}$at & $-0,84$ & $1,16 \mathrm{E}-10$ \\
\hline & & 211612_s_at & $-0,73$ & $2,51 \mathrm{E}-12$ \\
\hline & & 210904_s_at & $-0,66$ & $2,43 E-11$ \\
\hline & & 201888_s_at & $-0,60$ & 1,92E-09 \\
\hline \multirow[t]{2}{*}{ IRF4 } & Interferon regulatory factor 4 & 204562 at & $-0,74$ & $1,04 \mathrm{E}-10$ \\
\hline & & 216986_s_at & $-0,38$ & 1,07E-05 \\
\hline \multirow[t]{2}{*}{ PIK3CA } & phosphoinositide-3-kinase, & 206370 at & $-0,53$ & $1,33 \mathrm{E}-06$ \\
\hline & catalytic, alpha polypeptide & 206369_s_at & $-0,34$ & $1,72 \mathrm{E}-07$ \\
\hline PRDM1 & $\begin{array}{l}\text { PR domain containing } 1 \text {, with ZNF } \\
\text { domain }\end{array}$ & 228964_at & 0,47 & 3,47E-05 \\
\hline PTPRK & $\begin{array}{l}\text { Protein-tyrosine phosphatase } \\
\text { kappa }\end{array}$ & 203038_at & 0,62 & 7,05E-05 \\
\hline XBP1 & $\mathrm{X}$-box binding protein 1 & 200670_at & $-0,63$ & 1,36E-05 \\
\hline
\end{tabular}

\subsubsection{Validierung der differenziellen Expression von Genen der B-Zell- Differenzierung}

Aus der Genexpressionsanalyse der STAT6-siRNA-transfizierten L428-Zellen wurden die Gene BCL6, AICDA, IRF4, XBP1, PRDM1 und ID2, die eine Rolle in der B-Zell-Differenzierung - insbesondere bei der Keimzentrumsreaktion - spielen, zur Validierung ausgewählt. Die differenzielle Expression dieser Gene durch die STAT6-siRNA Transfektion wurde mittels qRT-PCR validiert (Tabelle 4.3).

Die Keimzentrumsreaktion von B-Lymphozyten ist eine komplex gesteuerte Reaktion, in der B-Zellen zu Plasmazellen oder Gedächtnis-B-Zellen differenzieren 
können (Einleitung Abschnitt 1.2). Dabei spielt eine strenge Regulation von verschiedenen Genen eine entscheidende Rolle.

Tabelle 4.3 Validierung der differenziellen Expression von Genen, die ein Rolle bei der BZell-Differenzierung spielen, durch die STAT6-siRNA Transfektion. Eine Veränderung der Expression der Gene wurde durch qRT-PCR ermittelt und ist als x-fache (fold change) Veränderung im Vergleich zu den Kontroll-Proben (Scrambled=1) dargestellt.

\begin{tabular}{lll}
\hline Gen-Symbol & Genexpressionsanalyse & qRT-PCR (fold change) \\
\hline AICDA & gehemmt & $0,58 \pm 0,23$ \\
BCL6 & gehemmt & $0,44 \pm 0,18$ \\
ID2 & aktiviert & $2,22 \pm 1,39$ \\
IRF4 & gehemmt & $0,30 \pm 0,06$ \\
PRDM1 & aktiviert & $0,89 \pm 0,11$ \\
XBP1 & gehemmt & $0,35 \pm 0,05$
\end{tabular}

Die Gene BCL6 und AICDA zeigen während der Keimzentrumsreaktion von B-Zellen eine hohe Expression. BCL6 ist ein transkriptioneller Repressor, der eine Rolle bei Proliferation der B-Zellen während der Keimzentrumsreaktion spielt. Die AICDA ist eine Cytidin-Deaminase, die essentielle Funktionen während der SHM und der CSR bei der Keimzentrumsreaktion von B-Zellen hat. Die Gene PRDM1, XBP1 und IRF4 werden während der Differenzierung zur Plasmazelle bzw. B-Gedächtnis-Zelle aktiviert und kennzeichnen somit das Ende der Keimzentrumsreaktion. BCL6 hemmt die Expression von PRDM1 und die Expression von BCL6 wird durch IRF4 gehemmt (Klein et al., 2008). Der Transkriptionsfaktor IRF4 ist in fast allen Fällen des cHL exprimiert, dessen Bedeutung ist jedoch bisher ungeklärt (Buettner et al., 2005).

Die Ergebnisse der Microarray-Analyse für die Gene XBP1, IRF4, AICDA, BCL6 und ID2 konnten durch die qRT-PCR bestätigt werden (Tabelle 4.3). Die qRT-PCR wies eine Hemmung aller 5 Gene durch die Transfektion der Zellen mit der STAT6-siRNA im Vergleich zu den Kontroll-Proben nach. Am stärksten sind die Faktoren IRF4 und XBP1 gehemmt. Die Expression von IRF4 geht auf das 0,30-fache $( \pm 0,06)$ der Expression in den Kontroll-Proben zurück. XBP1 wird um das 0,35-fache $( \pm 0.05)$ geringer exprimiert. Die Expression der Gene BCL6 und AICDA reduziert sich um ca. 50\% im Vergleich zur Expression in den KontrollProben. Für PRDM1 ergab sich keine Veränderung durch die Behandlung der L428-Zellen mit STAT6-siRNA. 
ID2 ist ein Inhibitor der E2F-Transkriptionsfaktor-Familie und die Expression von ID2 in B-Lymphozyten kann zur Unterdrückung der CSR führen (Abschnitt 1.2) (Gonda et al., 2003). Der E2F-Transkriptionsfaktor Pax5 aktiviert eine Reihe von B-Zell-typischen Faktoren unter anderem das Gen AICDA, das für die CSR und die SHM essentiell ist und dessen Hemmung durch die STAT6-siRNA hier bereits bestätigt wurde (Tabelle 4.3) (Gonda et al., 2003; Cobaleda et al., 2007). Im cHL wurde eine Expression von Pax5 nachgewiesen, aber ein Verlust der B-Zellspezifischen Faktoren durch eine vermehrte Expression von ID2 postuliert (Mathas et al., 2006; Renne et al., 2006). Die Genexpressionsanalyse der STAT6siRNA-transfizierten L428-Zellen zeigte eine erhöhte Expression von ID2 im Vergleich zu den Kontroll-Proben. Diese Aktivierung konnte mittels qRT-PCR bestätigt werden (Tabelle 4.3). Jedoch konnte diese Aktivierung lediglich in zwei der drei durchgeführten Replikate nachgewiesen werden, was zur großen Standardabweichung führt. Die vermehrte Expression von ID2 könnte über eine verstärkte Hemmung der E2F-Transkriptionsfaktor-Familie zur verminderten Expression von AICDA führen.

Auf Grund der Hemmung der IRF4-Expression durch die Transfektion der STAT6siRNA wurde hier die Expression des bekannten IRF4 Zielgens GATA3 mittels qRT-PCR analysiert, welches ebenfalls in cHL-Zellen exprimiert wird (Atayar et al., 2005; Lohoff et al., 2005). Die Analyse zeigte, dass in den STAT6-siRNAtransfizierten L428-Zellen die Expression von GATA3 auf das 0,56-fache $( \pm 0,27)$ der Expression in den Kontroll-Proben verringert ist. Die Hemmung ist geringer im Vergleich zur Hemmung von STAT6 und IRF4, und auf Grund der Heterogenität zwischen den drei Replikaten besteht eine hohe Standardabweichung.

Die Veränderung der Expression der Gene, die eine Bedeutung in der B-ZellDifferenzierung haben, durch die Transfektion der L428-Zellen mit STAT6-siRNA zeigt, dass STAT6 in dieser Zelllinie eine Rolle bei der Regulation dieser Faktoren spielt. Insbesondere IRF4 könnte hier ein wichtiges transkriptionelles Ziel von STAT6 sein, da in der Genexpressionsanalyse Faktoren enthalten sind, die sowohl während der Keimzentrumsreaktion von B-Lymphozyten als auch bei der T-Zelldifferenzierung von IRF4 reguliert werden. 


\subsubsection{Validierung der differenziellen Expression weiterer Gene}

Neben den Genen, die eine Rolle bei der B-Zelldifferenzierung spielen, wurden weitere Gene zur Validierung ausgesucht. Es wurden die Gene c-CBL, EphB1, IL13Ra, PTPRK, A-Myb und PIK3CA durch qRT-PCR untersucht (Tabelle 4.4). Zusätzlich zu den qRT-PCR-Analysen wurde die Proteinmenge von CD23, CD25 und CD52 auf der Zellmembran mittels Durchflusszytometrie untersucht.

Tabelle 4.4 Validierung der differenziellen Expression von weiteren Genen durch die STAT6siRNA Transfektion. Eine Veränderung der Expression der Gene wurde durch qRT-PCR ermittelt und ist als $\mathrm{x}$-fache (fold change) Veränderung im Vergleich zur Kontrolle (Scrambled=1) dargestellt.

\begin{tabular}{lll}
\hline Gen-Symbol & Regulation im Microarray & qRT-PCR (fold change) \\
\hline A-Myb & gehemmt & $0,50 \pm 0,14$ \\
CBL & gehemmt & $0,45 \pm 0,13$ \\
EphB1 & gehemmt & $0,65 \pm 0,29$ \\
IL13Ra & gehemmt & $0,36 \pm 0,12$ \\
PIK3CA & gehemmt & $1,18 \pm 0,79$ \\
PTPRK & aktiviert & $2,07 \pm 0,52$
\end{tabular}

Hemmung der Interleukin-13-Rezeptoruntereinheit IL13Ra1 durch Transfektion der STAT6-siRNA

Das Zytokin IL-13 gilt als ein autokriner Aktivator von STAT6 im cHL (Skinnider et al., 2001b). IL-13 bindet an den Rezeptorkomplex bestehend aus IL13Ra1 und IL4Ra und aktiviert über die Janus-Kinasen STAT6. Des Weiteren ist ein so genannter „Decoy“-Rezeptor IL13Ra2 bekannt, der über keine intrazelluläre Signaltransduktionsdomäne verfügt. Für diesen Rezeptor wurde eine transkriptionelle Aktivierung durch STAT6 beschrieben, und stellt somit eine negative Rückkopplungs-Schleife für die Aktivierung durch IL-13 dar (David et al., 2003). Die Genexpressionsanalyse ergab keine Regulation von IL13Ra2 durch die Transfektion der STAT6-siRNA in den L428-Zellen.

Die Genexpressionsanalyse der STAT6-siRNA-transfizierten L428-Zellen zeigte eine Reduktion der IL13Ra1-Expression. Dieses Ergebnis konnte in der qRT-PCR bestätigt werden. Die Expression von IL13Ra1 geht auf das 0,36-fache $( \pm 0,12)$ der Expression der Kontroll-Proben zurück. Die positive Regulation des IL13Ra1 durch STAT6 zeigt, dass in diesen Zellen die STAT6 aktivierende 
Rezeptoruntereinheit durch STAT6 selbst induziert werden könnte. Dies könnte auf eine positive - STAT6 aktivierende - Rückkopplungs-Schleife hindeuten.

Aktivierung des IL-2-Rezeptors CD25 auf der Zellmembran der STAT6-siRNAtransfizierten L428-Zellen

CD25 ist häufig in den Zellen des cHLs exprimiert (Skinnider et al., 2002b). In der cHL-Zelllinie L428 konnte die Expression von CD25 durch verschiedene Komponenten des Eppstein-Barr-Virus (EBV) gesteigert werden. Gleichzeitig konnte eine erhöhte Sekretion der löslichen Form von CD25 festgestellt werden (Kube et al., 1999; Vockerodt et al., 2001).

Die Genexpressionsanalyse der STAT6-siRNA-transfizierten L428-Zellen zeigte eine Aktivierung der drei IL-2 Rezeptorkomponenten IL-2R $\alpha$, IL-3R $\beta$ und IL-2R $\gamma$. Zur Validierung dieses Ergebnisses wurde die Veränderung der IL2Ra (CD25) Untereinheit auf der Zellmembran mittels durchflusszytometrischer Analyse untersucht (Abbildung 4.11). L428-Zellen, die mit der STAT6-siRNA-transfiziert wurden, zeigen einen größeren Anteil von CD25-positiven Zellen im Vergleich zu den Kontrollzellen. Der Anteil der CD25-positiven Zellen steigt von etwa 10\% auf etwa $40 \%$ an.

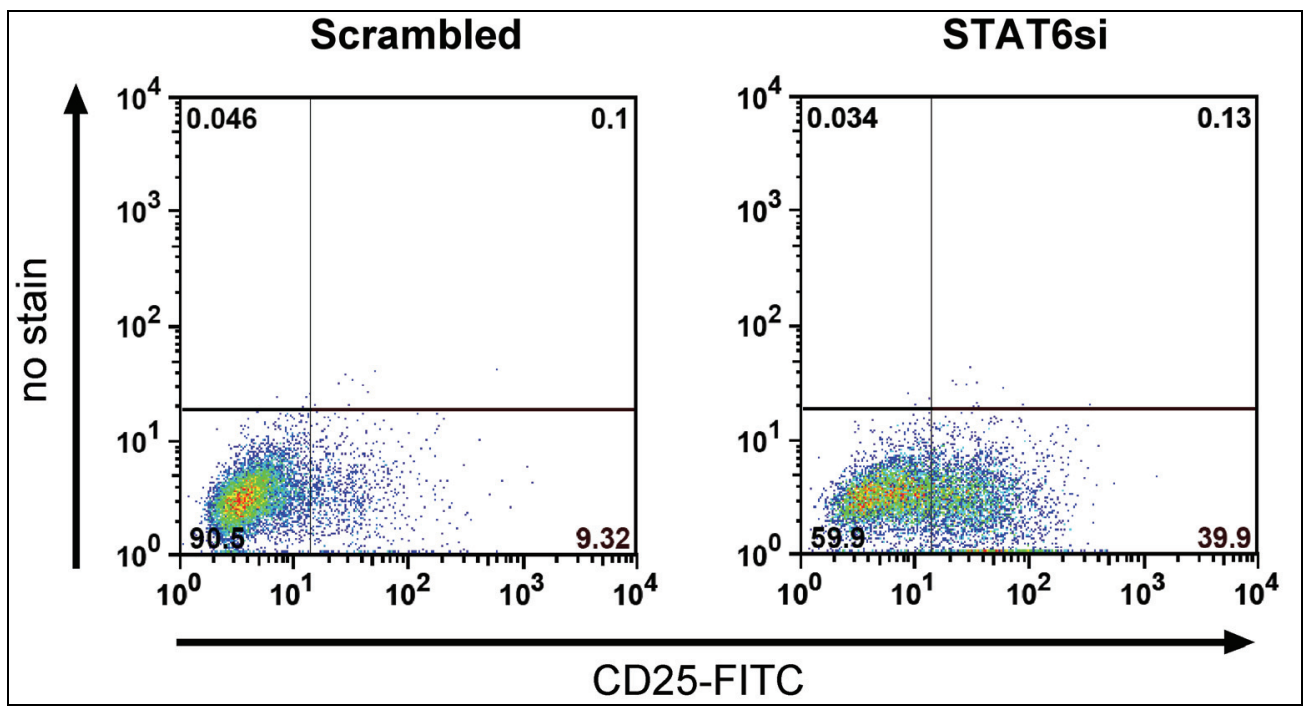

Abbildung 4.11 Steigerung von CD25 auf der Zelloberfläche bei Hemmung der STAT6Expression durch siRNA in L428-Zellen. Die Zellen wurden 48h nach der zweiten Transfektion mit STAT6-siRNAs mit anti-CD25-FITC Antikörpern inkubiert und die CD25-Expression mittels Durchflusszytometrie analysiert. Die Hemmung von STAT6 führt zu einer Steigerung der CD25positiven Zellen von 9,32\% auf 39,9\%. 
Hemmung der Expression der RTK EphB1 durch die STAT6-siRNA Transfektion

Eine Expression der Rezeptortyrosinkinase EphB1 wurde in primären Tumorgewebe von cHL-Patienten sowie in den cHL-Zelllinien - darunter auch in der hier analysierten cHL-Zelllinie L428 - nachgewiesen. Es wurde auf Grund der gleichzeitigen Expression des Liganden EphrinB1 eine autokrine Aktivierung dieser Kinase postuliert (Renne et al., 2005).

Die qRT-PCR-Analyse zeigte eine Expressionshemmung von EphB1 auf das 0,65-fache $( \pm 0,29)$ der Expression in den Kontrollen. Allerdings zeigten dabei nur drei von 5 Replikaten eine klare Hemmung der Expression $(0,44$-fache $( \pm 0,07)$ der Expression der Kontroll-Proben).

Auf Grund der Rolle von EphB1 bei der Zellmigration und -invasion, wurde hier die in vitro Invasionsfähigkeit der mit STAT6-siRNA-transfizierten L428-Zellen untersucht (Campbell et al., 2008) (Abbildung 4.12). Zur Analyse der Invasivität der STAT6-gehemmten L428-Zellen wurden die Zellen 48h nach der zweiten Transfektion der STAT6-siRNA bei gleicher Zellzahl in die obere Kammer eines Doppelkammersystems, das durch eine Matrigelschicht getrennt ist, überführt. Nach weiteren $48 \mathrm{~h}$ wurden die Zellen, die sich in der unteren Kammer befanden und somit durch die Matrigelschicht gewandert sind, gezählt.

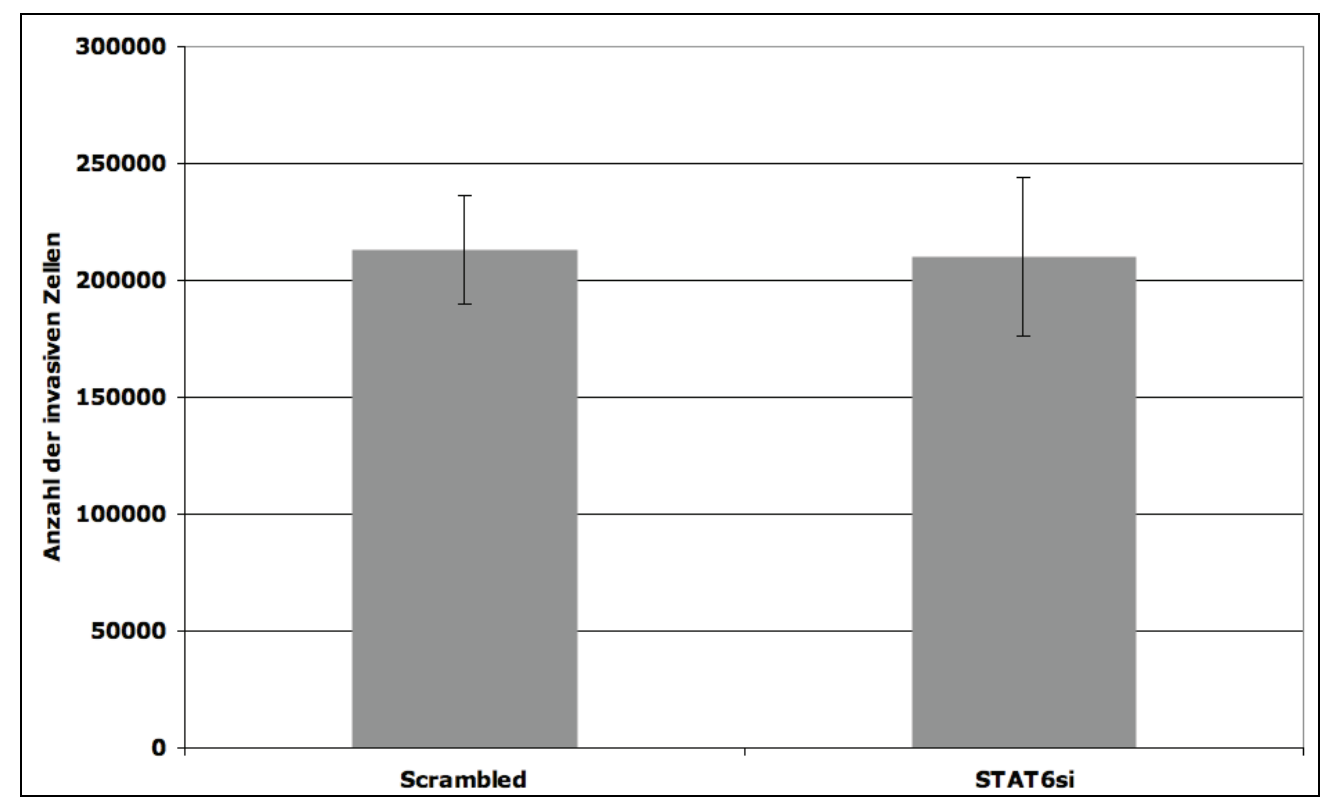

Abbildung 4.12 Analyse der Invasivität der L428-Zellen nach Transfektion der STAT6-siRNA. Die Zellinvasivität wurde durch ein Matrigel-Doppelkammersystem analysiert. 48h nach der zweiten Transfektion der siRNAs wurden die Zellen gezählt, die Zellzahl auf $5 \times 10^{5}$ Zellen/ml eingestellt und in das Doppelkammersystem überführt. Nach $48 \mathrm{~h}$ wurden die Zellen, die die Matrigelschicht durchdrungen haben, gezählt. Die Werte sind als Anzahl der invasiven Zellen dargestellt und die Fehlerbalken stellen die Standardabweichung von drei Wiederholungen dar. 
Der Vergleich zwischen den Kontroll-Proben (Scrambled) und den STAT6-siRNAtransfizierten L428-Zellen ergab keinen Unterschied in der Anzahl der invasiven Zellen (Abbildung 4.12). Allerdings wurde die Expression von EphB1 in den eingesetzten Zellen nicht parallel geprüft, so dass auf Grund der heterogenen differenziellen Expression von EphB1 in der qRT-PCR-Analyse weitere Versuche zur Invasionsfähigkeit durchgeführt werden müssen.

Aktivierung der Tyrosinphosphatase PTPRK durch die STAT6-siRNA Transfektion Die Protein-Tyrosin-Phosphatase kappa (PTPRK) ist ein negativer Regulator der Zellproliferation und des Überlebens der cHL-Zellen. Die Expression der PTPRK wird durch die Infektion der cHL-Zellen mit EBV gehemmt. Darüber hinaus aktiviert der TGF- $\beta$-Signalweg diese Phosphatase, der in cHL-Zellen aktiviert vorliegt (Skinnider et al., 2002b; Flavell et al., 2008).

In den STAT6-siRNA-transfizierten L428-Zellen konnte durch die Genexpressionsanalyse eine Aktivierung der PTPRK nachgewiesen werden. Dies konnte durch die qRT-PCR bestätigt werden. Die Expression von PTPRK steigt auf das 2,07-fache $( \pm 0.52)$ der Expression in den Kontroll-Proben an. STAT6 könnte an der Hemmung der PTPRK in cHL-Zellen beteiligt sein. Somit könnte diese Hemmung der PTPRK die Proliferation und das Überleben der cHL-Zellen fördern.

Reduktion von CD23 auf der Zellmembran der STAT6-siRNA-transfizierten L428Zellen

Der „low affinity“ Fce-Rezeptor CD23 (FCER2) ist ein bekanntes transkriptionelles Ziel von STAT6 (Kohler et al., 1993). Die Expression von CD23 wurde mit der Proliferation von B-Lymphozyten und dem Überleben von Keimzentrums-B-Zellen in Verbindung gebracht (Cairns et al., 1990; Liu et al., 1991). Auch in Zellen des cHLs wird CD23 häufig exprimiert (Jarrett et al., 1991). Jedoch ist die Funktion von CD23 im cHL unbekannt.

Die Regulation von CD23 in der Genexpressionsanalyse von STAT6-siRNAtransfizierten L428-Zellen bestätigt ein bereits bekanntes STAT6-Zielgen im Kontext des cHLs. Die durchflusszytometrische Analyse von CD23 mittels PE- 
gekoppelten Antikörper konnte die Verringerung von CD23 auf der Zellmembran bestätigen (Abbildung 4.13). Insbesondere die stark CD23 positiven Zellen sind nach der Hemmung von STAT6 nicht mehr vorhanden. Die mittlere FluoreszenzIntensität (MFI) in den Kontroll-Proben (Scrambled) liegt bei 44,0, wogegen die STAT6-gehemmten Proben einen Wert von 21,5 zeigten.

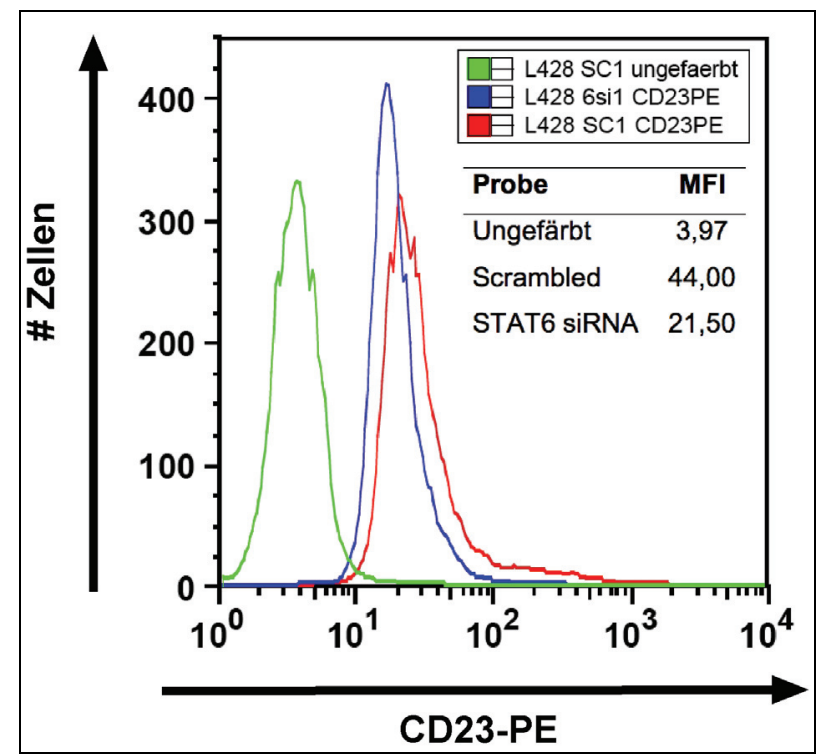

Abbildung 4.13 Verringerung von CD23 auf der Zellmembran in STAT6-siRNA-transfizierten L428-Zellen. Die Zellen wurden 48h nach der zweiten Transfektion mit STAT6-siRNAs mit antiCD23-PE Antikörpern inkubiert und die Menge an CD23 auf der Zellmembran mittels Durchflusszytometrie analysiert. Der Hauptanteil der Zellen in den STAT6-siRNA-transfizierten Proben (blau) zeigt eine geringere CD23 Menge als die Kontroll-Proben (rot). Insbesondere der Anteil der CD23-hochexprimierenden Zellen nimmt durch die Transfektion mit STAT6-siRNA ab. Die reduzierte CD23 Menge ist ebenfalls in der geringeren mittleren Fluoreszenz-Intensität (MFI) der STAT6-siRNA-transfizierten Proben zu erkennen.

Analyse von CD52 auf der Zellmembran der STAT6-siRNA-transfizierten L428Zellen

CD52 ist ein Oberflächenantigen, das durch Einsatz von humanisierten monoklonalen Antikörpern ein therapeutisches Ziel in verschiedenen hämatologischen Erkrankungen darstellt. Hierbei depletiert der Antikörper Alemtuzumab (Campath1) gesunde und maligne Lymphozyten, während hämatopoetische Stammzellen, Erythrozyten, Plasmazellen und Thrombozyten, die CD52 negativ sind, nicht beeinflusst werden (Moreton et al., 2003). Eine CD52-Expression im cHL konnte bisher nicht nachgewiesen werden (Rodig et al., 2006). Die in der Genexpressionsanalyse festgestellte Aktivierung von CD52 
durch die Hemmung von STAT6 in den L428-Zellen könnte somit die Suszeptibilität gegenüber Alemtuzumab verändern.

Um das Ergebnis der Genexpressionsanalyse auf Proteinebene zu bestätigen, wurde eine Färbung mit anti-CD52-FITC und anschließender durchflusszytometrischer Analyse durchgeführt (Abbildung 4.14). Die Analyse der STAT6-siRNA-transfizierten Zellen zeigte keine Erhöhung von CD52 auf der Zelloberfläche gegenüber den Kontrollzellen (Scrambled), so dass hier keine weiterführende Analyse zur Behandlung der L428-Zellen mit Alemtuzumab möglich war.

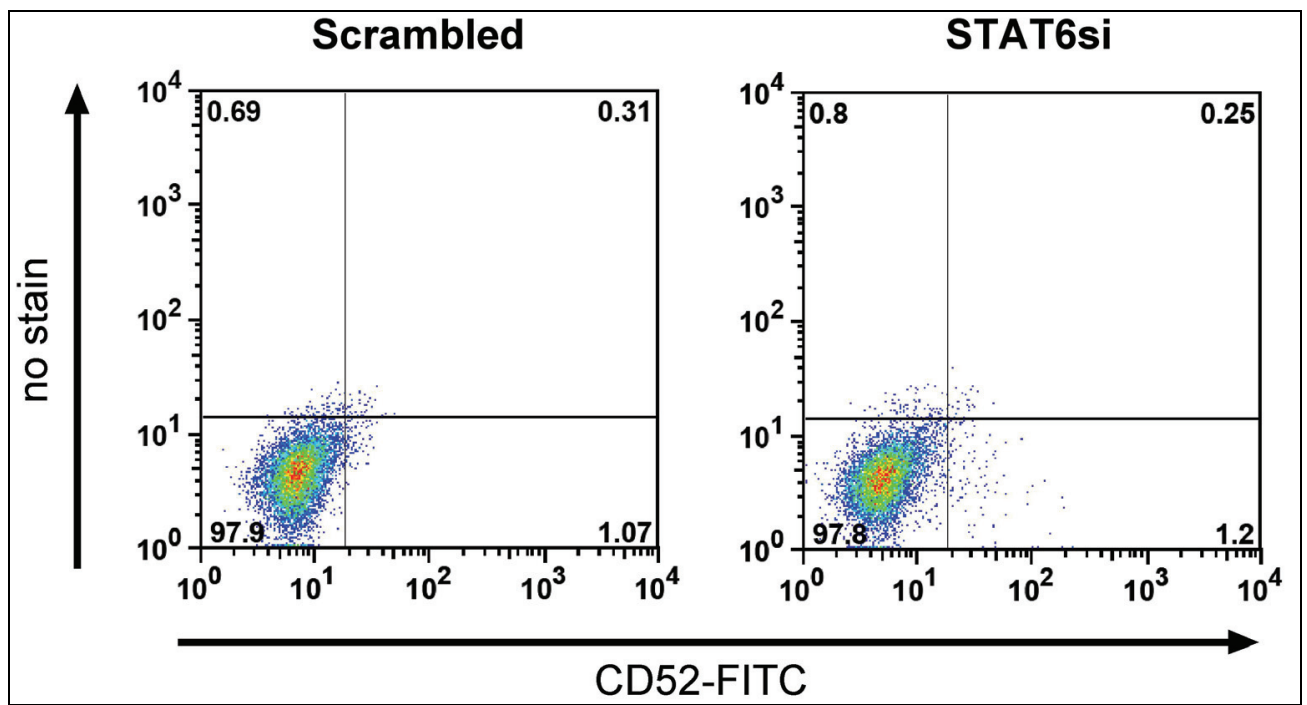

Abbildung 4.14 Keine Veränderung von CD52 auf der Zelloberfläche bei Hemmung der STAT6-Expression durch siRNA in L428-Zellen. Die Zellen wurden 48h nach der zweiten Transfektion mit STAT6-siRNAs mit anti-CD52-FITC Antikörpern inkubiert und die CD52Expression mittels Durchflusszytometrie analysiert.

Differenziellen Expression des Adapterproteins c-CBL bei Transfektion bei STAT6SiRNA

Das Protein C-CBL verfügt einerseits über eine E3-Ubiquitin-Ligase Aktivität, die zur Degradierung von Proteinen über das Proteasom führt. Andererseits kann C-CBL in verschiedenen Signaltransduktionsvorgängen als Adaptorprotein dienen und somit spezifische Protein-Protein-Interaktionen ermöglichen. Über diese Funktionen kann es sowohl als Negativ- als auch Positivregulator von verschiedenen Signaltransduktionsvorgängen fungieren. Es wurden darüber 
hinaus Varianten von c-CBL beschrieben, die onkogenes Potenzial haben (Thien et al., 2001; Dikic et al., 2003).

Die Genexpressionsanalyse der STAT6-siRNA-transfizierten L428-Zellen zeigte eine Hemmung der Expression von C-CBL gegenüber der Expression in den Kontroll-Proben. Dieses Ergebnis konnte in der qRT-PCR bestätigt werden. Die Transfektion der STAT6-siRNA führt zu einer Expressionsreduktion auf das 0,45-fache $( \pm 0,13)$ der Expression der Kontroll-Proben.

Des Weiteren wurde eine Immunoblotanalyse für das Protein c-CBL durchgeführt (Abbildung 4.15). Neben den mit STAT6-siRNA-transfizierten L428-Zellen (Abbildung 4.15A) wurden ebenfalls die untransfizierten cHL-Zelllinien L428, L1236, L591, KMH2, L540 und HDLM2 sowie die T-Zell-Lymphomzellinie Jurkat und die BL-Zelllinie Ramos (Abbildung 4.15B) untersucht.

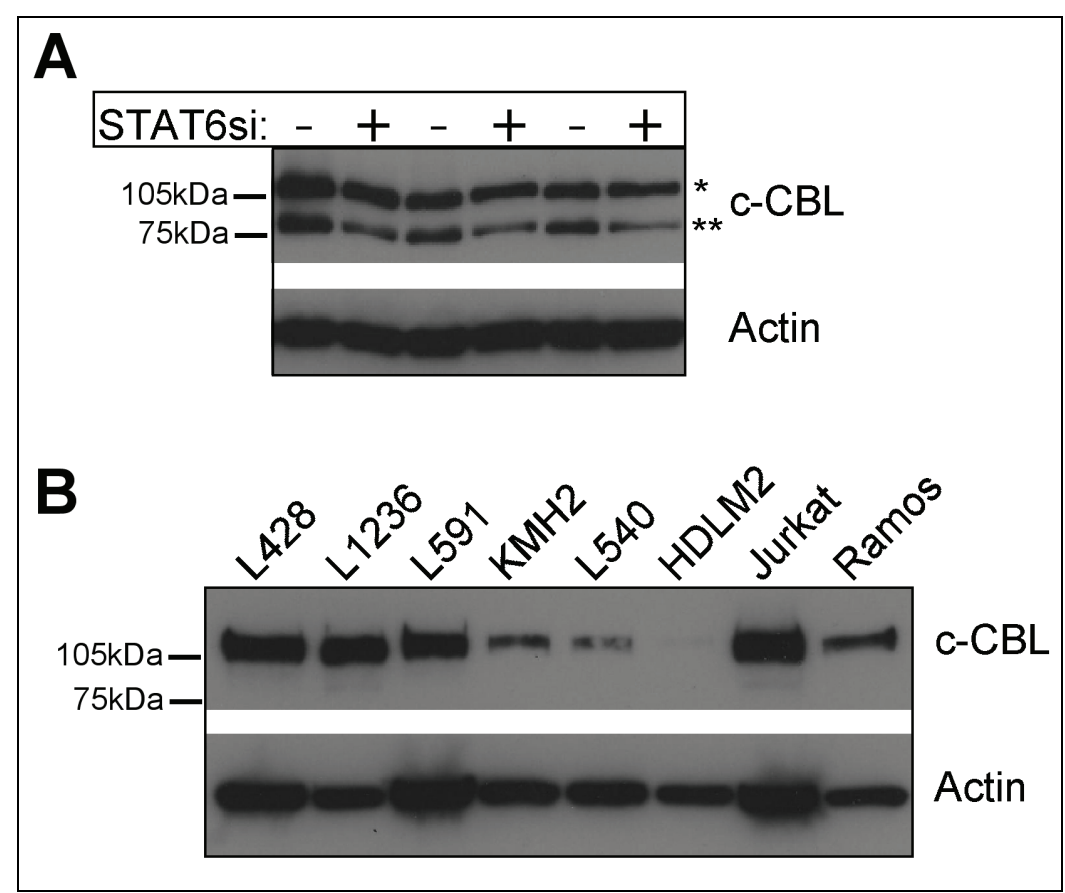

Abbildung 4.15 Analyse von c-CBL in Proteinlysaten von STAT6-siRNA-transfizierten L428Zellen (A) und cHL-Zelllinien (B). (A) Die STAT6-siRNA-transfizierten L428-Zellen zeigten in der Immunoblotanalyse in drei unabhängigen Versuchen zwei Banden für C-CBL. Die in der Literatur angegebene Bande von etwa $120 \mathrm{kDa}\left(^{*}\right)$ ist bei allen drei Versuchen sowohl in den Kontrollen als auch in den STAT6-gehemmten Proben unverändert. Eine kleinere Bande von etwa $85 \mathrm{kDa}\left({ }^{* *}\right)$ zeigt Unterschiede in der Proteinmenge zwischen Kontrollen und STAT6-gehemmten Proben. (B) Die Analyse der cHL-Zelllinien sowie den Zelllinien Jurkat und Ramos ergab in der Immunoblotanalyse nur eine Bande in allen Proben.

Die Proteinlysate der STAT6-siRNA-transifizerten L428-Zellen zeigten in der Immunoblotanalyse zwei spezifische Banden bei Inkubation mit dem C-CBL spezifischen Antikörper (Abbildung 4.15A). Eine Bande liegt bei etwa 120kDa und 
stimmt somit mit der Literaturangabe für das molekulare Gewicht von c-CBL überein $\left(^{*}\right)$. Die zweite Bande von etwa $85 \mathrm{kDa}$ ist in allen 3 unabhängigen Transfektionsversuchen vorhanden $\left.{ }^{(* *}\right)$. Die qRT-PCR-Analyse bestätigte die reduzierte Expression von $\mathrm{c}-\mathrm{CBL}$ auf Transkriptebene. In der Proteinanalyse zeigten sich lediglich Unterschiede in der Proteinmenge von c-CBL bei der $85 \mathrm{kDa}$ Bande $\left(^{* *}\right)$ bei Transfektion der STAT6-siRNA jedoch nicht bei der 120kDa Bande $\left({ }^{*}\right)$.

Die Immunoblotanalyse der untransfizierten $\mathrm{cHL}$-Zelllinien und den Zelllinien Jurkat und Ramos zeigte für alle Proteinlysate nur eine dominante Bande von etwa 120kDa (Abbildung 4.15B). Die Proteinprobe der untransfizierten L428 Zelllinie zeigte hier ebenfalls nur eine Bande. Sowohl die Entstehung der zweiten Bande von $85 \mathrm{kDa}$ in den transfizierten Proben als auch die Abnahme der Proteinmenge dieser Bande bedarf weiterer Analysen.

Hemmung des Transkriptionsfaktors A-Myb in STAT6-siRNA-transfizierten L428Zellen

Der Transkriptionsfaktor A-Myb wird vor allem in Zellen des BLs, der akuten lymphoblastischen Leukämie und der chronisch lymphatischen Leukämie exprimiert (Golay et al., 1996). Eine Rolle von A-Myb im cHL ist bisher nicht bekannt.

Die verringerte Expression von A-Myb konnte durch die qRT-PCR in den STAT6siRNA-transfizierten Zellen nachgewiesen werden. Die Expression von A-Myb sank auf das 0,50-fache $( \pm 0,14)$ der Expression in den Kontroll-Proben. Durch die Rolle von A-Myb bei der Proliferation von B-Lymphozyten könnte A-Myb auch bei der Proliferation von cHL-Zellen von Bedeutung sein (Golay et al., 1998). 
Validierung der differenziellen Expression der Proteinkinase-Untereinheit PIK3CA in STAT6-siRNA-transfizierten L428-Zellen

Es konnte gezeigt werden, dass der Phosphatidyl-Inositol-3-Kinase (PI3K)Signalweg mit dem Überleben der cHL-Zellen in Verbindung steht (Dutton et al., 2005; Georgakis et al., 2006b). Die katalytische PI3K-Untereinheit PIK3CA ( $p 110 \alpha$ ) ist von entscheidender Bedeutung für die Funktion des PI3K-Signalwegs und eine Expressionsaktivierung durch STAT6 könnte an der Funktion des Signalwegs in $\mathrm{cHL}-$ Zellen beteiligt sein.

Die Genexpressionsanalyse mittels Microarray der STAT6-siRNA-transfizierten L428-Zellen zeigt eine Reduktion der Expression von PIK3CA gegen über den Kontroll-Proben. Dieses Ergebnis konnte in der qRT-PCR nicht bestätigt werden. Es konnte keine Veränderung der Expression in den STAT6-siRNA-transfizierten Proben im Vergleich zu der Expression in den Kontroll-Proben festgestellt werden. 


\subsection{Genvariationsanalysen von Zytokinen und Zytokinrezeptoren}

\subsection{1 Überblick über die durchgeführten Genvariationsanalysen}

Im Rahmen dieser Dissertation wurden Genvariationen von Zytokinen und Zytokinrezeptoren analysiert. Hierzu wurden verschiedene Patientenkollektive verwendet.

Im Rahmen der NHL-B1/-B2-Studien der Deutschen Studiengruppe für hochmaligne Non-Hodgkin-Lymphome (DSHNHL) wurden Genvariationen des IL-10 Promotorbereichs von 500 NHL-Patienten analysiert. Hierbei wurden vor allem die distalen Genvariationen IL-10-7400InDel, IL-10_6752AT, IL-10-6208GC und IL-10-3538AT in Bezug auf den klinischen Verlauf der NHL-Patienten betrachtet. Vorherige Publikationen haben für die proximalen Genvariationen IL-10-1087AG, IL-10_824Cт und IL-10_597AC verschiedene Zusammenhänge zwischen dem Risiko der NHL Erkrankung und dem Krankheitsverlauf von NHL-Patienten festgestellt (Breen et al., 2003; Cunningham et al., 2003; Lech-Maranda et al., 2004; Berglund et al., 2005; Rothman et al., 2006). Diese Ergebnisse wurden im Patientenkollektiv der NHL-B1/B2-Studien der DSHNHL evaluiert. Die Resultate der Analysen der IL-10-Genvariationen der NHL-Patienten wurden bereits publiziert und sind im Anhang $8.2 \mathrm{zu}$ finden (Kube et al., 2008). Der Anteil der Dissertation an dieser Publikation bestand vorrangig in der Auswertung und Aufarbeitung der Daten, Interpretation der Ergebnisse und der Korrektur des Manuskripts.

In einem Patientenkollektiv von 228 DLBCL-Patienten wurden Polymorphismen der IL-4, IL-13 und IL-4Ra Gene analysiert. Auf Grund der besonderen Bedeutung dieser Faktoren bei der Th2-Immunantwort und auch als potenzielle Wachstumsfaktoren der Lymphomzellen, sollte hier der Einfluss der Variationen auf das Überleben der DLBCL-Patienten untersucht werden. Die Analyse der Genpolymorphismen im DLBCL-Patientenkollektiv ist im Abschnitt 4.3.2 zu finden. Die Genotypisierungen der Patienten wurde von Frederike von Bonin (MTA) unterstützt. Die statistische Überlebenszeitanalyse wurde von Samira Zeynalova (IMISE, Leipzig) durchgeführt.

Von 86 T-Zell-NHL-Patienten der NHL-B1/B2 und RICOVER-Studien der DSHNHL wurden ebenfalls die proximalen und distalen IL-10-Genvariationen untersucht. 
Zusätzlich wurde der IL-10 Serumwert der T-NHL-Patienten durch eine ELISA Analyse ermittelt. Eine Publikation, die sich mit den proximalen IL-10 SNPs in T-Zell-NHL-Patienten befasst hat, soll durch diese Studie validiert werden (Lee et al., 2007). Darüber hinaus soll der Einfluss der distalen IL-10-Genvariationen sowie des IL-10 Serumwerts auf den klinischen Verlauf der T-NHL-Patienten untersucht werden. Da die klinischen Parameter der Patienten im IMISE Institut in Leipzig vorliegen, befinden sich die erhobenen Daten zurzeit dort zur statistischen Analyse.

Von der Deutschen Hodgkin Studiengruppe (GSHG) (Dr. Re / Prof. Engert) wurden für die Analyse der Genpolymorphismen 300 Blutproben von HodgkinLymphom Patienten zur Verfügung gestellt. Es wurde zunächst die DNA aus den Proben extrahiert und im Anschluss die Analyse der Genvariationen durchgeführt. In diesem Patientenkollektiv wurden die distalen und proximalen IL-10Genvariationen, die IL-13 SNPs IL-13 ${ }_{\text {Q144R-AG }}$ und IL-13-1069CT sowie die IL-4RaPolymorphismen IL-4Ra $\mathrm{I}_{175 \mathrm{~V}-\mathrm{AG}}$ und IL-4Ra $\mathrm{Q}_{\mathrm{Q} 56 \mathrm{R}-\mathrm{AG}}$ untersucht. Derzeit gibt es nur eine Publikation, die sich mit den IL-10-Genvariationen in $184 \mathrm{HL}$ Patienten befasst hat (Hohaus et al., 2007). Die im Rahmen dieser Arbeit vorgenommenen Analysen umfassen sowohl proximale als auch distale IL-10-Genvariationen und schließen darüber hinaus weitere SNPs ein, die den klinischen Verlauf der HL Patienten beeinflussen könnten. Die Daten befinden sich derzeit in der statistischen Auswertung durch die GSHG in Bezug auf die klinischen Parameter der Hodgkin-Lymphom Patienten.

In einer Kooperation innerhalb des Graduiertenkollegs 1034 mit Prof. Emmert (Abt. Dermatologie) wurden die IL-10-Genvariationen in einem Kollektiv von 288 Patienten mit malignen Melanom analysiert. In diesem Zusammenhang sollte vor allem das Risiko der Erkrankung im Vergleich zu einer Kontrollgruppe, die aus gesunden Probanden besteht, in Bezug auf die Genvariationen analysiert werden. Die Daten befinden sich derzeit in der Auswertung. 


\subsubsection{Analyse von Th2-Zytokin- und Zytokinrezeptorgenvariationen in DLBCL-Patienten}

Um den Zusammenhang verschiedener Polymorphismen von Th2-Zytokin- bzw. Zytokinrezeptorgenen mit dem Überleben von Patienten mit DLBCL zu untersuchen, wurden 228 Patienten aus den NHL-B1/B2-Studien der DSHNHL für die Analyse ausgewählt. Diese Selektion ist repräsentativ für alle DLBCLPatienten innerhalb der Studie (Tabelle 2.2).

Innerhalb dieses Patientenkollektives wurden Polymorphismen der Gene von IL-4, IL-13 und des IL-4Ra mittels allelischer Diskriminierung untersucht. Bei den Genen von IL-4 und IL-13 handelt es sich jeweils um einen PromotorPolymorphismus und bei IL-4Ra wurden drei codierende Polymorphismen untersucht, die zu einem Aminosäureaustausch im Protein führen. In Tabelle 4.5 sind die SNP-Namen, RefSNP IDs, Genotypenverteilung innerhalb des Patientenkollektives sowie die p-Werte des Hardy-Weinberg-Gleichgewichts dargestellt. In diesem Patientenkollektiv befanden sich alle untersuchten Genvariationen im Gleichgewicht nach Hardy-Weinberg und konnten somit für weitere Analysen verwendet werden.

Tabelle 4.5 Analysierte Genpolymorphismen, Genotypenverteilung und Hardy-Weinberg Gleichgewicht (HWG).

\begin{tabular}{|c|c|c|c|c|c|c|}
\hline SNP-NAME & REFSNP ID & GENOTYP & $\begin{array}{c}\text { AS } \\
\text { VARIANTE }\end{array}$ & $\begin{array}{r}\text { ANZAHL } \\
\text { DER } \\
\text { PATIENTEN }\end{array}$ & $\begin{array}{r}\% \text { DER } \\
\text { PATIENTEN } \\
\end{array}$ & $\begin{array}{c}\text { HWG P- } \\
\text { WERT } \\
\left(X^{2}\right) \\
\end{array}$ \\
\hline \multirow[t]{3}{*}{ IL-4Ra I75V } & rs1805010 & AA & $175 / 175$ & 70 & 30.7 & 0.265 \\
\hline & & $A G$ & I75/V75 & 105 & 46.1 & \\
\hline & & GG & V75/V75 & 53 & 23.2 & \\
\hline \multirow[t]{3}{*}{ IL-4Ra S503P } & rs1805015 & TT & S503/S503 & 156 & 68.4 & 0.603 \\
\hline & & TC & S503/P503 & 66 & 28.9 & \\
\hline & & $\mathrm{CC}$ & P503/P503 & 6 & 2.6 & \\
\hline \multirow[t]{3}{*}{ IL-4Ra Q576R } & rs1801275 & AA & Q576/Q576 & 140 & 61.4 & 0.754 \\
\hline & & $A G$ & Q576/R576 & 79 & 34.6 & \\
\hline & & GG & R576/R576 & 9 & 3.9 & \\
\hline \multirow[t]{3}{*}{ IL-13 -1069 } & rs1800925 & $\mathrm{CC}$ & - & 141 & 61.8 & 0.219 \\
\hline & & CT & - & 81 & 35.3 & \\
\hline & & TT & - & 6 & 2.6 & \\
\hline \multirow[t]{3}{*}{ IL-4 -524 } & rs2243250 & $\mathrm{CC}$ & - & 161 & 70.6 & 1.000 \\
\hline & & CT & - & 62 & 27.2 & \\
\hline & & TT & - & 5 & 2.2 & \\
\hline
\end{tabular}


Die Daten wurden mit den klinischen Parametern der Patienten verglichen und eine Überlebenszeitanalyse für die einzelnen Genotypen im Patientenkollektiv erstellt. Diese Analyse wurde in Zusammenarbeit mit dem IMISE Institut Leipzig durchgeführt, das über die gesamten klinischen Daten der Studien der DSHNHL verfügt. 


\subsubsection{Einfluss der IL-4Ra I75V Genvariation auf das Überleben der DLBCL- Patienten}

Die Analyse der 5 untersuchten Polymorphismen zeigte für die Genvariation I75V des IL-4Ra signifikante Unterschiede in Bezug auf das Gesamtüberleben (OS) der DLBCL-Patienten. Alle anderen Genvariationen ergaben keine signifikanten Unterschiede in den Überlebensraten der DLBCL-Patienten (Tabelle 4.6).

Tabelle 4.6 Analyse der Genpolymorphismen in Bezug auf Gesamtüberleben und Ereignisfreies Überleben der DLBCL-Patienten.

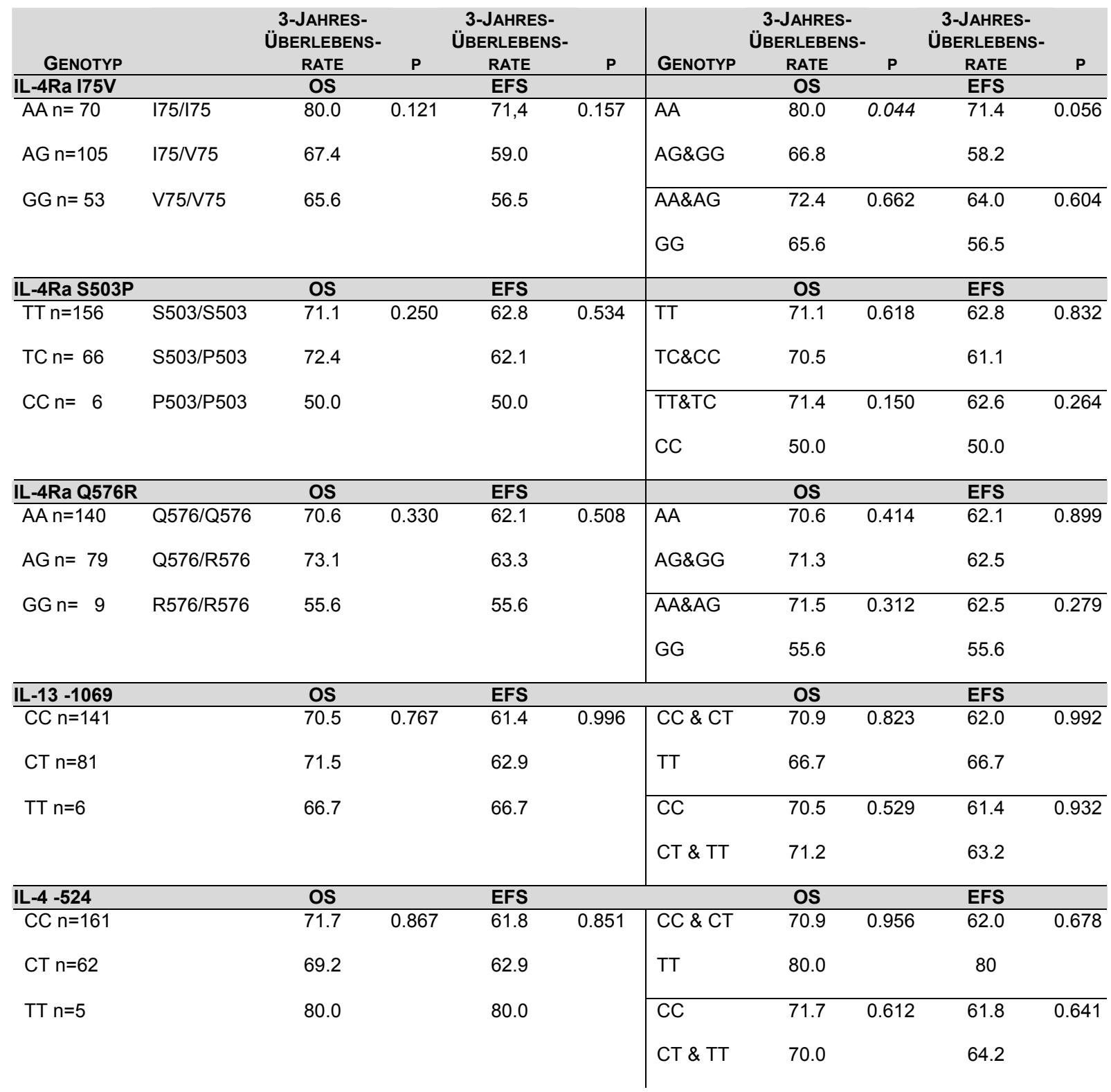


DLBCL-Patienten mit mindestens einem G-Allel der IL-4Ra $a_{175 V}$ Genvariation (IL-4Ra $\left.{ }_{175 V-A G} \& I L-4 R a_{175 V-G G}\right)$ haben eine verringerte Überlebensrate im Vergleich zu den homozygot A-Allelträgern (IL-4Ra $\left.{ }_{175 V-A A}\right)$. Das G-Allel codiert die Aminosäure Valin an Position 75 des IL-4Ra und das A-Allel die Aminosäure Isoleucin an Position 75 des IL-4Ra. Die 3-Jahres-Überlebensrate in Bezug auf

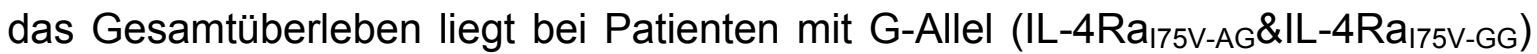
bei $66,8 \%$ gegenüber $80,0 \%$ bei Patienten mit zwei $A$-Allelen (IL-4Ra $\left.a_{175 V-A A}\right)(p=$ 0,044). Im Ereignis-freien Überleben (EFS) ist dieser Unterschied sichtbar (3-Jahres-Überlebensrate $\quad$ IL-4Ra ${ }_{175 V-A G} \& I L-4 R a_{175 V-G G:}$ 58,2\%; IL-4Ra ${ }_{175 V-A A:}$ $71,4 \%)$, führte aber zu keinem signifikanten Ergebnis $(p=0,056)$. Der Einfluss der IL-4 I75V Genvariation auf das Überleben der DLBCL-Patienten ist zur Verdeutlichung in Form von Kaplan-Meier-Kurven in Abbildung 4.16 dargestellt.

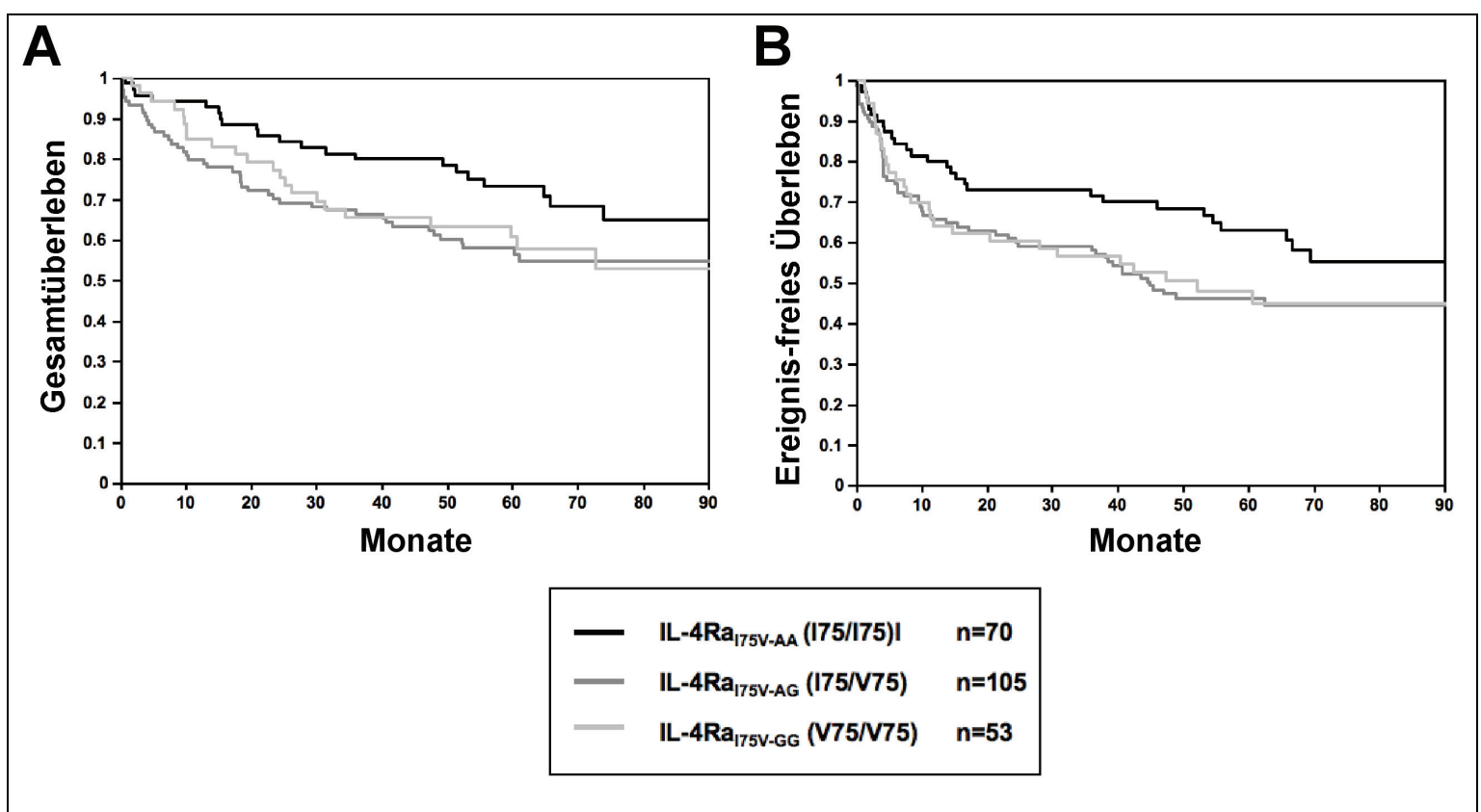

Abbildung 4.16 Gesamt- (A) und Ereignis-freies Überleben (B) der DLBCL-Patienten In Bezug zur IL-4Ra 175V Genvariation. Der Vergleich der I75V Genotypen zeigt Unterschiede im Überleben der DLBCL-Patienten. Patienten homozygot für das A-Allel (schwarze Linie) haben eine bessere Überlebensrate im Vergleich zu G-Allelträgern (graue Linien). Die entsprechenden 3-Jahresüberlebensraten sind der Tabelle 4.6 zu entnehmen.

Die anderen analysierten Genpolymorphismen des IL-4Ra sowie der Promotorpolymorphismus von IL-4 zeigen verringerte aber nicht signifikant unterschiedliche Überlebensraten zwischen den unterschiedlichen Genotypgruppen der DLBCL-Patienten. Dies könnte auf die geringe Frequenz des Minor-Allels zurückzuführen sein. Der Promotorpolymorphismus des IL-13 Gens 
zeigte bei der Überlebensanalyse der DLBCL-Patienten keinerlei Unterschiede zwischen den einzelnen Genotypen.

Weiterführend wurde eine multivariate Cox-Regressionsanalyse, adjustiert auf die Faktoren des IPI, für die IL-4Ra $a_{175 v}$ Genvariation durchgeführt (Tabelle 4.7).

Tabelle 4.7 Multivariate Analyse der IL-4Ra ${ }_{175 v}$ Genvariation auf die IPI Faktoren adjustiert (Cox-Regressions-Modell) in Bezug auf Gesamt- und Ereignis-freies Überleben.

\begin{tabular}{|c|c|c|c|c|c|c|}
\hline & os & & & FS & & \\
\hline FAKTOR & $\mathbf{R R}$ & $95 \% \mathrm{Cl}$ & $\mathbf{P}$ & $\mathbf{R R}$ & $95 \% \mathrm{Cl}$ & $\mathbf{P}$ \\
\hline $\mathrm{LDH}>\mathrm{N}$ & 2.1 & $(1.3 ; 3.6)$ & 0.003 & 1.7 & $(1.1 ; 2.8)$ & 0.024 \\
\hline Alter $>60$ Jahre & 2.6 & $(1.5 ; 4.5)$ & 0.001 & 2.1 & $(1.3 ; 3.3)$ & 0.002 \\
\hline Performance Status ECOG $>1$ & 2.5 & $(1.5 ; 4.1)$ & 0.001 & 2.6 & $(1.6 ; 4.2)$ & $<0.001$ \\
\hline Ann-Arbor-Klassifikation III/ IV & 1.4 & $(0.9 ; 2.3)$ & 0.123 & 1.5 & $(1.0 ; 2.2)$ & 0.054 \\
\hline Extranodal Befall > 1 & 1.6 & $(1.0 ; 2.7)$ & 0.064 & 1.3 & $(0.8 ; 2.0)$ & 0.321 \\
\hline IL-4Ra $a_{175 V-A G} \& I L-4 R a_{175 V-G G}$ vs. IL-4Ra & 1.9 & $(1.2 ; 3.2)$ & 0.011 & 1.5 & $(1.0 ; 2.3)$ & 0.076 \\
\hline
\end{tabular}

Es zeigte sich, dass im Vergleich zwischen Patienten mit IL-4Ra $a_{175 V-A G}$ \& IL-4Ra ${ }_{175 V-G G}$ Genotypen gegenüber Patienten mit IL-4Ra ${ }_{175 V-A A}$ Genotyp ein relatives Risiko $(R R)$ von $1,9(p=0,011)$ für eine schlechtere Überlebensrate besteht. Der 175V Genotyp ist somit ein unabhängiger Faktor gegenüber den prognostischen Faktoren des IPIs im analysierten DLBCL-Patientenkollektiv. 


\subsubsection{Einfluss des löslichen IL-4R (sIL-4R) Serumwertes in Kombination mit der IL-4Ra I75V Genvariation auf das Überleben der DLBCL- Patienten}

Lösliche Zytokinrezeptoren im Serum von Patienten können Einfluss auf den Verlauf von diversen Krankheiten haben. Im Rahmen der Analysen von Prof. Wolfram Jung (Abt. Hämatologie und Onkologie, Göttingen) konnte gezeigt werden, dass ein erhöhter Serumwert der löslichen Form des IL-4Ra (sIL-4R) einen ungünstigen Einfluss auf das Überleben von DLBCL-Patienten hat (unpublizierte Daten).

Um den Einfluss des slL-4R-Serumwertes in Kombination mit der IL-4Ra ${ }_{175 \mathrm{~V}}$ Genvariation zu untersuchen, wurde jede Genotypengruppe in Patienten mit hohem $(>115 \mathrm{pg} / \mathrm{ml})$ und niedrigem $(\leq 115 \mathrm{pg} / \mathrm{ml})$ slL-4R-Serumwert unterteilt. Für diese Patienten-Subgruppen wurde ebenfalls eine Überlebenszeitanalyse durchgeführt (Tabelle 4.8).

Tabelle 4.8 Gesamt- und Ereignis-freies Überleben der DLBCL-Patienten in Bezug zur IL-4Ra 175V Genvariation in Kombination mit dem sIL-4R-Serumwert. Die Auftrennung der einzelnen Genotypen nach hohen und niedrigen sIL-4R-Serumwerten zeigt signifikante Unterschiede für alle Gruppen (globaler $p<0.001$ ).

\begin{tabular}{|c|c|c|c|c|c|}
\hline GENOTYP & & & & $\begin{array}{c}\text { 3-JAHRES- } \\
\text { ÜBERLEBENSRATE } \\
(95 \% \mathrm{Cl})\end{array}$ & $\begin{array}{c}\text { 3-JAHRES- } \\
\text { ÜBERLEBENSRATE } \\
(95 \% \mathrm{Cl})\end{array}$ \\
\hline IL-4RA I75V & AS VARIANTE & SIL-4R-SERUMWERT & PATIENTEN & OS & EFS \\
\hline$A A$ & $175 / 175$ & $\leq 115 \mathrm{pg} / \mathrm{ml}$ & $n=51$ & $\begin{array}{c}84.3 \\
(74.3 ; 94.3)\end{array}$ & $\begin{array}{c}74.5 \\
(62.5 ; 86.5)\end{array}$ \\
\hline$A G$ & 175/V75 & $\leq 115 \mathrm{pg} / \mathrm{ml}$ & $\mathrm{n}=79$ & $\begin{array}{c}73.1 \\
(63.3 ; 82.9)\end{array}$ & $\begin{array}{c}64.6 \\
(54.0 ; 75.2\end{array}$ \\
\hline GG & V75/V75 & $\leq 115 \mathrm{pg} / \mathrm{ml}$ & $n=43$ & $\begin{array}{c}69.6 \\
(55.9 ; 83.3)\end{array}$ & $\begin{array}{c}62.7 \\
(48.2 ; 77.2)\end{array}$ \\
\hline $\mathrm{AA}$ & $175 / 175$ & $>115 \mathrm{pg} / \mathrm{ml}$ & $n=19$ & $\begin{array}{c}68.4 \\
(47.4 ; 89.4)\end{array}$ & $\begin{array}{c}63.2 \\
(41.4 ; 85.0\end{array}$ \\
\hline$A G$ & 175/V75 & $>115 \mathrm{pg} / \mathrm{ml}$ & $n=26$ & $\begin{array}{c}50.0 \\
(30.8 ; 69.2)\end{array}$ & $\begin{array}{c}42.3 \\
(23.3 ; 61.3)\end{array}$ \\
\hline GG & V75/V75 & $>115 \mathrm{pg} / \mathrm{ml}$ & $n=10$ & $\begin{array}{c}48.0 \\
(15.9 ; 80.1)\end{array}$ & $\begin{array}{c}30.0 \\
(1.6 ; 58.4)\end{array}$ \\
\hline
\end{tabular}

Wie in Tabelle 4.8 dargestellt, führt die Auftrennung der 3 verschiedenen IL-4Ra I75V Genotypen nach Patienten mit hohen bzw. niedrigen sIL-4R-Serumwerten zu einer weiteren Unterteilung in Patientengruppen mit signifikant unterschiedlichen Überlebensraten. Patienten mit IL-4Ra ${ }_{175 V-A A}$ Genotyp und niedrigen sIL-4RSerumwerten haben hier die höchsten Überlebensraten (3-Jahres-Überlebensrate: 84.3\% (OS) bzw. 74.5\% (EFS)). Die schlechtesten Überlebensraten ergeben sich 
für Patienten mit IL-4Ra $a_{175 V-A G}$ sowie IL-4Ra ${ }_{175 V-G G}$ Genotypen und hohen sIL-4RSerumwert (3-Jahres-Überlebensrate: 48.0-50.0\% (OS) bzw. 30.0-42.3\% (EFS)). Zur Veranschaulichung wurden für die Kaplan-Meier-Kurven die Genotypen IL-4Ra $a_{175 V-A G}$ zusammen mit IL-4Ra ${ }_{175 V-G G}$ dargestellt (Abbildung 4.17).

Patienten, charakterisiert durch den Genotyp IL-4Ra ${ }_{175 V-A A}$ und hohen sIL-4RSerumwert (schwarze unterbrochene Linie), haben während der ersten 50 Monate des Beobachtungszeitraumes ungefähr gleiche Überlebensraten wie Patienten mit den Genotypen IL-4Ra ${ }_{175 V-A G}$ und IL-4Ra ${ }_{175 V-G G}$, aber geringen sIL-4RSerumwerten (graue Linie).

Diese Analyse zeigt, dass die Kombination aus IL-4Ra|175V Genvariation zusammen mit dem slL-4R-Serumwert eine weitere Aufgliederung in Gruppen mit unterschiedlichem klinischem Verlauf der DLBCL-Patienten erlaubt.

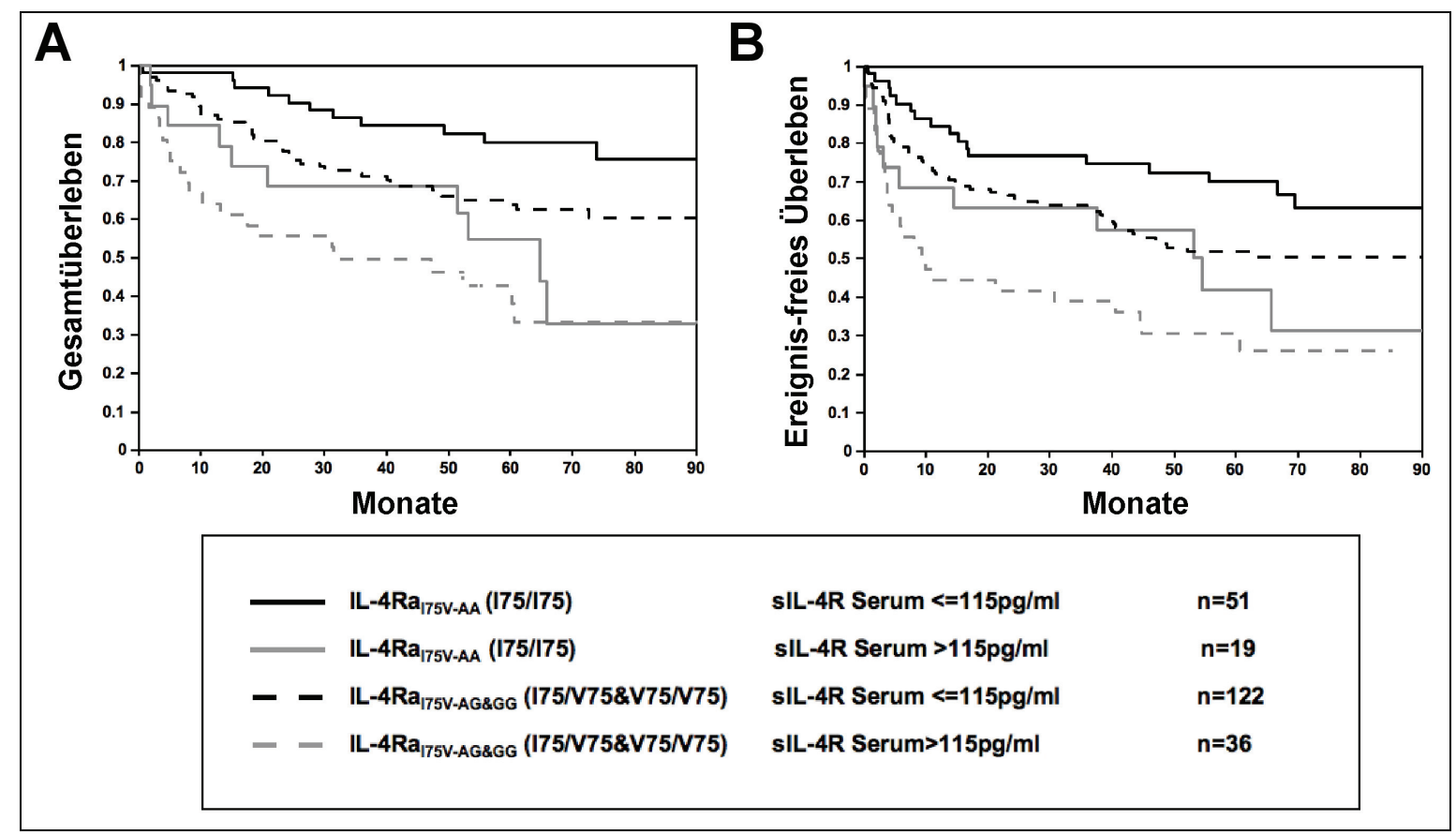

Abbildung 4.17 Gesamt- (A) und Ereignis-freies Überleben (B) der DLBCL-Patienten in Bezug zur IL-4Ra 175V Genvariation in Kombination mit dem sIL-4R-Serumwert. Patienten mit hohen sIL-4R-Serumwerten in Kombination mit IL-4Ra I75V-AG $_{\text {sowie IL-4Ra }}$ 175V-GG Genotypen (graue unterbrochene Linie) haben die niedrigsten Überlebensraten. Patienten mit niedrigen SIL-4RSerumwerten und IL-4Ra $a_{175 V-A A}$ Genotyp (schwarze Linie) zeigen die höchsten Überlebensraten. 


\section{DISKUSSION}

In dieser Arbeit wurden Zytokine und die sich anschließende Signaltransduktion über den Jak-STAT-Signalweg in malignen Lymphomen untersucht. Durch das hieraus entwickelte Verständnis der Biologie der Lymphome, können neue Ansätze entwickelt werden, die die Therapie der Patienten vor allem in Bezug auf die Nebenwirkungen verbessern.

In den ersten beiden Teilen dieser Arbeit wurde der durch Zytokine aktivierbare Jak-STAT-Signalweg im cHL betrachtet. Die Aktivierung der STATTranskriptionsfaktoren ist für das Überleben sowie die Proliferation der cHL-Zellen von großer Bedeutung (Kube et al., 2001a; Skinnider et al., 2002a; Holtick et al., 2005; Baus et al., 2006). Aus diesem Grund wurden die Janus-Kinasen als therapeutische Zielstruktur sowie die transkriptionellen Ziele der STATs analysiert. Aus der Analyse des Signalwegs ergeben sich neue Erkenntnisse, die unter therapeutischen und funktionellen Aspekten der Lymphomerkrankungen von Bedeutung sind.

Der dritte Teil der Arbeit befasste sich mit ererbten Genvariationen von Zytokinen und ihren Rezeptoren in Bezug auf den Krankheitsverlauf von malignen Lymphomen. Diese Variationen können zu einer Veränderung der Expression bzw. Funktion der Zytokine und ihren Rezeptoren beitragen. Die erzielten Ergebnisse könnten zukünftig zur Risikoabschätzung des Krankheitsverlaufs von Lymphompatienten eingesetzt werden. Durch Einteilung der Patienten in Risikoklassen kann somit eine individualisierte Therapie angestrebt werden.

\subsection{Rolle der Janus-Kinasen im $\mathrm{cHL}$}

\subsubsection{Aktivierung der Janus-Kinasen im cHL}

Im cHL konnte eine permanente Phosphorylierung von STAT3, STAT5 und STAT6 nachgewiesen werden (Kube et al., 2001a; Skinnider et al., 2002a; Weniger et al., 2006). Die Phosphorylierung der Janus-Kinasen als potenzielle Aktivatoren der STATs konnte im cHL bisher nur in zwei Zelllinien mit T-Zell-Ursprung (HDLM2 
und L540), nicht aber in Zelllinien mit B-Zell-Ursprung (KMH2) nachgewiesen werden (Cochet et al., 2006). Da 98\% der cHL-Fälle ihren Ursprung in B-Zellen haben und nur sehr selten in T-Zellen, wurden hier cHL-Zelllinien mit Abstammung aus B-Zellen (L428, L591 und L1236) untersucht (Bräuninger et al., 2006). Die in dieser Arbeit durchgeführte Immunpräzipitationsanalyse zeigt, dass die JanusKinasen auch in diesen cHL-Zelllinien aktiviert sind. Dabei wurden in den Zelllinien des cHLs keine Mutationen in Jak2 und Tyk2 gefunden, die zur Aktivierung der Proteine beitragen könnten. Die Abwesenheit der Jak2 V617F Mutation in cHLZellen wurde kürzlich auch in einer Publikation bestätigt (Melzner et al., 2006). Es ist daher wahrscheinlich, dass die Aktivierung der Janus-Kinasen über die Bindung von Zytokinen an die Zytokinrezeptoren stattfindet.

Die autokrine Aktivierung von STAT6 im cHL findet hauptsächlich über die Bindung von IL-13 an den IL-13-Rezeptor statt (Skinnider et al., 2001a; Skinnider et al., 2002a). IL-13 kann vor allem die Janus-Kinasen Jak1, Jak2 und Tyk2 aktivieren (Kelly-Welch et al., 2005). Die Aktivierung von Jak2 und Tyk2 in den drei analysierten cHL-Zelllinien L428, L1236 und L591 könnte also durch IL-13 verursacht sein und zur Aktivierung von STAT6 führen.

IL-21 wurde kürzlich als potenzieller autokriner Faktor für die Aktivierung von STAT3 und STAT5 im cHL beschrieben (Lamprecht et al., 2008; Scheeren et al., 2008). IL-21 aktiviert hauptsächlich Jak1 und Jak3 (Habib et al., 2003). Die Aktivierung von Jak1 und Jak3 in der cHL-Zelllinie L428 korreliert mit einer starken Phosphorylierung von STAT3 und STAT5 im Vergleich zur cHL-Zelllinie L1236. Die Inkubation der cHL-Zellen mit AG490 führt zu einer Hemmung der STAT3 Phosphorylierung (Kube et al., 2001a). AG490 gilt als spezifischer Jak2 Hemmstoff (Meydan et al., 1996). Daher könnte entweder auch die Jak2 an der Aktivierung von STAT3 beteiligt sein oder aber AG490 auch andere JanusKinasen hemmen.

Die Aktivierung der Janus-Kinasen in cHL-Zellen bietet aus therapeutischer Sicht die Möglichkeit einer Hemmung des Signalwegs durch spezifische Inhibitoren. So genannte „small molecules“ haben in den letzten Jahren Einzug in die Therapie verschiedener Tumorentitäten erhalten. Insbesondere der Proteintyrosinkinasehemmer Imatinib (Gleevec) erzielt bei der chronisch myeloischen Leukämie (CML) hohe Überlebenschancen (Fabbro et al., 2002). 
Im cHL konnte eine hemmende Wirkung der Proteintyrosinkinase-Inhibitoren der Tyrphostin-Familie AG490 und AG17 auf die Phosphorylierung von STAT3 und STAT6 gezeigt werden (Kube et al., 2001a; Holtick et al., 2005). Diese Hemmung der Janus-Kinasen durch AG17 ist der wahrscheinliche Grund für die bereits beschriebene Reduktion der STAT-Phosphorylierung bei Behandlung der CHLZellen mit AG17 (Holtick et al., 2005). Die Janus-Kinasen bieten somit eine molekulare Zielstruktur, dessen Aktivierung durch chemische Inhibition unterbunden werden kann.

Auf Grund der Rolle des Jak-STAT-Signalwegs in wichtigen physiologischen Prozessen, wie Zellproliferation und Zellüberleben, könnte die Inhibition der Janus-Kinasen von therapeutischem Interesse im $\mathrm{cHL}$ sein. Bisher sind allerdings noch keine spezifischen Inhibitoren des Jak-STAT-Signalwegs in klinischer Erprobung. Durch die wahrscheinliche Aktivierung der Janus-Kinasen durch die Bindung von Zytokinen an die entsprechenden Rezeptoren, könnten auch humanisierte Antikörper, die gegen die Zytokine oder die Rezeptoren gerichtet sind, für eine Therapie in Frage kommen. Solche Therapieansätze sind bereits für verschiedene Tumorentitäten in klinischer Erprobung (Rose-John et al., 2007). In cHL-Zelllinien bewirkte die vermehrte Expression des IL-13-,Decoy“-Rezeptors IL13Ra2 eine verminderte STAT6-Aktivierung und eine reduzierte Zellproliferation (Trieu et al., 2004). Ebenso führt die Behandlung der cHL-Zellen mit dem HistonDeacetylase-Inhibitor Vorinostat zum Abbau von STAT6, begleitet von einer reduzierten Zytokinproduktion und geringeren Überleben der Zellen (Buglio et al., 2008).

Diese Arbeiten zeigen, dass der Jak-STAT-Signalweg als Ziel für therapeutische Ansätze geeignet ist. Sowohl im cHL als auch in anderen Tumorentitäten könnte eine Inhibition des Jak-STAT-Signalwegs eine Verbesserung der Therapie der Patienten bringen, aber ebenso bei Autoimmunerkrankungen, die durch Zytokininduzierte Inflammationsprozesse charakerisiert sind, in Betracht gezogen werden. 


\subsubsection{HSP90 ist essentiell für die Jak-STAT-Signaltransduktion im cHL}

Im Rahmen der Arbeiten zur Aktivierung der Janus-Kinasen erschienen mehrere Publikationen zum Chaperon HSP90 im cHL, die für diese Arbeit von Interesse waren (Georgakis et al., 2006a; Janz et al., 2007).

HSP90 ist ein wichtiges Chaperon, das an der Stabilisierung vieler verschiedener Proteine beteiligt ist. Darunter befinden sich wichtige Komponenten verschiedener Signaltransduktionswege. Diese zentrale Stellung in vielen verschiedenen Signalwegen macht HSP90 zu einer übergeordneten Zielstruktur für Therapiestrategien von Tumorerkrankungen (Whitesell et al., 2005).

Bisher war die Rolle von HSP90 im Jak-STAT-Signalweg relativ unbekannt, aber eine Interaktion zwischen HSP90 und Jak1 sowie Jak2 konnte in HeLa-Zellen (Zervixkarzinom) nachgewiesen werden (Shang et al., 2006). Die Arbeiten von Georgakis et al. zeigten eine Überexpression von HSP90 im cHL und die Inkubation der cHL-Zellen mit dem HSP90-Inhibitor 17-AAG führt zu einer Hemmung der Zellproliferation und Induktion von Apoptose, was kürzlich durch eine weitere Arbeit bestätigt werden konnte (Georgakis et al., 2006a; Janz et al., 2007). Georgakis et al. zeigten weiterhin, dass eine Hemmung des PI3K/AKTsowie des ERK-Signalwegs bei Inkubation mit 17-AAG in den cHL-Zellen festzustellen ist, die neben den NFkB- und Jak-STAT-Signalwegen beide mit dem Überleben der cHL-Zellen anteilig verbunden sind (Zheng et al., 2003; Dutton et al., 2005; Georgakis et al., 2006b).

Auf Grund der Abhängigkeit der cHL-Zellproliferation vom Jak-STAT-Signalweg wurde in dieser Arbeit die Wirkung von HSP90 auf den Jak-STAT-Signalweg untersucht (Kube et al., 2001a; Skinnider et al., 2002a; Holtick et al., 2005; Baus et al., 2006; Cochet et al., 2006). Es konnte gezeigt werden, dass der HSP90Inhibitor 17-AAG zu einer Hemmung der Phosphorylierung von STAT1, -3, -5 und -6 führt. Ebenfalls konnte eine verringerte Proteinmenge von Jak1, Jak3 und Tyk2 festgestellt werden. Die Wirkung von 17-AAG auf Jak2 waren innerhalb der cHLZellinien divergierend. Im Unterschied zu 17-AAG bewirkte aber die HSP90siRNA eine Reduktion der Proteinmenge von Jak2 in den L428-Zellen. Dies könnte durch die unterschiedlichen Methoden bedingt sein. Insbesondere die betrachteten Zeitintervalle unterscheiden sich zwischen dem chemischen Inhibitor 17-AAG und der RNA-Interferenz gegen HSP90 (17-AAG: 24h; HSP90-siRNA: 96h). Die Wirkung von 17-AAG auf Jak2 muss aber in weiteren Analysen 
eingehender untersucht werden. Die verminderte Zellproliferation konnte bei reduziertem HSP90 durch den Einsatz der siRNA bestätigt werden. Der Effekt ist dabei geringer als beim Einsatz von 17-AAG, was auf die nicht vollständige Hemmung von HSP90 durch die RNA-Interferenz zurückzuführen sein könnte. Ebenfalls sind die Zeitintervalle, die für die Proliferationsanalyse der siRNAtransfizierten Zellen angewendet wurde, zu kurz, um größere Effekte zu sehen.

Diese Ergebnisse zeigen, dass HSP90 auch eine wichtige Rolle bei der Signaltransduktion über den Jak-STAT-Signalweg im cHL hat. HSP90 scheint an der Stabilisierung der Janus-Kinasen beteiligt $z u$ sein und die reduzierte Expression der Janus-Kinasen führt $z u$ einer Hemmung der STATPhosphorylierung. Diese Hemmung des Jak-STAT-Signalwegs trägt wesentlich zur Reduktion der Zellproliferation und dem Überleben der cHL-Zellen bei, auch wenn der Anteil neben den anderen Signalwegen noch zu klären ist.

Das $\mathrm{CHL}$ ist durch eine Aktivierung vieler Signalwege charakterisiert. Neben dem Jak-STAT-Signalweg ist vor allem der NFKB-Signalweg hier von Bedeutung (Bargou et al., 1997b; Hinz et al., 2002). Auch in diesem Signalweg scheint HSP90 wichtig zu sein, da zum einen die Hemmung von HSP90 über Geldanamycin zu einer Hemmung der NFkB-Aktivität in den cHL-Zellen führt und zum anderen NFKB an der transkriptionellen Aktivierung von HSP90 beteiligt ist (Broemer et al., 2004; Ammirante et al., 2008). Die Abbildung 5.1 fasst die Ergebnisse dieser Analyse und die aktuelle Literatur von HSP90 im cHL zusammen.

Der Einsatz von selektiven Proteintyrosinkinasehemmern zeigte, dass Tumorzellen in der Lage sind Resistenzen gegen diese Substanzen zu entwickeln. Die Entwicklung von Inhibitoren, die selektiv mehrere Zielstrukturen hemmen, werden daher heute als effektiveres Mittel zur Tumortherapie angesehen (Daub et al., 2004). Übergeordnete Strukturen, die aber besonders in Tumorzellen von Bedeutung sind, können dabei Angriffspunkte für eine Therapie darstellen. Derzeit sind in diesem Zusammenhang vor allem Strukturen, die die Epigenetik (DNAMethylierung und Histon-Acetylierung) sowie die Stabilität und Degradierung von Proteinen (Chaperone und Proteasom) betreffen, in der klinischen Erprobung für verschiedene Tumorentitäten. Die zentrale Rolle von des Chaperons HSP90 als Proteinstabilisator vieler Signalwege könnte neue Therapieansätze bieten. Zurzeit 
gibt es noch keine klinisch relevanten Inhibitoren für den Jak-STAT- oder den NFkB-Signalweg. Die Möglichkeit über die HSP90-Inhibition beide Signalwege zu hemmen, könnte zu einer Verbesserung der Therapie des $\mathrm{cHL}$ und anderen Tumorentitäten führen. Derzeit ist 17-AAG in klinischer Erprobung unter anderem auch bei verschiedenen Lymphomentitäten (Buglio et al., 2007). Darüber hinaus wurden oral verfügbare HSP90-Inhibitoren entwickelt, die für eine Therapie interessant sein könnten (Kasibhatla et al., 2007).

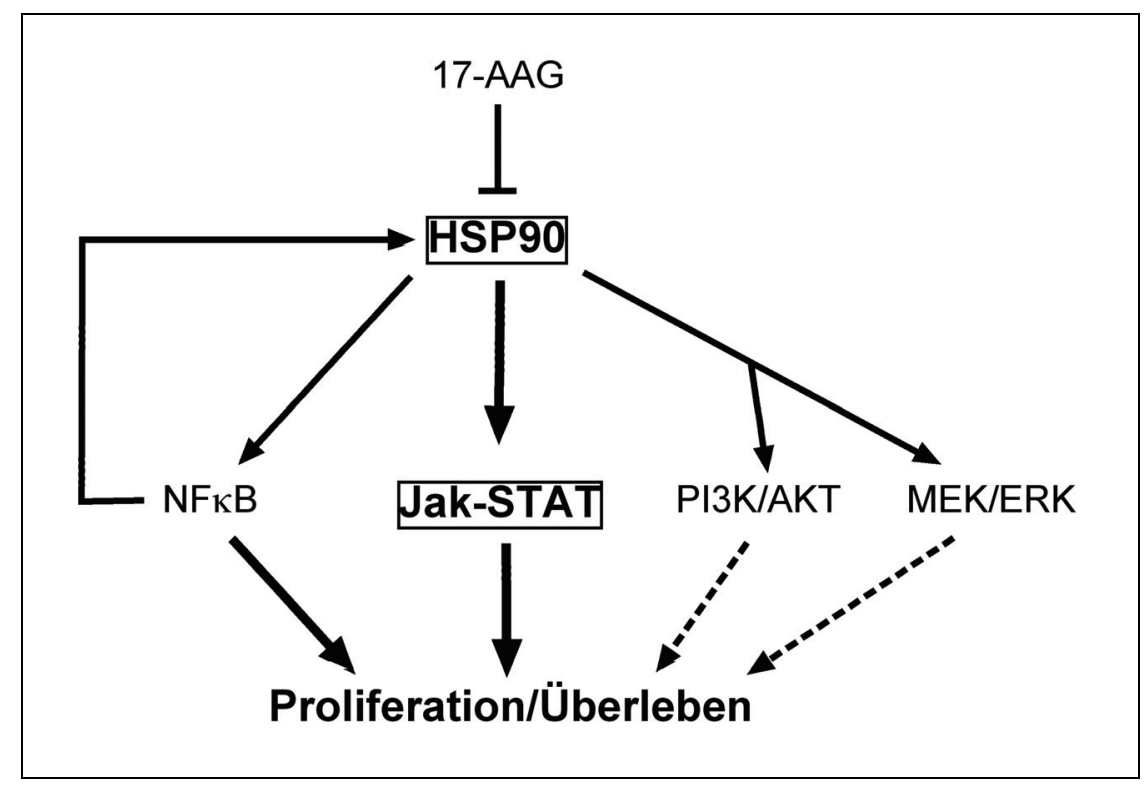

Abbildung 5.1 Schematische Darstellung der Rolle von HSP90 im cHL. HSP90 ist an der Funktion des NFKB- (Broemer et al., 2004), MEK/ERK- und PI3K/AKT- (Georgakis et al., 2006a) Signalwegs beteiligt. Ebenso konnte die Aktivierung von HSP90 durch NFKB nachgewiesen werden (Ammirante et al., 2008). In dieser Arbeit konnte gezeigt werden, dass HSP9O an der Proteinexpression der Janus-Kinasen und der davon abhängigen STAT-Phosphorylierung beteiligt ist. In den cHL-Zelllinien konnten klare Hinweise gefunden werden, dass diese Signalwege zum Überleben und Proliferation der cHL-Zellen beitragen, so dass HSP90 als therapeutischer Angriffspunkt von Interesse sein könnte. 


\subsection{Zielgene der Transkriptionsfaktoren STAT3 und STAT6 im cHL}

Verschiedene Arbeiten haben gezeigt, dass der Jak-STAT-Signalweg für das Überleben und die Proliferation der cHL-Zellen wichtig ist (Kube et al., 2001a; Skinnider et al., 2002a; Baus et al., 2006; Cochet et al., 2006).

Die Arbeitsgruppe Kube konnte erstmalig zeigen, dass die Hemmung von STAT3 mittels RNA-Interferenz eine Reduktion der cHL-Zellproliferation bewirkt (Holtick et al., 2005). Dafür wurden stabil transfizierte Klone verwendet, die eine short-hairpin (sh)RNA gegen die STAT3 mRNA exprimieren. In diesen Klonen wurde die Genexpression bei Hemmung von STAT3 in den L428-Zellen untersucht. Die Ergebnisse der Genexpressionsanalyse konnten jedoch nicht validiert werden. Der klonale Selektionsprozess könnte mit sekundären Veränderungen neben der Hemmung von STAT3 verbunden sein und dadurch die spezifischen Effekte der Reduktion von STAT3 überlagern. Die Verwendung der transienten Transfektion von siRNAs gegen STAT3 und STAT6 in den L428-Zellen zeigte sich als effizient, so dass dieses System für die weiteren Untersuchungen verwendet wurde. Hierfür ist keine klonale Selektion notwendig, so dass sekundäre Effekte gering gehalten werden.

Ein Nachteil der transienten Transfektion ist der eingeschränkte Beobachtungszeitraum der Effekte. Da sich nach wenigen Tage die Effekte der siRNAs verringern, lassen sich keine langen Zeiträume wie bei den stabilen Klonen analysieren. Auf RNA-Interferenz basierende Effekte, die z.B. die Zellproliferation oder das Überleben der Zellen beeinflussen, können in der Regel erst nach einigen Tagen analysiert werden (Ngo et al., 2006). Die Analyse der STAT3-gehemmten Klone zeigten eine reduzierte Zellproliferation nach 5 Tagen (Holtick et al., 2005). In der vorgelegten Arbeit wurde eine Analyse der Zellproliferation $72 \mathrm{~h}$ nach der zweiten transienten Transfektion durchgeführt, so dass die Effekte der Proliferationshemmung weniger ausgeprägt sind. Eine kürzlich erschienene Publikation bestätigt die hier gezeigte Reduktion der Zellproliferation bei Hemmung von STAT6 in L428-Zellen (Buglio et al., 2008). 


\subsubsection{Genexpressionsanalyse nach Hemmung von STAT3 und STAT6}

Zur Identifizierung der transkriptionellen Ziele von STAT3 und STAT6 wurde in dieser Arbeit eine Microarray-Analyse von L428-Zellen, die mit siRNA gegen STAT3 bzw. STAT6 transfiziert wurden, durchgeführt.

Die Analyse der verschiedenen Versuchsansätze ergab nur für einen Teil statistisch signifikante Unterschiede in der Genexpression. Die Hemmung von STAT6 in den L428 Proben führte zu einer großen Anzahl an Transkripten, die im Vergleich zur den Kontroll-siRNA-transfizierten Proben differenziell exprimiert waren. Die Hemmung von STAT3 zeigte jedoch keine statistisch signifikanten Ergebnisse. Bis auf die gehemmte Expression von STAT3 selbst, lag kein anderes Transkript in einer statistisch signifikanten differenziellen Expression vor. Daher wurden nur Gene, die durch die Expressionshemmung von STAT6 in der Genexpressionsanalyse signifikant differenziell exprimiert waren, zur weiteren Validierung herangezogen.

Es muss beachtet werden, dass die hier erzielten Ergebnisse nur in der Zelllinie L428 analysiert wurden. Die L428-Zellen sind im Gegensatz zu den anderen cHLZelllinien bei guter Viabilität zu transfizieren. Da die cHL-Zelllinien durch die Entstehung aus unterschiedlichen cHL-Subentitäten eine gewisse Heterogenität aufweisen, können die Ergebnisse nicht ohne weitere Bestätigung in anderen Zelllinien oder aber Primärmaterial von cHL-Patienten auf das gesamte cHL übertragen werden.

In einer Dissertation, die die Analyse der transkriptionellen Ziele von STAT6 in der cHL-Zelllinie L1236 beinhaltet, wurden 58 differenziell exprimierte Gene identifiziert (Baus, 2005). Zwischen diesen 58 Genen und den hier analysierten transkriptionellen Zielen von STAT6 in den L428-Zellen gab es 8 übereinstimmende Gene. In der Dissertation von D. Baus wurde ein lentivirales Vektor-System zur Transduktion der L1236-Zellen verwendet, um eine STAT6shRNA in den Zellen zu exprimieren. Ebenfalls wurde eine andere MicroarrayPlattform (Applied Biosystems) für die Genexpressionsanalyse verwendet. Die geringe Übereinstimmung der beiden Analysen ist neben der Verwendung von unterschiedlichen $\mathrm{cHL}$-Zelllinien, aber auch durch den methodischen Unterschied begründet. Andere Microarray-Analysen von cHL-Zelllinien wiesen trotz der gleichen Methodik eine große Unterschiede auf, so dass die Heterogenität der cHL-Zelllinien wahrscheinlich auch hier einen großen Einfluss hat (Hinz et al., 
2002). In Tabelle 5.1 sind die Gene aufgeführt, die in beiden Analysen differenziell exprimiert wurden.

Die Bestätigung der Expressionshemmung der IL-13-Rezeptoruntereinheit IL13Ra1 in der Analyse der L1236 Zelllinie, weißt darauf hin, dass dieses Ergebnis nicht nur eine Relevanz in der Zelllinie L428 hat, sondern auch für andere cHLZelllinien gelten könnte. Dies ist von besonderer Bedeutung, da STAT6 durch die Bindung von IL-13 an den IL-13-Rezeptor aktiviert wird und somit vermutlich eine autokrine Aktivierungsschleife vorliegt.

Tabelle 5.1 Gene, die in der Genexpressionsanalyse von D. Baus und der hier durchgeführten Arbeit differenziell exprimiert wurden (Baus, 2005).

\begin{tabular}{|c|c|c|c|}
\hline Gen-Symbol & Gen-Name & $\begin{array}{l}\text { Analyse } \\
\text { D. Baus } \\
\text { (L1236) }\end{array}$ & $\begin{array}{l}\text { Analyse } \\
\text { N. Schoof } \\
\text { (L428) }\end{array}$ \\
\hline TNFSF10 & TNF-related apoptosis inducing ligand TRAIL & aktiviert & aktiviert \\
\hline ENDOG & endonuclease G & gehemmt & gehemmt \\
\hline STAT1 & $\begin{array}{l}\text { signal transducer and activator of } \\
\text { transcription } 1\end{array}$ & aktiviert & aktiviert \\
\hline STAT6 & $\begin{array}{l}\text { signal transducer and activator of } \\
\text { transcription } 6\end{array}$ & gehemmt & gehemmt \\
\hline IL13RA1 & IL13 receptor alpha-1 & gehemmt & gehemmt \\
\hline CDKN1A & $\begin{array}{l}\text { cyclin-dependent kinase inhibitor } 1 \mathrm{~A} \text { ( } \mathrm{p} 21 \text {, } \\
\text { Cip1) }\end{array}$ & aktiviert & aktiviert \\
\hline MLLT1 & $\begin{array}{l}\text { myeloid/lymphoid or mixed-lineage leukemia } \\
\text { (trithorax homolog, Drosophila); translocated } \\
\text { to, } 1\end{array}$ & aktiviert & gehemmt \\
\hline MLLT3 & $\begin{array}{l}\text { myeloid/lymphoid or mixed-lineage leukemia } \\
\text { (trithorax homolog, Drosophila); translocated } \\
\text { to, } 3\end{array}$ & aktiviert & gehemmt \\
\hline
\end{tabular}

\subsubsection{Transkriptionelle Ziele von STAT6}

Durch die Genexpressionsanalyse der L428-Zellen mit gehemmter STAT6Expression konnte eine differenzielle Expression von Genen nachgewiesen werden, die eine Rolle in der Differenzierung von B-Zellen spielen. Insbesondere der Transkriptionsfaktor IRF4 könnte hier ein wichtiges transkriptionelles Ziel von STAT6 sein. Immunhistochemische Färbungen haben gezeigt, dass IRF4 in fast allen cHL-Fällen nachweisbar ist (Buettner et al., 2005; Natkunam et al., 2007). Die Rolle von IRF4 im cHL ist aber unbekannt. In BL-Zelllinien kann die Überexpression von IRF4 eine Differenzierung zu Plasmazellen auslösen, einhergehend mit einer reduzierten Proliferation der Zellen (Teng et al., 2007). In 
Zelllinien des multiplen Myeloms, deren Ursprung in Plasmazellen vermutet wird, wird IRF4 für das Überleben der Zellen benötigt (Shaffer et al., 2008). Die verminderte Expression von IRF4 durch RNA-Interferenz zeigte in Lymphomzellinien (NHLs und BLs) keine Effekte. Zelllinien des cHL wurden nicht untersucht.

IRF4 kann in Keimzentrums-B-Zellen durch den Transkriptionsfaktor NFkB bei Stimulation von CD40 aktiviert werden (Saito et al., 2007). Eine Analyse des humanen Promotor von IRF4 ergab, dass diese NFKB-DNA-Bindestelle ebenfalls ein GAS ( $\gamma$ activated site)-Motiv enthält, an das STAT-Proteine binden können. STAT6 konnte an dieser Bindungsstelle durch eine DNA-Affinitätsanalyse detektiert werden (Lehtonen et al., 2005). Prozesse der Keimzentrumsreaktion wie SHM und CSR werden durch IL-4 und CD40, respektive STAT6 und NFKB, reguliert. Diese Signale führen zur Aktivierung von IRF4 in B-Lymphozyten (Gupta et al., 1999). Da sowohl eine permanente Aktivierung von STAT6 als auch von NFKB im cHL bekannt ist, ist es möglich, dass die Expression von IRF4 hier ebenfalls von beiden Transkriptionsfaktoren abhängig ist. In der Zukunft müssen weitere Analysen mittels Chromatinimmunpräzipitation durchgeführt werden, welche die am IRF4 Promotor gebundenen Transkriptionsfaktoren in cHL-Zellen charakterisieren. Ebenso müssen Analysen der Funktion von IRF4 im cHL folgen.

IRF4 ist ein essentieller Faktor bei der B-Zell-Differenzierung zu Plasmazellen. Dabei aktiviert IRF4 den Trankriptionsfaktor XBP1 und hemmt transkriptionell den Centroblastenmarker BCL6 (Klein et al., 2006). Da die IRF4-Expression in den STAT6-siRNA-transfizierten L428-Zellen gehemmt ist, wäre eine Steigerung der BCL6-Expression durch das Fehlen des Repressors zu erwarten. Es zeigte sich jedoch in der qRT-PCR, dass die BCL6-Expression bei Hemmung von STAT6 erniedrigt war. IRF4 scheint also in den L428-Zellen keine Hemmung von BCL6 zu verursachen. In DLBCL-Zellinien wurden Mutationen in der IRF4 Bindungsstelle im Promotor von BCL6 gefunden, die zu einer verminderten transkriptionellen Hemmung von BCL6 durch IRF4 führen (Saito et al., 2007). BCL6 ist in etwa 25\% der cHL-Fälle exprimiert (Buettner et al., 2005; Natkunam et al., 2007). In den cHL-Fällen mit Koexpression von IRF4 und BCL6 wäre eine Mutationsanalyse der IRF4 Bindungsstelle im BCL6 Promotor sinnvoll.

BCL6 bindet an die gleichen DNA Sequenzen wie STAT6 und fungiert als kompetitiver transkriptioneller Repressor (Harris et al., 1999). Ob die Expression 
von BCL6 in den L428-Zellen zu einer Modulation der von STAT6 verursachten Genexpression führt, sollte ebenso überprüft werden.

In Abbildung 5.2 ist die mögliche Genregulation durch STAT6 in den L428-Zellen dargestellt.

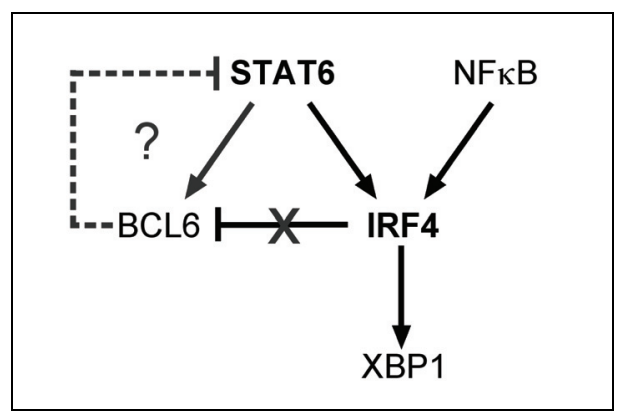

Abbildung 5.2 Schematische Darstellung der möglichen Genregulation von IRF4, BCL6 und XBP1 durch STAT6 in der cHL-Zelllinie L428. Die Expression der Faktoren IRF4, BLC6 und XBP1 wird durch die Hemmung STAT6 vermindert. IRF4 kann in B-Zellen die Expression von BCL6 hemmen und aktiviert XBP1. In den L428-Zellen scheint IRF4 die Expression von BCL6 nicht zu hemmen. Ebenfalls ist BCL6 ein transkriptioneller Repressor von STAT6 Zielgenen. Ob BCL6 in den L428-Zellen die Funktion von STAT6 an den Promotoren hemmt, ist unklar.

In T-Lymphozyten aktiviert IRF4 den Th2-spezifischen Transkriptionsfaktor GATA3 (Lohoff et al., 2002). GATA3 wird in den meisten cHL-Fällen exprimiert (Atayar et al., 2005). In der qRT-PCR konnte eine Reduktion von GATA3 in den STAT6siRNA-transfizierten L428-Zellen nachgewiesen werden.

Dies könnte bedeuten, dass IRF4 in den cHL-Zellen nicht nur B-Zell-spezifische Gene wie z.B. XBP1 aktiviert, sondern auch zur Expression von B-Zelluntypischen Genen wie GATA3 beiträgt. Pax5 unterdrückt in B-Zellen die Expression von B-Zell-untypischen Genen wie z.B. T-Zell- oder Makrophagenspezifische Gene (Cobaleda et al., 2007). Die Funktion von Pax5 wird im cHL aber durch die Expression von ID2 gehemmt (Mathas et al., 2006; Renne et al., 2006). Ebenfalls zeigen B-Lymphozyten von IRF4 ${ }^{-/-}$Mäusen eine vermehrte Expression von ID2 bei Stimulierung mit CD40 und IL-4 (Klein et al., 2006). Die verringerte Expression von IRF4 in den STAT6-siRNA-transfizierten L428-Zellen könnte somit zur höheren Expression von ID2 beitragen. Diese vermehrte ID2-Expression könnte zu einer verstärkten Inhibition von Pax5 führen, was zur verringerten Expression der transkriptionellen Ziele von Pax5 führt. Hierdurch könnte nicht nur der Verlust von B-Zell-typischen Genen, sondern auch die Expression der B-Zelluntypischen Gene wie GATA3 erklärt werden. IRF4 könnte eine zentrale Rolle in 
der Plastizität der cHL-Zellen spielen, da die hier durchgeführte Analyse nahelegt, dass sowohl Faktoren der B-Zell-Differenzierung als auch T-Zell-spezifische Faktoren durch IRF4 in den L428-Zellen reguliert werden.

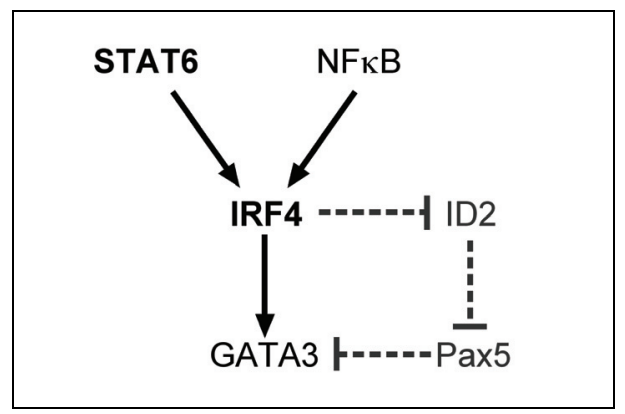

Abbildung 5.3 Schematische Darstellung der möglichen Regulationsvorgänge durch IRF4 in den L428-Zellen. Die Aktivierung von IRF durch STAT6 und NFKB könnte zur Aktivierung des Transkriptionsfaktors GATA3 beitragen. Dieser T-Zell-spezifische Faktor wird in B-Zellen von Pax5 unterdrückt. Die Funktion von Pax5 ist in $\mathrm{cHL}$-Zellen aber durch ID2 blockiert. Die verminderte Expression von IRF4 könnte zu einer erhöhten Expression von ID2 führen wie in IRF ${ }^{-/}$-B-Zellen ebenfalls gezeigt.

GATA3 aktiviert in Th2-Zellen eine Reihe von Zytokinen, die charakteristisch für das cHL sind (Zheng et al., 1997; Skinnider et al., 2002b). Darunter befindet sich auch das Zytokin IL-13, das als potenzieller autokriner Faktor für die Aktivierung von STAT6 in cHL-Zellen angesehen wird (Skinnider et al., 2002a). Im cHL könnte also STAT6 zur Aktivierung von IRF4 beitragen, das wiederum die Expression von GATA3 und respektiver Zytokinproduktion bewirkt. Diese Zytokine führen dann zu einer weiteren Aktivierung von STAT6 und bilden so eine autokrine Aktivierungsschleife.

Eine weitere Aktivierung dieser Schleife könnte durch die transkriptionelle Aktivierung der IL-13-Rezeptoruntereinheit IL-13Ra1 durch STAT6 in den cHLZellen entstehen. Die verminderte Expression von IL-13Ra1 in STAT6-siRNAtransfizierten L428-Zellen konnte durch die qRT-PCR bestätigt werden. Ebenso wurde in der cHL-Zellinie L1236 IL-13Ra1 als potenzielles STAT6 Zielgen identifiziert (Baus, 2005). Hierdurch könnte in den cHL-Zellen der IL-13/STAT6Signalweg weiter aktiviert werden. Der „Decoy“-Rezeptor von IL-13 IL-13Ra2 wurde bereits als STAT6 Zielgen beschrieben (David et al., 2003). Eine Hemmung dieses Gens konnte in der Genexpressionsanalyse nicht festgestellt werden. Eine endogene Expression des IL13Ra2 wurde in den Zelllinien L1236 und HDLM2 nicht nachgewiesen, so dass die negative Rückkopplungsschleife, die zur 
Deaktivierung des Signalwegs führt, in den cHL-Zellen nicht vorhanden sein könnte (Trieu et al., 2004).

Die Abbildung 5.4 fasst den möglichen Kreislauf der STAT6 Aktivierung zusammen. Es bedarf allerdings weiterer Analysen zur Überprüfung dieser Hypothesen und der Rolle von IRF4 im cHL.

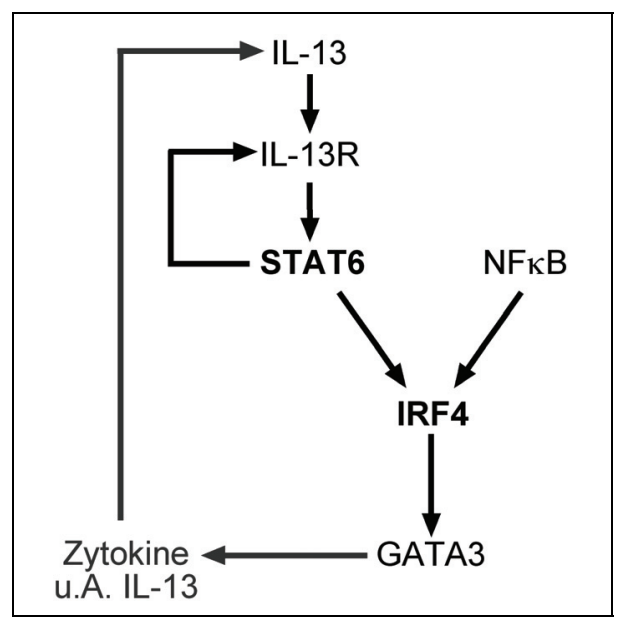

Abbildung 5.4 Schematische Darstellung der möglichen Aktivierungsschleife von STAT6 ausgehend von der Genexpressionsanalyse der STAT6-gehemmten L428-Zellen. Die Bindung von IL-13 an den Rezeptor aktiviert intrazellulär STAT6. STAT6 (zusammen mit NFkB) könnte IRF4 transkriptionell aktivieren und führt zur weiteren Expression des IL-13-Rezeptors. IRF4 wiederum aktiviert GATA3, ein Transkriptionsfaktor, der die Zytokin-Expression u.A. von IL-13 aktiviert.

Neben der differenziellen Expression der IL-13-Rezeptoruntereinheit IL13Ra1 konnte eine Aktivierung der IL-2-Rezeptoruntereinheit alpha (CD25) in den STAT6-siRNA-transfizierten Zellen nachgewiesen werden. Der IL-2-Rezeptor besteht aus den 3 Untereinheiten IL2R $\alpha$ (CD25), IL2R $\beta$ (CD122) und IL2R $\gamma$ (common gamma chain). Die Expression der CD25 Unterheit konnte im cHL nachgewiesen werden (Skinnider et al., 2002b). CD122 konnte in vielen CHLFällen sowie in den cHL-Zelllinien L428, KMH2 und HDLM2 gezeigt werden (Trümper et al., 1993). Die Expression von IL-2 konnte aber weder in den CHLZelllinien noch in Primärmaterial von cHL-Patienten detektiert werden (Skinnider et al., 2002b). Es wird daher angenommen, dass IL-2 kein autokriner Wachstumsfaktor im cHL ist. IL-2 könnte aber von den Tumor-umgebenden T-Zellen produziert werden und so eine Wirkung in den HRS-Zellen hervorrufen. Die Stimulation der cHL-Zelllinien mit IL-2 bewirkte aber keine Steigerung der Zellproliferation (Skinnider et al., 2002b). 
Wie die durchflusszytometrische Analyse zeigte, erhöht die Transfektion der STAT6-siRNA in die L428-Zellen die Expression von CD25. Hierdurch könnte das Antwortverhalten auf das Zytokin IL-2 moduliert werden oder vermehrt die lösliche Form von CD25 produziert werden.

Die Expression von CD25 konnte in der cHL-Zelllinie L428 durch verschiedene EBV Proteine gesteigert werden, einhergehend mit einer erhöhten Sekretion der löslichen Form von CD25 (Kube et al., 1999; Vockerodt et al., 2001). Der Serumwert der löslichen Form von CD25 hat einen negativen prognostischen Einfluss auf das Überleben der cHL-Patienten (Gause et al., 1992). Die Funktion der löslichen Form von CD25 könnte durch die Bindung von IL-2 die Proliferation der umgebenden T-Zellen reduzieren und somit immunsuppressiv wirken.

Neben der permanenten Aktivierung der STATs durch die Janus-Kinasen können potenziell auch RTKs an dieser Aktivierung beteiligt sein. Verschiedene RTKs konnten im cHL nachgewiesen werden (Renne et al., 2005). In diesem Zusammenhang wurde auch die Expression von EphB1 festgestellt. Die Familie der Eph-RTKs und ihre Liganden (Ephrine) haben eine essentielle Rolle in der Zellmigration und -adhäsion während der Entwicklung von Organismen. Ebenfalls wurde das Ephrin-System mit der Migration und Invasion von malignen Zellen in Verbindung gebracht (Campbell et al., 2008).

Für EphB1 wurde eine autokrine Aktivierung im $\mathrm{cHL}$ postuliert, da sowohl der Rezeptor als auch der Ligand EphrinB1 nachgewiesen werden konnte (Renne et al., 2005). Unklar bleibt jedoch, ob auch andere EphrinB-Liganden in den HRSZellen oder umgebenden Zellen produziert werden, da EphB1 mit allen EphrinBLiganden interagieren kann (Pasquale, 2004). Daher ist nicht auszuschließen, dass EphB1 auch bei der Interaktion der HRS-Zellen mit dem umgebenden Mikromillieu über andere EphrinB-Liganden eine Rolle spielt.

Die reduzierte Expression von EphB1 in den STAT6-siRNA-transfizierten Proben konnte nur in 3 von 5 Versuchsreplikaten nachgewiesen werden. Der Grund hierfür ist unklar. Weitere Versuche müssen durchgeführt werden, um die Regulation durch STAT6 zu bestätigen. Die in vitro Invasionsfähigkeit der L428Zellen wurde ebenfalls getestet, jedoch konnte kein Unterschied im Invasionsverhalten zwischen Kontroll-Proben und STAT6-siRNA-transfizierten L428-Zellen festgestellt werden. Der Einfluss von EphB1 in Bezug auf die 
Invasionsfähigkeit lässt sich aber hier nicht abschließend beurteilen, da diese Versuche auf Grund der limitierten Zellzahl unabhängig von den qRT-PCRAnalysen durchgeführt wurden. Weitere Versuche, in denen zuvor die EphB1Expression untersucht wurde, sollten hier in Bezug auf die Invasionsfähigkeit der cHL-Zellen durchgeführt werden.

Die Aktivität der RTKs wird vor allem von verschiedenen Proteintyrosinphosphatasen (PTPs) reguliert. Die Genexpressionsanalyse der STAT6-siRNA-transfizierten L428-Zellen ergab eine differenzielle Expression einer Reihe von PTPs. Mehr als 10 verschiedene PTPs waren dabei gehemmt bzw. aktiviert. STAT6 könnte somit eine zentrale Rolle bei der Regulation dieser PTPs haben, die wiederum diverse Signaltransduktionsvorgänge in den Zellen modulieren.

Unter diesen PTPs ist die PTPRK von besonderem Interesse, da hierzu bereits ein Zusammenhang mit dem cHL nachgewiesen werden konnte (Flavell et al., 2008). Die ektope Überexpression von PTPRK in der cHL-Zelllinie KMH2 führte zu einer Verminderung der Zellproliferation und Zellviabilität. Hemmung der endogenen PTPRK durch RNA-Interferenz zeigte wiederum eine gesteigerte Zellproliferation und Zellviabilität (Flavell et al., 2008). Ebenso konnte die Expression von PTPRK durch die Infektion der cHL-Zellen mit EBV vermindert werden. EBV könnte somit zum malignen Phänotyp der cHL-Zellen durch die verminderte Expression der PTPRK beitragen. Die hier gezeigte Aktivierung der PTPRK-Expression durch die Transfektion der STAT6-siRNA könnte bedeuten, dass STAT6 an der Expressionshemmung der PTPRK in den L428-Zellen beteiligt ist. Die Hemmung der PTPRK durch STAT6 könnte somit zur Proliferation und Überleben der cHLZellen beitragen.

Als Ziele der PTPRK sind verschiedene Komponenten von Signalwegen beschrieben. Neben den Tyrosinkinasen Src und EGFR kann der $\beta$-CateninSignalweg durch die PTPRK moduliert werden (Wang et al., 2005; Xu et al., 2005; Novellino et al., 2008). In weiterführenden Versuchen müssen die Ziele der PTPRK in den cHL-Zelllinien untersucht werden. Es muss dabei die Hypothese geprüft werden, ob die Aktivierung der RTKs im cHL durch die gehemmte Expression der PTPRK über STAT6 zustande kommen kann. 
Die Genexpressionsanalyse der STAT6-gehemmten L428-Zellen enthält weitere interessante Kandidatengene, die funktionell eine Rolle im cHL spielen könnten. Die Analysen der Faktoren c-CBL, A-Myb und CD23 zeigen, dass die Ergebnisse der Genexpressionsanalyse in vielen Fällen sowohl auf Transkript- als auch auf Proteinebene bestätigt werden können. In weiteren Analysen müssen diese Ergebnisse sowohl in anderen cHL-Zelllinien als auch in Tumorgewebe von cHLPatienten bestätigt werden. 


\subsection{Zytokin-Genvariationen in malignen Lymphomen}

Die Analyse von Genvariationen in malignen Lymphomerkrankungen soll zum Verständnis der Erkrankung und den unterschiedlichen Krankheitsverlauf der Patienten beitragen. Derzeit werden durch die Faktoren des IPI Patientencharakteristika beschrieben, die aber nicht die Biologie der Erkrankung erklären. Genvariationen können durch Änderung der Expression (z.B. regulatorische SNPs) oder der Funktion (z.B. codierende SNPs) der Genprodukte die Erkrankung beeinflussen.

Die hier analysierten Zytokin-Genvariationen könnten, durch die Bedeutung der Zytokine bei vielen physiologischen Vorgängen, mit dem Krankheitsverlauf der malignen Lymphome verbunden sein. Die Aktivierung des Jak-STAT-Signalwegs durch Zytokine kann zum Überleben und Proliferation der entarteten Zellen beitragen. Ebenso ist die Funktion der Zytokine bei der Interaktion zwischen Tumorzellen und nicht malignen Zellen entscheidend. So sind Zytokine essentielle Mediatoren von inflammatorischen Prozessen und an der Rekrutierung der entsprechenden Effektorzellen des Immunsystems an den Ort der Inflammation beteiligt. Sie führen aber auch zur Differenzierung der Lymphozyten innerhalb der adaptiven Immunantwort zu Effektorzellen mit spezifischen Funktionen. Darüber hinaus sind Zytokine an der Immunsuppression beteiligt, die wichtig für das Beenden der Immunantworten ist. Die koordinierte Expression der Zytokine sowie deren Rezeptoren ist essentiell für die Kommunikation zwischen verschiedenen Zellarten. Die Produktion von Zytokinen durch Tumorzellen kann diese Koordination stören und zu Prozessen führen, die von Vorteil für die Tumorzellen sind und so den Krankheitsverlauf der Patienten beeinflussen.

\subsubsection{IL-10-Genvariationen im malignen NHL}

Verschiedene proximale Genvariationen im 5'-flankierenden Bereich von IL-10 wurden mit dem Risiko der NHL Erkrankung sowie dem Krankheitsverlauf von malignen NHLs in Verbindung gebracht (Cunningham et al., 2003; Lech-Maranda et al., 2004). Diese Ergebnisse konnten jedoch in anderen Studien nicht bestätigt werden (Breen et al., 2003; Berglund et al., 2005). Arbeiten des internationalen Lymphomkonsortiums InterLymph zeigten einen Einfluss des distalen 
Polymorphismus IL-10_3538AT auf das Risiko einer NHL sowie DLBCL Erkrankung (Rothman et al., 2006). In einer Studie der Arbeitsgruppe Kube wurde sowohl der Einfluss der proximalen IL-10-Genvariationen als auch der Einfluss des distalen SNPs IL-10-3538AT auf das Risiko als auch den Krankheitsverlauf von malignen NHLs und des Subtyps DLBCL betrachtet (Kube et al., 2007). Weder ein Einfluss der Genvariationen auf das Risiko der Lymphomerkrankungen noch auf den Krankheitsverlauf konnte festgestellt werden. Das verwendete Patientenkollektiv der NHL-B1/B2-Studien der DSHNHL ist repräsentativ für maligne NHL Erkrankungen und zeichnet sich durch eine gleiche Behandlung der Patienten mit CHOP/CHOEP Therapieschema aus (Pfreundschuh et al., 2004a; Pfreundschuh et al., 2004b).

Die in dieser Arbeit durchgeführte Analyse der distalen IL-10-Genavariationen in malignen NHLs wurde ebenfalls im Patientenkollektiv der NHL-B1/B2-Studien durchgeführt. Neben der bereits erwähnten Repräsentativität der Studien, wurde hier die Analyse an einem großen Patientenkollektiv $(n=500)$ durchgeführt. Die Analyse der IL-10-Genvariationen zeigt, dass bestimmte distale IL-10Genvariationen mit dem Krankheitsverlauf der betrachteten NHL-Patienten korrelieren. Die homozygoten Träger der IL-10-7400Del Variante haben schlechtere Gesamtüberlebensraten (OS) als die Individuen, die durch die Genotypen IL-10-7400InDel und IL-10-7400InIn charakterisiert sind (Anhang 8.2 Fig. 2A). Die Individuen mit dem Haplotyp IL-10_6752TT, IL-10_6208CC, IL-10_3538AA (TCA/TCA) zeigen schlechtere Ereignis-freie Überlebensraten (EFS) (Anhang 8.2 Fig. 2F).

Die multivariate Analyse dieser Ergebnisse adjustiert auf die Risikofaktoren des IPI ergab für NHL-Patienten mit der IL-10-7400DelDel Genvariation ein 1,9-fach erhöhtes Risiko eines schlechten Krankeitsverlaufs. Dieses Ergebnis belegt die Unhabhängigkeit dieser Genvariation gegenüber den IPI Faktoren und es muss somit in weiteren Studien geprüft werden, ob die IL-10-7400InDel prognostisch für den klinischen Verlauf nutzbar ist. Hierbei ist allerdings zu beachten, dass die Frequenz der IL-10-7400Del Variante in der kaukasischen Bevölkerung relativ gering ist (ca. 3-4\%). Somit käme die zu definierende Subgruppe der NHL-Patienten mit schlechtem Krankheitsverlauf nur sehr selten vor, was die klinische Relevanz fraglich gestaltet.

Ebenfalls müssen diese Ergebnisse in Bezug auf die IL-10 Produktion betrachtet werden. Die in vitro Produktion von IL-10 kann durch verschiedene 
Promotorgenvariationen beeinflusst sein (Turner et al., 1997; Westendorp et al., 1997; Crawley et al., 1999; Gibson et al., 2001; Mörmann et al., 2004; Rieth et al., 2004). Der IL-10-7400DelDel Genotyp konnte mit einer hohen IL-10-Expression und der TCA Haplotyp mit einer mittelhohen IL-10-Expression in Verbindung gebracht werden (Mörmann et al., 2004; Rieth et al., 2004). Inwiefern die Ergebnisse der Analyse der Genvariationen mit dem IL-10 Serumwert der NHL-Patienten korreliert, ist unklar. Dennoch stimmen die Ergebnisse der in vitro Analysen und der Einfluss der Genvariationen auf das Überleben der NHL-Patienten mit der Beobachtung überein, dass ein hoher IL-10 Serumwert in NHL-Patienten einen negativen prognostischen Einfluss hat (Blay et al., 1993; Sarris et al., 1999; Bohlen et al., 2000; Vassilakopoulos et al., 2001; Aydin et al., 2002).

Die Wirkung von IL-10 in der malignen NHL Erkrankung ist unklar. IL-10 ist ein Wachstumsfaktor für B-Lymphozyten (Benjamin et al., 1994). Durch Abstammung der meisten NHLs aus B-Lymphozyten könnte IL-10 eine Wirkung auf die Lymphomzellen haben, was die Vermehrung der Lymphomzellen anregen würde und so den aggressiven Verlauf der Lymphomerkrankung beschleunigen könnte.

Ausserdem ist IL-10 ein immunsupprimierendes Zytokin (Moore et al., 2001). Die hohe Expression in Lymphompatienten könnte somit dazu beitragen, dass die Tumorzellen nicht durch das Immunsystem eliminiert werden können und dies zu einem schlechteren klinischen Verlauf führt. IL-10 ist auch an der Differenzierung von T-Lymphozyten zu den immunsuppressiven $T_{\text {regs }}$ beteiligt (Moore et al., 2001). In einer kürzlich erschienenen Arbeit konnte gezeigt werden, dass der Anteil der $\mathrm{T}_{\text {regs }}$ in NHL-Patienten erhöht ist und das die Menge der $\mathrm{T}_{\text {regs }}$ mit dem klinischen Verlauf korreliert (Mittal et al., 2008). Somit könnte die genetisch vererbte Kapazität IL-10 zu produzieren über die Menge der $\mathrm{T}_{\text {regs }}$ mit dem klinischen Verlauf der NHL-Patienten verbunden sein.

Ungeklärt ist aber, welche Zellen im Lymphomgewebe IL-10 produzieren und welche den Rezeptor für IL-10 tragen. Dies ließe sich durch immunhistochemische Färbungen auf histologischen Gewebsschnitten von NHL-Patienten klären. Die Färbung von IL-10 ist schwierig, da Zytokine zum einen instabile Proteine sind und zum anderen durch die Sezernierung von IL-10, die IL-10 produzierende Zelle nicht unbedingt identifiziert werden kann. Bei der Färbung des IL-10-Rezeptors wäre vor allem die Frage interessant, ob hauptsächlich die Lymphomzellen, die Lymphom-assoziierten Zellen oder beide den Rezeptor tragen. Daraus ließe sich 
schließen, an welche Zellen IL-10 hauptsächlich bindet und demnach wirkt. Bei einem ausreichend großen Patientenkollektiv ließen sich weitere Hypothesen testen wie z.B. die Korrelation zwischen Krankheitsverlauf und den unterschiedlichen Gruppen der IL-10-Rezeptor-Expression (Lymphom, Lymphomassoziiert, beides) oder die Korrelation der IL-10-Genvariationen und der Menge der Lymphom-assoziierten $\mathrm{T}_{\text {regs }}$ oder anderen umgebenden Zelltypen wie z.B. Makrophagen.

\subsubsection{Variationen in Th2-Zytokin- und Zytokinrezeptorgenen im DLBCL} Die Analyse der IL-10-Genvariationen in den 500 Patienten mit malignen NHL wurde ebenso in der NHL-Subgruppe der DLBCLs $(\mathrm{N}=319)$ durchgeführt (Anhang 8.2) (Kube et al., 2008). Dabei wurden keine Assoziationen der Genvariationen mit dem Überleben der DLBCL-Patienten festgestellt. Aus diesem Grund wurden weitere Genvariationen von Zytokinen und ihren Rezeptoren in DLBCL-Patienten analysiert.

Im Rahmen von Th2-Immunreaktionen werden über die Zytokine IL-4 und IL-13 Prozesse der Keimzentrumsreaktion ausgelöst. So ist z.B. das IL-4 induzierte Gen AICDA an der somatischen Hypermutation und dem Ig-Isotypenklassenwechsel beteiligt (Dedeoglu et al., 2004; Pasqualucci et al., 2004). Diese Prozesse spielen auch bei der Lymphomagenese des DLBCLs eine entscheidende Rolle und könnten den klinischen Verlauf der Erkrankung beeinflussen (Pasqualucci et al., 2001; Lu et al., 2005). Darüber hinaus konnte eine unterschiedliche Aktivierung von Signalwegen durch IL-4 in den Zelllinien der DLBCL Subgruppen GCB und ABC nachgewiesen werden (Lu et al., 2005). In GCB-DLBCL-Zelllinien wird durch IL-4 hauptsächlich STAT6 aktiviert, was zu einer Erhöhung der Zellproliferation führt. In ABC-DLBCL-Zelllinien wird durch IL-4 hautpsächlich der AKT-Signalweg aktiviert und die Proliferation der Zellen gesenkt. Darüber hinaus wird der IL-4Ra in GCB-DLBCLs gegenüber den ABC-DLBCLs vermehrt exprimiert (Lu et al., 2005).

In dieser Arbeit wurden Polymorphismen der Schlüsselelemente der Th2Immunantwort IL-4, IL-13 und deren Rezeptor IL-4Ra in DLBCL-Patienten untersucht. Es konnte ein Einfluss des IL-4Ra ${ }_{175 V}$-Polymorphismus auf das 
Überleben der untersuchten DLBCL-Patienten festgestellt werden. Patienten, die durch die Isoleucin-Variante (homozygot IL-4Ra $175 \mathrm{~V}-\mathrm{A}$ ) charakterisiert sind, haben dabei einen besseren Krankheitsverlauf als die Individuen mit mindestens einer Valin-Variante (IL-4Ra|175V-AG und IL-4Ra|175V-GG). In der multivariaten Analyse, adjustiert auf die Faktoren des IPI, ergab sich ein 1,9-fach erhöhtes Risiko einer schlechten Prognose im Gesamtüberleben für Patienten, die durch die ValinVarianten (IL-4Ra $\left.\right|_{175 V-A G}$ und IL-4Ra $a_{175 V-G G}$ ) charakterisiert sind. Dieser Wert liegt im Bereich der relativen Risiken der IPI-Faktoren. Der IL-4Ra $a_{175 V}$-Polymorphismus könnte somit als unabhängiger Risikofaktor für das Überleben der DLBCLPatienten dienen. Dieses Ergebnis muss aber in unabhängigen Studien bestätigt werden. Hierzu würde sich die kürzlich veröffentlichte RICOVER Studie der DSHNHL anbieten, da sich hier gleichzeitig der Einfluss des zur Therapie hinzugefügten Rituximab Antikörpers auf die hier erzielten Ergebnisse analysieren ließe (Pfreundschuh et al., 2008).

Die anderen untersuchten Polymorphismen IL-4Ra S503P, IL-4Ra $_{\text {Q576R, IL-4_-524CT }}$ und IL-13-1069CT zeigten keine signifikanten Auswirkungen auf das Überleben der DLBCL-Patienten. Bei Betrachtung der 3-Jahresschätzer fallen jedoch Unterschiede bei den Polymorphismen IL-4Ra ${ }_{S 503 P}$, IL-4Ra $a_{\text {Q576R }}$ und IL-4-524CT in den Überlebensraten der Patienten auf (Tabelle 4.6). Bei den SNPs IL-4Ra $a_{5503 P}$ und IL-4Ra ${ }_{\text {Q576R }}$ haben Individuen homozygot für das Minor-Allel und beim IL-4-524CT Träger homozygot für das Major-Allel geringere Überlebensraten im Vergleich zu den anderen beiden Genotypen. Da aber die Frequenz der MinorAllele bei diesen Polymorphismen nur sehr gering ist, wurde hier keine statistische Signifikanz erreicht. Allerdings sollte in einer größeren Studie überprüft werden, ob der Unterschied in den Überlebensraten bei entsprechender Fallzahl zu manifestieren ist. Der Promotorpolymorphismus von IL-13 zeigte keine tendenziellen Unterschiede im Überleben der DLBCL-Patienten, so dass davon auszugehen ist, dass dieser SNP keinen Einfluss auf den Krankheitsverlauf der DLBCL-Patienten hat.

Auf Grund des negativen Einflusses des löslichen IL-4R im Patientenserum auf das Überleben der DLBCL-Patienten, wurden in dieser Arbeit die verschiedenen Genotypen der IL-4Ra $175 \mathrm{~V}$ Genvariation in Kombination mit dem sIL-4R-Serumwert in den DLBCL-Patienten analysiert. Diese Aufgliederung in Patienten mit hohem bzw. niedrigem sIL-4R-Serumgehalt unterteilt die DLBCL-Patienten in weitere 
Subgruppen mit unterschiedlichem Krankheitsverlauf. Patienten, die einen hohen sIL-4R-Serumwert und den negativen Einfluss der IL-4Ra ${ }_{175 V}$ Valin-Varianten (IL4Ra $a_{175 V-A G}$ und IL-4Ra $\left.a_{175 V-G G}\right)$ haben, zeigten die schlechtesten Überlebensraten. Patienten mit niedrigen sIL-4R-Serumwerten und der IL-4Ra ${ }_{175 \mathrm{~V}}$ Isoleucin-Variante (IL-4Ra I75V-AA $\left._{1}\right)$ haben hierbei die höchsten Überlebensraten. Mit dieser kombinierten Analyse aus einem Serumwert, der den aktuellen Status des Patienten widerspiegelt, und einem ererbten genetischen Parameter, der den Krankheitsverlauf beeinflusst, lässt sich in dieser Analyse für etwa $20 \%$ der DLBCL-Patienten ein guter und für etwa $16 \%$ der Patienten ein schlechter Krankheitsverlauf feststellen. Auch wenn dieses Ergebnis in der multivariaten Analyse nicht signifikant ist, könnten kombinatorische Analysen wie diese in Zukunft neue Ansätze der Risikobewertung für Lymphompatienten bieten.

Im Gegensatz zu den Promotorpolymorphismen, die sich auf die Expression der Gene auswirken können, können codierende Polymorphismen, die zu einem Aminosäureaustausch im Protein führen, sich auf die Funktion, Stabilität sowie Lokalisation des Proteins auswirken. Der funktionelle Unterschied zwischen der Isoleucin- und der Valin-Variante des IL-4Ra $a_{175 V}$-Polymorphismus ist bisher noch unzureichend verstanden. Trotz des einfachen Austauschs einer aliphatischen Aminosäure (Isoleucin) gegen eine andere (Valin) scheint sich dieser Austausch auf die Signaltransduktion des IL-4Ra auszuwirken (Mitsuyasu et al., 1998; Stephenson et al., 2004). Es konnte für die Isoleucin Variante eine verstärkte Aktivierung von STAT6 nachgewiesen werden. Eine mögliche Erklärung könnte die veränderte Affinität zu IL-4 sein, wie sie im Mausmodel für die Variation IL4Ra $\mathrm{R}_{\mathrm{T} 4 \mathrm{I}}$ (auch T49l genannt bei Subtraktion der 15 Aminosäuren des Signalpeptids) beschrieben worden ist (Shirakawa et al., 2000). Neben strukturellen Veränderungen des Rezeptors gibt es Hinweise auf eine Kopplung zwischen der IL-4Ra ${ }_{175 V}$ Genvariation und einem IL-4Ra Promotorpolymorphismus, der die Expression des IL-4Ra Gens beeinflussen könnte (Hackstein et al., 2001). Ein Promotorpolymorphismus des IL-4Ra wurde breits mit dem Risiko einer T-NHL-Erkrankung in Verbindung gebracht (Lan et al., 2006). Kürzlich konnte der gleiche Promotorpolymorphismus des IL-4Ra mit dem Krankheitsverlauf von DLBCL-Patienten korreliert werden (Habermann et al., 2008). Diese Ergebnisse unterstreichen, dass Genvariationen des IL-4Ra für die 
Inzidenz sowie den Verlauf von Lymphomerkrankungen von Bedeutung sein könnten.

Der IL-4Ra ${ }_{175 V}$-Polymorphismus wurde mit verschiedenen virale Erkrankungen, wie z.B. dem Gebärmutterhalskrebs, AIDS und Respiratory-Syncytial-Virus Bronchiolitis in Verbindung gebracht (Hoebee et al., 2003; Soriano et al., 2005; Ivansson et al., 2007). Virale Infektionen werden hauptsächlich durch Th1-Immunantworten beseitigt, so dass es möglich ist, dass der IL-4Ra $a_{175 V}$ Polymorphismus einen Einfluss auf das Th1/Th2-Gleichgewicht hat (Ivansson et al., 2007). Ein ebensolches Ungleichgewicht wurde in DLBCL-Patienten beschrieben (Mori et al., 2001). Somit könnte die veränderte Expression von Zytokinen oder die Veränderung der Reaktion auf die Zytokinproduktion zu Prozessen führen, die den Krankheitsverlauf von DLBCL-Patienten beeinflusst. Daher könnten genetische Variationen innerhalb dieser Elemente einen Einfluss auf die Prognose von DLBCL-Patienten haben, wie hier für den IL-4Ra ${ }_{175 V}$ Polymorphismus gezeigt. 


\subsection{Ausblick}

Die Aktivierung der Janus-Kinasen in den CHL-Zellen bietet die Möglichkeit einer zielgerichteten Hemmung, die auch in der Therapie der cHL-Patienten von Bedeutung sein könnte. Die Entwicklung neuer Therapien, die gezielt auf Tumorassoziierte Strukturen gerichtet ist, soll die Therapie-bedingten Toxizitäten sowie die Anzahl der Lymphompatienten, die nicht auf die konventionelle Chemo- und Strahlentherapie ansprechen, verringern. Weitere Untersuchungen müssen folgen, um zu klären, welche Janus-Kinasen jeweils an der Aktivierung der verschiedenen STAT-Transkriptionsfaktoren beteiligt sind. Ebenso muss geklärt werden, welche Zytokine zur Aktivierung der einzelnen Janus-Kinasen führen. Diese Analysen können dazu beitragen die zentralen Janus-Kinasen zu identifizieren, so dass eine spezifischere Intervention möglich ist. Ebenso müssen die kürzlich in der Literatur beschriebenen autokrinen Aktivatoren von STAT3 und STAT6 im cHL - IL-13 und IL-21 - als Ziele im Rahmen einer Antikörper-vermittelten Therapie untersucht werden.

Die in dieser Arbeit gezeigte Abhängigkeit des Jak-STAT-Signalweg von HSP90 bietet einen neuen Therapieansatz für cHL-Patienten, da für HSP90 bereits Hemmstoffe in der klinischen Erprobung sind. Diese Ergebnisse sind nicht nur für cHL-Patienten von Bedeutung, sondern auch in anderen Tumorentitäten, die eine permanente Aktivierung des Jak-STAT-Signalwegs aufweisen. In den hier durchgeführten Analysen gab es zwischen dem HSP90-Inhibitor 17-AAG und der RNA-Interferenz gegen HSP90 Unterschiede in der Minderung der Proteinmenge von Jak2 in zwei cHL-Zelllinien. Hier muss weitergehend untersucht werden, wie es zu dieser unterschiedlichen Wirkung kommt.

Die potenziellen STAT6 Zielgene, die in dieser Arbeit identifiziert wurden, enthalten eine Vielzahl von Genen, die für den malignen Phänotyp der cHL-Zellen von Bedeutung sein könnten. Diese Ergebnisse legen die Grundlage für eine weitere funktionelle Analyse der Faktoren in den Zellen des cHLs. Dazu sollten die direkten Zielgene von STAT6 durch Chromatin-Immunpräzipitationen identifiziert werden und ihre Funktion durch Hemmung bzw. erhöhter Expression untersucht werden. 
Insbesondere muss dabei IRF4 in den cHL-Zellen näher untersucht werden. In weiteren Analysen muss die Aktivierung von IRF4 über STAT6 bzw. NFкB durch Chromatin-Immunpräzipitation charakterisiert werden. Ebenso muss die Beteiligung von IRF4 an der aberranten Expression des Transkriptionsfaktors GATA3 und respektiver Zytokinproduktion untersucht werden. Dabei sollte ebenso analysiert werden, ob diese Faktoren an der autokrinen Aktivierung von STAT6 über IL-13 beteiligt sind. In diesem Zusammenhang muss auch die Aktivierung der IL-13-Rezeptoruntereinheit IL13Ra1 durch STAT6 weiter analysiert werden, da hierdurch eine weitere Aktivierung von STAT6 durch die autokrine Schleife zustande kommen könnte.

Weitere Faktoren, die als STAT6 Zielgene näher untersucht werden müssen, sind der transkriptionelle Repressor BCL6, die RTK EphB1 sowie die Proteintyrosinphosphatase PTPRK. Diese Faktoren könnten mit der Aufrecherhaltung des malignen Phänotyps in den cHL-Zellen verbunden sein und bedürfen so einer näheren Betrachtung.

Durch die in dieser Arbeit durchgeführte Methode der Genexpressionsanalyse konnten keine signifikant differenziell exprimierten Gene bei der Hemmung des Transkriptionsfaktors STAT3 identifiziert werden. Auch hier müssen weitere Analysen folgen, da dieser Faktor permanent aktiviert ist und ein Zusammenhang mit der Proliferation der Zellen mehrfach dargestellt werden konnte (Kube et al., 2001a; Holtick et al., 2005; Baus et al., 2006). Hier wäre ein alternativer experimenteller Ansatz wie z.B. die „ChIP-on-Chip“-Technologie eine Möglichkeit zur Identifizierung der transkriptionellen Ziele von STAT3.

Die Analyse der Genvariationen der Zytokine und Zytokinrezeptoren führte zur Identifizierung von Polymorphismen, die mit dem Überleben von NHL- bzw. DLBCL-Patienten korrelieren. Diese Ergebnisse müssen in weiteren unabhängigen Studien validiert werden. Hierfür bietet sich die RICOVER Studie der DSHNHL an, in der die CHOP-Therapie mit der CHOP-Therapie im Zusatz von Rituximab in Patienten mit malignen NHL verglichen wurde (Pfreundschuh et al., 2008). Dabei könnte neben der Validierung der Ergebnisse in Patienten, die nach CHOP-Therapie behandelt wurden, auch der Einfluss der Genvariationen auf das Überleben der Patienten in der neuen Standardtherapie mit Rituximab untersucht werden. Zukünftig könnten nach den Validierungsstudien diese 
Genvariationen als prognostische Marker neben den Faktoren des IPI für Lymphomentitäten eingeführt werden.

Weiterführend müssen die funktionellen Aspekte der Polymorphismen untersucht werden. Die Promotorpolymorphismen von IL-10 können die Expression von IL-10 beeinflussen. Der zu Grunde liegende Mechanismus ist aber weitgehend unverstanden und bedarf weiterer Analysen. Ebenfalls wäre die Untersuchung der Lokalisation des IL-10-Rezeptors in Tumorgeweben von Lymphompatienten sinnvoll, da man unterscheiden könnte, ob der IL-10-Rezeptor hauptsächlich auf den Tumorzellen oder den Tumor-umgebenden Zellen vorhanden ist. Darüber können Erkenntnisse gewonnen werden, die die Wirkung von IL-10 als Wachstumsfaktor der Lymphomzellen von der immunsuppressiven Wirkung von IL-10 auf die Tumor-umgebenden Zellen trennen.

Der codierende Polymorphismus des IL-4-Rezeptors alpha 175V hat Auswirkungen auf die intrazelluläre Signaltransduktion des Rezeptors. Es wäre interessant zu untersuchen, wie dies zur Veränderung der Überlebensraten von DLBCLPatienten führt. Der Polymorphismus könnte zu einer Veränderung der Balance zwischen Th1- und Th2-Immunantworten führen, die die Beseitigung der Tumorzellen durch das Immunsystem beeinflussen. Auch hier wäre es von großem Interesse zu untersuchen, welche Zellen im Tumorgewebe den IL-4Rezeptor exprimieren, um zu definieren, ob hauptsächlich die Tumorzellen oder die Tumor-umgebenden Zellen durch die IL-4Ra Genvariation beeinflusst werden. Ebenso wäre eine Analyse der IL-4Ra Genvariation in den DLCBL Subgruppen GCB und $A B C$ sinnvoll, da hier konträre Wirkungen von IL-4 auf die Lymphomzellen postuliert wurden (Lu et al., 2005). Da die Genvariation IL-4Ra|175V die Signaltransduktion des Rezeptors modulieren könnte, wäre es von großem Interesse, ob es hierbei Unterschiede zwischen GCB- und ABC-DLBCLs gibt. Dies ließe sich durch immunhistochemische Färbungen auf „tissue Microarrays" von Tumorgeweben der Lymphompatienten durchführen. 


\section{ZUSAMMENFASSUNG}

Die derzeitige Therapie von Lymphompatienten ist mit einer hohen Belastung an Nebenwirkungen sowie Therapie-assoziierten Sekundärneoplasien verbunden. Ebenfalls sind Risikofaktoren, die den Verlauf der Erkrankungen beeinflussen, unzureichend definiert. Um eine Verbesserung der Therapie zu erreichen, müssen biologische Faktoren identifiziert werden, die Einfluss auf die Lymphomerkrankung nehmen und als Ziele in der Therapie dienen können. In dieser Arbeit wurden unter diesen Aspekten Zytokine und die respektive Signaltransduktion über den Jak-STAT-Signalweg untersucht.

Im ersten Teil konnte die Aktivierung der Janus-Kinasen in den Zelllinien des klassischen Hodgkin-Lymphoms (cHL) nachgewiesen werden. Des Weiteren konnte gezeigt werden, dass die Hemmung des Chaperon HSP90 durch das Geldanamycin-Derivat 17-AAG oder RNA-Interferenz gegen HSP90 zu einer Hemmung des Jak-STAT-Signalwegs einhergehend mit einer reduzierten Proliferation der cHL-Zellen führt.

Im zweiten Teil der Arbeit konnten durch Genexpressionsanalysen Zielgene von STAT6 im cHL identifiziert und teilweise validiert werden. Unter diesen Genen sind vor allem der Transkriptionsfaktor IRF4, die IL-13-Rezeptoruntereinheit IL13Ra1, die Rezeptortyrosinkinase EphB1 und die Proteinphosphatase PTPRK zu erwähnen. Diese Faktoren könnten mit dem malignen Phänotyp der Zellen verbunden sein und neue Ziele im Sinne einer Therapieoptimierung werden.

Im dritten Teil der Arbeit konnte eine Korrelation zwischen vererbten Variationen in Zytokin- und Zytokinrezeptorengenen und dem Verlauf von Lymphomerkrankungen dargestellt werden. Hierbei ergab sich für die distale IL-10 Promotorgenvariation IL-10-7400Del ein schlechterer Krankheitsverlauf für Patienten mit malignen NHL und ein besserer Krankheitsverlauf für Patienten mit DLBCL, die eine IL-4-Rezeptor alpha Genvariante tragen. Es muss nun in zusätzlichen Studien geprüft werden, ob diese Variationen als prognostische Marker zusätzlich zum International Prognostic Index einsetzbar sind.

Die Ergebnisse dieser Arbeit belegen die Bedeutung von Zytokinen und ihrer Signaltransduktion im Sinne einer Entwicklung neuer Therapien und der Risikoabschätzung von Lymphompatienten. 


\section{LITERATURVERZEICHNIS}

Adams, C., D. J. Aldous, S. Amendola, P. Bamborough, et al. (2003). "Mapping the kinase domain of Janus Kinase 3." Bioorganic \& Medicinal Chemistry Letters 13(18): 3105-3110.

Aldinucci, D., K. Olivo, D. Lorenzon, D. Poletto, et al. (2005). "The role of interleukin-3 in classical Hodgkin's disease." Leuk Lymphoma 46(3): 30311.

Alizadeh, A. A., M. B. Eisen, R. E. Davis, C. Ma, et al. (2000). "Distinct types of diffuse large B-cell lymphoma identified by gene expression profiling." Nature 403(6769): 503-11.

Ammirante, M., A. Rosati, A. Gentilella, M. Festa, et al. (2008). "The activity of hsp90 alpha promoter is regulated by NF-kappa B transcription factors." Oncogene 27(8): 1175-8.

Atayar, C., S. Poppema, T. Blokzijl, G. Harms, et al. (2005). "Expression of the Tcell transcription factors, GATA-3 and T-bet, in the neoplastic cells of Hodgkin lymphomas." Am J Pathol 166(1): 127-34.

Aydin, F., M. Yilmaz, F. Ozdemir, H. Kavgaci, et al. (2002). "Correlation of serum IL-2, IL-6 and IL-10 levels with International Prognostic Index in patients with aggressive non-Hodgkin's lymphoma." Am J Clin Oncol 25(6): 570-2.

Bargou, R., F. Emmerich, D. Krappmann, K. Bommert, et al. (1997a). "Constitutive nuclear factor-kappab-RelA activation is required for proliferation and survival of Hodgkin's disease tumor cells." Journal of Clinical Investigation 100(12): 2961-2969.

Bargou, R. C., F. Emmerich, D. Krappmann, K. Bommert, et al. (1997b). "Constitutive NFkB-RelA activation is required for proliferation and survival of Hodgkin disease tumor cells." J Clin Invest 100: 2961-2974.

Batzler, W. U., K. Giersiepen, S. Hentschel, G. Husmann, et al. (2008). "Cancer in Germany, 2003 - 2004. Incidence and Trends. Sixth edition." Robert Koch Institute (ed.) and Association of Population-based Cancer Registries in Germany (ed.).

Baus, D. (2005). "Die Bedeutung des JAK/STAT-Signalweges für die Pathogenese des klassischen Hodgkin-Lymphoms." Dissertation, Johann Wolfgang Goethe-Universität, Frankfurt am Main.

Baus, D. and E. Pfitzner (2006). "Specific function of STAT3, SOCS1, and SOCS3 in the regulation of proliferation and survival of classical Hodgkin lymphoma cells." Int J Cancer 118(6): 1404-13. 
Baxter, E. J., L. M. Scott, P. J. Campbell, C. East, et al. (2005). "Acquired mutation of the tyrosine kinase JAK2 in human myeloproliferative disorders." Lancet 365(9464): 1054-61.

Benjamin, D., C. D. Park and V. Sharma (1994). "Human B cell interleukin 10." Leuk Lymphoma 12(3-4): 205-10.

Berglund, M., U. Thunberg, G. Roos, R. Rosenquist, et al. (2005). "The interleukin10 gene promoter polymorphism (-1082) does not correlate with clinical outcome in diffuse large B-cell lymphoma." Blood 105(12): 4894-5; author reply 4895.

Blay, J. Y., N. Burdin, F. Rousset, G. Lenoir, et al. (1993). "Serum interleukin-10 in non-Hodgkin's lymphoma: a prognostic factor." Blood 82(7): 2169-74.

Blum, K. A., J. L. Johnson, D. Niedzwiecki, G. P. Canellos, et al. (2007). "Single agent bortezomib in the treatment of relapsed and refractory Hodgkin lymphoma: cancer and leukemia Group B protocol 50206." Leuk Lymphoma 48(7): 1313-9.

Bohlen, H., M. Kessler, M. Sextro, V. Diehl, et al. (2000). "Poor clinical outcome of patients with Hodgkin's disease and elevated interleukin-10 serum levels. Clinical significance of interleukin-10 serum levels for Hodgkin's disease." Ann Hematol 79(3): 110-3.

Bradford, M. M. (1976). "A rapid and sensitive method for the quantitation of microgram quantities of protein utilizing the principle of protein-dye binding." Anal Biochem 72: 248-54.

Bräuninger, A., R. Schmitz, D. Bechtel, C. Renne, et al. (2006). "Molecular biology of Hodgkin's and Reed/Sternberg cells in Hodgkin's lymphoma." Int J Cancer 118(8): 1853-61.

Breen, E. C., W. J. Boscardin, R. Detels, L. P. Jacobson, et al. (2003). "NonHodgkin's B cell lymphoma in persons with acquired immunodeficiency syndrome is associated with increased serum levels of IL10, or the IL10 promoter -592 C/C genotype." Clin Immunol 109(2): 119-29.

Broemer, M., D. Krappmann and C. Scheidereit (2004). "Requirement of Hsp90 activity for IkappaB kinase (IKK) biosynthesis and for constitutive and inducible IKK and NF-kappaB activation." Oncogene 23(31): 5378-86.

Buettner, M., A. Greiner, A. Avramidou, H. M. Jack, et al. (2005). "Evidence of abortive plasma cell differentiation in Hodgkin and Reed-Sternberg cells of classical Hodgkin lymphoma." Hematol Oncol 23(3-4): 127-32.

Buglio, D., G. Georgakis and A. Younes (2007). "Novel small-molecule therapy of Hodgkin lymphoma." Expert Rev Anticancer Ther 7(5): 735-40. 
Buglio, D., G. V. Georgakis, S. Hanabuchi, K. Arima, et al. (2008). "Vorinostat inhibits STAT6-mediated TH2 cytokine and TARC production and induces cell death in Hodgkin lymphoma cell lines." Blood 112(4): 1424-33.

Cairns, J. A. and J. Gordon (1990). "Intact, 45-kDa (membrane) form of CD23 is consistently mitogenic for normal and transformed B lymphoblasts." Eur $\mathrm{J}$ Immunol 20(3): 539-43.

Campbell, T. N. and S. M. Robbins (2008). "The Eph receptor/ephrin system: an emerging player in the invasion game." Curr Issues Mol Biol 10(1-2): 61-6.

Catlett-Falcone, R., T. H. Landowski, M. M. Oshiro, J. Turkson, et al. (1999). "Constitutive activation of Stat3 signaling confers resistance to apoptosis in human U266 myeloma cells." Immunity 10(1): 105-15.

Chanock, S. (2001). "Candidate genes and single nucleotide polymorphisms (SNPs) in the study of human disease." Dis Markers 17(2): 89-98.

Cobaleda, C., A. Schebesta, A. Delogu and M. Busslinger (2007). "Pax5: the guardian of B cell identity and function." Nat Immunol 8(5): 463-70.

Cochet, O., C. Frelin, J. F. Peyron and V. Imbert (2006). "Constitutive activation of STAT proteins in the HDLM-2 and L540 Hodgkin lymphoma-derived cell lines supports cell survival." Cell Signal 18(4): 449-55.

Couper, K. N., D. G. Blount and E. M. Riley (2008). "IL-10: the master regulator of immunity to infection." J Immunol 180(9): 5771-7.

Crawley, E., R. Kay, J. Sillibourne, P. Patel, et al. (1999). "Polymorphic haplotypes of the interleukin-10 5' flanking region determine variable interleukin-10 transcription and are associated with particular phenotypes of juvenile rheumatoid arthritis." Arthritis Rheum 42(6): 1101-8.

Cunningham, L. M., C. Chapman, R. Dunstan, M. C. Bell, et al. (2003). "Polymorphisms in the interleukin 10 gene promoter are associated with susceptibility to aggressive non-Hodgkin's lymphoma." Leuk Lymphoma 44(2): $251-5$.

Daub, H., K. Specht and A. Ullrich (2004). "Strategies to overcome resistance to targeted protein kinase inhibitors." Nat Rev Drug Discov 3(12): 1001-10.

Dave, S. S., K. Fu, G. W. Wright, L. T. Lam, et al. (2006). "Molecular diagnosis of Burkitt's lymphoma." N Engl J Med 354(23): 2431-42.

David, M. D., J. Bertoglio and J. Pierre (2003). "Functional characterization of IL13 receptor alpha2 gene promoter: a critical role of the transcription factor STAT6 for regulated expression." Oncogene 22(22): 3386-94.

Dedeoglu, F., B. Horwitz, J. Chaudhuri, F. W. Alt, et al. (2004). "Induction of activation-induced cytidine deaminase gene expression by IL-4 and CD40 
ligation is dependent on STAT6 and NFkappaB." Int Immunol 16(3): 395404.

Diehl, V., H. H. Kirchner, M. Schaadt, C. Fonatsch, et al. (1981). "Hodgkin's disease: establishment and characterization of four in vitro cell lies." J Cancer Res Clin Oncol 101(1): 111-24.

Dikic, I., I. Szymkiewicz and P. Soubeyran (2003). "Cbl signaling networks in the regulation of cell function." Cell Mol Life Sci 60(9): 1805-27.

Dong, C. (2008). "TH17 cells in development: an updated view of their molecular identity and genetic programming." Nat Rev Immunol 8(5): 337-48.

Drexler, H. G., G. Gaedicke, M. S. Lok, V. Diehl, et al. (1986). "Hodgkin's disease derived cell lines HDLM-2 and L-428: comparison of morphology, immunological and isoenzyme profiles." Leuk Res 10(5): 487-500.

Dutton, A., G. M. Reynolds, C. W. Dawson, L. S. Young, et al. (2005). "Constitutive activation of phosphatidyl-inositide 3 kinase contributes to the survival of Hodgkin's lymphoma cells through a mechanism involving Akt kinase and mTOR." J Pathol 205(4): 498-506.

Eskdale, J., G. Gallagher, C. L. Verweij, V. Keijsers, et al. (1998). "Interleukin 10 secretion in relation to human IL-10 locus haplotypes." Proc Natl Acad Sci U S A 95(16): 9465-70.

Fabbro, D., D. Parkinson and A. Matter (2002). "Protein tyrosine kinase inhibitors: new treatment modalities?" Curr Opin Pharmacol 2(4): 374-81.

Fernandez-Botran, R. (2000). "Soluble cytokine receptors: novel immunotherapeutic agents." Expert Opin Investig Drugs 9(3): 497-514.

Fischer, M., M. Bijman, D. Molin, F. Cormont, et al. (2003). "Increased serum levels of interleukin-9 correlate to negative prognostic factors in Hodgkin's lymphoma." Leukemia 17(12): 2513-6. 
Flavell, J. R., K. R. Baumforth, V. H. Wood, G. L. Davies, et al. (2008). "Downregulation of the TGF-beta target gene, PTPRK, by the Epstein-Barr virus encoded EBNA1 contributes to the growth and survival of Hodgkin lymphoma cells." Blood 111(1): 292-301.

Gause, A., W. Jung, R. Schmits, A. Tschiersch, et al. (1992). "Soluble CD8, CD25 and CD30 antigens as prognostic markers in patients with untreated Hodgkin's lymphoma." Ann Oncol 3 Suppl 4: 49-52.

Georgakis, G. V., Y. Li, G. Z. Rassidakis, H. Martinez-Valdez, et al. (2006a). "Inhibition of heat shock protein 90 function by 17-allylamino-17demethoxy-geldanamycin in Hodgkin's lymphoma cells down-regulates Akt kinase, dephosphorylates extracellular signal-regulated kinase, and induces cell cycle arrest and cell death." Clin Cancer Res 12(2): 584-90.

Georgakis, G. V., Y. Li, G. Z. Rassidakis, L. J. Medeiros, et al. (2006b). "Inhibition of the phosphatidylinositol-3 kinase/Akt promotes $\mathrm{G} 1$ cell cycle arrest and apoptosis in Hodgkin lymphoma." Br J Haematol 132(4): 503-11.

Gibson, A. W., J. C. Edberg, J. Wu, R. G. Westendorp, et al. (2001). "Novel single nucleotide polymorphisms in the distal IL-10 promoter affect IL-10 production and enhance the risk of systemic lupus erythematosus." J Immunol 166(6): 3915-22.

Glimelius, I., A. Edstrom, R. M. Amini, M. Fischer, et al. (2006). "IL-9 expression contributes to the cellular composition in Hodgkin lymphoma." Eur J Haematol 76(4): 278-83.

Golay, J., V. Broccoli, G. Lamorte, C. Bifulco, et al. (1998). "The A-Myb transcription factor is a marker of centroblasts in vivo." J Immunol 160(6): 2786-93.

Golay, J., M. Luppi, S. Songia, C. Palvarini, et al. (1996). "Expression of A-myb, but not c-myb and B-myb, is restricted to Burkitt's lymphoma, slg+ B-acute lymphoblastic leukemia, and a subset of chronic lymphocytic leukemias." Blood 87(5): 1900-11.

Gonda, H., M. Sugai, Y. Nambu, T. Katakai, et al. (2003). "The balance between Pax5 and Id2 activities is the key to AID gene expression." J Exp Med 198(9): 1427-37.

Gupta, S., M. Jiang, A. Anthony and A. B. Pernis (1999). "Lineage-specific modulation of interleukin 4 signaling by interferon regulatory factor 4 ." J Exp Med 190(12): 1837-48. 
Habermann, T. M., S. S. Wang, M. J. Maurer, L. M. Morton, et al. (2008). "Host immune gene polymorphisms in combination with clinical and demographic factors predicts late survival in diffuse large B-cell lymphoma patients in the pre-rituximab era." Blood.

Habib, T., A. Nelson and K. Kaushansky (2003). "IL-21: a novel IL-2-family lymphokine that modulates $\mathrm{B}, \mathrm{T}$, and natural killer cell responses." J Allergy Clin Immunol 112(6): 1033-45.

Hackstein, H., M. Hecker, S. Kruse, A. Bohnert, et al. (2001). "A novel polymorphism in the 5' promoter region of the human interleukin-4 receptor alpha-chain gene is associated with decreased soluble interleukin-4 receptor protein levels." Immunogenetics 53(4): 264-9.

Hanahan, D. and R. A. Weinberg (2000). "The hallmarks of cancer." Cell 100(1): 57-70.

HapMap (2003). "The International HapMap Project." Nature 426(6968): 789-96.

Harris, M. B., C. C. Chang, M. T. Berton, N. N. Danial, et al. (1999).

"Transcriptional repression of Stat6-dependent interleukin-4-induced genes by BCL-6: specific regulation of iepsilon transcription and immunoglobulin $\mathrm{E}$ switching." Mol Cell Biol 19(10): 7264-75.

Heinrich, P. C., I. Behrmann, S. Haan, H. M. Hermanns, et al. (2003). "Principles of interleukin (IL)-6-type cytokine signalling and its regulation." Biochem $\mathrm{J}$ 374(Pt 1): 1-20.

Hinz, M., P. Lemke, I. Anagnostopoulos, C. Hacker, et al. (2002). "Nuclear factor kappaB-dependent gene expression profiling of Hodgkin's disease tumor cells, pathogenetic significance, and link to constitutive signal transducer and activator of transcription 5a activity." J Exp Med 196(5): 605-17.

Hodgkin, T. (1832). "On some morbid appearances of the absorbent glands and spleen." Medical Chirurgical Transactions 17: 68-114.

Hoebee, B., E. Rietveld, L. Bont, M. Oosten, et al. (2003). "Association of severe respiratory syncytial virus bronchiolitis with interleukin-4 and interleukin-4 receptor alpha polymorphisms." J Infect Dis 187(1): 2-11.

Hofmann, S. R., R. Ettinger, Y. J. Zhou, M. Gadina, et al. (2002). "Cytokines and their role in lymphoid development, differentiation and homeostasis." Curr Opin Allergy Clin Immunol 2(6): 495-506.

Hohaus, S., M. Giachelia, A. Di Febo, M. Martini, et al. (2007). "Polymorphism in cytokine genes as prognostic markers in Hodgkin's lymphoma." Ann Oncol 18(8): 1376-81. 
Hollegaard, M. V. and J. L. Bidwell (2006). "Cytokine gene polymorphism in human disease: on-line databases, Supplement 3." Genes Immun 7(4): 269-76.

Holloway, A. F., S. Rao and M. F. Shannon (2002). "Regulation of cytokine gene transcription in the immune system." Mol Immunol 38(8): 567-80.

Holtick, U., M. Vockerodt, D. Pinkert, N. Schoof, et al. (2005). "STAT3 is essential for Hodgkin lymphoma cell proliferation and is a target of tyrphostin AG17 which confers sensitization for apoptosis." Leukemia 19(6): 936-44.

Hummel, M., S. Bentink, H. Berger, W. Klapper, et al. (2006). "A biologic definition of Burkitt's lymphoma from transcriptional and genomic profiling." $\mathrm{N}$ Engl J Med 354(23): 2419-30.

Hunninghake, G. M., M. E. Soto-Quiros, L. Avila, J. Su, et al. (2007). "Polymorphisms in IL13, total IgE, eosinophilia, and asthma exacerbations in childhood." J Allergy Clin Immunol 120(1): 84-90.

Ivansson, E. L., I. M. Gustavsson, J. J. Magnusson, L. L. Steiner, et al. (2007). "Variants of chemokine receptor 2 and interleukin 4 receptor, but not interleukin 10 or Fas ligand, increase risk of cervical cancer." Int J Cancer 121(11): 2451-7.

Izban, K. F., M. Ergin, Q. Huang, J. Z. Qin, et al. (2001). "Characterization of NFkappaB expression in Hodgkin's disease: inhibition of constitutively expressed NF-kappaB results in spontaneous caspase-independent apoptosis in Hodgkin and Reed-Sternberg cells." Mod Pathol 14(4): 297310.

Janeway, C., P. Travers, M. Walport and M. Shlomchik (2005). "Immunobiology." Garland Science Publishing.

Janz, M., T. Stuhmer, L. T. Vassilev and R. C. Bargou (2007). "Pharmacologic activation of p53-dependent and p53-independent apoptotic pathways in Hodgkin/Reed-Sternberg cells." Leukemia 21(4): 772-9.

Jarrett, R. F., A. Armstrong, B. S. Wilkins and D. B. Jones (1991). "Immunohistochemical determination of CD23 expression in Hodgkin's disease using paraffin sections." J Pathol 164(4): 345-6.

Joos, S., M. Granzow, H. Holtgreve-Grez, R. Siebert, et al. (2003). "Hodgkin's lymphoma cell lines are characterized by frequent aberrations on chromosomes 2p and 9p including REL and JAK2." Int J Cancer 103(4): 489-95.

Joos, S., M. Kupper, S. Ohl, F. von Bonin, et al. (2000). "Genomic imbalances including amplification of the tyrosine kinase gene JAK2 in CD30+ Hodgkin cells." Cancer Res 60(3): 549-52. 
Jundt, F., I. Anagnostopoulos, R. Forster, S. Mathas, et al. (2002). "Activated Notch1 signaling promotes tumor cell proliferation and survival in Hodgkin and anaplastic large cell lymphoma." Blood 99(9): 3398-403.

Kahl, B. (2008). "Chemotherapy combinations with monoclonal antibodies in nonHodgkin's lymphoma." Semin Hematol 45(2): 90-4.

Kamesaki, H., S. Fukuhara, E. Tatsumi, H. Uchino, et al. (1986). "Cytochemical, immunologic, chromosomal, and molecular genetic analysis of a novel cell line derived from Hodgkin's disease." Blood 68(1): 285-92.

Karin, M. and F. R. Greten (2005). "NF-kappaB: linking inflammation and immunity to cancer development and progression." Nat Rev Immunol 5(10): 749-59.

Kashkar, H., A. Deggerich, J. M. Seeger, B. Yazdanpanah, et al. (2007). "NFkappaB-independent down-regulation of XIAP by bortezomib sensitizes HL B cells against cytotoxic drugs." Blood 109(9): 3982-8.

Kashkar, H., M. Kronke and J. M. Jurgensmeier (2002). "Defective Bax activation in Hodgkin B-cell lines confers resistance to staurosporine-induced apoptosis." Cell Death Differ 9(7): 750-7.

Kasibhatla, S. R., K. Hong, M. A. Biamonte, D. J. Busch, et al. (2007). "Rationally designed high-affinity 2-amino-6-halopurine heat shock protein 90 inhibitors that exhibit potent antitumor activity." J Med Chem 50(12): 2767-78.

Keen, L. J. (2002). "The extent and analysis of cytokine and cytokine receptor gene polymorphism." Transpl Immunol 10(2-3): 143-6.

Kelly-Welch, A., E. M. Hanson and A. D. Keegan (2005). "Interleukin-13 (IL-13) pathway." Sci STKE 2005(293): cm8.

Khoury, J. D., L. J. Medeiros, G. Z. Rassidakis, M. A. Yared, et al. (2003). "Differential expression and clinical significance of tyrosine-phosphorylated STAT3 in ALK+ and ALK- anaplastic large cell lymphoma." Clin Cancer Res 9(10 Pt 1): 3692-9.

Kirchner, H. H., H. Burrichter, H. Stein, C. Fonatsch, et al. (1983). "[Properties of Hodgkin cell lines. Possible significance for pathophysiology and clinical medicine]." Dtsch Med Wochenschr 108(24): 936-44. 
Klein, G., B. Giovanella, A. Westman, J. S. Stehlin, et al. (1975). "An EBVgenome-negative cell line established from an American Burkitt lymphoma; receptor characteristics. EBV infectibility and permanent conversion into EBV-positive sublines by in vitro infection." Intervirology 5(6): 319-34.

Klein, U., S. Casola, G. Cattoretti, Q. Shen, et al. (2006). "Transcription factor IRF4 controls plasma cell differentiation and class-switch recombination." Nat Immunol 7(7): 773-82.

Klein, U. and R. Dalla-Favera (2008). "Germinal centres: role in B-cell physiology and malignancy." Nat Rev Immunol 8(1): 22-33.

Kohler, I. and E. P. Rieber (1993). "Allergy-associated I epsilon and Ec epsilon receptor II (CD23b) genes activated via binding of an interleukin-4-induced transcription factor to a novel responsive element." Eur J Immunol 23(12): 3066-71.

Kruse, S., T. Japha, M. Tedner, S. H. Sparholt, et al. (1999). "The polymorphisms S503P and Q576R in the interleukin-4 receptor alpha gene are associated with atopy and influence the signal transduction." Immunology 96(3): 36571.

Kube, D., U. Holtick, M. Vockerodt, T. Ahmadi, et al. (2001a). "STAT3 is constitutively activated in Hodgkin cell lines." Blood 98(3): 762-70.

Kube, D., T. D. Hua, M. Kloss, B. Kulle, et al. (2007). "The interleukin-10 gene promoter polymorphism -1087AG does not correlate with clinical outcome in non-Hodgkin's lymphoma." Genes Immun 8(2): 164-7.

Kube, D., T. D. Hua, F. von Bonin, N. Schoof, et al. (2008). "Effect of Interleukin10 Gene Polymorphisms on Clinical Outcome of Patients with Aggressive Non-Hodgkin's Lymphoma: An Exploratory Study." Clin Cancer Res 14(12): 3777-84.

Kube, D., H. Rieth, J. Eskdale, P. G. Kremsner, et al. (2001b). "Structural characterisation of the distal 5 ' flanking region of the human interleukin-10 gene." Genes Immun 2(4): 181-90.

Kube, D., M. Vockerodt, O. Weber, K. Hell, et al. (1999). "Expression of epsteinbarr virus nuclear antigen 1 is associated with enhanced expression of CD25 in the Hodgkin cell line L428." J Virol 73(2): 1630-6.

Lacronique, V., A. Boureux, V. D. Valle, H. Poirel, et al. (1997). "A TEL-JAK2 fusion protein with constitutive kinase activity in human leukemia." Science 278(5341): 1309-12.

Laemmli, U. K. (1970). "Cleavage of structural proteins during the assembly of the head of bacteriophage T4." Nature 227(5259): 680-5. 
Lai, R., G. Z. Rassidakis, L. J. Medeiros, V. Leventaki, et al. (2003). "Expression of STAT3 and its phosphorylated forms in mantle cell lymphoma cell lines and tumours." J Pathol 199(1): 84-9.

Lamprecht, B., S. Kreher, I. Anagnostopoulos, K. Johrens, et al. (2008). "Aberrant expression of the Th2 cytokine IL-21 in Hodgkin lymphoma cells regulates STAT3 signaling and attracts Treg cells via regulation of MIP-3\{alpha\}." Blood.

Lan, Q., T. Zheng, N. Rothman, Y. Zhang, et al. (2006). "Cytokine polymorphisms in the Th1/Th2 pathway and susceptibility to non-Hodgkin lymphoma." Blood 107(10): 4101-8.

Lech-Maranda, E., L. Baseggio, J. Bienvenu, C. Charlot, et al. (2004). "Interleukin10 gene promoter polymorphisms influence the clinical outcome of diffuse large B-cell lymphoma." Blood 103(9): 3529-34.

Lee, J. J., D. H. Kim, N. Y. Lee, S. K. Sohn, et al. (2007). "Interleukin-10 gene polymorphism influences the prognosis of T-cell non-Hodgkin lymphomas." Br J Haematol 137(4): 329-36.

Lehtonen, A., V. Veckman, T. Nikula, R. Lahesmaa, et al. (2005). "Differential expression of IFN regulatory factor 4 gene in human monocyte-derived dendritic cells and macrophages." J Immunol 175(10): 6570-9.

Levine, R. L., M. Wadleigh, J. Cools, B. L. Ebert, et al. (2005). "Activating mutation in the tyrosine kinase JAK2 in polycythemia vera, essential thrombocythemia, and myeloid metaplasia with myelofibrosis." Cancer Cell 7(4): 387-97.

Liu, Y. J., J. A. Cairns, M. J. Holder, S. D. Abbot, et al. (1991). "Recombinant 25$\mathrm{kDa}$ CD23 and interleukin 1 alpha promote the survival of germinal center B cells: evidence for bifurcation in the development of centrocytes rescued from apoptosis." Eur J Immunol 21(5): 1107-14.

Lohoff, M. and T. W. Mak (2005). "Roles of interferon-regulatory factors in Thelper-cell differentiation." Nat Rev Immunol 5(2): 125-35.

Lohoff, M., H. W. Mittrucker, S. Prechtl, S. Bischof, et al. (2002). "Dysregulated T helper cell differentiation in the absence of interferon regulatory factor 4." Proc Natl Acad Sci U S A 99(18): 11808-12. 
Lu, X., H. Nechushtan, F. Ding, M. F. Rosado, et al. (2005). "Distinct IL-4-induced gene expression, proliferation, and intracellular signaling in germinal center B-cell-like and activated B-cell-like diffuse large-cell lymphomas." Blood 105(7): 2924-32.

Lucey, D. R., M. Clerici and G. M. Shearer (1996). "Type 1 and type 2 cytokine dysregulation in human infectious, neoplastic, and inflammatory diseases." Clin Microbiol Rev 9(4): 532-62.

Mathas, S., M. Janz, F. Hummel, M. Hummel, et al. (2006). "Intrinsic inhibition of transcription factor E2A by HLH proteins ABF-1 and Id 2 mediates reprogramming of neoplastic B cells in Hodgkin lymphoma." Nat Immunol 7(2): 207-15.

Melzner, I., M. A. Weniger, C. K. Menz and P. Möller (2006). "Absence of the JAK2 V617F activating mutation in classical Hodgkin lymphoma and primary mediastinal B-cell lymphoma." Leukemia 20(1): 157-8.

Meydan, N., T. Grunberger, H. Dadi, M. Shahar, et al. (1996). "Inhibition of acute lymphoblastic leukaemia by a Jak-2 inhibitor." Nature 379(6566): 645-8.

Mitsuyasu, H., K. Izuhara, X. Q. Mao, P. S. Gao, et al. (1998). "lle50Val variant of IL4R alpha upregulates IgE synthesis and associates with atopic asthma." Nat Genet 19(2): 119-20.

Mittal, S., N. A. Marshall, L. Duncan, D. J. Culligan, et al. (2008). "Local and systemic induction of CD4+CD25+ regulatory T-cell population by nonHodgkin lymphoma." Blood 111(11): 5359-70.

Monti, S., K. J. Savage, J. L. Kutok, F. Feuerhake, et al. (2005). "Molecular profiling of diffuse large B-cell lymphoma identifies robust subtypes including one characterized by host inflammatory response." Blood 105(5): 1851-61.

Moore, K. W., R. de Waal Malefyt, R. L. Coffman and A. O'Garra (2001). "Interleukin-10 and the interleukin-10 receptor." Annu Rev Immunol 19: 683-765.

Moreton, P. and P. Hillmen (2003). "Alemtuzumab therapy in B-cell lymphoproliferative disorders." Semin Oncol 30(4): 493-501.

Mori, T., R. Takada, R. Watanabe, S. Okamoto, et al. (2001). "T-helper (Th)1/Th2 imbalance in patients with previously untreated B-cell diffuse large cell lymphoma." Cancer Immunol Immunother 50(10): 566-8.

Mörmann, M., H. Rieth, T. D. Hua, C. Assohou, et al. (2004). "Mosaics of gene variations in the Interleukin-10 gene promoter affect interleukin-10 production depending on the stimulation used." Genes Immun 5(4): 246-55. 
Nakamura, E., Y. Megumi, T. Kobayashi, T. Kamoto, et al. (2002). "Genetic polymorphisms of the interleukin-4 receptor alpha gene are associated with an increasing risk and a poor prognosis of sporadic renal cell carcinoma in a Japanese population." Clin Cancer Res 8(8): 2620-5.

Natkunam, Y., E. D. Hsi, P. Aoun, S. Zhao, et al. (2007). "Expression of the human germinal center-associated lymphoma (HGAL) protein identifies a subset of classic Hodgkin lymphoma of germinal center derivation and improved survival." Blood 109(1): 298-305.

Ngo, V. N., R. E. Davis, L. Lamy, X. Yu, et al. (2006). "A loss-of-function RNA interference screen for molecular targets in cancer." Nature 441(7089): 106-10.

Novellino, L., A. De Filippo, P. Deho, F. Perrone, et al. (2008). "PTPRK negatively regulates transcriptional activity of wild type and mutated oncogenic betacatenin and affects membrane distribution of beta-catenin/E-cadherin complexes in cancer cells." Cell Signal 20(5): 872-83.

Pasquale, E. B. (2004). "Eph-ephrin promiscuity is now crystal clear." Nat Neurosci 7(5): 417-8.

Pasqualucci, L., R. Guglielmino, J. Houldsworth, J. Mohr, et al. (2004). "Expression of the AID protein in normal and neoplastic B cells." Blood 104(10): 3318-25.

Pasqualucci, L., P. Neumeister, T. Goossens, G. Nanjangud, et al. (2001). "Hypermutation of multiple proto-oncogenes in B-cell diffuse large-cell lymphomas." Nature 412(6844): 341-6.

Pfreundschuh, M., J. Schubert, M. Ziepert, R. Schmits, et al. (2008). "Six versus eight cycles of bi-weekly CHOP-14 with or without rituximab in elderly patients with aggressive CD20+ B-cell lymphomas: a randomised controlled trial (RICOVER-60)." Lancet Oncol 9(2): 105-16.

Pfreundschuh, M., L. Trümper, M. Kloess, R. Schmits, et al. (2004a). "Two-weekly or 3-weekly CHOP chemotherapy with or without etoposide for the treatment of elderly patients with aggressive lymphomas: results of the NHL-B2 trial of the DSHNHL." Blood 104(3): 634-41. 
Pfreundschuh, M., L. Trümper, M. Kloess, R. Schmits, et al. (2004b). "Two-weekly or 3-weekly CHOP chemotherapy with or without etoposide for the treatment of young patients with good-prognosis (normal LDH) aggressive lymphomas: results of the NHL-B1 trial of the DSHNHL." Blood 104(3): 62633.

Rajewsky, K. (1996). "Clonal selection and learning in the antibody system." Nature 381(6585): 751-8.

Re, D., A. Hofmann, J. Wolf, V. Diehl, et al. (2000). "Cultivated H-RS cells are resistant to CD95L-mediated apoptosis despite expression of wild-type CD95." Exp Hematol 28(3): 348.

Re, D., M. Müschen, T. Ahmadi, C. Wickenhauser, et al. (2001). "Oct-2 and Bob-1 deficiency in Hodgkin and Reed Sternberg cells." Cancer Res 61(5): 20804.

Re, D., R. K. Thomas, T. Zander and V. Diehl (2005). "Problems and promises of targeted therapy for Hodgkin's lymphoma." Nat Clin Pract Oncol 2(1): 2-3.

Reed, D. (1902). "On the pathological changes in Hodgkin's disease with special reference to its relation to tuberculosis." John Hopkins Hospital Reports 10: 133-193.

Renne, C., J. I. Martin-Subero, M. Eickernjager, M. L. Hansmann, et al. (2006). "Aberrant expression of ID2, a suppressor of B-cell-specific gene expression, in Hodgkin's lymphoma." Am J Pathol 169(2): 655-64.

Renne, C., K. Willenbrock, R. Kuppers, M. L. Hansmann, et al. (2005). "Autocrineand paracrine-activated receptor tyrosine kinases in classic Hodgkin lymphoma." Blood 105(10): 4051-9.

Renne, C., K. Willenbrock, J. I. Martin-Subero, N. Hinsch, et al. (2007). "High expression of several tyrosine kinases and activation of the PI3K/AKT pathway in mediastinal large B cell lymphoma reveals further similarities to Hodgkin lymphoma." Leukemia 21(4): 780-7.

Rieth, H., M. Mörmann, A. J. Luty, C. A. Assohou-Luty, et al. (2004). "A three base pair gene variation within the distal 5'-flanking region of the interleukin-10 (IL-10) gene is related to the in vitro IL-10 production capacity of lipopolysaccharide-stimulated peripheral blood mononuclear cells." Eur Cytokine Netw 15(2): 153-8.

Rodig, S. J., J. S. Abramson, G. S. Pinkus, S. P. Treon, et al. (2006). "Heterogeneous CD52 expression among hematologic neoplasms: implications for the use of alemtuzumab (CAMPATH-1H)." Clin Cancer Res 12(23): 7174-9.

Romagnani, S. (1997). "The Th1/Th2 paradigm." Immunol Today 18(6): 263-6. 
Rose-John, S. and H. Schooltink (2007). "Cytokines are a therapeutic target for the prevention of inflammation-induced cancers." Recent Results Cancer Res 174: 57-66.

Rosenwasser, L. J. (1999). "Promoter polymorphism in the candidate genes, IL-4, IL-9, TGF-beta1, for atopy and asthma." Int Arch Allergy Immunol 118(2-4): 268-70.

Rothman, N., C. F. Skibola, S. S. Wang, G. Morgan, et al. (2006). "Genetic variation in TNF and IL10 and risk of non-Hodgkin lymphoma: a report from the InterLymph Consortium." Lancet Oncol 7(1): 27-38.

Saito, M., J. Gao, K. Basso, Y. Kitagawa, et al. (2007). "A signaling pathway mediating downregulation of BCL6 in germinal center B cells is blocked by BCL6 gene alterations in B cell lymphoma." Cancer Cell 12(3): 280-92.

Sarris, A. H., K. O. Kliche, P. Pethambaram, A. Preti, et al. (1999). "Interleukin-10 levels are often elevated in serum of adults with Hodgkin's disease and are associated with inferior failure-free survival." Ann Oncol 10(4): 433-40.

Schaadt, M., C. Fonatsch, H. Kirchner and V. Diehl (1979). "Establishment of a malignant, Epstein-Barr-virus (EBV)-negative cell-line from the pleura effusion of a patient with Hodgkin's disease." Blut 38(2): 185-90.

Scheeren, F. A., S. A. Diehl, L. A. Smit, T. Beaumont, et al. (2008). "IL-21 is expressed in Hodgkin lymphoma and activates STAT5: evidence that activated STAT5 is required for Hodgkin lymphomagenesis." Blood 111(9): 4706-15.

Schneider, U., H. U. Schwenk and G. Bornkamm (1977). "Characterization of EBV-genome negative "null" and " $T$ " cell lines derived from children with acute lymphoblastic leukemia and leukemic transformed non-Hodgkin lymphoma." Int J Cancer 19(5): 621-6.

Schnittger, S., U. Bacher, W. Kern, M. Schroder, et al. (2006). "Report on two novel nucleotide exchanges in the JAK2 pseudokinase domain: D620E and E627E." Leukemia 20(12): 2195-7.

Schwering, I., A. Brauninger, U. Klein, B. Jungnickel, et al. (2003). "Loss of the Blineage-specific gene expression program in Hodgkin and Reed-Sternberg cells of Hodgkin lymphoma." Blood 101(4): 1505-12.

Shaffer, A. L., N. C. Emre, L. Lamy, V. N. Ngo, et al. (2008). "IRF4 addiction in multiple myeloma." Nature 454(7201): 226-31.

Shang, L. and T. B. Tomasi (2006). "The heat shock protein 90-CDC37 chaperone complex is required for signaling by types I and II interferons." J Biol Chem 281(4): 1876-84. 
Shipp, M. A. (1994). "Prognostic factors in aggressive non-Hodgkin's lymphoma: who has "high-risk" disease?" Blood 83(5): 1165-73.

Shirakawa, I., K. A. Deichmann, I. Izuhara, I. Mao, et al. (2000). "Atopy and asthma: genetic variants of IL-4 and IL-13 signalling." Immunol Today 21(2): 60-4.

Skinnider, B. F., A. J. Elia, R. D. Gascoyne, B. Patterson, et al. (2002a). "Signal transducer and activator of transcription 6 is frequently activated in Hodgkin and Reed-Sternberg cells of Hodgkin lymphoma." Blood 99(2): 618-26.

Skinnider, B. F., A. J. Elia, R. D. Gascoyne, L. H. Trümper, et al. (2001a). "Interleukin 13 and interleukin 13 receptor are frequently expressed by Hodgkin and Reed-Sternberg cells of Hodgkin lymphoma." Blood 97(1): 250-5.

Skinnider, B. F., U. Kapp and T. W. Mak (2001b). "Interleukin 13: a growth factor in hodgkin lymphoma." Int Arch Allergy Immunol 126(4): 267-76.

Skinnider, B. F. and T. W. Mak (2002b). "The role of cytokines in classical Hodgkin lymphoma." Blood 99(12): 4283-97.

Smyth, G. K. (2004). "Linear models and empirical bayes methods for assessing differential expression in microarray experiments." Stat Appl Genet Mol Biol 3: Article3.

Soriano, A., F. Lozano, H. Oliva, F. Garcia, et al. (2005). "Polymorphisms in the interleukin-4 receptor alpha chain gene influence susceptibility to HIV-1 infection and its progression to AIDS." Immunogenetics 57(9): 644-54.

Souabni, A., C. Cobaleda, M. Schebesta and M. Busslinger (2002). "Pax5 promotes $\mathrm{B}$ lymphopoiesis and blocks $\mathrm{T}$ cell development by repressing Notch1." Immunity 17(6): 781-93.

Staerk, J., A. Kallin, J. B. Demoulin, W. Vainchenker, et al. (2005). "JAK1 and Tyk2 activation by the homologous polycythemia vera JAK2 V617F mutation: cross-talk with IGF1 receptor." J Biol Chem 280(51): 41893-9.

Stasi, R., L. Zinzani, P. Galieni, V. M. Lauta, et al. (1995). "Clinical implications of cytokine and soluble receptor measurements in patients with newlydiagnosed aggressive non-Hodgkin's lymphoma." Eur J Haematol 54(1): 917.

Stein, H., T. Marafioti, H. D. Foss, H. Laumen, et al. (2001). "Down-regulation of BOB.1/OBF.1 and Oct2 in classical Hodgkin disease but not in lymphocyte predominant Hodgkin disease correlates with immunoglobulin transcription." Blood 97(2): 496-501. 
Stephenson, L., M. H. Johns, E. Woodward, A. L. Mora, et al. (2004). "An IL-4R alpha allelic variant, I50, acts as a gain-of-function variant relative to $\mathrm{V} 50$ for Stat6, but not Th2 differentiation." J Immunol 173(7): 4523-8.

Sternberg, C. (1898). "Über eine eigenartige unter dem Bilde der Pseudoleukämie verlaufende Tuberkolose des lymphatischen Apparates." Zeitschrift für Heilkunde 19: 21-90.

Teng, Y., Y. Takahashi, M. Yamada, T. Kurosu, et al. (2007). "IRF4 negatively regulates proliferation of germinal center B cell-derived Burkitt's lymphoma cell lines and induces differentiation toward plasma cells." Eur J Cell Biol 86(10): 581-9.

Thien, C. B. and W. Y. Langdon (2001). "Cbl: many adaptations to regulate protein tyrosine kinases." Nat Rev Mol Cell Biol 2(4): 294-307.

Torlakovic, E., A. Tierens, H. D. Dang and J. Delabie (2001). "The transcription factor PU.1, necessary for B-cell development is expressed in lymphocyte predominance, but not classical Hodgkin's disease." Am J Pathol 159(5): 1807-14.

Towbin, H., T. Staehelin and J. Gordon (1979). "Electrophoretic transfer of proteins from polyacrylamide gels to nitrocellulose sheets: procedure and some applications." Proc Natl Acad Sci U S A 76(9): 4350-4.

Trieu, Y., X. Y. Wen, B. F. Skinnider, M. R. Bray, et al. (2004). "Soluble interleukin13Ralpha2 decoy receptor inhibits Hodgkin's lymphoma growth in vitro and in vivo." Cancer Res 64(9): 3271-5.

Trümper, L. H., G. Brady, A. Bagg, D. Gray, et al. (1993). "Single-cell analysis of Hodgkin and Reed-Sternberg cells: molecular heterogeneity of gene expression and p53 mutations." Blood 81(11): 3097-115.

Turner, D. M., D. M. Williams, D. Sankaran, M. Lazarus, et al. (1997). "An investigation of polymorphism in the interleukin-10 gene promoter." Eur $\mathrm{J}$ Immunogenet 24(1): 1-8.

van den Berg, A., L. Visser and S. Poppema (1999). "High expression of the CC chemokine TARC in Reed-Sternberg cells. A possible explanation for the characteristic T-cell infiltratein Hodgkin's lymphoma." Am J Pathol 154(6): 1685-91.

Vassilakopoulos, T. P., G. Nadali, M. K. Angelopoulou, M. P. Siakantaris, et al. (2001). "Serum interleukin-10 levels are an independent prognostic factor for patients with Hodgkin's lymphoma." Haematologica 86(3): 274-81.

Vockerodt, M., H. Tesch and D. Kube (2001). "Epstein-Barr virus latent membrane protein-1 activates CD25 expression in lymphoma cells involving the NFkappaB pathway." Genes Immun 2(8): 433-41. 
Wang, S. E., F. Y. Wu, I. Shin, S. Qu, et al. (2005). "Transforming growth factor \{beta\} (TGF-\{beta\})-Smad target gene protein tyrosine phosphatase receptor type kappa is required for TGF-\{beta\} function." Mol Cell Biol 25(11): 4703-15.

Weniger, M. A., I. Melzner, C. K. Menz, S. Wegener, et al. (2006). "Mutations of the tumor suppressor gene SOCS-1 in classical Hodgkin lymphoma are frequent and associated with nuclear phospho-STAT5 accumulation." Oncogene 25(18): 2679-84.

Westendorp, R. G., J. A. Langermans, T. W. Huizinga, C. L. Verweij, et al. (1997). "Genetic influence on cytokine production in meningococcal disease." Lancet 349(9069): 1912-3.

Whitesell, L. and S. L. Lindquist (2005). "HSP90 and the chaperoning of cancer." Nat Rev Cancer 5(10): 761-72.

WHO (2003). "Pathology and Genetics of Tumours of Haematopoetic and Lymphoid Tissues." IARC Press, Lyon.

Wolf, J., U. Kapp, H. Bohlen, M. Kornacker, et al. (1996). "Peripheral blood mononuclear cells of a patient with advanced Hodgkin's lymphoma give rise to permanently growing Hodgkin-Reed Sternberg cells." Blood 87(8): 341828.

Xu, Y., L. J. Tan, V. Grachtchouk, J. J. Voorhees, et al. (2005). "Receptor-type protein-tyrosine phosphatase-kappa regulates epidermal growth factor receptor function." J Biol Chem 280(52): 42694-700.

Yu, H. and R. Jove (2004). "The STATs of cancer--new molecular targets come of age." Nat Rev Cancer 4(2): 97-105.

Zheng, B., P. Fiumara, Y. V. Li, G. Georgakis, et al. (2003). "MEK/ERK pathway is aberrantly active in Hodgkin disease: a signaling pathway shared by CD30, CD40, and RANK that regulates cell proliferation and survival." Blood 102(3): 1019-27.

Zheng, W. and R. A. Flavell (1997). "The transcription factor GATA-3 is necessary and sufficient for Th2 cytokine gene expression in CD4 T cells." Cell 89(4): 587-96.

Zitvogel, L., A. Tesniere and G. Kroemer (2006). "Cancer despite immunosurveillance: immunoselection and immunosubversion." Nat Rev Immunol 6(10): 715-27. 


\section{ANHANG}

\subsection{Abkürzungsverzeichnis}

\begin{tabular}{|c|c|}
\hline${ }^{\circ} \mathrm{C}$ & Grad Celsius \\
\hline 17-AAG & 17-Allylaminogeldanamycin \\
\hline A & Adenosin \\
\hline A.bidest & Wasser zweifach destilliert \\
\hline Abb. & Abbildung \\
\hline $\mathrm{ABC}$ & aktivierte B-Zellen (engl.: activated B-cells) \\
\hline$A B L$ & engl.: Abelson murine leukemia viral oncogene homolog 1 \\
\hline AG17 & a-Cyano-(3,5-di-t-butyl-4-hydroxy)cinnamonitril \\
\hline AG490 & a-Cyano-(3,4-dihydroxy)-N-benzylcinnamid \\
\hline AIDS & engl.: Aquired Immune Deficiency Syndrom \\
\hline ALL & akute lymphatische Leukämie \\
\hline APS & Ammoniumpersulfat \\
\hline AS & Aminosäure \\
\hline BL & Burkitt-Lymphom \\
\hline bp & Basenpaar \\
\hline BSA & Rinderserumalbumin (engl.: bovine serum albumin) \\
\hline bzw. & beziehungsweise \\
\hline $\mathrm{C}$ & Cytidin \\
\hline ca. & circa \\
\hline CD & engl.: cluster of differentiation \\
\hline cDNA & komplement"are DNA (engl.: complementary DNA) \\
\hline $\mathrm{cHL}$ & klassisches Hodgkin-Lymphom (engl.: classical Hodgkin-Lymphoma) \\
\hline CHOEP & $\begin{array}{l}\text { Cyclophosphamid, Hydroxydaunorubicin (Doxorubicin), Oncovin } \\
\text { (Vincristin), Etoposid, Prednisolon }\end{array}$ \\
\hline $\mathrm{CHOP}$ & $\begin{array}{l}\text { Cyclophosphamid, Hydroxydaunorubicin (Doxorubicin), Oncovin } \\
\text { (Vincristin), Prednisolon }\end{array}$ \\
\hline CML & chronisch myeloische Leukämie \\
\hline CSR & Ig-Isotypenwechsel (engl.: class switch recombination) \\
\hline CT & engl.: cycle threshold \\
\hline $\mathrm{Da}$ & Dalton \\
\hline Del & Deletion \\
\hline DLBCL & diffus großzelliges B-Zell-Lymphom (engl.: diffuse large B-cell lymphoma) \\
\hline DMSO & Dimethylsulfoxid \\
\hline DNA & Desoxyribonukleinsäure (engl.: desoxyribonucleic acid) \\
\hline DNase & Desoxyribonuklease \\
\hline dNTP & Desoxynukleotidtriphosphat \\
\hline DSHNHL & Deutschen Studiengruppe für hochmaligne Non-Hodgkin-Lymphome \\
\hline EBV & Epstein-Barr-Virus \\
\hline ECL & engl.: enhanced chemiluminescence \\
\hline ECOG & engl.: Eastern Cooperative Oncology Group \\
\hline EDTA & Ethylendiamintetraessigsäure \\
\hline EFS & engl.: event-free survival \\
\hline ELISA & engl.: enzyme-linked immuno sorbent assay \\
\hline et al. & und andere (lat.: et alii) \\
\hline etc. & und so weiter (lat.: et cetera) \\
\hline Fa. & Firma \\
\hline FACS & engl.: fluorescence activated cell sorting \\
\hline FAM & 6-FAM-phosphoramidit \\
\hline FBS & fetales Kälberserum (engl.: fetal bovine serum) \\
\hline $\mathrm{Fc}$ & konstante Region eines Antikörpers (engl.: fragment crystallizable) \\
\hline FDC & follikuläre dendritische Zelle (engl.: follicular dendritic cell) \\
\hline
\end{tabular}




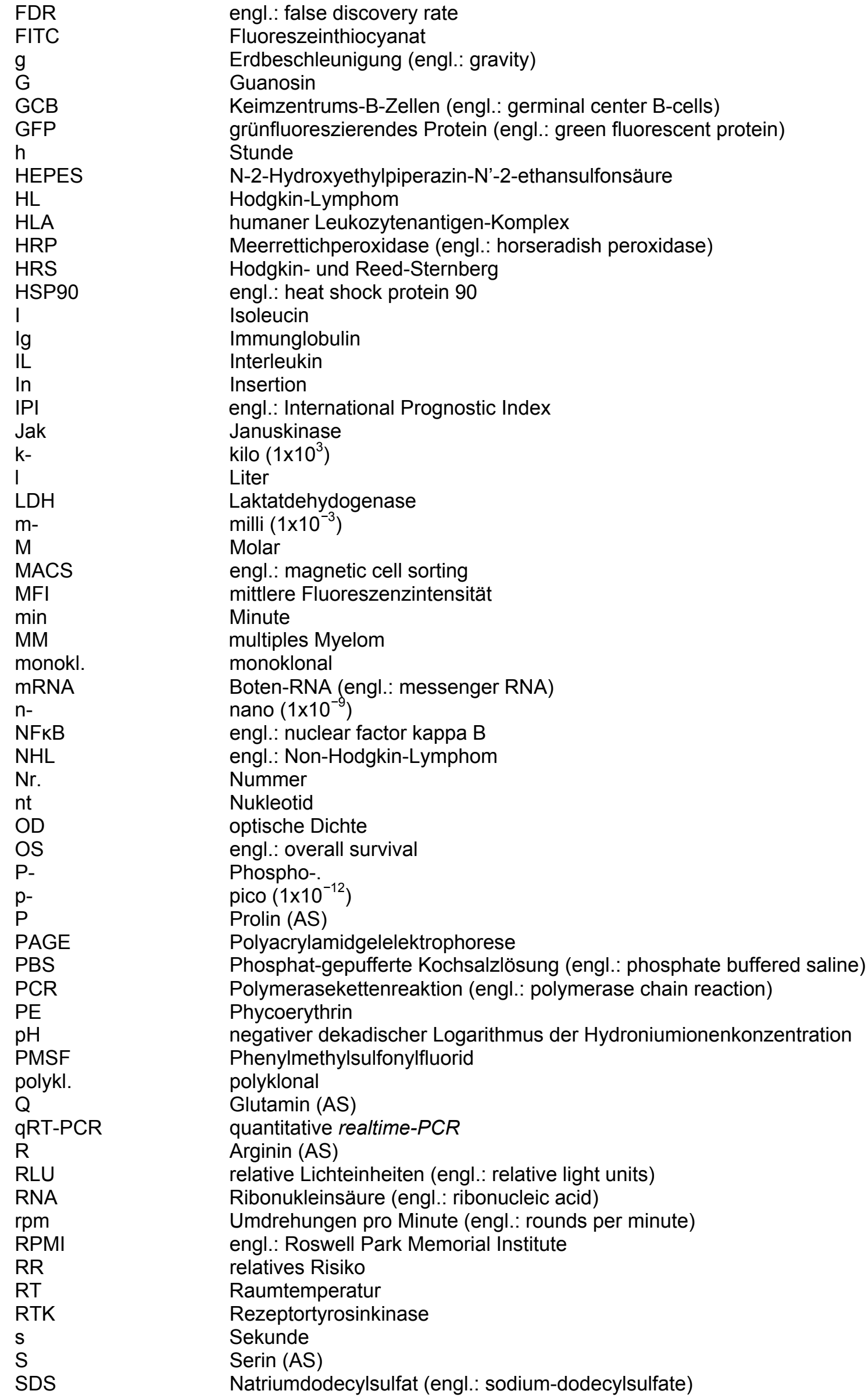




SH2
SHM
shRNA
siRNA
SNP
Sog.
STAT
T
Tab.
Taq
TBE
TBS
TEMED
TM
TNF
Tris
TritonX-100
Tween
Tyk2
U
u.a.
üNW
UTR
V
V
v/v
w/v
WT
z.B.
$\mu-$

engl.: src-homology 2

somatische Hypermutation

engl.: short hairpin RNA

engl.: short interference RNA

engl.: single nucleotide polymorphism

so genannte

engl.: signal transducer and activator of transcription

Thymidin

Tabelle

Thermus aquaticus

Tris-Borat-EDTA

Tris-gepufferte Kochsalzlösung (engl.: tris buffered saline)

$\mathrm{N}, \mathrm{N}, \mathrm{N}$ ', N'-Tetramethylendiamin

engl.: Trademark

Tumornekrosefaktor

Tris-hydroxymethyl-aminomethan

Octylphenoxypolyethoxyethan

Polyoxyethylensorbitanmonolaurat

Tyrosinkinase 2

Unit

und anderes

über Normalwert

Untranslatierte Region

Volt

Valin (AS)

Volumen/Volumen

Gewicht/Volumen (engl.: weight/volume)

Wildtyp

zum Beispiel

mikro $\left(1 \times 10^{-6}\right)$ 


\title{
8.2 Publikation Kube et al. Clin. Cancer. Res. (2008)
}

\author{
Imaging, Diagnosis, Prognosis
}

\section{Effect of Interleukin-10 Gene Polymorphisms on Clinical Outcome of Patients with Aggressive Non-Hodgkin's Lymphoma: An Exploratory Study}

Dieter Kube, ${ }^{1}$ Thanh-Duc Hua, ${ }^{1}$ Frederike von Bonin, ${ }^{1}$ Nils Schoof, ${ }^{1}$ Samira Zeynalova, ${ }^{3}$ Marita Klöss, ${ }^{3}$ Daniela Gocht, ${ }^{1}$ Bernd Potthoff, ${ }^{1}$ Mladen Tzvetkov, ${ }^{2}$ Jürgen Brockmöller, ${ }^{2}$ Markus Löffler, ${ }^{3}$ Michael Pfreundschuh, ${ }^{4}$ and Lorenz Trümper ${ }^{1}$

\begin{abstract}
Purpose: Current chemotherapy can achieve high response rates in aggressive non-Hodgkin's lymphoma (NHL), but the factors that influence regression and survival remain unknown. The present exploratory study tested the hypothesis whether interleukin-10 (IL-10) polymorphisms predict clinical outcome, leukocytopenia, or infectivity during therapy. IL-10 was chosen because immune alterations are a major risk factor for $\mathrm{NHL}$, and $\mathrm{IL}-10$ is a cytokine involved in inflammatory processes associated with clinical outcome.

Experimental Design: Five hundred patients with aggressive NHL treated with CHOP/CHOEP were analyzed for $/ L-10$ gene polymorphisms, including distal loci -7400 InDel, -6752AT ( $r$ 6676671), and -6208CG (rs10494879) in comparison with proximal loci -3538AT (rs1800890), -1087AG (rs1800896), and -597AC (rs1800872) according to the incidence and outcome of the lymphoma.

Results: No differences in allele frequencies or haplotypes were found comparing a cohort of patients with aggressive $\mathrm{NHL}$ /diffuse large B-cell lymphoma with a healthy control group. Patients with aggressive NHL characterized by IL-10 -7400 DelDel had shorter overall survival periods compared with the other genotypes $(P=0.004)$. The 3 -year rate is $43.4 \%$ for $\mathrm{IL}-10_{-7400 \mathrm{DelDel}}$ and $73.4 \%$ for $\mathrm{IL}-10_{-7400 \mathrm{In}}$ and $\mathrm{IL}-10_{-7400 \mathrm{InDel}}$ together. A significant increased risk for event-free survival is found for carriers of the genotype IL-10 6752 TT-6208CC-3538AA $(P=0.047)$. Multivariate analysis of $\mathrm{IL}-10_{-7400}$ gene variation in relation to overall survival adjusted to international prognostic index revealed a relative risk of 1.9 for carriers of IL-10 $-7400 \mathrm{Del}$. Del $(P=0.037)$. No associations were found analyzing diffuse large B-cell lymphoma patients separately.

Conclusion: Our results indicate that $/ L-10$ gene variations could be associated to the clinical course of aggressive $\mathrm{NHL}$, which points out the importance of host factors and respective genetic elements for treatment response.
\end{abstract}

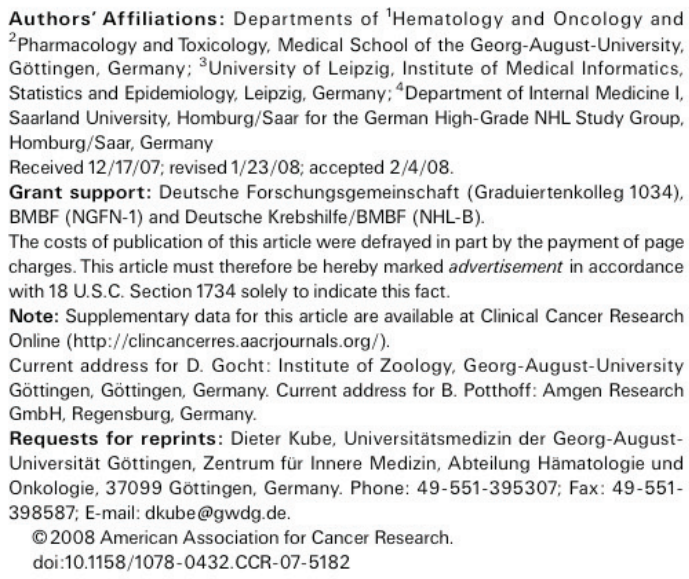

Authors' Affiliations: Departments of 'Hematology and Oncology and ${ }^{2}$ Pharmacology and Toxicology, Medical School of the Georg-August-University, Göttingen, Germany; ${ }^{3}$ University of Leipzig, Institute of Medical Informatics, Statistics and Epidemiology, Leipzig. Germany: ${ }^{4}$ Department of Internal Medicine I, Saarland University, Homburg/Saar for the German High-Grade NHL Study Group, Homburg/Saar, Germany

Received 12/17/07; revised 1/23/08; accepted 2/4/08.

Grant support: Deutsche Forschungsgemeinschaft (Graduiertenkolleg 1034), BMBF (NGFN-1) and Deutsche Krebshilfe/BMBF (NHL-B).

The costs of publication of this article were defrayed in part by the payment of page charges. This article must therefore be hereby marked advertisement in accordance with 18 U.S.C. Section 1734 solely to indicate this fact.

Note: Supplementary data for this article are available at Clinical Cancer Research Online (http://clincancerres.aacrjournals.org/)

Current address for D. Gocht: Institute of Zoology, Georg-August-University Göttingen, Göttingen, Germany. Current address for B. Potthoff: Amgen Research $\mathrm{GmbH}$, Regensburg, Germany.

Requests for reprints: Dieter Kube, Universitätsmedizin der Georg-AugustUniversităt Göttingen, Zentrum für Innere Medizin Abteilung Hämetologie und Universitat Gottingen, Zentrum fur Innere Medizin, Abtellang Hamatologie und Onkologie, 37099 Go Zingen, Germa

C2008 American Association for Cancer Research.

doi:10.1158/1078-0432.CCR-07-5182

With conventional chemotherapy, long-term remission can be achieved in approximately $50 \%$ of patients with disseminated "aggressive" non-Hodgkin's lymphoma (NHL). The disease incidence is increasing, but etiologic factors contributing to this phenomenon remain still largely unknown. Although it is a curable disease, many patients do not achieve complete remission or they relapse after conventional chemotherapy. Tumor- and host-related variables, differences in the response to therapy, may be related to genetic factors of the host $(1,2)$. Deregulated components of the immune system, for example, cytokines, may be linked to the incidence and clinical course of lymphomas by the development of acute or chronic inflammatory reactions at tumor sites. Deregulated expression of defined subsets of cytokines was found to be associated with the transformation of lymphatic cells either as autocrine growth factors for the transformed cells or as factors rebuilding the tumor microenvironment, likely affecting tumor progression and dissemination (3).

Some reports support the hypothesis that common genetic variants in immune and inflammatory response genes can 
affect the risk and clinical outcome of NHL as well as side effects of therapy like infections or hematotoxicity (for review, see refs. 4-6).

The magnitude and profile of immune responses are regulated to a large extent by cytokines. The extent to which cytokines secretion varies between individuals with consequent variations in the intensity of a given immune response could be defined in part by regulatory gene variations. Several regulatory genetic elements associated with differences in cytokine secretion have been identified in genes coding for cytokines, in part also associated with disease outcome (for review, see refs. 7,8$)$. These regulatory polymorphisms are therefore thought to be partially responsible for interindividual differences to cope with a given challenge to the immune system. Specific cytokine genotypes may be beneficial by creating a "proinflammatory" phenotype that may predispose to chronic inflammatory diseases or to a more severe form of inflammatory disease with a worse clinical outcome. However, the mechanisms underlying differences in immune response between individuals are complex but include inherited genetic variation.

Interleukin-10 (IL-10) is an important immunoregulatory cytokine in man. IL-10 is part of a balanced network of cytokines and can be cancer promoting (immunosuppressive; stimulation of cell proliferation) or cancer inhibiting (antiangiogenic; refs. 9-11). IL-10 is produced by several cells including normal and neoplastic B cells, stimulated monocytes/macrophages, and subsets of T cells. IL-10 has been implicated in certain infectious diseases, autoimmunity, transplantation tolerance, and tumorigenesis (for review, see also refs. 4, 9, 12, 13).

Polymorphisms in the IL-10 $5^{\prime}$-flanking region genetically affect interindividual differences in IL-10 production (14-23). Variable associations between IL-10 production capacity and either the $I L-10$ microsatellite alleles, single nucleotide polymorphisms (SNP), or SNP haplotypes in the 7-kb $I L-10$ 5 'flanking region have been reported $(14,16-18,23)$.
In most studies, the major proximal haplotypes GCC, ACC, or ATA formed by SNPs IL-10 $10_{-1087 \mathrm{AG}}$, IL-10 $10_{-824 \mathrm{CT}}$, and IL-10 597AC were found to be related to the in vitro IL-10 production capacity. The ATA haplotype was described as IL-10 low producer. $(14,16-18,23)$ Several studies have reported that these proximal $I L-10$ promoter polymorphisms may be related with increased risk of a diverse range of diseases (reviewed in ref. 4). This indicates that genetic variations within the $I L-10$ gene locus are relevant in vivo.

Recent reports provided evidence that a risk to develop NHL or the clinical outcome of patients suffering from diffuse large B-cell lymphoma (DLBCL) might be related to certain $I L-10$ promoter gene variations. In one study, it was reported that proximal genotypes or haplotypes with low IL-10 expression are a risk factor for aggressive lymphoma, whereas a second study suggest that genotypes of high expression potential are a risk factor for developing lymphoma in patients with AIDS $(24,25)$. An InterLymph epidemiologic multicenter study described the IL-10 3538 A regulatory SNP to be associated with for increased risk to develop NHL (26). This, however, was no verified in a subgroup from Germany/Heidelberg (27). In our study, allele frequencies of lymphoma patients are comparable with those of unmatched healthy controls (28). A French study (GELA) showed that in DLBCL patients the IL-10 ${ }_{-1087 \mathrm{G}}$ allele may be a risk factor for disease susceptibility, but this could not be verified in a cohort from Scandinavia $(29,30)$. In addition, no correlation to any clinical variables was found as described in the GELA study $(29,30)$. Analyzing the $I L-10$ gene loci at $-3538(\mathrm{~A} / \mathrm{T}),-1354(\mathrm{~A} / \mathrm{G}),-824(\mathrm{C} / \mathrm{T})$, and $-597(\mathrm{~A} / \mathrm{C})$, we did not find any difference in overall survival (OS) or event-free survival (EFS) for NHL patients (28). However, these studies differed to some extent in terms of age range, lymphoma subtype, modest study size, and partially insufficient power.

The aim of this study was to analyze distal gene variation within the 5'-flanking region of the $I L-10$ gene in a large, representative, equally treated cohort of patients suffering

Table 1. Clinical characteristics and diagnosis of patients with aggressive NHL

\begin{tabular}{|c|c|c|c|}
\hline Patient characteristics & $\begin{array}{l}\text { All patients } \\
\text { in NHL-B1/B2 trials } \\
(N=1,399)\end{array}$ & $\begin{array}{l}\text { All patients analyzed } \\
\text { for IL-10 gene variations } \\
(n=500)\end{array}$ & $\begin{array}{l}\text { DLBCL patients } \\
\text { analyzed for IL10 } \\
\text { gene variations }(n=319)\end{array}$ \\
\hline \multicolumn{4}{|l|}{ Sex } \\
\hline Male & $789(56)$ & $280(56)$ & $180(56)$ \\
\hline Female & $610(44)$ & $220(44)$ & $139(44)$ \\
\hline Age, median (min; max) & $60(18 ; 75)$ & $62(23 ; 75)$ & $62(23 ; 75)$ \\
\hline Serum LDH $>N$ & $316(23)$ & $123(25)$ & $85(27)$ \\
\hline Age $>60$ y & $689(49)$ & $273(55)$ & $178(56)$ \\
\hline Performance status ECOG >1 & $163(12)$ & $65(13)$ & $46(14)$ \\
\hline Ann Arbor stage III/IV & $567(41)$ & $202(40)$ & $122(38)$ \\
\hline No. extranodal sites $\geq 2$ & $276(20)$ & $104(21)$ & $61(19)$ \\
\hline \multicolumn{4}{|l|}{ IPI* } \\
\hline Low $(\mathrm{IPI}=0,1)$ & $840(60)$ & $280(56)$ & $173(54)$ \\
\hline Low intermediate (IPI $=2$ ) & $250(18)$ & $99(20)$ & $66(21)$ \\
\hline High intermediate (IPI $=3$ ) & $170(12)$ & $67(13)$ & $46(14)$ \\
\hline High $(\mathrm{IPI}=4,5)$ & $139(10)$ & $54(11)$ & $34(11)$ \\
\hline Bulky tumor $(\geq 7.5 \mathrm{~cm})$ present & $467(33)$ & $164(33)$ & $109(34)$ \\
\hline B symptoms & $402(29)$ & $142(28)$ & $86(27)$ \\
\hline Extranodal involvement & $698(50)$ & $252(50)$ & $153(48)$ \\
\hline
\end{tabular}

NOTE: Values in table expressed as total number of patients (\%), unless otherwise indicated. For additional information about the histology of patients with aggressive $\mathrm{NHL}$, refer to Supplementary File 1.

${ }^{*} \mathrm{LDH}>\mathrm{N}$, age $>60$ years, ECOG $>1$, stage III/IV, and number of extranodal sites $\geq 2$ 


\begin{tabular}{|c|c|c|c|}
\hline Genotypes & Control, $n(\%)$ & NHL patients, $n(\%)$ & $\boldsymbol{P}$ \\
\hline \multicolumn{4}{|l|}{-7400InDel } \\
\hline InIn & $150(64)$ & $305(61)$ & $0.995 *$ \\
\hline InDel & $72(31)$ & $178(36)$ & $0.110^{\dagger}$ \\
\hline DelDel $^{\ddagger}$ & $14(6)$ & $17(3)$ & $0.505^{\S}$ \\
\hline \multicolumn{4}{|l|}{$-6752 A T$} \\
\hline AA & $91(39)$ & $176(35)$ & $0.399 *$ \\
\hline AT & $113(48)$ & $250(50)$ & $0.655^{\dagger}$ \\
\hline$\pi^{ \pm}$ & $32(14)$ & $74(15)$ & $0.376^{\S}$ \\
\hline \multicolumn{4}{|l|}{$-6208 C G$} \\
\hline $\mathrm{CC}^{ \pm}$ & $44(19)$ & $80(16)$ & $0.928^{*}$ \\
\hline CG & $110(47)$ & $262(52)$ & $0.371^{\dagger}$ \\
\hline GG & $82(35)$ & $158(32)$ & $0.395^{\S}$ \\
\hline \multicolumn{4}{|l|}{-3538AT } \\
\hline $\mathrm{AA}^{ \pm}$ & $33(14)$ & $74(15)$ & $0.962 *$ \\
\hline AT & $122(52)$ & $249(50)$ & $0.769^{\dagger}$ \\
\hline$\pi$ & $81(34)$ & $177(35)$ & $0.775^{\S}$ \\
\hline \multicolumn{4}{|l|}{$-1087 A G$} \\
\hline AA & $67(28)$ & $134(27)$ & $0.766^{*}$ \\
\hline AG & $108(46)$ & $253(51)$ & $0.333^{\dagger}$ \\
\hline $\mathrm{GG}^{ \pm}$ & $61(26)$ & $113(23)$ & $0.651^{\S}$ \\
\hline \multicolumn{4}{|l|}{$-597 A C$} \\
\hline $\mathrm{AA}^{ \pm}$ & $14(6)$ & $26(5)$ & $0.436 *$ \\
\hline AC & $98(42)$ & $196(39)$ & $0.683^{\dagger}$ \\
\hline CC & $124(53)$ & $278(56)$ & $0.437^{\S}$ \\
\hline
\end{tabular}

${ }^{*}$ Genic comparison (allele).

${ }^{\dagger}$ Minor homozygotes vs. heterozygotes + major homozygotes.

¥ Minor genotype.

$\S$ Major homozygotes vs. heterozygote + minor homozygotes.

from aggressive NHL and their role in predisposing an individual to lower remission rates, OS, or shorter periods of EFS and whether these associations are distinctive for DLBCL subtypes. The comparison of these gene variations with clinical variables such as EFS and OS revealed that distal regulatory gene variations of the $I L-10$ gene are related to some extent to poor prognosis of patients with aggressive NHL.

\section{Materials and Methods}

Patients and treatment. Lymphoma patients included into this study were from the NHL-B1/B2 study from the German NHL Study Group as described recently (Supplementary File 1; refs. 31, 32). The study was conducted in accordance with the Declaration of Helsinki. The protocol was approved by the ethics review committee of each participating center. All patients gave written informed consent. Patients were eligible if they had previously untreated, biopsy-confirmed aggressive NHL according to the Revised European-American Lymphoma Classification (translated into the WHO classification).

In this analysis, we included 500 patients from NHL-B1 and NHL-B2 studies. Three hundred and ninety-seven patients within this cohort were already genotyped for proximal SNPs at $-1087 \mathrm{~A} / \mathrm{G}$ ( $\mathrm{rs} 1800896)$, $-597 \mathrm{~A} / \mathrm{C}$ (rs1800872), and $-3538 \mathrm{~A} / \mathrm{T}$ (rs1800890) as published recently (28). Clinical characteristics of the 500 patients eligible for this study are shown in Table 1 and are representative for all 1,399 NHL-B 1 and NHL-B2 patients. The respective histology presented in Supplementary File 1 is based on a blinded central pathology review by a panel of expert hematopathologists.
The control group included 236 healthy blood donors. All samples were taken with no regard to sex or age, and donors were free of any chronic diseases.

Genotyping analyses. Blood samples and DNA isolation, multiplex PCR, and Taqman real-time PCR were done.

DNA from 236 unrelated healthy blood donors was included into this analysis as described previously $(23,33)$. DNA samples from 500 lymphoma patients were isolated by the same procedure and were described previously $(23,28,34)$.

For the analysis of the genetic polymorphisms of the IL-10 5'-flanking region, a multiplex assay was used as described recently $(23,28,33)$. Within the multiplex assay, the -7400 InDel gene variation was analyzed as well as SNPs at -6752A/T (rs6676671), -6208C/G (rs10494879), $-597 \mathrm{~A} / \mathrm{C}$ (rs1800872), and $-3538 \mathrm{~A} / \mathrm{T}$ (rs 1800890). In addition, the SNPs at $-1087 \mathrm{~A} / \mathrm{G}(\mathrm{rs} 1800896),-6752 \mathrm{~A} / \mathrm{T}(\mathrm{rs} 6676671),-6208 \mathrm{C} / \mathrm{G}$ (rs 10494879), -597A/C (rs1800872), and -3538A/T (rs1800890) were analyzed by Taqman SNP genotyping assays (for details, see Supplementary File 2).

Statistical analysis. For the analysis of the IL-10 polymorphisms, 500 patients were selected from the NHL-B1/B2 study population, considering the factors of the international prognostic index [IPI; age $>60$ years, lactate dehydrogenase $(\mathrm{LDH})>\mathrm{N}$, Eastern Cooperative Oncology Group (ECOG) $>1$, stage III/IV, >1 extranodal involvement], bulky disease, and B symptoms to be representative for the NHL-B1/B2 trial population.

Genetic data were analyzed using GENEPOP software. Analysis included tests for Hardy-Weinberg equilibrium and genotypic and allelic differentiation between healthy controls and lymphoma patients. Haplotype analysis was done using Arlequin software and http:// www.bioinf.mdc-berlin.de/projects/hap/. WHO grades for leukocytopenia and infection, genic, genotypic, and allelic differentiation between groups were analyzed using the $x^{2}$ test and, if required, Fisher's exact test.

EFS was defined as time from first day of therapy to progressive disease under therapy or failure to achieve complete remission or $\mathrm{CR}$ unconfirmed (that is, no change or partial remission associated with additional therapy), additional therapy in excess of that prescribed in the protocol, relapse or death from any cause, whichever came first. OS was defined as time from first day of therapy to death from any cause. Patients without an event in EFS or OS were censored at the last day with valid information for the respective endpoint. EFS and OS were estimated according to Kaplan-Meier and compared by log-rank test.

Multivariate analyses were done with the use of Cox proportional hazards models to estimate hazard ratios for evolving an event. Nominal significance level was at 0.05 (two-sided). We are aware of the problem of multiple comparisons and therefore have chosen to extract the most prominent aspect. Statistical analyses were done with SPSS (version 11.5) software.

\section{Results}

IL-10 gene polymorphisms in patients with aggressive NHL and in healthy control subjects. The IL-10 5'-flanking gene variations at IL-10-7400InDel, IL-10-6752AT, IL-10 $-6208 \mathrm{CG}$, IL-10. $3538 \mathrm{AT}, \mathrm{IL}-10_{-1087 \mathrm{AG}}$, and IL-10 $0_{-597 \mathrm{AC}}$ were analyzed in $500 \mathrm{NHL}$ patients. Allele frequencies, genotypes, and haplotypes were defined and compared with corresponding healthy controls. In Table 2, genic and genotypic data are summarized for the IL-10 gene variations. For the IL-10 -740 innel gene variation only, the genotype IL-10 $10_{-700 D e l D e l}$ is less frequently present in the group of patients with NHL. However, this difference is not significant $(P=0.110)$. The testing showed that there are no significant differences between healthy controls and NHL patients in our study as well as for the other analyzed gene loci.

Our control group of 236 healthy blood donors was taken with no regard to sex or age, and donors were free of any chronic diseases. Therefore, this is not a classic case-control 


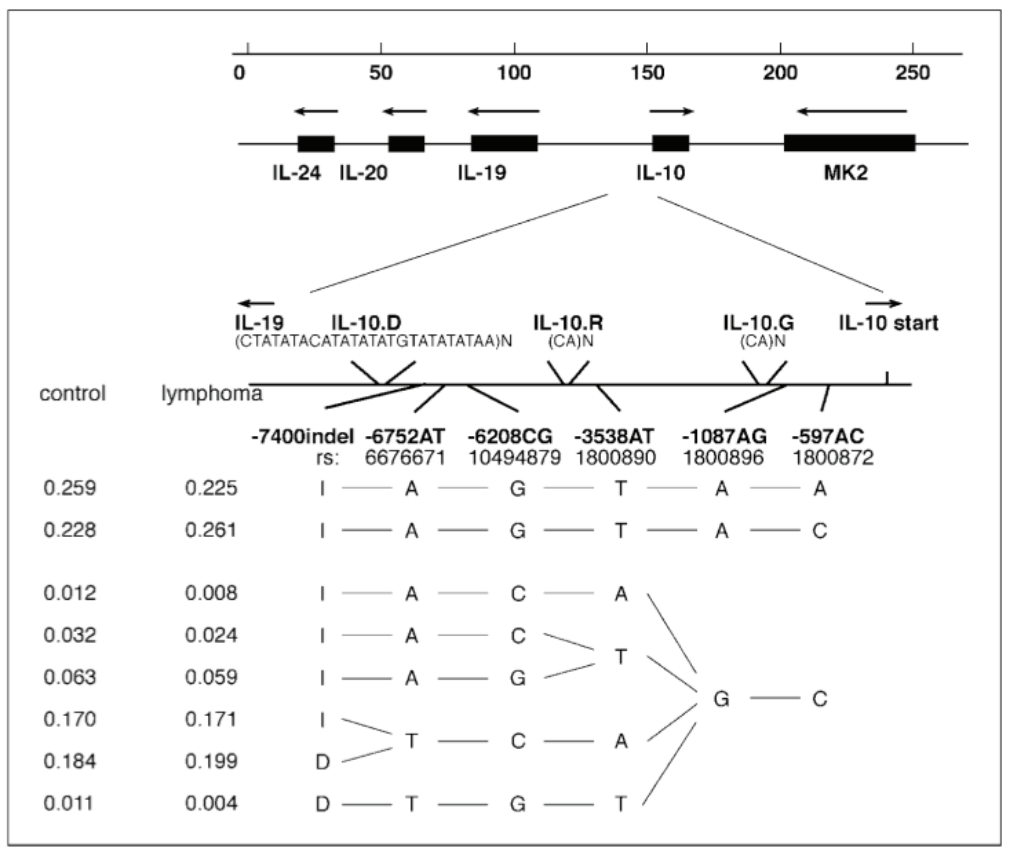

Fig. 1. Graphical view of the extended haplotypes of the $5^{\prime}$-flanking region of the IL-10 gene. IL-10 gene variations -7400 , $-6752,-6208,-3538,-1087$, and -597 in relation to the $1 L-10$ promoter microsatellites (start) of the $/ L-10$, IL-10.D and the ATG (start) of the $/ L-10$ gene as described in Kube et al. (22) and Mormann et al. (23). rop, schematic view of the $14-10$ al/3il extended haplotype frequencies are shown for the healthy controls (contro $n=236$ ) and the NHL patients (lymphom $n=500$ ). No significant differences in $n=500$ ). No significant differences in of $-3538,-1087$, and -597 have been genotyped in a previous study in 379 lymphoma patients. study. However, a comparison of genotype distribution for IL-10 $10_{-3538 \mathrm{AT}}$ and IL- $10_{-1087 \mathrm{AG}}$ of our control group with published data from EPILymph Germany performing a classic case-control study revealed no relevant differences (Supplementary Table S1; refs. 26, 27). The Hardy-Weinberg test showed no significant differences between observed and suspected numbers of homozygotes or heterozygotes for the analyzed gene variations of the $I L-10$ gene in both groups (Supplementary Table S1). The same is found for the subgroup of 319 DLBCL patients within our study (Supplementary Table S2).

Based on the presented genotyping data, respective haplotypes of the 5 -flanking region of the $I L-10$ gene were estimated. All haplotypes with a frequency higher than 3\% are shown in Fig. 1. Haplotype estimation was done for both healthy controls and NHL patients. Four major haplotypes are present: IAGTAA, IAGTAC, ITCAGC, and DTCAGC (IL-10 gene variations -7400, $-6752,-6208,-3538,-1087$, and -597). The IL-10-7400Del locus seems to be nearly exclusively linked with IL- $10_{-1087 \mathrm{G}}$. The further analysis of haplotypes reveals no significant differences between healthy controls and lymphoma patients.

IL-10 polymorphisms and aggressive NHL outcome. The clinical prognostic features incorporated in the IPI, including age, LDH level, performance status, clinical stage and number of extranodal sites, mostly reflect the disease extension and the patient's characteristics. Therefore, we compared gene variations of the 5 '-flanking region of the $I L-10$ gene with these clinical variables, including hematotoxicity or infections according to WHO grades. Among 500 NHL patients, no associations were found between $I L-10$ gene variations and five single IPI prognostic factors ( $\mathrm{LDH}>\mathrm{N}$, ECOG $>1$, extranodal involvement $>1$, stage $>$ II, and age $>60$ years).
Infection WHO grade 3 or 4 during the first cycle of chemotherapy ranged between $0 \%$ for patients characterized by IL-10-7400DelDel and 5.6\% carrying IL-10-3538AA. However these differences were not significant between analyzed genotypes (data not shown). Similar results were obtained when taking into account all cycles of chemotherapeutic treatment. The rate of cycles with infection grade 3 or 4 was also not significant.

Leukocytopenia as a variable of hematotoxicity of chemotherapy was analyzed in relation to $I L-10$ gene variations. For the gene variation IL-10 $597 \mathrm{AC}$, we observed a risk to develop leukocytopenia with WHO grade 3 or 4 for heterozygous patients. Leukocytopenia of WHO grades 3 and 4 was observed in $37 \%$ and $39 \%$ cycles for homozygous AA and CC patients, respectively, and in $45 \%$ cycles for heterozygous AC patient $(P=0.002)$. The rates of patients with leukocytopenia grades 3 and 4 were $38 \%, 31 \%$, and $47 \%$ for patients with AA, CC, and AC, respectively $(P=0.001)$

Univariate analysis of OS and EFS of 500 NHL patients in comparison with $I L-10$ gene variations showed a significantly shorter OS for the $I L-10$ genotype IL-10-740oDelDel (Table 3 Fig. 2A). The respective 3-year survival rates were significantly reduced. Within this period, only $43.4 \%$ of patients carrying IL-10-7400DelDel survived [95\% confidence interval (95\% CI), $19 \%, 68 \%$, whereas $72.3 \%$ (95\% CI, $67 \%, 77 \%$ ) or $75.3 \%$ $(95 \% \mathrm{CI}, 69 \%, 82 \%)$ of patients carrying IL-10 IL-10-740oInDel, respectively, had no event of death $(P=0.009)$ The OS rate for the IL-10-7400DelDel genotype is shown in more detail as a Kaplan-Meier plot in Fig. 2A. The OS difference between patients carrying IL-10-7400DelDel and patients with the other genotypes together was also significant $(P=0.004$ 
Table 3). The IL-10-7400DelDel genotype has been described recently as "IL-10 high producer" (35). The 3-year survival rates for patients with IL-10 -6752 TT was $64.6 \%$ (95\% CI, 53\%, 76\%) and $73.7 \%(95 \% \mathrm{CI}, 69 \%, 78 \%)$ for patients with IL- $10_{-6752 \mathrm{AT}}$ and $\mathrm{IL}-10_{-6752 \mathrm{AA}}$ together with a borderline significance $(P=0.051$; Table 3$)$. The OS rate for the IL-10_6752тT genotype is also shown in more detail as a Kaplan-Meier plot in Fig. 2B. For $\mathrm{IL}-10_{-6208 \mathrm{CG}}, \mathrm{IL}-10_{-3538}, \mathrm{IL}-10_{-1087}$, and $\mathrm{IL}-10_{-597 \mathrm{AC}}$ gene variations, no significant shorter cumulative OS periods were observed (Table 3)

The analysis of EFS showed no significant differences when analyzing single loci. However, the $I L-10$ genotypes IL-10-7400DelDel and IL-10 $10_{-6752 \mathrm{TT}}$ were characterized by a trend toward shorter EFS periods $(P=0.091$ and 0.063 , respectively; Fig. 2C and D).

A haplotypic analysis showed that almost all patients (16 of 17) characterized by a homozygous genotype IL-10 -7400 Del were also homozygous for IL-10-6752T as part of the haplotype DelTCAGC (IL-10 gene variations $-7400,-6752,-6208,-3538$, -1087, and -597) and have an unfavorable disease outcome. When comparing OS or EFS of homozygous carriers for the TCA haplotype (IL-10 gene variations $-6752,-6208$, and -3538) with all other genotypes, a significant association with EFS $(P=0.047)$ and a borderline significance for OS $(P=0.064)$ were observed (Fig. $2 \mathrm{E}$ and $\mathrm{F}$ ).

In a multivariate analysis, we investigated the effect of the genotype variations after adjusting for the five IPI risk factors (age $>60$ years, elevated pretreatment LDH, ECOG performance state $>1$, advanced stage III/IV, and $>1$ extranodal involvement). Only genotype IL-10 $10_{-7400 \text { DelDel }}$ compared with IL-10-7400Insins and IL-10-740InsiDel had a clear trend of increasing risk (relative risk, 1.9) and was significant in OS $(P=0.037$; Table 4$)$. The estimated relative risk of 1.9 is comparable with that of the variables used in clinical practice. Analysis of the subgroup of 319 DLBCL patients showed no significant differences between healthy controls and NHL patients (Supplementary Table S2). For the OS, the 3-year rate

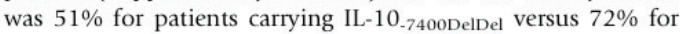
patients carrying IL-10 $-7400 \mathrm{InIn}$ and IL-10-7400InDel $(P=0.096$; small number of patients with IL-10 -7400 DelDel; $n=11$ ). For all other analyzed gene loci, no significant OS and EFS differences were observed.

\section{Discussion}

The role of inherited factors in the extent of IL-10 deregulation in malignant disorders is still controversial. The preliminary data obtained thus far indicate that additional larger studies of patients are required to confirm initial results in the understanding of the role of IL-10 in lymphoma development. We report one of the first analyses of the association between far distal gene variations of the IL-10 5 -flanking region and aggressive NHL within the thus far largest homogenously treated aggressive NHL patients group with 500 individuals representing the NHL-B1/B2 study from the DSHNHL study group. The results of the present exploratory study strongly support the hypothesis that genetic polymorphisms within the chromosomal locus 1q31/32 of the 5 '-flanking region of the $I L-10$ gene are associated with adverse prognostic factors and predict poor outcome of aggressive NHL. In this study, we show that patients suffering from aggressive NHL carrying the IL-10 genotype

\begin{tabular}{|c|c|c|c|c|c|c|c|c|c|}
\hline Genotype & 3-y rate os & $\boldsymbol{P}$ & 3-y rate EFS & $\boldsymbol{P}$ & Genotype & 3-y rate os & $P$ & 3-y rate EFS & $\boldsymbol{P}$ \\
\hline \multicolumn{10}{|l|}{-7400} \\
\hline $\operatorname{InIn}(n=305)$ & 72.3 & \multirow[t]{3}{*}{0.009} & 59.1 & \multirow[t]{3}{*}{0.190} & InIn; InDel & 73.4 & \multirow[t]{3}{*}{0.004} & 60.4 & \multirow[t]{3}{*}{0.091} \\
\hline InDel $(n=178)$ & 75.3 & & 62.5 & & DelDel & 43.4 & & 39.2 & \\
\hline DelDel $(n=17)$ & 43.4 & & 39.2 & & & & & & \\
\hline \multicolumn{10}{|l|}{-6752} \\
\hline AA $(n=176)$ & 72.8 & \multirow[t]{3}{*}{0.143} & 60.3 & \multirow[t]{3}{*}{0.166} & $\mathrm{AA} ; \mathrm{AT}$ & 73.7 & \multirow[t]{3}{*}{0.051} & 60.8 & \multirow[t]{3}{*}{0.064} \\
\hline AT $(n=250)$ & 74.4 & & 61.2 & & $\pi$ & 64.6 & & 53.2 & \\
\hline$\Pi(n=74)$ & 64.6 & & 53.2 & & & & & & \\
\hline \multicolumn{10}{|l|}{-6208} \\
\hline $\mathrm{CC}(n=80)$ & 68.8 & \multirow[t]{3}{*}{0.448} & 59.4 & \multirow[t]{3}{*}{0.768} & GG; CG & 73.1 & \multirow[t]{3}{*}{0.365} & 59.7 & \multirow[t]{3}{*}{0.499} \\
\hline CG $(n=262)$ & 74.4 & & 59.9 & & $\mathrm{CC}$ & 68.8 & & 59.4 & \\
\hline $\mathrm{GG}(n=158)$ & 70.9 & & 59.6 & & & & & & \\
\hline \multicolumn{10}{|l|}{-3538} \\
\hline AA $(n=74)$ & 66.3 & \multirow[t]{3}{*}{0.172} & 56.2 & \multirow[t]{3}{*}{0.217} & $\mathrm{AT} ; \mathrm{TT}$ & 73.5 & \multirow[t]{3}{*}{0.116} & 60.3 & \multirow[t]{3}{*}{0.137} \\
\hline AT $(n=249)$ & 75.2 & & 61.4 & & AA & 66.3 & & 56.2 & \\
\hline$\Pi(n=177)$ & 71.0 & & 58.7 & & & & & & \\
\hline \multicolumn{10}{|l|}{-1087} \\
\hline $\mathrm{AA}(n=134)$ & 71.7 & \multirow{3}{*}{0.788} & 60.6 & \multirow{3}{*}{0.936} & $A A ; A G$ & 73.4 & \multirow{3}{*}{0.553} & 60.1 & \multirow[t]{3}{*}{0.733} \\
\hline AG $(n=253)$ & 74.2 & & 59.8 & & GG & 69.1 & & 58.5 & \\
\hline GG $(n=113)$ & 69.1 & & 58.5 & & & & & & \\
\hline \multicolumn{10}{|l|}{-597} \\
\hline $\mathrm{AA}(n=26)$ & 71.6 & \multirow[t]{3}{*}{0.666} & 52.4 & \multirow[t]{3}{*}{0.778} & $\mathrm{CC} ; \mathrm{AC}$ & 72.4 & \multirow[t]{3}{*}{0.416} & 60.1 & \multirow[t]{3}{*}{0.480} \\
\hline AC $(n=196)$ & 72.7 & & 59.5 & & $A A$ & 71.6 & & 52.4 & \\
\hline $\mathrm{CC}(n=278)$ & 72.2 & & 60.5 & & & & & & \\
\hline
\end{tabular}

NOTE: Patients characterized by the genotypes $\mathrm{IL}-10_{-7400 \mathrm{DelDel}}$ or $\mathrm{IL}-10_{-6752 \pi}$ had a poorer prognosis compared with the other genotypes respectively. Italic $P$ values are significant. For continuative description of significant results, see also Fig. 2 . 


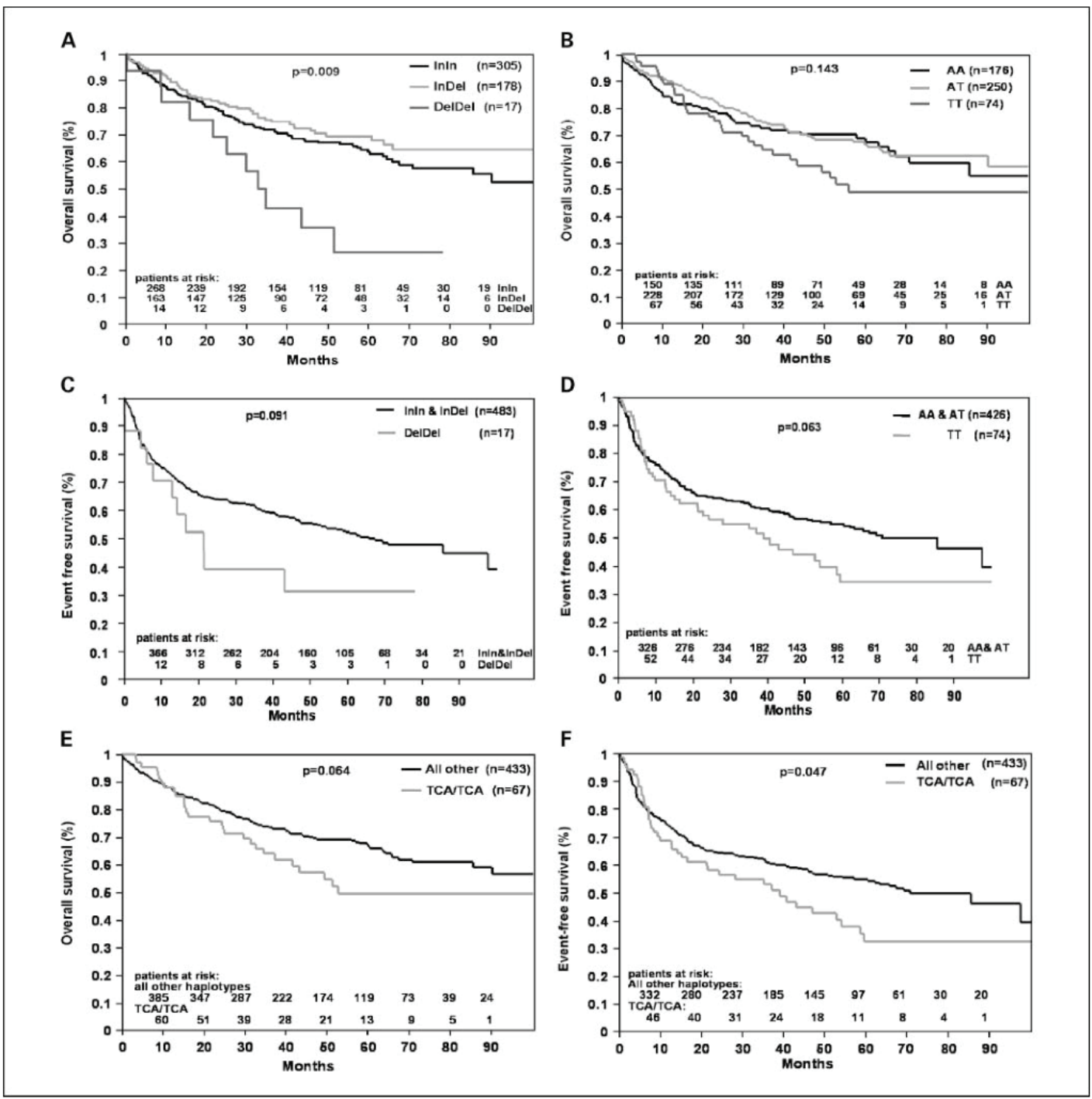

Fig. 2. OS and EFS of patients suffering from aggressive $N H L$ in relation to gene variations of the $/ L-10$ gene 5 '-flanking region. Comparison of genotypes for OS in $(A)$

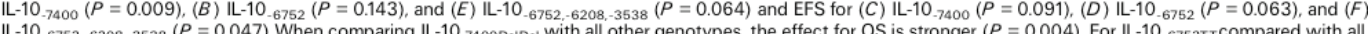

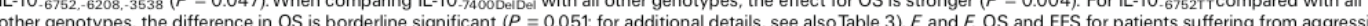
NHL compared with the homozygous genotype IL-10 still can develop an event (OS or EFS) at defined time points (here 10-month interval monitored).

IL-10-7400DelDel have a shorter cumulative OS. In addition, homozygous carriers for TCA haplotypes (IL-10 gene variations $-6752,-6208$, and -3538 ) have poor EFS.

The multivariate analysis of the most distal gene variation an insertion/deletion mutation at -7400 revealed a 1.9 -fold increased risk for carriers of the deletion on both alleles to have a poor prognosis (OS; Table 4). This observed relative risk is comparable with those estimated by analyzing clinical variables (age $>60$ years and ECOG $>1$ ), which have a relative risk of 2.0 or 2.1 , respectively.

The increased relative risk of carriers of -7400DelDel has to be discussed also in the context of the IL-10 production capacity of respective healthy carriers. In a recent work, we showed that this genotype is characterized by an extremely high IL-10 expression capacity after in vitro stimulation with lipopolysaccharide (35). The IL-10-7400DelDel genotype is rare 


\begin{tabular}{|c|c|c|}
\hline Factor & Relative risk ( $95 \% \mathrm{CI}$ ) & $\boldsymbol{P}$ \\
\hline $\mathrm{LDH}>\mathrm{N}$ & $1.7(1.2-2.5)$ & 0.005 \\
\hline Age $>60 y$ & $2.0(1.3-3.0)$ & 0.001 \\
\hline ECOG $>1$ & $2.1(1.4-3.0)$ & $<0.001$ \\
\hline Stage III/IV & $1.5(1.0-2.1)$ & 0.029 \\
\hline Extranodal involvement $>1$ & $1.0(0.7-1.4)$ & 0.888 \\
\hline DelDel vs InsIns, InsDel & $1.9(1.0-3.6)$ & 0.037 \\
\hline
\end{tabular}

in Caucasians as well as in other thus far analyzed geographic regions from central Africa or Vietnam (23). ${ }^{5}$ This could suggest that additional gene variations probably in linkage disequilibrium to the described haplotype are important but not yet identified. Follow-up analysis will be needed to investigate additional gene variations across the chromosomal region $1 \mathrm{q} 31 / 32$ as suggested recently by Lan et al. (36). Several DNase I-hypersensitive sites on a conserved $40-\mathrm{kb}$ region between IL-19 and IL-10 genes revealed three functional enhancer elements, which reflect changes of the chromatin structure associated with $I L-10$ gene expression. Two of these enhancer elements with influence on IL-10 gene expression are located in comparable distances to the transcriptional start site of $I L-10$ as the analyzed far distal gene variations $(37-43)$. Whether these chromatin changes are also affected by far distal IL-10 gene variations and influence therefore the differential IL-10 expression level remains to be analyzed in the future.

Promoter polymorphisms, including so-called regulatory SNPs, have been subject to the most scrutiny, particularly with regard to possible influence on regulation of gene transcription. The mechanism behind this for the IL-10 gene is still unknown probably because of the close proximity of -1087AG to the IL-10.G microsatellite; the IL-10.R microsatellite may affect IL-10 expression levels $(17,19)$. At this stage, the precise role of $I L-10$ promoter gene variations, individually or as part of defined proximal or distal haplotypes, in determining IL-10 expression is still a subject awaiting answers, including the question of allele-specific regulation (44). For example, the haplotype TCA (IL-10 -6752T-6208C-3538A) associated with poor EFS of NHL patients showed in in vitro experiments an intermediate response to lipopolysaccharide $(23,35)$. In addition, patients carrying IL-10 $3538 \mathrm{AA}$ are characterized by an increased risk to display an IPI $>2(P=0.025$ and 0.033 respectively) in both aggressive NHL and respective DLBCL patients. Patients with IPI $>2$ are about twice more often $\left(>20 \%\right.$ ) homozygous for IL- $10_{-3538 \text { A }}$ (for additional details, see

${ }^{5}$ Kube et al., unpublished observations.
Supplementary Table S3). However, after Bonferroni correction for multiple testing, these differences would be not longer significant. This observation that patients homozygous for IL-10 $3538 \mathrm{AA}$ may have a higher risk for IPI $>2$ and that carriers of IL-10-7400DelDel and IL- $10_{6752 \mathrm{TT}}$ are characterized by shorter cumulative OS may support the hypothesis that specific cytokine gene variations or polymorphisms in regulatory regions of cytokine genes are markers of tumor progression. Our finding of an increased risk to develop leukocytopenia WHO grades 3 and 4 when carrying both IL- $10_{-597 \mathrm{~A}}$ and IL- $10_{-597 \mathrm{C}}$ alleles adds some new aspect but does not fit to the current understanding of IL-10 production capacity and therefore remains to be elucidated by additional studies and in vitro experiments.

The clinical outcome of patients suffering from DLBCL was not related to proximal $I L-10$ promoter gene variations as described by other investigations. There was no significant difference in OS and EFS in the subgroup of DLBCL patients, but remarkably the genotype IL-10 -7400 DelDel had a clear trend in OS. Apparently these conflicting data may in part reflect the pleiotropic functions of IL-10 as cancer promoter or inhibitor in relation to the biological growth patterns of the lymphoma subgroups (11). Furthermore, differences in cancer karyotype complexity are also defining the disease state. In addition, antigenic and nonantigenic stimuli may be affecting the IL-10 expression by the lymphoma cells or their microenvironment (45).

Gene expression data have started to delineate the known molecular heterogeneity of aggressive NHL into distinct molecular entities but underlined the role of host response factors in some subtypes of these lymphomas (46-48). Bringing together molecular classifications, epidemiologic findings with well-designed clinical trials and respective in vitro analysis will help us understand the regulatory role of inherited IL-10 expression in the pathogenesis of lymphoma (49). Our major finding about an association between the IL-10 genotype IL-10-7400DelDel and the significant shorter cumulative OS or that of the haplotype TCA (IL-10 -6752T-6208C-3538A) with poor EFS of NHL patients is, however, not yet suitable as a prognostic factor in routine use.

In this work, we have chosen to extract the most prominent clinical aspect and defined a new focused hypothesis for further validation study: IL-10 -7400 DelDel or the haplotype TCA (IL-10. 6752T-6208C-3538A) could be a risk factor for poor clinical outcome for patients with aggressive NHL. This hypothesis can now be verified in independent patient cohort, for example, within the DSHNHL RICOVER study, or even in cohorts from other study groups with comparable expert hematopathologist review and treatment regimen.

Disclosure of Potential Conflicts of Interest

No potential conflicts of interest were disclosed.
References

1. Kaiser U, Uebelacker I, Abel U, et al. Randomized study to evaluate the use of high-dose therapy as part of primary treatment for "aggressive" lymphoma. Clin Oncol 2002,20.4413-9.

2. Wunderlich A, Kloess M, Reiser M, et al. Practicability and acute haematological toxicity of 2- and 3-weekly CHOP and CHOEP chemotherapy for aggressive non-Hodgkin's lymphoma: results from
the NHL-B trial of the German High-Grade Nona Study Group (DSHNHL) Ann Oncol 2003:14:881-93.

3. Lin WW, Karin M. A cytokine-mediated link between innate immunity, inflammation, and cancer. J Clin Invest 2007;117:1175-83
4. Hollegaard MV, Bidwell JL. Cytokine gene polymorhism in human disease: on-line databases, supplement 3. Genes Immun 2006;7:269-76. 5. Howell WM, Rose-Zerilli MJ. Interleukin-10 polymorphisms, cancer susceptibility and prognosis. Fam Cancer 2006,5:143-9.

6. Lossos IS, Morgensztern D. Prognostic biomarkers 
in diffuse large B-cell lymphoma. J Clin Oncol in diffuse large B-cell
$2006 ; 24: 995-1007$.

7. Bidwell J, Keen L, Gallagher G, et al. Cytokine gene polymorphism in human disease: on-line databases, polymorphism in human disease: on-line
supplement 1. Genes Immun 2001:2:61-70

8. Haukim N, Bidwell JL, Smith AJP, et al. Cytokine gene polymorphism in human disease: on-line databases, supplement 2. Genes Immun 2002;3:313-30. 9. Moore KW, de Waal Malefyt R, Coffman RL, O'Garra
A. Interleukin- 10 and the interleukin-10 receptor. Annu Rev Immunol 2001;19:683-765.

10. Cervenak L, Morbidelli L, Donati D, et al. Abolished angiogenicity and tumorigenicity of Burkitt lymphoma by interleukin-10. Blood 2000;96:2568-73.

11. Mocellin S, Marincola FM, Young HA. Interleukin-10 and the immune response against cancer: a counterpoint. J Leukoc Biol 2005;78:1043-51.

12. Blay JY, Burdin N, Rousset F, et al. Serum interleukin-10 in non-Hodgkin's lymphoma: a prognostic factor. Blood 1993:82:2169-74.

13. Benjamin D, Park CD, SharmaV. Human B cell interleukin 10. Leuk Lymphoma 1994;12:205-10.

14. Turner D, Williams D, Sankaran D, Lazarus M, Sinnott P. Hutchinson I. An investigation of polymorphism in the interleukin-10 gene promoter. Eur J Immunogenet 1997:24:1-8

15. Westendorp R, Langermans $J$, Huizinga $T$, et al. Genetic influence on cytokine production and fatal meningococcal disease. Lancet 1997;349:170 - 3 .

16. Gibson AW, Edberg JC, Wu J, Westendorp RG, Huizinga TW, Kimberly RP. Novel single nucleotide polymorphisms in the distal IL-10 promoter affect IL-10 production and enhance the risk of systemic lupus erythematosus. Jimmunol 2001,166.3915-22.

17. Eskdale J, Gallagher G, Verweij C, Keijsers V, Westendorp R, Huizinga T. Interleukin 10 secretion in relation to human IL-10 locus haplotypes. Proc Natl Acad Sci U S A 1998:95:9465-70.

18. Crawley E, Kay R, Sillibourne J, Hutchinson I, Woo P. Polymorphic haplotypes of the IL-10 $5^{\prime}$ flanking region determine variable IL-10 transcription and are associated with particular phenotypes of juvenile rheumatoid

19. Eskdale J, Kube D, Tesch H, Gallagher G. Mapping of the human IL10 gene and further characterization of the 5 flanking sequence. Immunogenetics $1997,46.120-8$. 20. Gallagher G, Dickensheets H, Eskdale J, et al. Cloning, expression and initial characterisation of interleukin-19 (IL-19), a novel homologue of human interleukin-10 (IL-10). Genes Immun 2000;1:442-50. 21. D'Alfonso S, Rampi M, Rolando V, Giordano M, Momigliano Richiardi P. New polymorphisms in the 22. Kube D, Rieth H, Eskdale J, Kremsner P, Gallagher 22. Kube $D$, Rieth $H$, Eskdale J, Kremsner P, Gallagher
G. Structural characterisation of the distal $5^{\prime}$ flanking G. Structural characterisation of the distal 5 llanking
region of the human interleukin-10 gene. Genes region of the human
3. Mormann M, Rieth H, Hua TD, et al. Mosaics of gene variations in the Interleukin-10 gene promote stimulation used. Genes Immun 2004;5:246-55.

24. Cunningham L Chapman C Dunstan R, Bell Joske D. Polymorphisms in the interleukin 10 gen promoter are associated with susceptibility to aggressive non-Hodgkin's lymphoma. Leuk Lymphom 2003:44:251-5.

25. Breen EC, Boscardin WJ, Detels R, et al. Non-Hodgkin's $B$ cell lymphoma in persons with acquired immunodeficiency syndrome is associated with increased serum levels of IL10, or the IL10 promoter $-592 \mathrm{C} / \mathrm{C}$ genotype. Clin Immunol 2003:109:119-29.

26. Rothman N, Skibola CF, Wang SS, et al. Genetic variation in TNF and IL10 and risk of non-Hodgkin lymphoma: a report from the InterLymph Consortium Lancet Oncol 2006;7:27-38

7. Nieters A, Beckmann L, Deeg E, Becker N. Ge polymorphisms in Toll-like receptors, interleukin-10, and interleukin-10 receptor $\alpha$ and lymphoma risk. Genes Immun 2006;7:615-24.

8. Kube D, Hua TD, Kloss M, et al. The interleukin-10 gene promoter polymorphism -1087AG does not correlate with clinical outcome in non-Hodgkin's lymphoma. Genes Immun 2007;8:164-7.

29. Lech-Maranda E, Baseggio L, Bienvenu J, et Interleukin-10 gene promoter polymorphisms influ作 phoma. Blood 2004;103:3529-34.

0. Berglund M, Thunberg U, Roos G, Rosenquist $R$ Enblad G. The interleukin-10 gene promoter polymophism $(-1082)$ does not correlate with clinical outcome in diffuse large B-cell lymphoma. Blood 200 105:4894-5; author reply 5 .

1. Pfreundschuh M, Trumper L, Kloess M, et al. Twoweekly or 3-weekly CHOP chemotherapy with without etoposide for the treatment of elderly patient trial of the DSHNHL. Blood 2004;104:634-4

32. Pfreundschuh M, Trumper L, Kloess $M$, et al. Twoweekly or 3-weekly CHOP chemotherapy with without etoposide for the treatment of young patient with good-prognosis (normal LDH) aggressive lymphomas: results of the NHL-B1 trial of the DSHNHL. Blood 2004;104:626-33

33. Kube D, Mörmann M, Tomiuk J, Hua T, Kremsner P. Vockerodt M. Simultaneous analysis of interle kin-10 gene microsatellites and single-nucleotide polymorphisms in parallel with tumour necrosis factor and interferon- $\gamma$ short tandem repeats by fluorescence-based polymerase

34. Wojnowski L, Kulle B, Schirmer M, et al. $N A D(P) H$ oxidase and multidrug resistance protein genetic polymorphisms are associated with doxorubicin-indu
35. Rieth $\mathrm{H}$, Mormann M, Luty AJ, et al. A three base pair gene variation within the distal $5^{\prime}$-flanking region of the interleukin-10 (IL-10) gene is related to the ride-stimule production capacity of lipopolysacchaEur Cytokine Netw 2004;15:153-8.

36. Lan $\mathrm{Q}$, Zheng T, Rothman $\mathrm{N}$, et al. Cytokine polymorphisms in the Th1/Th2 pathway and susceptibility to non-Hodgkin lymphoma. Blood 2006;107:4101 -8 37. Jones EA, Flavell RA. Distal enhancer elements transcribe intergenic RNA in the IL-10 family gen cluster. J Immunol 2005;175:7437-46.

38. Im SH, Hueber A, Monticelli S, Kang KH, Rao A. Chromatin-level regulation of the IL10 gene in T cells. J Biol Chem 2004;279:46818-25. 39. Zhang X, Edwards JP, Mosser DM. Dynamic and
transient remodeling of the macrophage IL-10 promoter d
$1282-8$.

. Wang ZY, Sato H, Kusam S, Sehra S, Toney LM, Dent AL. Regulation of $1 \mathrm{~L}-10$ gene expression in Th2 cells by Jun proteins. J Immunol 2005;174:2098-105.

1. ShoemakerJ, Saraiva M, O'Garra A. GATA-3 directly remodels the IL-10 locus independently of IL- 4 in CD4 ${ }^{+}$Tcells. J Immunol 2006;176:3470-9.

2. Saraiva M, Christensen JR, Tsytsykova AV, et al. dentification of a macrophage-specific chromati signature in the IL-10 locus. J Immunol 2005;175: $1041-6$

3. Lucas M, Zhang X, Prasanna V, Mosser DM. ERX activation following macrophage FcyR ligation leads 政-10 locus. J Immu nol 2005; 175:469-77.

44. Kurreeman FA, Schonkeren JJ, Heijmans BT, Toes RE, HuizingaTW. Transcription of the IL10 gene revea allele-specific regulation at the mRNA level. Hum Mo Genet 2004;13:1755-62

45. Farinha P, Masoudi H, Skinnider BF, et al. Analysis of multiple biomarkers shows that lymphoma-assocated macrophage (LAM) content is an independent predictor of survival in follicular lymphoma (FL). Blood

6. Hummel M, Bentink S, Berger $\mathrm{H}$, et al. A biologic definition of Burkitt's lymphoma from transcription Med 2006:354 $2419-30$

7. Alizadeh AA, Eisen MB, Davis RE, et al. Distinct types of diffuse large B-cell lymphoma identified by gene expression profiling. Nature 2000;403:503-11. 48. Rosenwald A, Wright G, Leroy K, et al. Molecular diagnosis of primary mediastinal $B$ cell lymphom identifies a clinically favorable subgroup of diffuse large B cell lymphoma related to Hodgkin lymphoma

9. Kwiatkowski D. Genetic dissection of the molecula re infection. Intensive Care Med 2000.26.589-97. 


\title{
9. LEBENSLAUF
}

Nils Schoof

Düstere Str. 23

37073 Göttingen

$\begin{array}{ll}\text { Geburtsdatum: } & \text { 15. Mai } 1980 \\ \text { Geburtsort: } & \text { Bonn } \\ \text { Familienstand: } & \text { ledig } \\ \text { Staatsangehörigkeit: } & \text { Deutsch }\end{array}$

\section{Schulbildung}

1986 bis 1990

1990 bis 1999
Grundschule Longenburg, Königswinter

Gymnasium Pädagogium Otto-Kühne-Schule, Bonn

Abitur Mai 1999

\section{Studium}

Oktober 2000 bis September 2005

\section{Studium an der Georg-August-Universität Göttingen im Diplomstudiengang Biologie}
Hauptfach:
Biochemie
1. Nebenfach:
Humangenetik
2. Nebenfach:
Immunologie

Mündliche Prüfungen im November 2004

Diplomarbeit Januar 2005 bis September 2005 zum Thema:

„Analyse der Wirkung des Protein-Tyrosin-Kinase-Inhibitors AG17 in Hodgkin-Lymphom-Zelllinien"

in der Abt. Hämatologie \& Onkologie, Universitätsmedizin Göttingen,

Betreuer: $\quad$ PD Dr. Dieter Kube

Prof. Dr. Rüdiger Hardeland

\section{Promotion}

Seit Oktober 2005

\author{
Stipendiat des DFG Graduiertenkolleg 1034 \\ „Die Bedeutung genetischer Polymorphismen in der Onkologie: \\ Von den Grundlagen zur individualisierten Therapie" \\ Sprecher: Prof. Dr. Jürgen Brockmöller \\ Promotion zum Thema: \\ "Onkogenomische Aspekte Zytokin-assoziierter Signaltransduktion“ \\ in der Abt. Hämatologie \& Onkologie, Universitätsmedizin Göttingen, \\ Betreuer: PD Dr. Dieter Kube \\ Prof. Dr. Bernd Herrmann
}




\section{VERÖFFENTLICHUNGEN}

\section{Publikationen}

Juni 2005

Juni 2008

In Vorbereitung

In Vorbereitung

In Vorbereitung
Holtick, U., M. Vockerodt, D. Pinkert, N. Schoof, et al. (2005). "STAT3 is essential for Hodgkin lymphoma cell proliferation and is a target of tyrphostin AG17 which confers sensitization for apoptosis." Leukemia 19(6): 936-44.

Kube, D., T. D. Hua, F. von Bonin, N. Schoof, et al. (2008). "Effect of Interleukin-10 Gene Polymorphisms on Clinical Outcome of Patients with Aggressive Non-Hodgkin's Lymphoma: An Exploratory Study." Clin Cancer Res 14(12): 3777-84.

Schoof N., von Bonin F., Trümper L., Kube D. „HSP90 is essential for Jak-STAT signaling in classical Hodgkin Lymphoma cells“

Schoof N., von Bonin F., Zeynalova S., Ziepert M., Jung W., Löffler M., Pfreundschuh M., Trümper L., Kube D. „Favorable impact of the Interleukin-4 receptor allelic variant 175 on the survival of diffuse large Bcell lymphoma patients: A large prospective clinical trial“

Schoof N., von Bonin F., König I, Mössner R, Krüger U., Reich R, Volkenandt M., Ziegler M., Böckmann L., Kuschal C., Thoms K., Kube D., Emmert S. „Distal and proximal Interleukin-10 promoter polymorphisms associated with risk of cutaneous melanoma development: A case-control study"

\section{Kongressbeiträge}

2005

2006

2006

2007

2007

2007
Posterpräsentation, Signal Transduction Society Meeting 2005, Weimar Schoof N., Pinkert D., Kussebi N., Vockerodt M., et al. „STAT3 is essential for Hodgkin lymphoma cell proliferation and is a target of tyrphostin AG17“"

Posterpräsentation, Signal Transduction Society Meeting 2006, Weimar Schoof N., von Bonin F., Feuerborn A., Trümper L., Kube D. „Multitargetkinase inhibitors disrupting Jak-STAT signaling in Hodgkin lymphoma cells"

Posterpräsentation, Cytokines 2006, Wien

Schoof N., Feuerborn A., Pinkert D., Trümper L., Kube D. „Functional role of Jak-STAT signaling in classical Hodgkin lymphoma“

Posterpräsentation, Jahrestagung der DGFI 2007, Heidelberg

Schoof N., von Bonin F., Trümper L., Kube D. „Janus kinases are targets of tyrphostin AG17 and HSP90-inhibitor 17-AAG in classical Hodgkin Lymphoma“

Posterpräsentation, 7th Symposium on Hodgkin Lymphoma, Köln Schoof N., von Bonin F., Trümper L., Kube D.: Janus kinases are targets of tyrphostin AG17 and HSP90-inhibitor 17-AAG in classical Hodgkin Lymphoma

Vortrag, Aggressive Lymphoma Workshop 2007, Göttingen

Schoof N., Hua T-D., von Bonin F., Zeynalova S. et al. „Distal Interleukin-10 gene promoter gene variations are related to decreased overall survival in patients with aggressive NHL" 


\section{Danksagungen}

Prof. Dr. Bernd Herrmann danke ich herzlich für die Betreuung und der Vertretung meiner Doktorarbeit seitens der biologischen Fakultät der Georg-AugustUniversität Göttingen.

Mein besonderer Dank gilt PD Dr. Dieter Kube, der neben der Übernahme des Korreferats mir stets bei allen Fragen und Problem im Laboralltag und darüber hinaus zur Verfügung stand. Durch inn wurden die Jahre meiner Doktorarbeit sehr lehrreich. Vorallem waren unsere Diskussionen nie einseitig, sondern ich habe sie als konstruktiv und sehr förderlich wahrgenommen.

Ebenfalls gilt ein großes Dankeschön Herrn Prof. Dr. Lorenz Trümper, der mir die Durchführung dieser Arbeit ohne Einschränkungen und Komplikationen in seiner Abteilung ermöglicht hat.

Meiner lieben Arbeitsgruppe und Abteilung möchte ich für die Hilfe im Laboralltag und der schönen Arbeitsatmosphäre danken. Sowas hat man selten! Hierbei möchte ich vor allem Frederike von Bonin erwähnen, die mir immer gerne bei allen anstehenden Tätigkeiten und Fragen sehr geholfen hat.

Weiterer Dank gilt meinen Kooperationspartnern, die mich bei meiner Arbeit unterstützt haben. Besonders sind hierbei Frau Zeynalova aus dem IMISE Institut Leipzig, Stefan Bentink vom Institut für funktionelle Genomik der Universität Regensburg, Dr. Daniel Re von der GHSG und Prof. Dr. Steffen Emmert aus der Dermatologie Göttingen dankenswert zu erwähnen.

Dem DFG Graduiertenkolleg 1034 möchte ich für die finanzielle Unterstützung sowie das gute Ausbildungsprogramm, was mir geboten wurde, danken. Das wöchentliche Zusammenkommen unter "Leidensgenossen“ sowie die Klausurtagungen gaben mir gute Anregungen und Motivation.

Zuletzt gilt natürlich meiner Familie und meinen Freunden hier ein RiesenDankeschön. Ohne Eure Unterstützung, Ablenkung und den Spaß mit Euch wäre ich mit Sicherheit nicht an diesen Punkt gekommen. 